
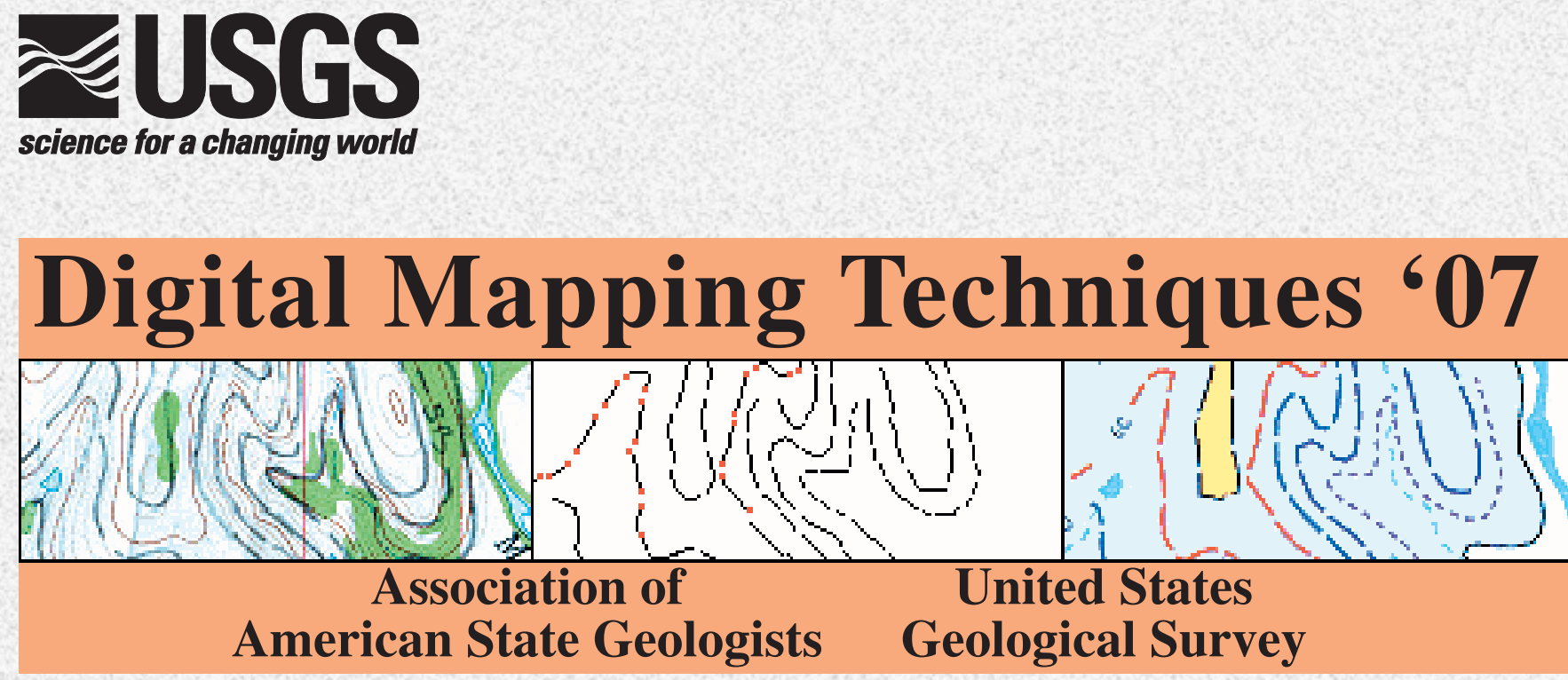

\title{
Digital Mapping Techniques ‘07 - Workshop Proceedings
}

May $20-23,2007$

Columbia, South Carolina

Convened by the

Association of American State Geologists and the United States Geological Survey Hosted by the South Carolina Geological Survey

Open-File Report 2008-1385 


\section{Digital Mapping Techniques '07- Workshop Proceedings}

Edited by David R. Soller

May 20-23, 2007

Columbia, South Carolina

Convened by the

Association of American State Geologists

and the

United States Geological Survey

Hosted by the

South Carolina Geological Survey

U.S. GEOLOGICAL SURVEY OPEN-FILE REPORT 2008-1385 2008 
This report is preliminary and has not been reviewed for conformity with the U.S. Geological Survey editorial standards. Any use of trade, product, or firm names in this publication is for descriptive purposes only and does not imply endorsement by the

U.S. Government or State Governments. 


\section{CONTENTS}

\section{Introduction}

By David R. Soller (U.S. Geological Survey) …............................................... 1

\section{Oral Presentations}

The National Geologic Map Database Project - 2007 Report of Progress

By David R. Soller (U.S. Geological Survey) ........................................................ 11

National Cooperative Soil Survey National Soil Information System

By Jim R. Fortner (USDA-Natural Resources Conservation Service) ......................... 21

Importance of Historical Elevation Data

By Gayle H. McColloch, Jr. and Jane S. McColloch

(West Virginia Geological Survey)

The National Map - Products And Services

By William J. Carswell and Stafford Binder (U.S. Geological Survey)....................... 35

When Maps Were Scribed: USGS Geologic Map Production in the 1970's

By Will R. Stettner and Paul Mathieux (U.S. Geological Survey)

Open Access Journal Publication: Implementation, Copyright and Dissemination, Using

The Journal of Maps as a Case Study

By Mike J. Smith (Kingston University)

The National Cooperative Geologic Mapping Program and Insight Into the

Future of Geologic Map Production

By Randall C. Orndorff, Peter T. Lyttle, Laurel M. Bybell, and Lydia Quintana

(U.S. Geological Survey) 47

Geologic Field Mapping Using a Rugged Tablet Computer

By Kent D. Brown and Douglas A. Sprinkel (Utah Geological Survey)..................... 53

Proposal for an ArcGeology Version 1-A Geodatabase Design for

Digital Geologic Maps using ArcGIS ${ }^{\circledR}$

By Jordan T. Hastings, Gary L. Raines, Lorre A. Moyer (U.S. Geological Survey)...... 59

Exchanging Observations and Measurements: a Generic Model and Encoding

By Simon J. D. Cox (CSIRO)

Idaho Geologic Map Data in a Statewide Geodatabase

By Loudon R. Stanford (Idaho Geological Survey) and Steve Mulberry (ESRI) ......... 79

\section{Poster Presentations}

Alaska Mapper: A Web-based Tool to Access Land Ownership and Other State-wide Geospatial Data

By Kenneth R. Papp and Peter Parker (Alaska Division of Geological and Geophysical Surveys). 
Seamless Digital Geological Map of Japan 1:200,000, and its Application

By Toshie Igawa, Koji Wakita, and Shinji Takarada (Geological Survey of Japan)

Integrated Geological Map Database and Geological Information Index

By Koji Wakita, Shinji Takarada, and Yasuaki Murata (Geological Survey of Japan)... 93

Developing a Web Site to Provide Geologic Data and Map Products for Allen County, Indiana

By Robin F. Rupp, Jennifer Olejnik, Nancy R. Hasenmueller, Marni D. Karaffa, A. Chris Walls, Prem Radhakrishnan, and Nathan K. Eaton (Indiana Geological Survey).

Glacial Striae Observations for Ireland Compiled from Historic Records

By Mike J. Smith, Jasper Knight, and Kenneth S. Field (Kingston University)

GIS Tools for 3-D Surficial Mapping in Ohio

By James McDonald, Richard R. Pavey, Erik R. Venteris, and Joseph G. Wells (Ohio Division of Geological Survey)

Mapping Potential Geologic Hazards for Proposed Highway Construction Projects in Pennsylvania: Route 15 in Lycoming County

By Stuart O. Reese (Pennsylvania Geological Survey).

Old Mapping and New LiDAR......a Reality Check

By Thomas G. Whitfield (Pennsylvania Geological Survey)

DNAG Geologic Map of North America GIS Implementation: Overview and Progress

By Christopher P. Garrity and David R. Soller (U.S. Geological Survey).....

Compilation and Production of the 1:500,000-scale Geologic Map of Washington State, and Some Aspects of 1:24,000-scale Map Production at the Washington Division of Geology and Earth Resources

By J. Eric Schuster, Charles G. Caruthers, Anne C. Heinitz, and Karen D. Meyers (Washington Division of Geology and Earth Resources) 


\title{
Introduction
}

\author{
By David R. Soller \\ U.S. Geological Survey \\ 926-A National Center \\ Reston, VA 20192 \\ Telephone: (703) 648-6907 \\ Fax: (703) 648-6977 \\ e-mail: drsoller@usgs.gov
}

The Digital Mapping Techniques '07 (DMT'07) workshop was attended by 85 technical experts from 49 agencies, universities, and private companies, including representatives from 27 state geological surveys (see Appendix A). This workshop, hosted by the South Carolina Geological Survey, from May 20-23, 2007, on the University of South Carolina campus in Columbia, South Carolina, was similar in nature to the previous ten meetings (see Appendix B). As in the previous meetings, the objective was to foster informal discussion and exchange of technical information. It is with great pleasure that I note that the objective was successfully met, as attendees continued to share and exchange knowledge and information, and renew friendships and collegial work begun at past DMT workshops.

Each DMT workshop has been coordinated by the Association of American State Geologists (AASG) and U.S. Geological Survey (USGS) Data Capture Working Group, the latter of which was formed in August 1996 to support the AASG and the USGS in their effort to build a National Geologic Map Database (see Soller, this volume, and http://ngmdb.usgs.gov/ info/standards/datacapt/). The Working Group was formed because increased production efficiencies, standardization, and quality of digital map products were needed for the databaseand for the State and Federal geological surveys - to provide more high-quality digital maps to the public.

At the 2007 meeting, oral and poster presentations and special discussion sessions emphasized: 1) methods for creating and publishing map products (here, "publishing" includes Web-based release); 2) field data capture software and techniques, including the use of LIDAR; 3) digital cartographic techniques; 4) migration of digital maps into ArcGIS Geodatabase format; 5) analytical GIS techniques; and 6) continued development of the National Geologic Map Database.

\section{ACKNOWLEDGMENTS}

I thank the South Carolina Geological Survey (SCGS) and their Director and State Geologist, William Clendenin, for hosting this meeting. It was a real pleasure to work with Erin Hudson and Scott Howard, who coordinated the events. I also thank Jennifer Krauser, Joe Koch, Chris Terry and Matt Nichols, Melissa Clare Beaty, Kimberly Meitzen, and Gary Taylor, for their hard work that ensured the meeting's success.

I also thank the members of the Data Capture Working Group (Warren Anderson, Kentucky Geological Survey; Elizabeth Campbell, Virginia Division of Mines and Geology; Rob Krumm and Barb Stiff, Illinois State Geological Survey; Scott McColloch, West Virginia Geological and Economic Survey; George Saucedo, California Geological Survey; and Tom Whitfield, Pennsylvania Geological Survey) for advice in planning the workshop's content.

And, last but not least, I thank all attendees for their participation; their enthusiasm and expertise were the primary reasons for the meeting's success.

\section{PRESENTATIONS AND POSTERS}

The workshop included 21 oral presentations and 30 posters. Many are supported by a short paper contained in these Proceedings. The papers describe technical and procedural approaches that currently meet some or all needs for digital mapping at the respective agency. There is not, of course, a single "solution" or approach to digital mapping that will work for each agency or for each program or group within an agency; personnel and funding levels, and the schedule, data format, and manner in which we must deliver our information to the public require that each agency design their own approach. However, the value of this workshop and other forums like it is through their roles in helping to design or refine these agency-specific approaches to digital mapping, and to find applicable approaches used by other agencies. In other words, communication helps us to avoid having to "reinvent the wheel."

During the course of the 11 annual DMT meetings, it has been my pleasure to meet, and work with, the many talented people who have authored papers in these Proceedings. As the 
subjects addressed by the DMT meetings have become even more essential to the Nation's geological surveys, the demands placed on them have risen to the point where many authors scarcely have time to address their work fully. Predictably, less time is then available to compose written summaries of their work; I'm sure the readers (or at least other editors) can sympathize with this predicament. Therefore, I include with this Introduction a list of all presentations and posters (Appendix C). If the reader finds an interesting title that isn't recorded in these Proceedings, I encourage them to contact the authors directly. Further, some presentations and related information is available for download at http://ngmdb.usgs.gov/Info/dmt/ DMT07presentations.html.

\section{THE NEXT DMT WORKSHOP}

The twelfth annual DMT meeting will be held in the Spring of 2008, on the campus of University of Idaho, in Moscow, Idaho. Please consult the Web site (http://ngmdb.usgs. gov/Info/dmt/) for additional information about this and other DMT meetings. 


\section{Appendix A. List of workshop attendees}

[Grouped by affiliation]

Alaska Division of Geological and Geophysical Surveys Kenneth Papp

Arizona Geological Survey/USGS

Stephen Richard

Arkansas Geological Commission

Jerry Clark

Doug Hanson

Nathan Taylor

Bureau de Recherches Geologiques et Minieres

Francois Robida

British Geological Survey

Ian Jackson

C Tech Development Corporation

Reed Copsey

California Geological Survey

George Saucedo

Colorado Geological Survey

Nicholas Watterson

Colorado State University / National Park Service Ron Karpilo

Stephanie O'Meara

CSIRO

Simon Cox

ESRI

Steve Mulberry

Geological Survey of Canada

Boyan Brodaric

Geological Survey of Japan

Toshie Igawa

Koji Wakita

Georgia Geologic Survey

Mark Cocker

Geoscience Australia

Lesley Wyborn

Idaho Geological Survey

Jane Freed

Loudon Stanford

Illinois State Geological Survey

Jane Domier

Indiana Geological Survey

Robin Rupp

\author{
Kingston University \\ Mike Smith \\ Louisiana Geological Survey \\ Robert Paulsell \\ Michigan Geological Survey \\ John Esch \\ Minnesota Geological Survey \\ Harvey Thorleifson \\ Missouri Geological Survey \\ Chris Vierrether \\ Montana Bureau of Mines and Geology \\ Susan M. Smith \\ National Park Service \\ Andrea Croskrey \\ Georgia Hybels \\ David Shelley \\ Natural Resources Canada \\ John Broome \\ Parm Dhesi \\ Dave Everett \\ Mike Sigouin \\ Nevada Bureau of Mines and Geology \\ Jennifer Mauldin
}

New Mexico Division of Geology and Mineral Resources

Glen Jones

North Carolina Division of Land Resources

Jeff Reid

Ohio Division of Geological Survey

James McDonald

Oregon Department of Geology and Mineral Industries

Mark Sanchez

Pennsylvania Geological Survey

Stuart Reese

Thomas Whitfield

Portland State University

David Percy

South Carolina Department of Natural Resources, Hydrology Lee Mitchell

South Carolina Geodetic Survey

Lewis Lapine

Matt Wellslager 
South Carolina Geological Survey

Melissa Clare Beaty

Will Doar

Scott Howard

Erin Hudson

Jennifer Krauser

Ralph Willoughby

U.S. Geological Survey

Gregory Allord

Stafford Binder

Bill Carswell

Jonathan Craigue

Mary DiGiacomo-Cohen

Chris Garrity

Jordan Hastings

Bruce Johnson

Gary Merrill

Randall Orndorff

Lisa Rukstales

David Soller

Nancy Stamm

Will Stettner

University of Alabama

Douglas Behm

University of North Carolina, Charlotte Randi Clapham

University of Minnesota

Paul Morin
University of Nebraska-Lincoln

Paul Hanson

University of South Carolina

Kimberly Meitzen

USDA - Natural Resources Conservation Service Jim Fortner

Utah Geological Survey

Kent Brown

Basia Matyjasik

Virginia Division of Mineral Resources Elizabeth Campbell

Washington Division of Geology and Earth Resources Chuck Caruthers

Anne Heinitz

Karen Meyers

West Virginia Geological Survey

Jane McColloch

Scott McColloch

Wisconsin Geological \& Natural History Survey

Kathy Roushar

Wyoming State Geological Survey

Allory Deiss

David Lucke

Phyllis Ranz 
Appendix B. Previous Digital Mapping Techniques Workshops.

1997:

Hosted by the Kansas Geological Survey, Lawrence, Kansas, June 2-5. 73 technical experts attended, from 30 state geological surveys, the USGS, and the Geological Survey of Canada.

Soller, D.R., editor, 1997, Proceedings of a workshop on digital mapping techniques: Methods for geologic map data capture, management, and publication: U.S. Geological Survey Open-File Report 97-269, 120 p., available at $h t t p: / /$ pubs.usgs.gov/of/of97-269/.

1998:

Hosted by the Illinois State Geological Survey in Champaign, Illinois, May 27-30. More than 80 technical experts attended, mostly from the state geological surveys and the USGS.

Soller, D.R., editor, 1998, Digital Mapping Techniques '98Workshop Proceedings: U.S. Geological Survey Open-File Report 98-487, 134 p., available at http://pubs.usgs.gov/of/ of $98-487 /$.

1999:

Hosted by the Wisconsin Geological and Natural History Survey in Madison, Wisconsin, May 19-22. 91 selected technical experts from 42 agencies, universities, and private companies attended, including representatives from 30 state geological surveys.

Soller, D.R., editor, 1999, Digital Mapping Techniques '99Workshop Proceedings: U.S. Geological Survey Open-File Report 99-386, 216 p., available at http://pubs.usgs.gov/of/ of 99-386/front.html.

2000:

Hosted by the Kentucky Geological Survey in Lexington, Kentucky, May 17-20. 99 technical experts from 42 agencies, universities, and private companies attended, including representatives from 28 state geological surveys.

Soller, D.R., editor, 2000, Digital Mapping Techniques '00Workshop Proceedings: U.S. Geological Survey Open-File Report 00-325, 209 p., available at http://pubs.usgs.gov/of/ of $00-325 \%$.

2001:

Hosted by the Geological Survey of Alabama, in Tuscaloosa, Alabama, May 20-23. 108 technical experts from 48 agencies, universities, and private companies attended, including representatives from 31 state geological surveys.
Soller, D.R., editor, 2001, Digital Mapping Techniques '01Workshop Proceedings: U.S. Geological Survey Open-File Report 01-223, 248 p., available at http://pubs.usgs.gov/ of $/ 2001 / 0 f 01-223 /$.

2002:

Hosted by the Utah Geological Survey, in Salt Lake City, Utah, May 19-22. More than 100 technical experts from 40 agencies, universities, and private companies attended, including representatives from 30 state geological surveys.

Soller, D.R., editor, 2002, Digital Mapping Techniques '02Workshop Proceedings: U.S. Geological Survey Open-File Report 02-370, 214 p., available at http://pubs.usgs.gov/ of/2002/of02-370/.

2003:

Hosted by the Pennsylvania Geological Survey, in Millersville, Pennsylvania, June 1-4. Nearly 90 technical experts from 36 agencies, universities, and private companies attended, including representatives from 22 state geological surveys.

Soller, D.R., editor, 2003, Digital Mapping Techniques '03Workshop Proceedings: U.S. Geological Survey Open-File Report 03-471, 262 p., available at http://pubs.usgs.gov/ of $/ 2003 / 0 f 03-471 /$.

2004:

Hosted by the Oregon Department of Geology and Mineral Industries, in Portland, Oregon, May 16-19. Nearly 100 technical experts from 40 agencies, universities, and private companies attended, including representatives from 22 state geological surveys.

Soller, D.R., editor, 2004, Digital Mapping Techniques '04Workshop Proceedings: U.S. Geological Survey Open-File Report 2004-1451, 220 p., available at http://pubs.usgs.gov/ of/2004/1451/.

2005:

Hosted by the Louisiana Geological Survey, in Baton Rouge, Louisiana, April 24-27. More than 100 technical experts from 47 agencies, universities, and private companies attended, including representatives from 25 state geological surveys.

Soller, D.R., editor, 2005, Digital Mapping Techniques '05Workshop Proceedings: U.S. Geological Survey Open-File Report 2005-1428, 268 p., available at http://pubs.usgs.gov/ of/2005/1428/. 
2006:

Hosted by the Ohio Geological Survey, in Columbus, Ohio, June 11-14. More than 115 technical experts from 49 agencies, universities, and private companies attended, including representatives from 27 state geological surveys.

Soller, D.R., editor, 2007, Digital Mapping Techniques '06Workshop Proceedings: U.S. Geological Survey Open-File Report 2007-1285, 217 p., available at http://pubs.usgs.gov/ of/2007/1285/. 


\section{Appendix C. List of oral and poster presentations, and discussion sessions.}

Oral Presentations:

OneGeology - noble aspiration or pragmatic solution (... or both?)

By Ian Jackson (Director of Information, British Geological Survey), John Broome (Head, ESS Data Management Policy \& Strategy, Natural Resources Canada), and Harvey Thorleifson (Director, Minnesota Geological Survey)

The U.S. National Geologic Map Database

By David R. Soller (U.S. Geological Survey), Harvey Thorleifson (Minnesota Geological Survey), and Nancy R. Stamm (U.S. Geological Survey)

USDA-NRCS National Soil Information System By Jim R. Fortner (USDA - Natural Resources Conservation Service)

Importance of Historical Elevation Data

By Gayle H. McColloch, Jr. and Jane S. McColloch (West Virginia Geological Survey)

Discussion Session - "The National Map: Products and Services"

By William Carswell and Stafford Binder (U.S. Geological Survey)

Geologic Map Production During the 70s at the U.S. Geological Survey

By Will Stettner, Linda Masonic, and Paul Mathieux (U.S. Geological Survey)

Open Access Journal Publication: methods of implementation and copyright issues using the Journal of Maps as a case study

By Mike J. Smith (Kingston University)

New Developments in Data Management Policy \& Strategy in the Earth Sciences Sector/Geological Survey of Canada By John Broome (Head, ESS Data Management Policy \& Strategy, Natural Resources Canada)

BGS information: The highs (and lows) of 2006/07 By Ian Jackson (Director of Information, British Geological Survey)

The National Cooperative Geologic Mapping Program and Insight Into the Future of Geologic Map Production By Randall C. Orndorff (U.S. Geological Survey)
Discussion Session - "Can we develop National guidelines or standards for database format and content?"

A discussion of commonly-used practices, and whether guidelines can, and should be developed. Led by Dave Soller (U.S. Geological Survey)

Geologic Field Mapping Using a Ruggedized Tablet Computer By Kent D. Brown, Douglas A. Sprinkel, Basia Matyjasik, and J. Buck Ehler (Utah Geological Survey)

South Carolina Virtual Reference Station Network - Centimeter Positional Accuracy in Real Time for South Carolina By Lew Lapine and Matt Wellslager (South Carolina Geodetic Survey)

Workflow and distribution of USGS manuscripts and illustrations

By Greg Allord (U.S. Geological Survey)

Introduction to the NGMDB "Phase 3" Prototype Data Portal By David R. Soller (U.S. Geological Survey), David Percy (Portland State University), Steve Richard (Arizona Geological Survey), and Jon Craigue (University of Arizona/ U.S. Geological Survey)

3D Volumetric Visualization with EVS and MVS By Reed Copsey (C Tech Development Corporation)

The challenge of efficiently building closed volumetric 3D geological models that are scientifically rigorous: an Australian perspective

By Richard Lane and Lesley Wyborn (Geoscience Australia)

Classrooms, Museums and Mapping in Antarctica; What new techniques mean to you

By Paul J. Morin (University of Minnesota)

Proposed Arc Geology Version 1

By Gary L. Raines, Jordan T. Hastings, and Lorre A. Moyer (U.S. Geological Survey)

Progress Report on Development of GeoSciML By Steve Richard (Arizona Geological Survey) and the IUGS CGI Data Model Collaboration Working Group

Exchanging observations and measurements: a generic model and encoding

By Simon J.D. Cox (CSIRO Exploration \& Mining, Australia)

Discussion Session — "ESRI products and Geodatabase implementation" - Loudon R. Stanford (Idaho Geological Survey) and Steve Mulberry (ESRI Atlanta) provided a presentation on "Idaho Geologic Map Data In a Statewide Geodatabase: Design, Data Management Tools, and Online Distribution". Steve Mulberry (ESRI), provided an overview of ESRI products, and addressed questions posed by the attendees. 
Discussion Session - Digital Cartography - Discussion of technical issues related to cartography, methods for communicating/sharing this knowledge (e.g., Cartographic Resources website), and an update on implementation of the FGDC Standard for Geologic Map Symbolization. Led by Dave Soller (U.S. Geological Survey)

\section{Poster Presentations (listed alphabetically, by agency):}

Alaska Mapper, a Web-based tool to access land ownership and other state-wide geospatial data

By Kenneth R. Papp (AK Division of Geological \& Geophysical Surveys) and Peter Parker (AK Department of Natural Resources)

The IUGS CGI Concept Definitions Working Group By Steve Richard (Arizona Geological Survey) and the IUGS CGI Data Model Collaboration Working Group

Geology of Mount Magazine State Park and Vicinity, Logan County, Arkansas

By Scott M. Ausbrooks, Charles G. Stone, and Boyd R. Haley; digital compilation by Jerry W. Clark (Arkansas Geological Commission)

Geologic Report of Little River County, Arkansas By William D. Hanson and Benjamin F. Clardy; digital compilation by Tiffaney Celis (Arkansas Geological Commission)

Geology of the Crater of Diamonds State Park and Vicinity, Pike County, Arkansas

By William D. Hanson, J. Michael Howard, and Benjamin F. Clardy; digital compilation by Nathan H. Taylor (Arkansas Geological Commission)

Virtual Geologic Field Trip to Rocky Mountain National Park, Colorado

By James R. Chappell, Ronald D. Karpilo, Jason Isherwood, Heather I. Stanton, Philip Reiker and Stephanie A. O'Meara (Colorado State University)

GeoSciML Testbed 2 Demonstration

By Boyan Brodaric (Geological Survey of Canada), Bruce Johnson (U.S. Geological Survey, and Francois Robida (BRGM)

Mapping Halifax Harbour - the making of a GSC Bulletin By Gordon B.J. Fader, Robert O. Miller and Phil O'Regan (Geological Survey of Canada)

Seamless Digital Geological Map of Japan 1:200,000, and its application

By Toshie Igawa, Koji Wakita, and Shinji Takarada (Geological Survey of Japan)
Integrated Geological Map Database and Geological Information Index

By Koji Wakita, Shinji Takarada, and Yasuaki Murata (Geological Survey of Japan)

On-line FIncs System for the Management and Delivery of Fluid Inclusion Data

By Terrence P. Mernagh, Dale Percival, Evgeniy N. Bastrakov, and Lesley A.I. Wyborn (Geoscience Australia)

The Australian Landslides Data Model

By Monica Osuchowski (Geoscience Australia), Rob Atkinson (Social Change Online), Simon Cox (CSIRO Division of Exploration and Mining), and Nick Ardlie and Stuart Girvan Australia)

The Australian Mineral Occurrence Data Exchange Model By Adele Seymon and Bruce Simons (GeoScience Victoria), Oliver Raymond (Geoscience Australia), Gary Andrews (Northern Territory Geological Survey), Terry Denaro (Geological Survey of Queensland), Greg Jenkins (Primary Industries and Resources SA, Government of South Australia), Peter Lewis (Geological Survey of New South Wales), James Llorca (GeoScience Victoria), Marcus McClenaghan (Mineral Resources Tasmania), Alistair Ritchie (GeoScience Victoria), Jafar Taheri (Mineral Resources Tasmania), Ian Withnall (Geological Survey of Queensland), Andrew Wygralak (Northern Territory Geological Survey), and Lesley Wyborn (Geoscience Australia)

Idaho Geological Survey Digital Geologic Map Data Model v3.1b: ESRI Geodatabase Schema Diagram By Loudon Stanford (Idaho Geological Survey) and Steve Mulberry (ESRI)

Developing a Web Site To Provide Geologic Data and Map Products for Allen County, Indiana

By Robin F. Rupp, Jennifer Olejnik, Nancy R. Hasenmueller, Marni D. Karaffa, A. Chris Walls, Prem Radhakrishnan, and Nathan K. Eaton (Indiana Geological Survey)

A map of glacial striae observations for Ireland compiled from historic records

By M. J. Smith (Kingston University), J. Knight (University of Exeter), and K. Field (Kingston University)

GIS tools for 3-D surficial mapping in Ohio By James McDonald, Richard R. Pavey, Erik R. Venteris, and Joseph G. Wells (Ohio Geological Survey)

Relative Earthquake Induced Hazard Maps and Identified Landslide Hazard Map for Six Counties in the Mid-Willamette Valley, Including Yamhill, Marion, Polk, Benton, Linn, and Lane Counties, Oregon

By William Burns, R. Jon Hofmeister, Rudie Watzig, and Yumei Wang (Oregon Department of Geology and Mineral Industries) 
Landslide Mapping Using LiDAR Data Technology

By Mark A. Sanchez (Oregon Department of Geology and Mineral Industries)

Mapping Potential Geologic Hazards for Proposed Highway Construction Projects in Pennsylvania: Route 15 in Lycoming County

By Stuart Reese (Pennsylvania Geological Survey)

Old mapping and new LiDAR...... reality check

By Tom Whitfield (Pennsylvania Geological Survey)

USDA-NRCS National Soil Information System By Jim R. Fortner (USDA - Natural Resources Conservation Service)

Combining mixed sources, unknown projections, and varying resolutions with state line faults to create coherent source and assessment unit outlines for the 2007 USGS Illinois Basin Oil and Gas Assessment

By Joseph A. East (U.S. Geological Survey)

Progress Report on Database Development for the Geologic Map of North America

By Christopher P. Garrity and David R. Soller (U.S. Geological Survey)

The National Geologic Map Database

By David R. Soller (U.S. Geological Survey), Harvey

Thorleifson (Minnesota Geological Survey), and Nancy R.

Stamm (U.S. Geological Survey)
The FGDC Standard for Geologic Map Symbolization By David R. Soller and Taryn Lindquist (U.S. Geological Survey)

Divisions of Geologic Time - Major Chronostratigraphic and Geochronologic Units

By the Geologic Names Committee of the U.S. Geological Survey

Congaree River Floodplain Inundation Model: Developing A Decision Support Tool for Congaree National Park, South Carolina

By Kimberly M. Meitzen (University of South Carolina)

Creating an Integrated Geologic Data System in Virginia By Elizabeth Campbell (Virginia Division of Mineral Resources)

Compilation and Production of the 1:500,000-scale Geologic Map of Washington State, and Some Aspects of 1:24,000scale Map Production at the Washington Division of Geology and Earth Resources

By J. Eric Schuster, Charles G. Caruthers, Anne C. Heinitz, and Karen D. Meyers (Washington Division of Geology and Earth Resources) 



\title{
The National Geologic Map Database Project - 2007 Report of Progress
}

\author{
By David R. Soller \\ U.S. Geological Survey \\ 926-A National Center \\ Reston, VA 20192 \\ Telephone: (703) 648-6907 \\ Fax: (703) 648-6977 \\ e-mail: drsoller@usgs.gov
}

Development and management of geologic map databases for support of societal decisionmaking and scientific research is a critical need. The National Geologic Mapping Act of 1992 (http://ncgmp.usgs.gov/ncgmpabout/ngmact/ ngmact 1992) and its subsequent reauthorizations mandate the creation and maintenance of a National Geologic Map Database (NGMDB, http://ngmdb.usgs.gov) as a national archive of spatially referenced geoscience data, including geology, paleontology, and geochronology. The Act further stipulates that all new information contributed to the NGMDB must adhere to technical and science standards that are to be developed as needed under the guidance of the NGMDB project. Development of a national database and its attendant standards is a daunting task that requires close collaboration among all geoscience agencies in the U.S., at the State and Federal levels. The Act, therefore, creates the environment within which the USGS and the Association of American State Geologists (AASG) can collaborate to build the NGMDB and also serve the needs of their own agencies.

From the guidelines in the National Geologic Mapping Act, and through extensive discussions and forums with the geoscience community and with the public, a general strategy for building the NGMDB was defined in 1995. Based on continued public input, the NGMDB has evolved from a concept to a set of resources that substantially help the Nation's geological surveys provide to the public, in a more efficient manner, standardized digital geoscience information.

The NGMDB is designed to be a comprehensive reference tool and data management system for spatial geoscience information in paper and digital form. It consists of the following: 1) a Map Catalog containing limited metadata for all paper and digital geoscience maps and book publications that contain maps (including maps of any part of the Nation, published by any agency), online viewable images of paper and digital maps, and links to online data; 2) the U.S. Geologic Names Lexicon; 3) the Mapping in Progress Database; 4) nationwide geologic map coverage at intermediate and small scales; 5) an online database of geologic maps (predominantly in vector format; planned as a distributed system); 6) a set of Web interfaces to permit access to these products; and 7) a set of standards and guidelines to promote more efficient use and management of spatial geoscience information. The NGMDB system is a hybrid - some aspects are centralized and some are distributed, with the map information held by various cooperators (for example, the State geological surveys). Through a primary entry point on the Web, users can browse and query the NGMDB, and obtain access to the information wherever it resides.

The Congressional mandate for state-federal collaboration has proven invaluable, facilitating progress on many technical issues that would otherwise have been much more difficult to achieve. The NGMDB's long record of accomplishment owes a significant debt to its many collaborators, and to the institutions with which it interacts (Appendix A). Each year in these Proceedings, and at numerous meetings and presentations, technical plans and progress are reported. In order to minimize repetition in this report, I have limited the background and explanatory information, which are contained in previous reports of progress (Appendix $\mathrm{B}$; in particular the 2005 report).

\section{PROJECT ORGANIZATION}

The project consists of a set of related tasks that will develop, over time, a NGMDB with increasing complexity and utility. This is being accomplished through a network of geoscientists, computer scientists, librarians, and others committed to supporting the project's objectives. Phase One of this project principally involves the building of a comprehensive Geoscience Map Catalog of bibliographic records and online images of all available paper and digital maps, and many books, guidebooks, and journal articles that either include maps or describe the geology of an area; although the project's name refers only to maps, the Catalog contains information 
related to the numerous earth-science themes specified in the National Geologic Mapping Act of 1992. Critical to this first phase is the design and development of the U.S. Geologic Names Lexicon (Geolex), the Mapping in Progress Database, and the National Paleontology Database. Phase Two addresses the development of standards and guidelines for geologic map and database content and format. Phase Three is a long-term effort to develop a distributed database containing nationwide geologic map coverage at multiple map scales, populated according to a set of content and format specifications that are standardized through general agreement among all partners in the NGMDB (principally the AASG and USGS); this database will be integrated with the databases developed in Phase One. The NGMDB project's technology and standards development efforts also are coordinated with various international bodies, including the Federal Geographic Data Committee, ESRI, the North American Geologic Map Data Model Steering Committee (NADM), the U.S. National Science Foundation's database management and interoperability projects, the IUGS Commission on the Management and Application of Geoscience Information ("IUGS CGI"), the IUGS Commission on Stratigraphy, the IUGS-affiliated Commission for the Geological Map of the World, and the International Association of Mathematical Geology (IAMG).

A full realization of the project's third phase is not assured and will require a strong commitment among the cooperators as well as adequate technology, map data, and funding. The project will continue to assess various options for development of this database, based on realistic funding projections and other factors. During the development of these phases of the NGMDB, extensive work will be conducted to generate Web interfaces and search engines and to continually improve them, and to develop the data management and administrative protocols necessary to ensure that the NGMDB will function efficiently in the future. The NGMDB's databases and project information can be found at $h t t p: / /$ ngmdb.usgs.gov.

\section{PROGRESS IN 2007}

\section{Phase One}

A wealth of geoscience information is available in various paper and digital formats. With the emergence of the Internet and Web, the public has come to expect rapid, easy, and unfettered access to government data holdings. Geoscience data must therefore become widely available via the Web, and the concepts presented in its products must be understandable to the public. If our information is more readily available to the public, and if tools are offered to help integrate and provide access to that information, its utility may be greatly increased.

However, providing effective public Web access to our products presents a real challenge for each geoscience agency, because of new and rapidly evolving technology, restricted funding, new requirements from the user community, and the somewhat confusing array of websites at which various types and quality of information can be found. To help address these challenges, Phase One focuses on providing simple, straightforward access to a broad spectrum of geoscience information, and forms the stable platform upon which the other NGMDB tasks and capabilities are based.

Specific accomplishments in 2007 include:

1. Expanded the Geoscience Map Catalog by about 3700 records, to a total of about 78,000 records. This includes 37,500 USGS publications in map, book, and open-file series, 27,000 state geological survey publications, and 13,500 products by other publishers. About 4700 existing records were updated; these mostly consisted of links to newlyonline versions of the publication.

2. Engaged 49 states in the process of entering Map Catalog records. This resulted in the addition of about 2700 new records for state geological survey publications.

3. Increased the number of links from the Map Catalog to online publications, including map images, from about 10,000 to 15,000 .

4. Continued to expand and revise Geolex (U.S. Geologic Names Lexicon), with a major update completed in mid-year. This update included the addition of $\sim 1500$ synopses, 500 references, and 70 geologic units.

5. Significantly revised the Geolex web interface to: a) allow more flexible search of geologic names; b) provide search results that include units related to that name; and c) provide forms for users and project personnel to assist in making additions and corrections.

6. Engaged 12 state geological surveys in a systematic review of Geolex, partly in cooperation with the USGS Energy Resources Program.

7. Under agreement with the USGS Publications Warehouse (PW), obtained 7000 map images scanned by the PW, and have processed 3200 for direct service via the Map Catalog image viewer. The agreement was undertaken to minimize duplication between the two systems, integrate them, and provide to the user the image viewer most appropriate for the publication format (e.g., MrSID format for large-format maps via NGMDB, and $\mathrm{Dj} V u$ format for multi-page documents via $\mathrm{PW}$ ).

8. Configured a 7-TB computer for short-term storage of map images and for image processing. Loaded to this computer $4.1 \mathrm{~TB}$ of images scanned by NGMDB or obtained from cooperators. 
9. Received approval by USGS National Cooperative Geologic Mapping Program (NCGMP) and their Federal Advisory Committee for a plan to make images of selected EDMAP-grant deliverables publicly available via the Map Catalog (e.g., http://ngmdb.usgs.gov/Prodesc/proddesc_81551. htm). Unpublished GIS files of these maps will be archived and password-protected in the NGMDB, for later use by researchers.

10. Completed a significant effort to include in the Map Catalog a geographic search (see http://ngmdb. usgs.gov/ngmdb/ngm_compsearch.html). This new function allows the user to visually define the geographic boundary of their search. In a future redesign of the entire site, the geographic search is expected to serve a central, organizing role.

11. Created a set of monthly web statistics that identify the extent to which state geological survey publications are accessed via the Map Catalog. These statistics will be provided to each state geologist.

12. Evaluated user response to a prototype application that generates a file to display Map Catalog search results in Google Earth. Based on public comments received, this application will be further developed.

13. In response to NCGMP and AASG requests, and in part to address NCGMP performance metrics required by the Office of Management and Budget, provided: a) index maps showing areas in the U.S. that have been geologically mapped at various scales and time periods, and b) computations including the number of square miles geologically mapped at intermediate and more detailed scales (see Soller, 2005).

14. Worked with NCGMP to improve their data-entry procedure for the Mapping in Progress database, focusing on database redesign and adding information most useful to NCGMP management.

15. Gave numerous project presentations to scientists and managers at USGS, AASG, and other scientific meetings, whereby details of the project were explained and participation in building various NGMDB standards and databases was increased.

16. Completed several hundred productive interchanges with Map Catalog and Geolex users, via the NGMDB feedback form and other mechanisms. These users vary widely in interest and background, and include school children, homeowners, local government planners, and professional geologists.

\section{Phase Two}

Geoscience information increasingly is available in digital format. Within an agency, program, or a project, there are standard practices for the preparation and distribution of this information. However, widely accepted standards and/ or guidelines for the format, content, and symbolization of this information do not yet exist. Such standards are critical to the broader acceptance, comprehension, and use of geoscience information by the non-professional and professional alike. Under the mandate of the National Geologic Mapping Act, the NGMDB project serves as one mechanism for coordinating and developing the standards and guidelines that are deemed necessary by the U.S. and international geoscience community.

The NGMDB project leads or assists in development of standards and guidelines for digital database and map preparation, publication, and management. This activity is a challenging one that entails a lengthy period of conceptual design, documentation, and test-implementation. For example: 1) a conceptual data model must be shown to be implementable in a commonly-available GIS such as ESRI's ArcGIS; 2) a datainterchange standard must be demonstrated to be an effective mechanism for integrating (e.g., through the NGMDB portal) the many and varied data systems maintained by the state geological surveys, USGS, and others; and 3) a map symbolization standard must be implemented in, for example, Postscript or ArcGIS before it can be used to create a map product. Then, of course, each proposed standard must become widely adopted; otherwise, it isn't really a standard. Internationally, the NGMDB participates in venues that help to develop and refine the U.S. standards. These venues also bring our work to the international community, thereby promoting greater standardization with other countries.

Specific accomplishments in 2007 include:

1. Coordinated work on the new Federally-endorsed (FGDC) geologic map symbolization standard, especially preparation of the printed version of the standard, and the Postscript implementation, which will be a USGS publication. Responded to inquiries and comments from users. Redesigned the FGDC Geologic Data Subcommittee website, and posted the PDF version of the standard there (http://ngmdb. usgs.gov/fgdc_gds/).

2. Served as Chair of the FGDC Geologic Data Subcommittee.

3. Organized and led the eleventh annual "Digital Mapping Techniques" workshop. Developed the agenda, solicited presentations, and worked to prepare the workshop proceedings. Edited and prepared for publication the workshop Proceedings from the previous year's meeting (DMT '06, Columbus, $\mathrm{OH})$. These meetings have helped the geosci- 
ence community to converge on more standardized approaches for digital mapping and GIS analysis.

4. Served as committee Secretary and as member of the U.S. Geologic Names Committee. Assisted in proposal of geologic time scale and color scheme that was adopted by the USGS (http://pubs.usgs.gov/ $\left.f_{s} / 2007 / 3015 /\right)$.

5. Served as Coordinator of the North American Geologic Map Data Model Steering Committee (NADMSC) and managed the NADM website (http:// nadm-geo.org/).

6. Served as U.S. representative to DIMAS, the global standards body serving the Commission for the Geological Map of the World (http://www.geology. cz/dimas). Provided technical information and guidance on data model and science terminology standards under development in North America, and participated in DIMAS initiatives to develop global standards.

7. Served as the U.S. Council Member to the IUGS Commission for the Management and Application of Geoscience Information ("CGI", http://www.cgiiugs.org/).

8. Participated in the IUGS CGI's Interoperability Working Group (https://www.seegrid.csiro.au/twiki/ bin/view/CGIModel/InteroperabilityWG). Helped to develop consensus for international standards for a geologic data model. Contributed to development of the GeoSciML schema, which is proposed as an international data-exchange standard for geoscience information.

9. Served as IUGS CGI liaison to the Multi-Lingual Thesaurus Working Group. This group is enabling global exchange of geoscience information by developing a common science vocabulary that is translated into many languages.

10. Served as USGS technical representative to the international "OneGeology" project ( $h t t p: / / w w w$. onegeology.org/). Provided technical guidance and support to the project.

11. Participated in USGS-AASG meetings on "Geoinformatics", intended to identify common ground for building the infrastructure needed to support projects such as the NGMDB.

12. Continued to interact with ESRI regarding: a) collaboration on an ArcGIS Geology Data Model that could be compatible with the NGMDB data model now under development; and b) ESRI implementation of the FGDC geologic map symbolization standard.

\section{Phase Three}

It is a commonly held vision that the National Geologic Map Database will be a repository of geologic map and related information, managed in a system distributed among the USGS and State geological surveys. The system would offer public access to complex, attributed vector and raster geoscience data, and allow users to perform queries, create derivative maps, and download source and derived map data. To realize this vision requires: 1) close collaboration among the partners; 2) a flexible and evolving set of standards, guidelines, and data management protocols; 3) a clear understanding of the technical challenges to building such a system; and 4) an adequate source of funding. Phase Three is designed to foster an environment where the distributed database system can be prototyped while these requirements are being addressed by the partners. The NGMDB is prototyping a system with two components: 1) a centralized database containing digital geologic map coverage for the U.S. at selected intermediate and small scales, and 2) distributed access to a more comprehensive set of map data held by the NGMDB collaborators (principally the state geological surveys). All information in the system would retain metadata that clearly indicates its source (e.g., who created the source map and, ideally, details on the origin and modifications to a particular contact, fault, or map unit attributes).

This is a long-term effort whose fully realized form is, at this time, difficult to predict. Because it is a complex task that depends on data availability, technological evolution, skilled personnel (in high demand and, therefore, in short supply), and the ability for all participants to reach consensus on the approach, the scope and details of Phase Three are systematically explored and developed through prototypes. Each prototype addresses aspects of the database design, implementation in GIS software (e.g., ArcGIS), standard science terminologies, and software tools designed to facilitate data entry. Each prototype is presented to the participants and the public for comment and guidance. The focus of new prototypes is guided by the comments received.

For example, in FY01 the NGMDB completed a major prototype in cooperation with the Kentucky Geological Survey, the Geological Survey of Canada, the University of California at Santa Barbara, and the private sector (Soller and others, 2002). The principal goal was to implement the NADM draft standard logical data model in a physical system, and to demonstrate certain very basic, essential characteristics of the envisioned system. That prototype was demonstrated and discussed at numerous scientific meetings, and its data model contributed to development of the North American conceptual data model. The project then considered plans to improve that system by adding more complex geologic data and software functionality. However, it would have required significant new funding at a time when technology and geoscience community ideas on database design were rapidly evolving. Therefore, a more limited approach is being pursued in the current prototype, in which draft NGMDB science 
terminologies, a NADM-based database design, and data-entry tools were devised in order for the project to develop a Map Data Portal that offers public access to a simplified view of GIS data held by various cooperating agencies.

Specific accomplishments include:

1. Significant advances were made in design of the NGMDB prototype Map Data Portal. Components developed in previous years (e.g., a NADM-derived data model (Richard and others, 2004 and 2005), a Data-Entry Tool, and NADM-derived science terminologies) were brought together to demonstrate for USGS and AASG consideration a system model in which the full richness and variability of map information content is managed by the publishing agencies or other repositories, with a subset of the information made available via the NGMDB data portal for browsing and querying and, on a limited basis, for downloading in formats such as Arc shapefiles and GeoSciML. Our overall philosophy is to provide through this Portal a simplified view, a glimpse, of the maps and, as in the Map Catalog, to then direct the user to the source (the publishing agency) to obtain the actual data. Because the information provided through this
Portal uses standardized, controlled science terms, it presents a somewhat unified or harmonized view of the source maps, which should assist users in understanding the basic aspects of a region's geology.

Technical and management involvement in Portal development, and the datasets served therein, was obtained from the geological surveys of Washington, Oregon, Idaho, and Arizona, and from Portland State University and the University of Arizona. The NGMDB Map Data Portal was demonstrated at the GSA Geoinformatics'07, DMT'07, and AASG'07 annual meetings - the response from management and technical staff was highly favorable, encouraging development to proceed.

The Portal's general design and workflow are shown in Figure 1. Map data are incorporated into the Portal's database by means of a data-import tool that facilitates attribution of map units with controlled vocabulary terms. The tool, which manages the map data in a local copy of NGMDB's database design, then exports it to an interchange format for loading into the Portal's PostGIS database. Presently, we are using Shapefiles as the interchange format, but envision using GeoSciML when it

\section{NGMDB Data Portal (Phase 3)}

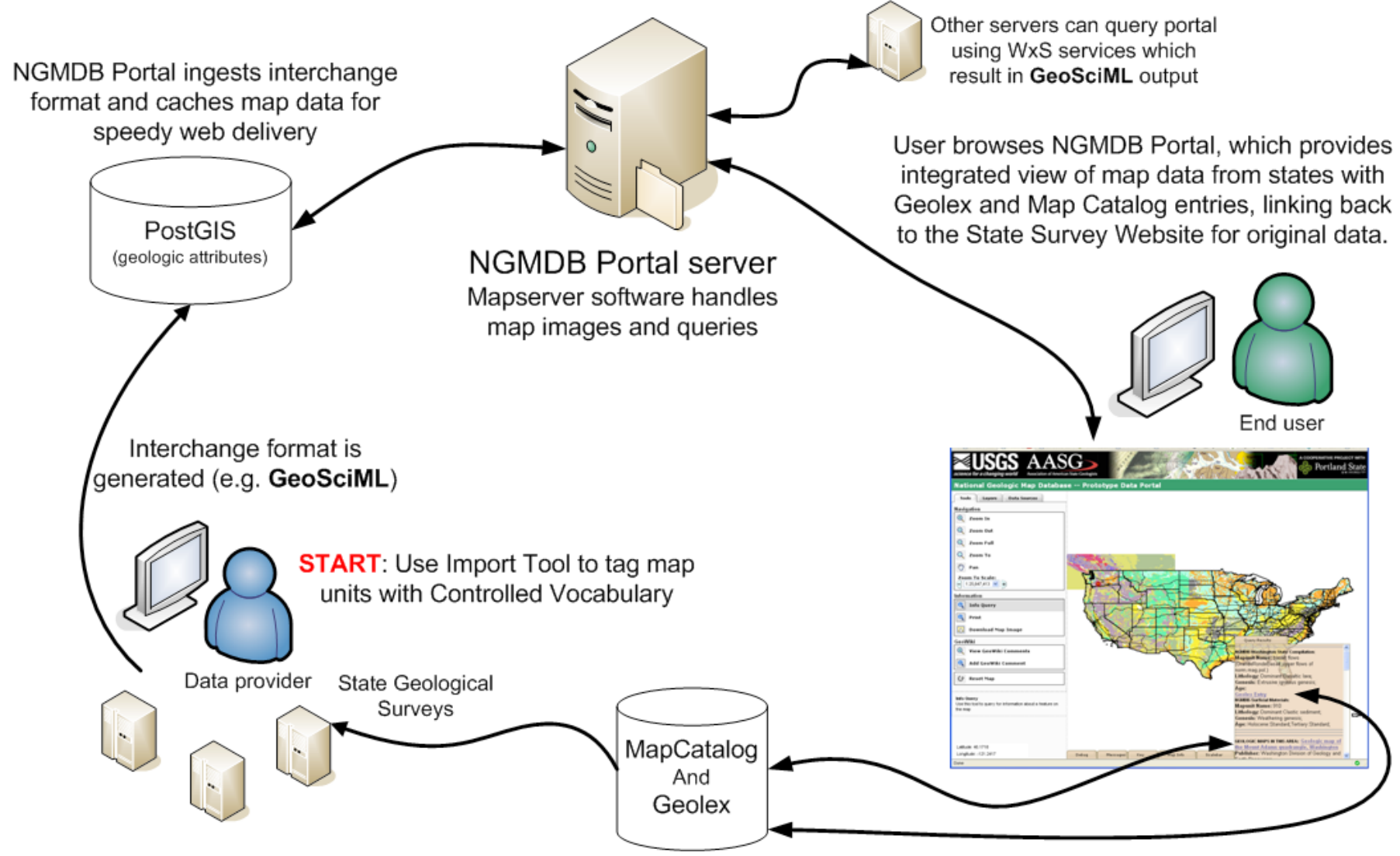

Figure 1. The NGMDB prototype Map Data Portal - general design and workflow. See text for explanation. 
has matured and stabilized. When the map attributes and geometry are loaded into PostGIS, various map portrayals (e.g., geologic materials, geologic age) are prepared and cached as images. This pre-processing is essential in a portal of this type, because we intend to only provide the user with a quick overview of the geology rather than serving as a platform for in-depth query and analysis - for those needs, we link users to the source data, as shown along the bottom of the Figure. Mapserver software and an open-source interface (Map-Fu) provide the user with map display and simple queries such as "identify" a map unit. For that query, the displayed information includes links to the source map (in the NGMDB Map Catalog) and to geologic name information (in Geolex). These links provide the mechanism to direct users to the agency that published and maintains the source map data, and is our first step in tying this Portal to the Phase One databases. The Portal also will provide access to the map data through one or more OGC-compliant Web Services (hence "WxS" in Figure 1); this is intended to promote direct user access to the database, as well as access by other portals.

2. Concluded work for the Database Interoperability Testbed \#2, which was sponsored by the IUGS CGI's Interoperability Working Group; this testbed demonstrated among eight agencies worldwide a limited implementation of the draft international geoscience data-interchange format, GeoSciML. This is a vitally important activity for the NGMDB, and for the USGS and AASG in general. The NGMDB contribution involved the USGS, Arizona Geological Survey, Portland State University, Oregon Department of Geology and Mineral Industries, and the University of Arizona. Began work on enhancements to GeoSciML, in preparation for release of a new version to support Testbed \#3, which will be conducted in 2008 .

3. In order to create modern, small-scale, consistent geologic map coverage for the U.S., the NGMDB project is converting the recently published Geologic Map of North America (GMNA) to digital format. This is a daunting task, and so an area was selected in which a prototype map database would be developed (it included part of the U.S., Canada, and the Pacific Ocean). The prototype map database was created and subjected to peer review at the DMT'06 meeting (Garrity and Soller, 2007). This prototype demonstrated the feasibility of converting the enormously complex map files from Adobe Illustrator to ArcGIS.

\section{ACKNOWLEDGMENTS}

I thank the NGMDB project staff and collaborators for their enthusiastic participation and expertise, without whom the project would not be possible. In particular, I thank:
Nancy Stamm (USGS, Reston; Geolex database manager and associate project chief); Alex Acosta, Dennis McMacken, Michael Gishey, Ed Pfeifer, and Jana Ruhlman (USGS, Flagstaff, Phoenix, and Tucson, AZ; Website and database management), Chuck Mayfield (USGS, Menlo Park; Map Catalog content), Robert Wardwell and Justine Takacs (USGS, Vancouver, WA, and Reston, VA; Image Library), Steve Richard (Arizona Geological Survey / USGS, Tucson, AZ; Phase 3 - data model and science terminology), Jon Craigue (University of Arizona /USGS, Tucson, AZ; Phase 3 - data-entry tool), and David Percy (Portland State University; Phase 3 Data Portal). I also thank the many committee members who provided technical guidance and standards (Appendix A).

\section{REFERENCES}

Garrity, C.P., and Soller, D.R., 2007, Prototype GIS Database for the DNAG Geologic Map of North America, in D.R. Soller, ed., Digital Mapping Techniques '06 - Workshop Proceedings: U.S. Geological Survey Open-file Report 2007-1285, p. 197-201, available at http://pubs.usgs.gov/ of/2007/1285/pdf/Garrity.pdf.

Richard, S.M., Craigue, J.A., and Soller, D.R., 2004, Implementing NADM C1 for the National Geologic Map Database, in D.R. Soller, ed., Digital Mapping Techniques '04 - Workshop Proceedings: U.S. Geological Survey Open-file Report 2004-1451, p. 111-144, available at http://pubs.usgs. gov/of/2004/1451/richard/.

Richard, S.M., Craigue, J.A., and Soller, D.R., 2005, NGMDB Geologic Map Feature Class Model, in D.R. Soller, ed., Digital Mapping Techniques '05 - Workshop Proceedings: U.S. Geological Survey Open-file Report 2005-1428, p. 143-158, available at http://pubs.usgs.gov/of/2005/1428/ richard/.

Soller, D.R., 2005, Assessing the Status of Geologic Map Coverage of the United States-A New Application of the National Geologic Map Database, in D.R. Soller, ed., Digital Mapping Techniques '05 - Workshop Proceedings: U.S. Geological Survey Open-file Report 2005-1428, p.41-47, available at $h t t p: / / p u b s . u s g s . g o v / o f / 2005 / 1428 /$ soller2/.

Soller, D.R., 2006, The National Geologic Map Database Project: Overview and Progress, in D.R. Soller, ed., Digital Mapping Techniques '06 - Workshop Proceedings: U.S. Geological Survey Open-file Report 2007-1285, p. 7-13, available at http://pubs.usgs.gov/of/2007/1285/pdf/Soller. $p d f$.

Soller, D.R., Brodaric, Boyan, Hastings, J.T., Wahl, Ron, and Weisenfluh, G.A., 2002, The central Kentucky prototype: An object-oriented geologic map data model for the National Geologic Map Database: U.S. Geological Survey Open-File Report 02-202, 38 p., available at http://pubs. usgs.gov/of/2002/of02-202/. 


\section{Appendix A. Principal committees and people collaborating with the National Geologic Map Database project.}

\author{
Geologic Data Subcommittee of the Federal Geographic \\ Data Committee:
}

Dave Soller (U.S. Geological Survey and Subcommittee Chair)

Jerry Bernard (USDA-Natural Resources Conservation Service)

Mark Crowell (Dept. of Homeland Security, Federal Emergency Mgmt. Agency)

Jim Gauthier-Warinner (U.S. Forest Service, Minerals and Geology Management)

Laurel T. Gorman (U.S. Army Engineer Research and Development Center)

John L. LaBrecque (National Aeronautics and Space Administration)

Lindsay McClelland (National Park Service)

Jay Parrish (State Geologist, Pennsylvania Geological Survey)

George F. Sharman (NOAA National Geophysical Data Center)

Dave Zinzer (Minerals Management Service)

\section{Map Symbol Standards Committee:}

Dave Soller (U.S. Geological Survey and Committee Coordinator)

Tom Berg (State Geologist, Ohio Geological Survey) Bob Hatcher (University of Tennessee, Knoxville)

Mark Jirsa (Minnesota Geological Survey)

Taryn Lindquist (U.S. Geological Survey)

Jon Matti (U.S. Geological Survey)

Jay Parrish (State Geologist, Pennsylvania Geological Survey) Jack Reed (U.S. Geological Survey)

Steve Reynolds (Arizona State University)

Byron Stone (U.S. Geological Survey)

\section{AASG/USGS Data Capture Working Group:}

Dave Soller (U.S. Geological Survey and Working Group Chair)

Warren Anderson (Kentucky Geological Survey)

Rick Berquist (Virginia Geological Survey)

Elizabeth Campbell (Virginia Division of Mineral Resources)

Rob Krumm (Illinois State Geological Survey)

Scott McCulloch (West Virginia Geological and Economic Survey)

Gina Ross (Kansas Geological Survey)

George Saucedo (California Geological Survey)

Barb Stiff (Illinois State Geological Survey)

Tom Whitfield (Pennsylvania Geological Survey)
DMT Listserve:

Maintained by Doug Behm, University of Alabama

North American Data Model Steering Committee:

Dave Soller (U.S. Geological Survey and Committee Coordinator)

Tom Berg (Ohio Geological Survey)

Boyan Brodaric (Geological Survey of Canada and Chair of the Data Model Design Technical Team)

Peter Davenport (Geological Survey of Canada)

Bruce Johnson (U.S. Geological Survey and Chair of the Data Interchange Technical Team)

Rob Krumm (Illinois State Geological Survey)

Scott McColloch (West Virginia Geological and Economic Survey)

Steve Richard (Arizona Geological Survey)

Loudon Stanford (Idaho Geological Survey)

Jerry Weisenfluh (Kentucky Geological Survey)

IUGS Commission for the Management and Application of Geoscience Information:

Dave Soller (U.S. Geological Survey, Council Member)

Conceptual Model/Interchange Task Group (of the Interoperability Working Group of the IUGS Commission for the Management and Application of Geoscience Information):

Steve Richard (Arizona Geological Survey / U.S. Geological Survey, Task Group Member)

DIMAS (Digital Map Standards Working Group of the Commission for the Geological Map of the World):

Dave Soller (U.S. Geological Survey, Working Group Member)

NGMDB contact-persons in each State geological survey:

These people help the NGMDB with the Geoscience Map Catalog and GEOLEX. Please see http://ngmdb.usgs.gov/ info/statecontacts.html for this list.

These groups have fulfilled their mission and are no longer active:

\section{NGMDB Technical Advisory Committee:}

Boyan Brodaric (Geological Survey of Canada)

David Collins (Kansas Geological Survey)

Larry Freeman (Alaska Division of Geological \& Geophysical Surveys)

Jordan Hastings (University of California, Santa Barbara)

Dan Nelson (Illinois State Geological Survey)

Stephen Richard (Arizona Geological Survey)

Jerry Weisenfluh (Kentucky Geological Survey) 


\section{AASG/USGS Metadata Working Group:}

Peter Schweitzer (U.S. Geological Survey and Working Group Chair)

Dan Nelson (Illinois State Geological Survey)

Greg Hermann (New Jersey Geological Survey)

Kate Barrett (Wisconsin Geological and Natural History Survey)

Ron Wahl (U.S. Geological Survey)

\section{AASG/USGS Data Information Exchange Working Group:}

Dave Soller (U.S. Geological Survey and Working Group Chair)

Ron Hess (Nevada Bureau of Mines and Geology)

Ian Duncan (Virginia Division of Mineral Resources)

Gene Ellis (U.S. Geological Survey)

Jim Giglierano (Iowa Geological Survey)

\section{AASG/USGS Data Model Working Group:}

Gary Raines (U.S. Geological Survey and Working Group Chair)

Boyan Brodaric (Geological Survey of Canada)

Jim Cobb (Kentucky Geological Survey)

Ralph Haugerud (U.S. Geological Survey)

Greg Hermann (New Jersey Geological Survey)

Bruce Johnson (U.S. Geological Survey)

Jon Matti (U.S. Geological Survey)

Jim McDonald (Ohio Geological Survey)

Don McKay (Illinois State Geological Survey)

Steve Schilling (U.S. Geological Survey)

Randy Schumann (U.S. Geological Survey)

Bill Shilts (Illinois State Geological Survey)

Ron Wahl (U.S. Geological Survey) 


\section{Appendix B. List of progress reports on the National Geologic Map Database, and proceedings of the Digital Mapping Techniques workshops.}

Soller, D.R., editor, 2007, Digital Mapping Techniques '06Workshop Proceedings: U.S. Geological Survey Open-File Report 2007-1285, 217 p., available at http://pubs.usgs.gov/ of/2007/1285/.

Soller, D.R., editor, 2005, Digital Mapping Techniques '05Workshop Proceedings: U.S. Geological Survey Open-File Report 2005-1428, 268 p., available at http://pubs.usgs.gov/ of/2005/1428/.

Soller, D.R., editor, 2004, Digital Mapping Techniques '04Workshop Proceedings: U.S. Geological Survey Open-File Report 2004-1451, 220 p., available at http://pubs.usgs.gov/ of/2004/1451/.

Soller, D.R., editor, 2003, Digital Mapping Techniques '03Workshop Proceedings: U.S. Geological Survey Open-File Report 03-471, 262 p., available at http://pubs.usgs.gov/ of/2003/of03-471/.

Soller, D.R., editor, 2002, Digital Mapping Techniques '02Workshop Proceedings: U.S. Geological Survey Open-File Report 02-370, 214 p., available at http://pubs.usgs.gov/ of $/ 2002 /$ of02-370/.

Soller, D.R., editor, 2001, Digital Mapping Techniques '01Workshop Proceedings: U.S. Geological Survey Open-File Report 01-223, 248 p., available at http://pubs.usgs.gov/ of/2001/of01-223/.

Soller, D.R., editor, 2000, Digital Mapping Techniques '00Workshop proceedings: U.S. Geological Survey Open-file Report 00-325, 209 p., available at http://pubs.usgs.gov/of/ of $00-325 \%$.

Soller, D.R., editor, 1999, Digital Mapping Techniques '99Workshop proceedings: U.S. Geological Survey Open-file Report 99-386, 216 p., available at http://pubs.usgs.gov/of/ of99-386/front.html.

Soller, D.R., editor, 1998, Digital Mapping Techniques '98Workshop Proceedings: U.S. Geological Survey Open-File Report 98-487, 134 p., available at http://pubs.usgs.gov/of/ of $98-487 /$.

Soller, D.R., editor, 1997, Proceedings of a workshop on digital mapping techniques: Methods for geologic map data capture, management, and publication: U.S. Geological Survey Open-File Report 97-269, 120 p., available at http:// pubs.usgs.gov/of/of97-269/.
Soller, D.R., 2007, The National Geologic Map Database Project: Overview and Progress, in D.R. Soller, ed., Digital Mapping Techniques '06 - Workshop Proceedings: U.S. Geological Survey Open-file Report 2007-1285, p. 7-13, available at http://pubs.usgs.gov/of/2007/1285/pdf/Soller. $p d f$.

Soller, D.R., Berg, T.M., and Stamm, N.R., 2005, The National Geologic Map Database Project: Overview and Progress, in D.R. Soller, ed., Digital Mapping Techniques '05 - Workshop Proceedings: U.S. Geological Survey Open-file Report 2005-1428, p. 23-40, available at http://pubs.usgs.gov/ of/2005/1428/soller1/.

Soller, D.R., Berg, T.M., and Stamm, N.R., 2004, The National Geologic Map Database project: Overview and progress, in Soller, D.R., ed., Digital Mapping Techniques '04Workshop Proceedings: U.S. Geological Survey Open-File Report 2005-1451, p.15-31, available at http://pubs.usgs. gov/of/2004/1451/soller/.

Soller, D.R., and Berg, T.M., 2003, The National Geologic Map Database project: Overview and progress, in Soller, D.R., ed., Digital Mapping Techniques '03-Workshop Proceedings: U.S. Geological Survey Open-File Report 03-471, p. 57-77, available at http://pubs.usgs.gov/of/2003/ of03-471/soller1/.

Soller, D.R., and Berg, T.M., 2002, The National Geologic Map Database: A progress report, in Soller, D.R., editor, Digital Mapping Techniques ' $02-$ Workshop proceedings: U.S. Geological Survey Open-file Report 02-370, p. 75-83, available at $h t t p: / / p u b s . u s g s . g o v / o f / 2002 / o f 02-370 /$ soller2. html.

Soller, D.R., and Berg, T.M., 2001, The National Geologic Map Database-A progress report, in Soller, D.R., editor, Digital Mapping Techniques ' $01-$ Workshop proceedings: U.S. Geological Survey Open-file Report 01-223, p. 51-57, available at $h t t p: / / p u b s . u s g s . g o v / o f / 2001 / o f 01-223 /$ soller 1. html.

Soller, D.R., and Berg, T.M., 2000, The National Geologic Map Database-A progress report, in Soller, D.R., editor, Digital Mapping Techniques ' 00 -Workshop proceedings: U.S. Geological Survey Open-file Report 00-325, p. 27-30, available at http://pubs.usgs.gov/of/of00-325/soller2.html.

Soller, D.R., and Berg, T.M., 1999a, Building the National Geologic Map Database: Progress and challenges, in Derksen, C.R.M, and Manson, C.J., editors, Accreting the continent's collections: Geoscience Information Society Proceedings, v. 29, p. 47-55, available at http://ngmdb.usgs. gov/info/reports/gisproc98.html. 
Soller, D.R., and Berg, T.M., 1999b, The National Geologic Map Database-A progress report, in Soller, D.R., editor, Digital Mapping Techniques '99-Workshop proceedings: U.S. Geological Survey Open-file Report 99-386, p. 31-34, available at http://pubs.usgs.gov/of/of99-386/soller1.html.

Soller, D.R., and Berg, T.M., 1998, Progress Toward Development of the National Geologic Map Database, in Soller, D.R., editor, Digital Mapping Techniques '98-Workshop proceedings: U.S. Geological Survey Open-file Report 98-487, p. 37-39, available at http://pubs.usgs.gov/of/of98487/soller2.html.
Soller, D.R., and Berg. T.M., 1997, The National Geologic Map Database-A progress report: Geotimes, v. 42, no. 12, p. 29-31, available at http://ngmdb.usgs.gov/info/reports/ geotimes97.html.

Soller, D.R., and Berg, T.M., 1995, Developing the National Geologic Map Database: Geotimes, v. 40, no. 6, p. 16-18, available at http://ngmdb.usgs.gov/info/reports/geotimes 95 . html. 


\title{
National Cooperative Soil Survey National Soil Information System
}

\author{
By Jim R. Fortner \\ National Soil Survey Center \\ Natural Resources Conservation Service \\ 100 Centennial Mall North, Rm. 152 \\ Lincoln, NE 68508-3866 \\ Phone: (402) 437-5755 \\ Fax: (402) 437-5336 \\ email: jim.fortner@lin.usda.gov
}

\section{BRIEF HISTORY AND STATUS OF SOIL SURVEY}

The organized soil survey effort began in the United States in 1899. The Soil Conservation Service (SCS), now called Natural Resources Conservation Service (NRCS), was designated the lead agency by legislation in 1951. SCS was assigned responsibility for mapping all privately owned land in the Nation. Publicly owned land is the responsibility of the respective managing agency. In the 1950s, the National Cooperative Soil Survey (NCSS) was formed. The NCSS consists of NRCS (which is the lead agency), partners (including other Federal land management agencies such as the United States Forest Service, the Bureau of Land Management, the Bureau of Indian Affairs, and the National Park Service), State Agricultural Experiment Stations, and local governmental entities.

In the same timeframe in which the NCSS was formed, the so-called modern era of soil survey began with the publication of reports based on soil survey areas. In the eastern two-thirds of the United States, the soil survey area generally coincides with a county or parish. In the western one-third, the survey area is commonly a part or parts of one or more counties or is publicly-owned land. To date, more than 95 percent of privately owned land has been surveyed and 92 percent of all land has been surveyed (Figure 1).

In the late 1960s, computer records were created for the estimated soil properties and interpretations of the various soil types identified in soil surveys. In the mid-1980s, a state-bystate database of these records was developed. In 1994, the current NASIS (National Soil Information System) transactional database was implemented in each state. In 2000, the NASIS databases were combined into a national centralized database.
Digitizing of soil maps began in the mid-1980s. During this period, standards for map compilation and map digitizing were developed. These standards are known as the SSURGO (Soil Survey Geographic) standards, and are available at http://soils.usda.gov/technical/handbook/contents/part647. html\#06. In the mid-1990s, a concentrated effort was begun to digitize all the completed soil maps for the Nation according to these established standards. This effort is scheduled for completion in early 2008. Unmapped areas will be digitized as they are mapped, as part of the ongoing mapping effort. The goal is to have all privately owned land surveyed by 2012 .

Late in 2003, the Soil Data Warehouse and Soil Data Mart were established to house all official soil survey (SSURGO) data and to be the central delivery point for that data. The Soil Data Warehouse stores various versions of the data dating from 2003, while the Soil Data Mart makes only the current version of data available for distribution to a wide-ranging list of customers, including the general public. Downloads of data are by individual soil survey areas.

In 2005, the Web Soil Survey (WSS) was brought online to provide public access to, and online viewing of, information in the Soil Data Mart. Figure 2 shows a schematic of how the various components of the National Soil Information System fit together. More information about the various components will be given later in this paper.

\section{How did we get here?}

- Development of the current soil survey product involved a number of significant milestones. One of the major milestones was the establishment of the National Cooperative Soil Survey organization itself. Through the NCSS, a number of standards have been developed for:

- Describing and analyzing soils 


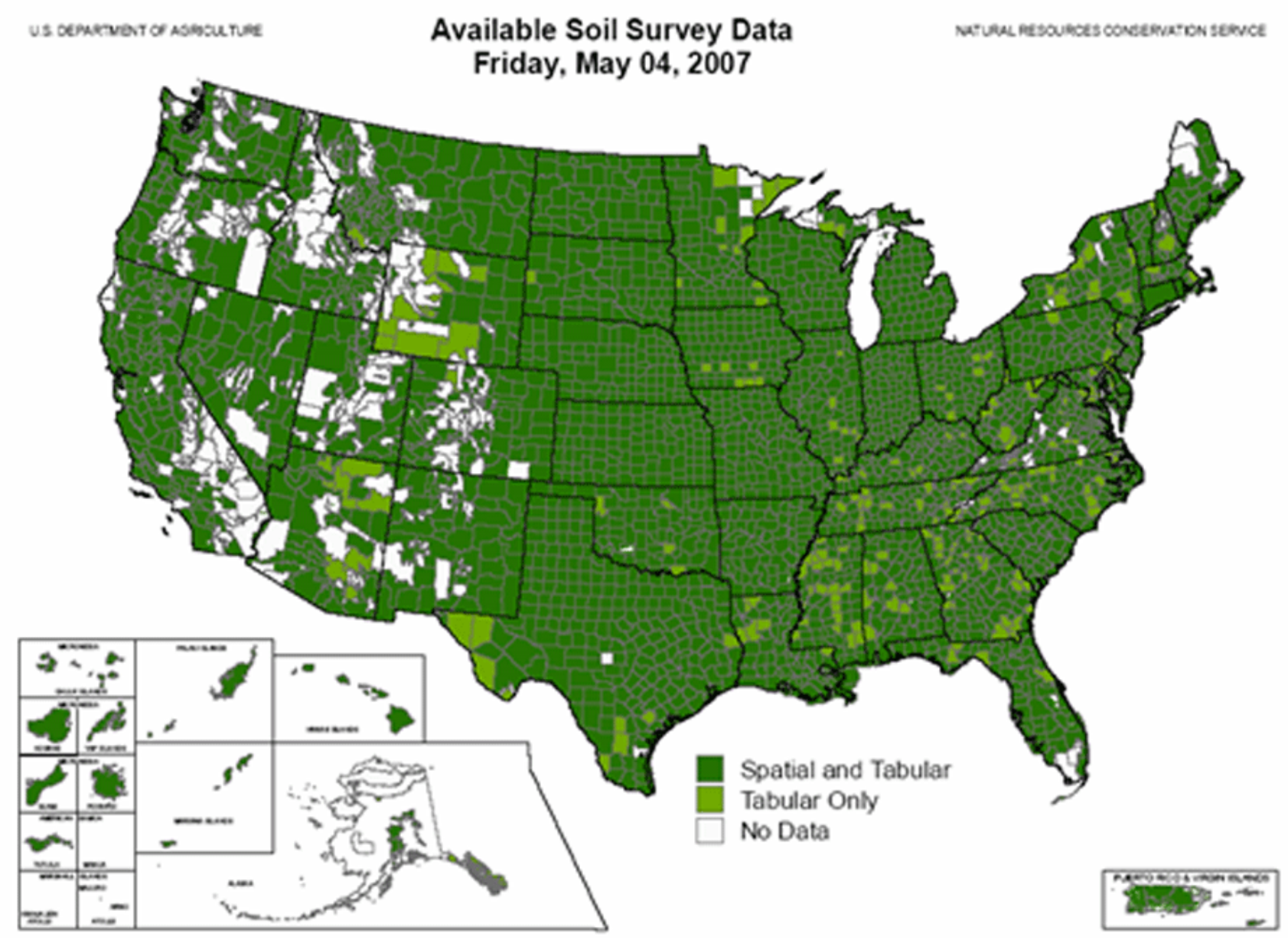

Figure 1. Soil survey data availability for the United States, possessions, and territories. For the darker green areas, maps have been digitized and are available through the Soil Data Mart and Web Soil Survey. The lighter green areas have been surveyed but are not yet digitized. White areas remain to be mapped.

- Classification of soils-Soil Taxonomy (http://soils. usda.gov/technical/classification/taxonomy/)

- Mapping scales, intensity, and procedures, including joins (joins include joining datasets and maps between soil survey areas, and between individual map sheets within a soil survey area.)

- Quality-control and quality-assurance procedures

- Database structure and content

- Map compilation and digitizing specifications

- FGDC Soil Data Standard (http://www.fgdc.gov/ standards/projects/FGDC-standards-projects/soils/ soil997.PDF)

- Interpretation criteria

- Publication format and content

- Data delivery formats.

Unless noted otherwise, these standards are documented in the National Soil Survey Handbook at http://soils.usda.gov/ technical/handbook/ and other technical references maintained by the Natural Resources Conservation Service.

The use of these standards has enabled the development of a database of soil survey data and information that is reasonably consistent across the United States. This effort continues through annual conferences to discuss and resolve ongoing and emerging issues related to soil survey and protection of this most basic of natural resources.

Information about the National Cooperative Soil Survey and its conferences can be found at http://soils.usda.gov/ partnerships/ncss/. National NCSS conferences are held in odd-numbered years, with four regional conferences being held in even-numbered years. Locations rotate throughout the regions. They are open to anyone interested in the subject matter. There is a Soil Survey Standards branch of the NRCS National Soil Survey Center that facilitates the disposition of proposed changes or additions to existing standards. 


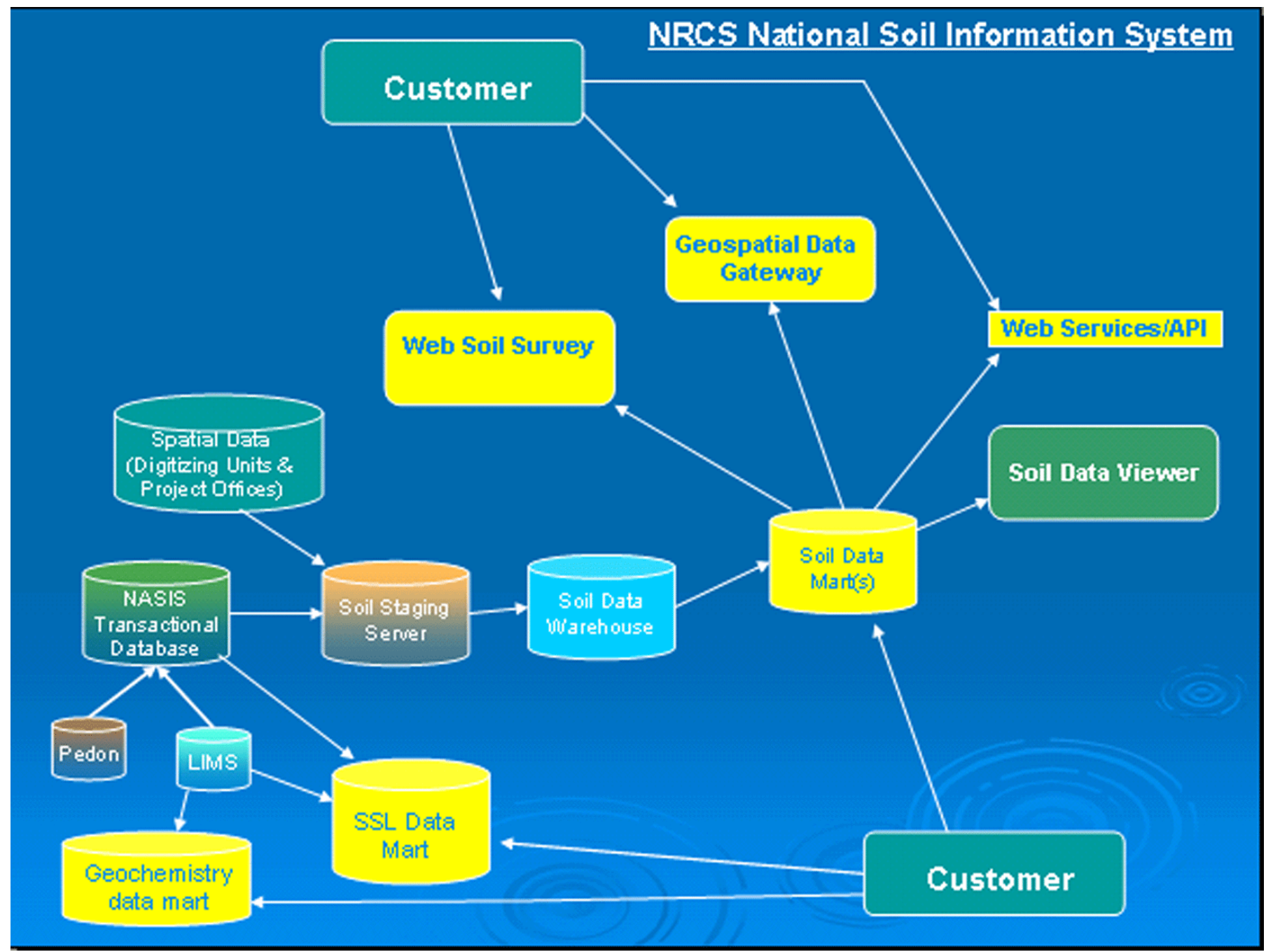

Figure 2. A schematic of the overall NRCS National Soil Information System showing data flow pathways. Major parts of the information system are explained elsewhere in this paper.

\section{MAJOR COMPONENTS OF THE NATIONAL SOIL INFORMATION SYSTEM}

\section{NASIS}

NASIS (the National Soils Information System computer application and database) is a centralized transactional database of tabular soil property and interpretive data about the soils of the United States. It includes onsite detailed descriptions of soils from about 250,000 locations. These descriptions are primarily used as supporting documentation for the soil description and the ranges of physical and chemical properties of soil map unit components. Full laboratory characterization data are available for about 32,000 of these sites. NASIS also includes the data for about 350,000 soil map units and about 1 million map unit components that accompany the soil maps. A major function of NASIS is the ability to generate soil interpretations for the map unit components using standard interpretation criteria and an interpretation system based on fuzzy logic. NCSS field soil scientists log into this database via a Web-based application to input and manage soil survey data on a daily basis.

The method of developing the digital soil maps is currently a parallel process that occurs outside the NASIS database. The soil map files are developed by the seven NRCS digitizing centers, which either digitize the hard copy maps from the field scientists or perform QC/QA functions on field-digitized maps to ensure they meet established standards. When digital map files for a soil survey area are completed, they are placed on a staging server, where they are merged with accompanying tabular data files from NASIS. Following final checking and certification, these merged files then move to the Soil Data Warehouse for storage. 


\section{Soil Data Warehouse}

This database provides central storage for the various versions of official soil survey data, including both the soil maps and the descriptive, tabular data about each soil. Periodically, a new version of data for a particular soil survey area will be exported from NASIS, certified, and posted to the warehouse database. It may contain enhanced data since the previous version because additional data elements in the database were populated, errors were corrected, data were modified after the gathering of additional documentation, and other factors. This database is not a public access point, but it is possible to retrieve older versions of data if needed.

\section{Soil Data Mart}

The Soil Data Mart contains the current version of official data from the Soil Data Warehouse and makes it publicly available for distribution to a wide-ranging list of customers. The data can be downloaded in a standard SSURGO database format for use in a local Geographic Information System (GIS), or the tabular portion of the data can be viewed online via generation of standard tabular data reports. Downloaded datasets are packaged into individual soil survey area files and are time stamped and versioned for reference purposes. Each downloaded dataset includes an FGDC compliant metadata file. Viewing of soil maps is not available here, but is available through the Web Soil Survey (see below). The Soil Data Mart can be accessed at http:// soildatamart.nrcs.usda.gov/.

\section{Soil Data Mart Web Services}

These web services provide a mechanism for users to directly access the Soil Data Mart database and acquire spatial and/or tabular data they need by writing custom SQL queries against the database. These services provide:

- The customers with the ability to link their GIS applications directly to the Soil Data Mart database and acquire soil data needed for their local application without the need to actually download a whole soil survey areas dataset as described above.

- The ability for customers to select their spatial area of interest, such as a watershed, farm field, ownership boundary, study area, etc., irrespective of soil survey area boundaries

- The flexibility to select only those data attributes of interest (spatial and/or tabular data)

- Delivery of data in various formats (HTML, XML, and ASCII delimited) for import into a customer's database system

- Data can be acquired in real-time or queued for later delivery via ftp link.
These Web services can be accessed at http:// sdmdataaccess.nrcs.usda.gov/.

\section{Web Soil Survey}

The Web Soil Survey (Figure 3) is a Web application that provides producers, governmental agencies, consultants, and others with electronic access to, and online viewing of, relevant soil and related information needed to make wise land use and management decisions. Web Soil Survey (WSS) provides an alternative to traditional hardcopy soil survey publication and a means for quicker delivery of information. It provides electronic access to full soil survey report content and access to the most current data available.

With WSS, customers can outline their geographic area of interest (AOI), as shown in (Figure 4), and can obtain available soil survey maps (Figure 5) and associated map unit data and interpretations. Thematic maps showing soil interpretations (Figure 6), various physical (Figure 7) and chemical (Figure 8) soil properties, and soil qualities (Figure 9) can be generated for the AOI. Tabular data reports (Figure 10) like those from the Soil Data Mart also can be generated. This information can be viewed online, or PDF files (Figure 11) can be generated for downloading or printing.

Web Soil Survey has a Shopping Cart function (no cost involved) that allows the user to collect a variety of thematic maps, tabular data reports, and desired explanatory information that they the user decides are important or of interest to their identified resource concern into a Custom Soil Resource Report for the AOI. Some introductory material, soil map, and map unit descriptions are automatically added to the report. When the user goes through Check Out the contents of the Shopping Cart are assembled into a single PDF file for viewing, saving or printing. Web Soil Survey can be accessed at http://websoilsurvey.nrcs.usda.gov/app/.

Enhancements to the Web Soil Survey application continue. A new version is to be released in Summer 2008. Major enhancements in this version will be a Search function to help users locate desired information in the system. Users can input a keyword or phase and the system will return one or more links to sections that contain the word or phrase. Also included in this version will be a distance measuring tool, a direct link to a glossary of soil related terms, the ability for the user to download the raw data from the Soil Data Mart that has been clipped to the AOI boundary, and the ability to tile soil and thematic maps to multiple pages. Additional and larger computer servers will also be installed in order improve performance of the system.

Future enhancements planned include the ability for the user to Save their defined AOI for later use, the ability for the user to identify multiple tracts of land within an AOI, and the ability to import an AOI boundary from an outside application. Increasing the allowable size of an AOI is also desired. 


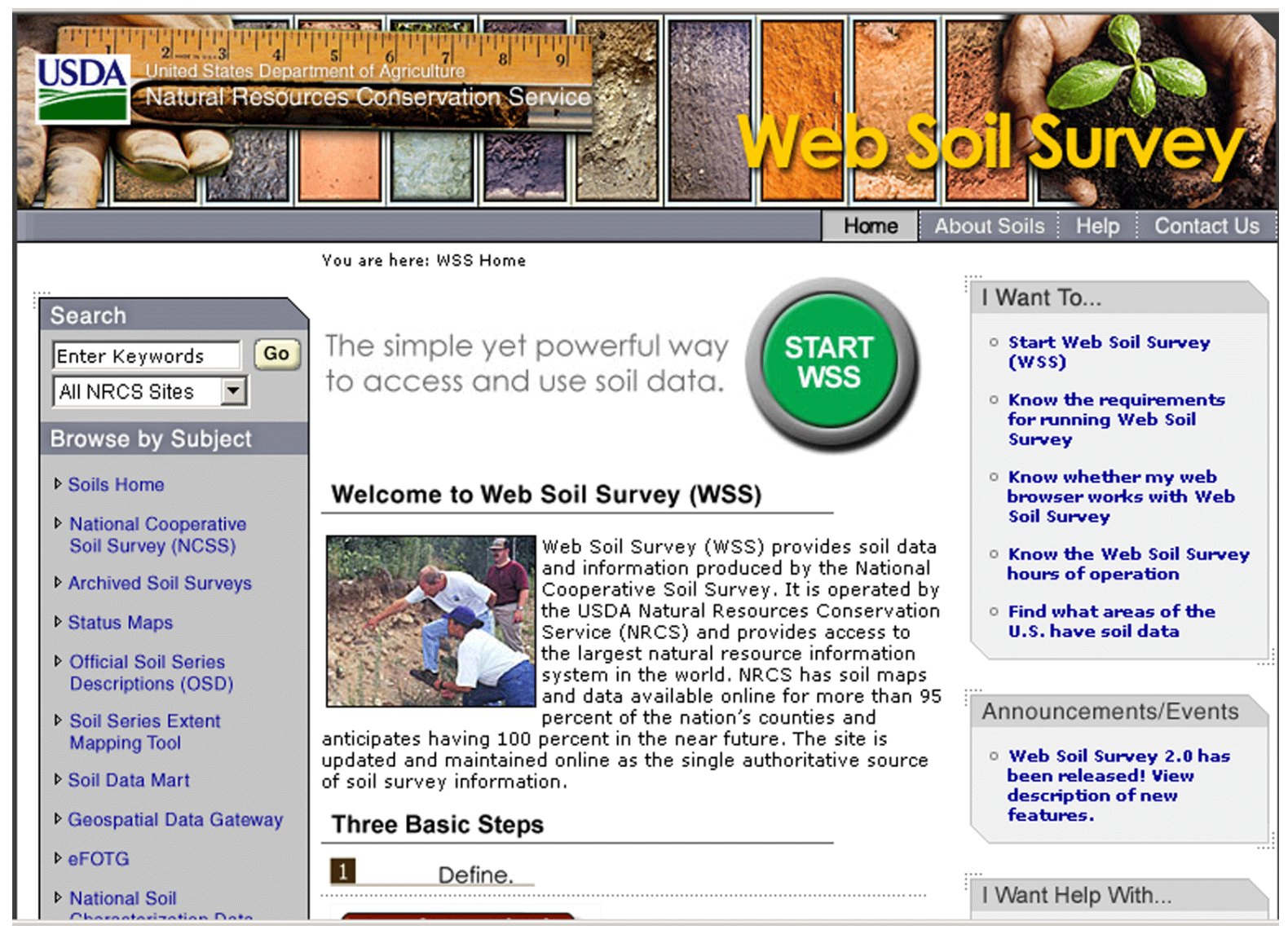

Figure 3. Web Soil Survey homepage.

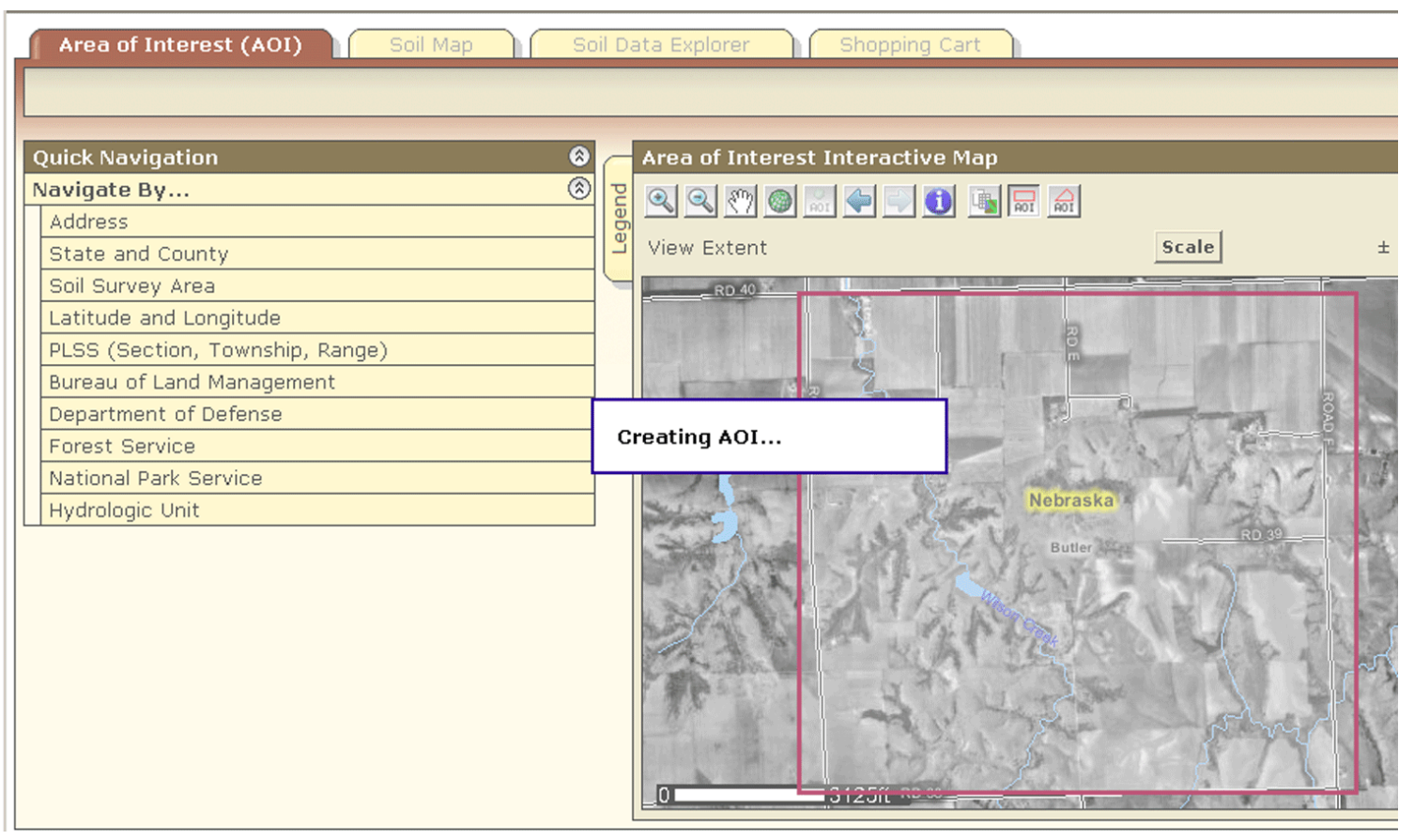

Figure 4. Defining the Area of Interest (AOI) in Web Soil Survey. A number of navigational tools are available for finding the AOI. 


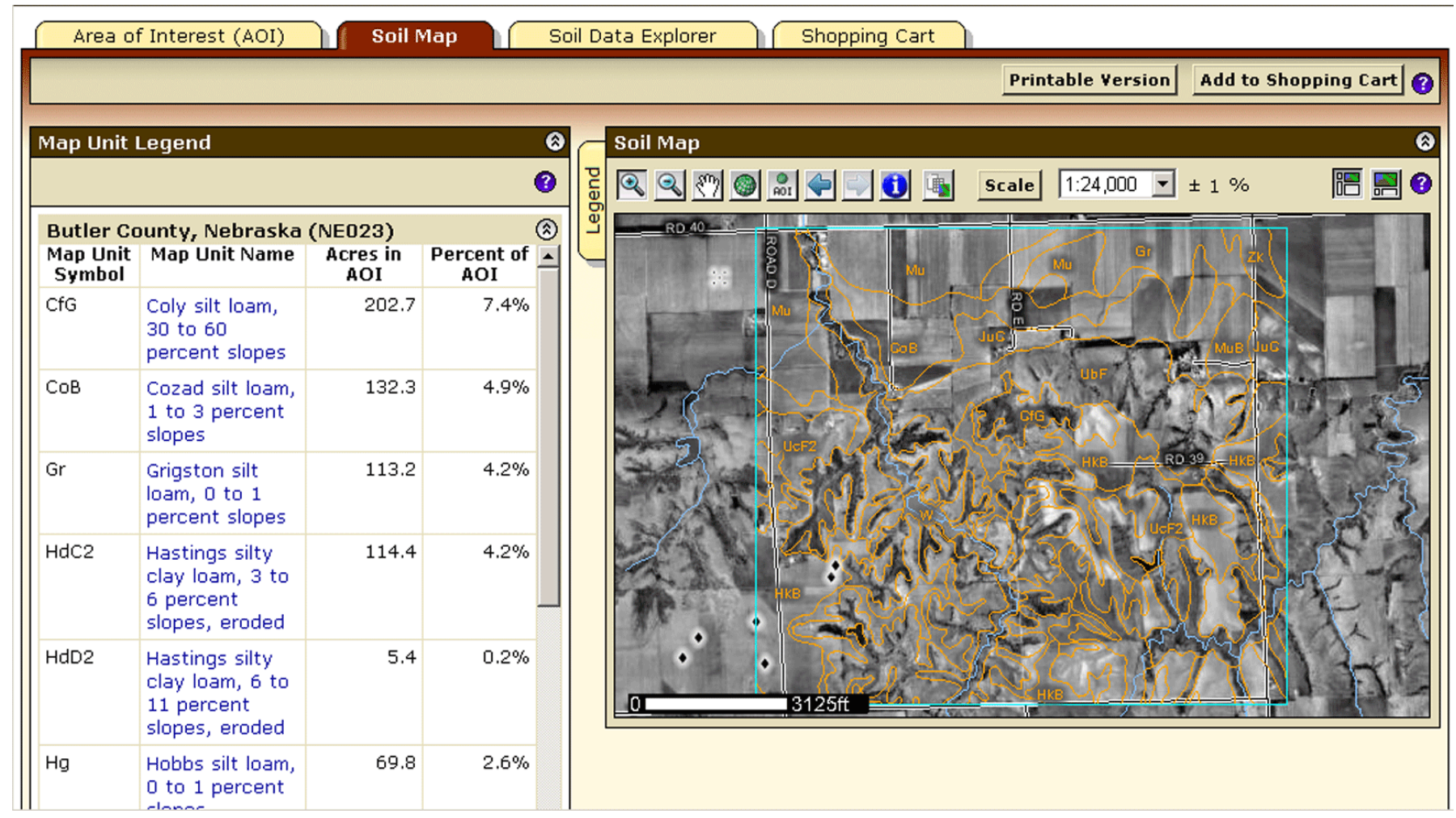

Figure 5. By selecting the Soils Map tab, the soil map of the AOI is displayed along with a list of map units in the area and their extents within the AOI. Clicking the highlighted map unit names displays a map unit description of that map unit.

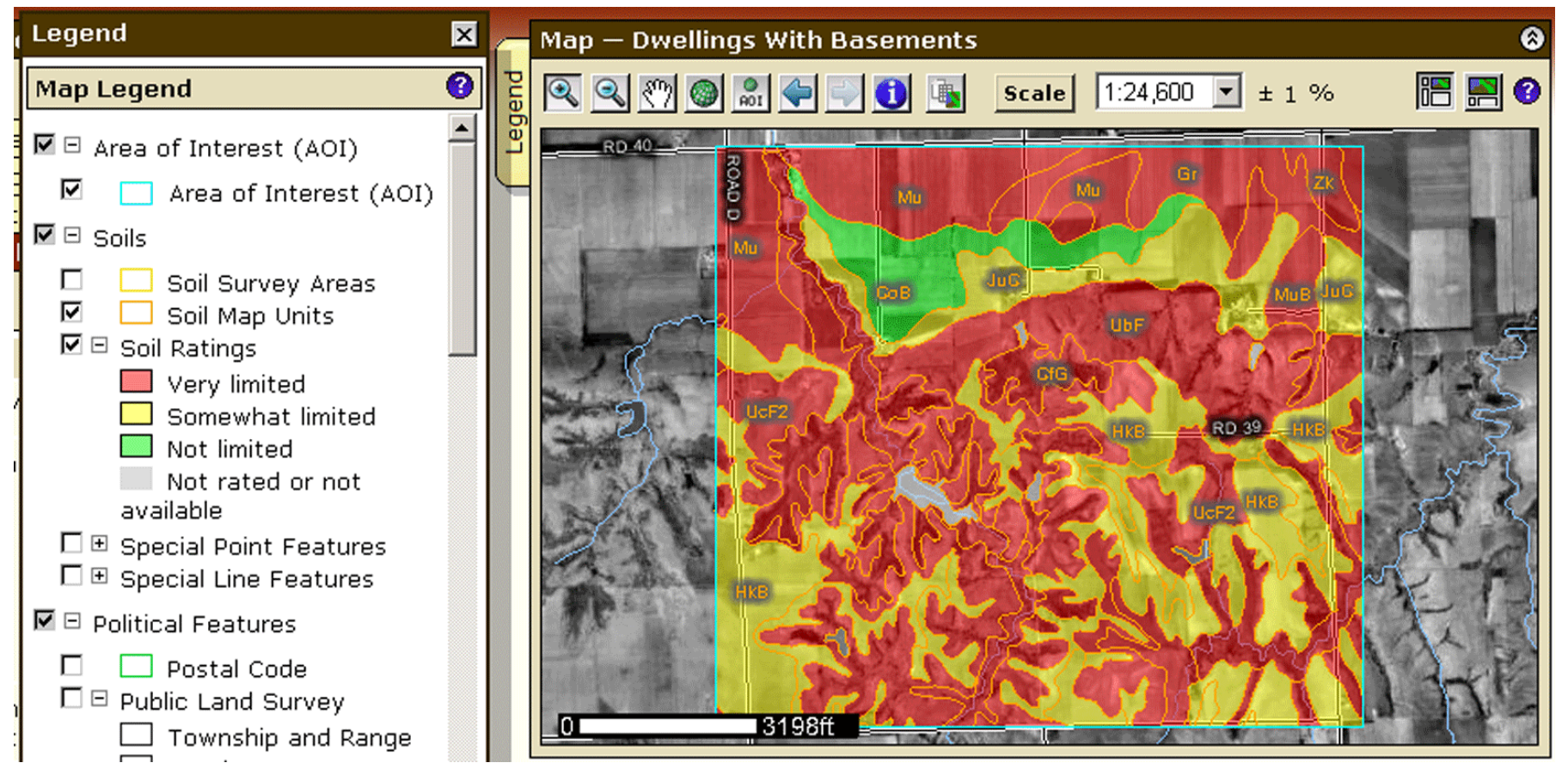

Figure 6. Thematic map showing soil interpretations available from the Web Soil Survey; here, the degree of limitations for dwellings with basements. 


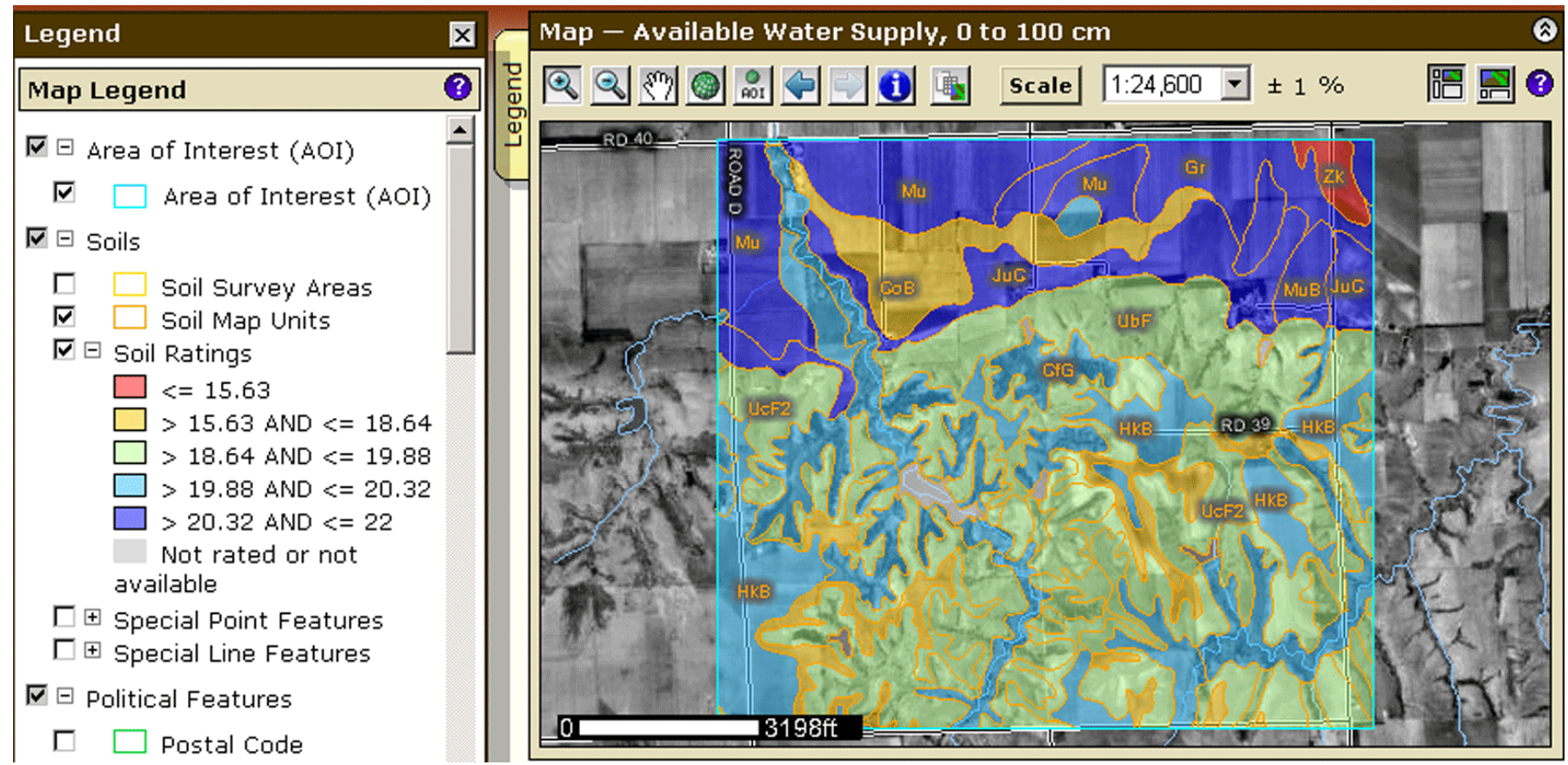

Figure 7. Thematic map showing available water capacity in 0 - to $100-\mathrm{cm}$ zone of each map unit.

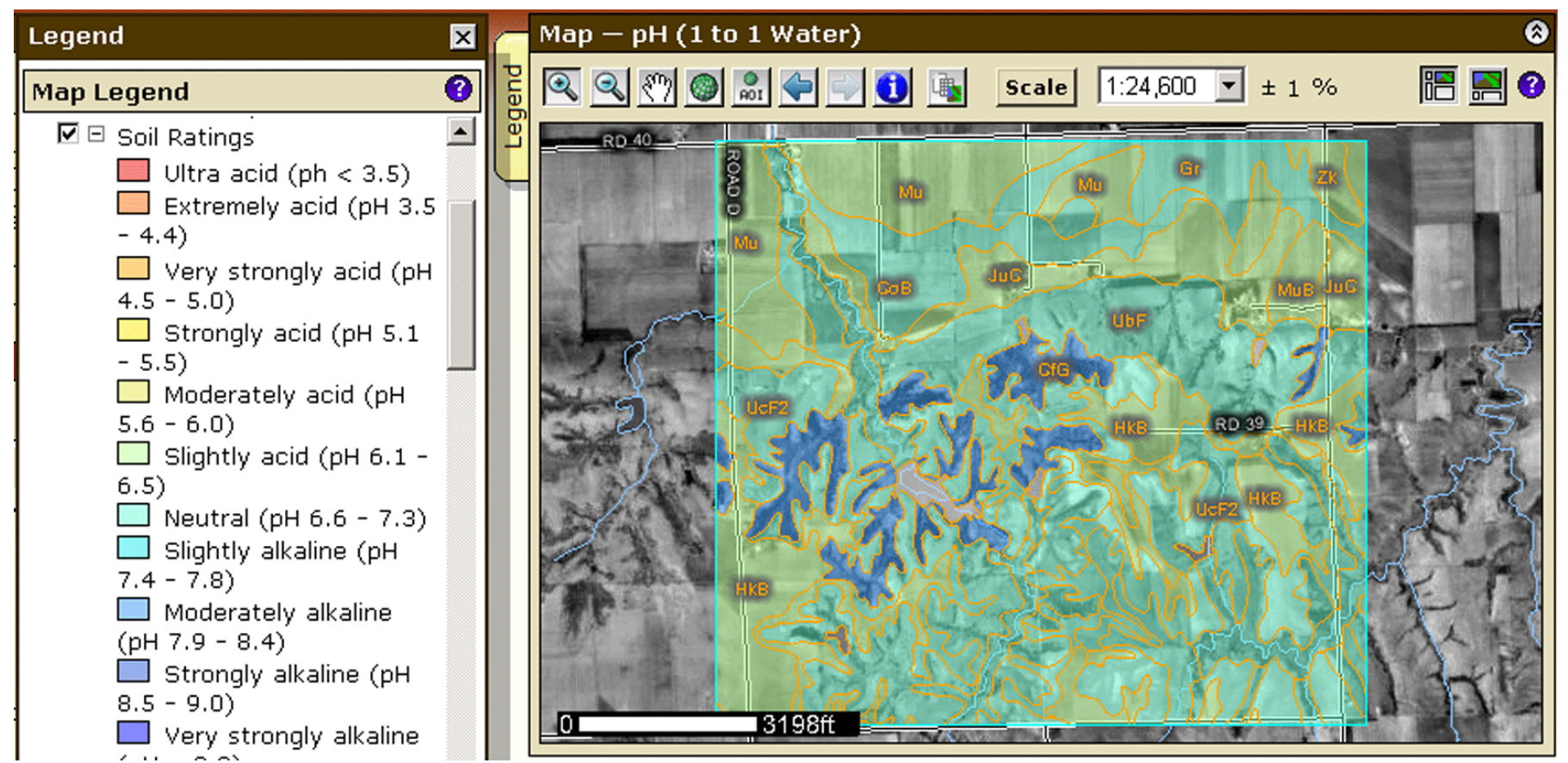

Figure 8. Thematic map showing $\mathrm{pH}$ in the surface layer of each map unit. 


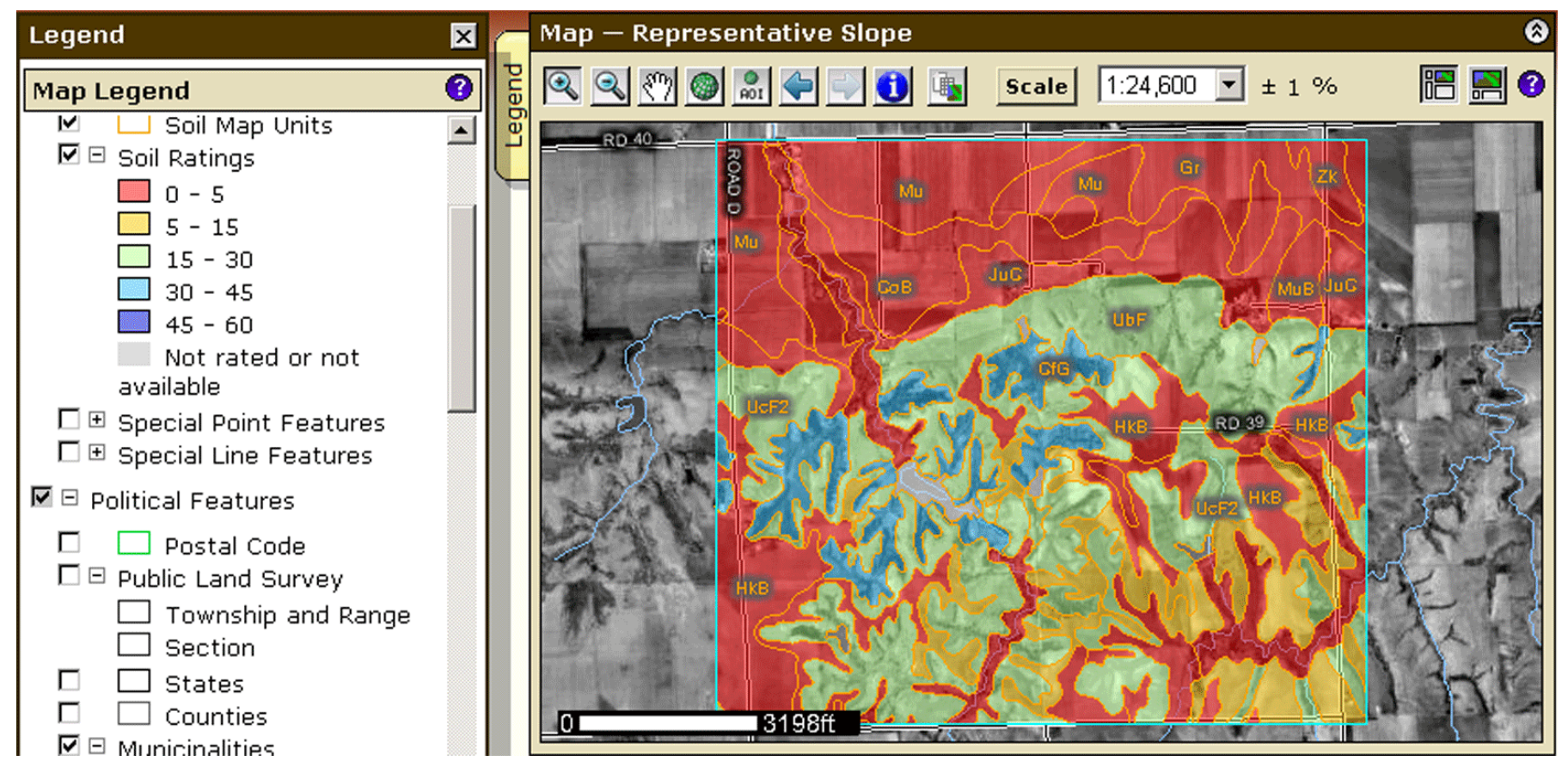

Figure 9. Thematic map showing representative percent slope of each map unit.

\begin{tabular}{|c|c|c|c|c|}
\hline \multicolumn{5}{|l|}{ Butler County, Nebraska } \\
\hline \multirow[t]{2}{*}{ Map unit symbol and name } & \multirow{2}{*}{$\begin{array}{l}\text { Pct. } \\
\text { of } \\
\text { map } \\
\text { unit }\end{array}$} & \multirow{2}{*}{$\begin{array}{l}\text { Component } \\
\text { name }\end{array}$} & \multicolumn{2}{|c|}{ Land Capability Subclass } \\
\hline & & & Nonirrigated & Irrigated \\
\hline \multicolumn{5}{|l|}{$\begin{array}{l}\mathrm{CfG}-\text { Coly silt loam, } 30 \text { to } 60 \\
\text { percent slopes }\end{array}$} \\
\hline & 100 & Coly & $7 e$ & - \\
\hline \multicolumn{5}{|l|}{$\begin{array}{l}\mathrm{CoB}-\mathrm{Cozad} \text { silt loam, } 1 \text { to } 3 \\
\text { percent slopes }\end{array}$} \\
\hline & 100 & Cozad & $2 e$ & $2 e$ \\
\hline \multicolumn{5}{|l|}{$\begin{array}{l}\text { Gr-Grigston silt loam, } 0 \text { to } 1 \\
\text { percent slopes }\end{array}$} \\
\hline & 99 & Grigston & 1 & 1 \\
\hline \multicolumn{5}{|l|}{$\begin{array}{l}\text { HdC2-Hastings silty clay } \\
\text { loam, } 3 \text { to } 6 \text { percent slopes, } \\
\text { eroded }\end{array}$} \\
\hline & 99 & Hastings & $3 e$ & $3 e$ \\
\hline \multicolumn{5}{|l|}{$\begin{array}{l}\text { HdD2-Hastings silty clay } \\
\text { loam, } 6 \text { to } 11 \text { percent } \\
\text { slopes, eroded }\end{array}$} \\
\hline & 99 & Hastings & $4 e$ & $4 \mathrm{e}$ \\
\hline \multicolumn{5}{|l|}{$\begin{array}{l}\text { Hg-Hobbs silt loam, } 0 \text { to } 1 \\
\text { percent slopes }\end{array}$} \\
\hline & 99 & Hobbs & $2 w$ & $2 w$ \\
\hline
\end{tabular}

Figure 10. Tabular data report generated from Web Soil Survey. 


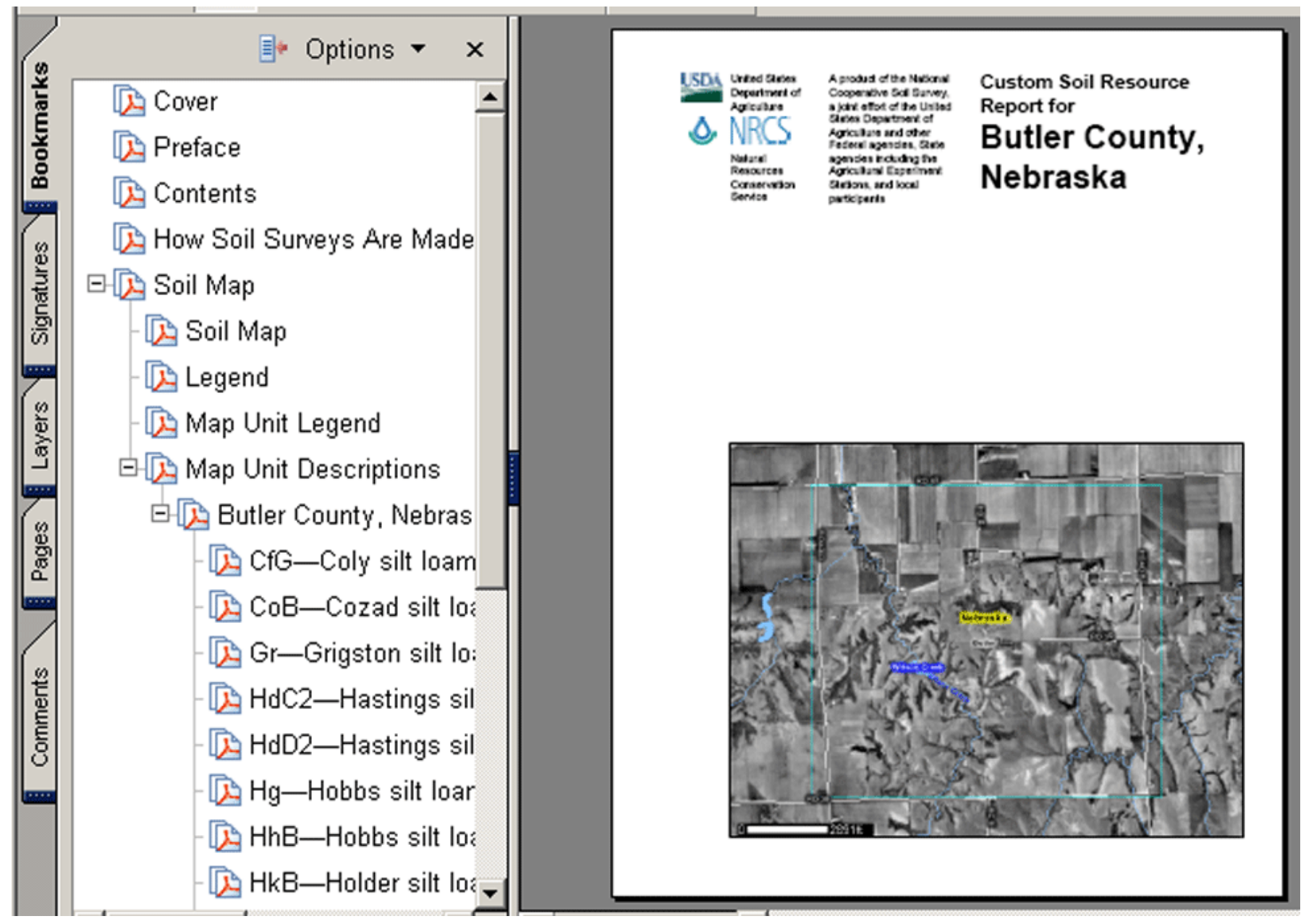

Figure 11. PDF report document generated by Web Soil Survey using the Shopping Cart function. Content of the report can be customized by the customer; hence the name "Custom Soil Resource Report for..." Individual thematic maps and tabular reports can be added as desired. The basic soil map, map unit legend, and map unit descriptions are added by default. 



\title{
Importance of Historical Elevation Data
}

\author{
By Gayle H. McColloch, Jr. and Jane S. McColloch \\ West Virginia Geological and Economic Survey \\ 1 Mont Chateau Road \\ Morgantown, WV 26508-8079 \\ Telephone: (304) 594-2331 \\ Fax: (304) 594-2575 \\ mccolloch@geosrv.wvnet.edu, janemc@geosrv.wvnet.edu
}

\section{INTRODUCTION}

Our recent geologic mapping projects are performed as part of the joint AASG/USGS Statemap program. We begin with products of the West Virginia Geological and Economic Survey's Coal Bed Mapping Program (CBMP). This program captures and analyzes mineral resource data to produce a series of GIS data sets that model coal resources statewide. The primary foci of this program are to produce data that can be input into modeling software to establish the value of coal beds to produce mineral tax assessments and, since the Quecreek Mine rescue on July 28, 2002 in Somerset County, PA, capturing mining data geographically and stratigraphically.

Products of the CBMP include:

- Bed structure (vector contours and grids)

- Bed thickness (vector contours and grids)

- Bed partings (vector contours and grids)

- Mined areas

- Bed discontinuities

- Coal boundaries

- Bed thickness point locations

- Bed elevation point locations.

\section{GEOLOGIC MAPPING METHODOLOGY}

In Carboniferous rocks of the Appalachian Plateau, formation contacts commonly are widespread coal beds or other persistent horizons. Many, but not all, of these coal beds are economically important. Examples of stratigraphically important, persistent horizons from our current mapping area that are not economic resources include the Ames limestone and shale of the Upper Pennsylvanian Conemaugh Group and the Jollytown coal bed of the Upper Pennsylvanian (basal Permian?) Dunkard Group.

Because one focus of the CBMP is to determine economic coal resources, our first task is to determine if important coal beds have not been mapped or are not considered economic resources within our study area, and to identify where gaps in CBMP data exist and where additional stratigraphic data are needed.

After analyzing previous work, we collect additional data from new fieldwork, records on file at WVGES, and other sources such as state Division of Highways borings. The new data are used to fill in the gaps in CBMP data products. Our first product is a series of elevation grids representing all important horizons not mapped by CBMP. Outcrop lines are generated by intersecting the horizons with digital elevation models (DEMs). We generally use 2003 1/9 arc second DEMs (USGS et al, 2005a) derived from West Virginia State Addressing and Mapping Board photography completed in the first half of 2003 (USGS et al, 2005b), but for areas where the original topography has been significantly altered we sometimes need to work with older topographic information, as explained in this paper.

Outcrops of all important horizons, including the CBMP products, are plotted on topographic bases to produce field maps (Figure 1). The outcrops plotted on these field maps are field checked, and outcrops lines and structure contours are revised as necessary. Revised structure contours are used to generate new grids. Since we also have 2003 digital orthophoto quarter quads (DOQQs) with 2-meter pixel resolution, the final step is to digitally overlay onto DOQQs the final, corrected outcrops and examine the linework for otherwise inaccesible problem areas. These outcrops are used to construct open file report maps and ultimately to produce GIS datasets. Cross sections for these open-file maps are created by generating profiles of all important horizons using the elevation grids and the DEM.

\section{TOPOGRAPHIC COMPLICATIONS RELATED TO HUMAN ACTIVITY}

Selecting the proper topographic data for a geologic mapping project is important because human activities, or the manner in which the DEM was generated, can produce 


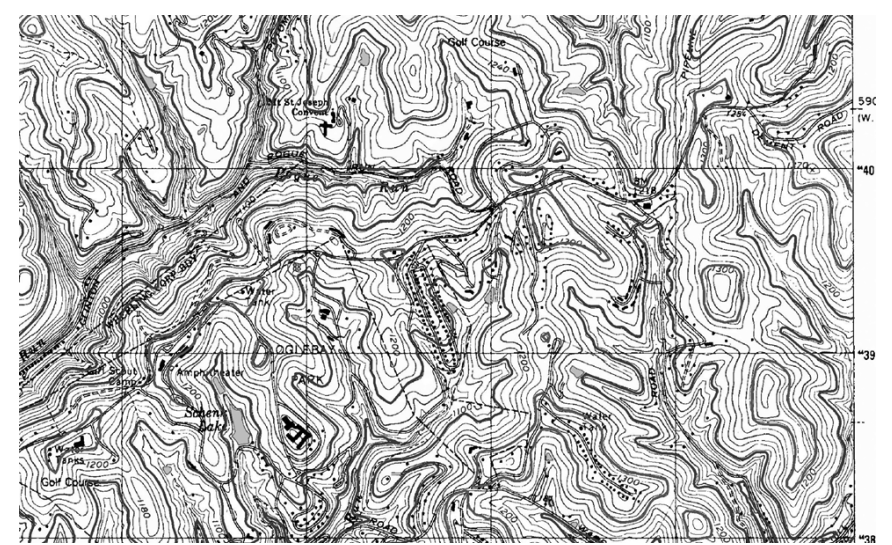

Figure 1. Grayscale image of the provisional geologic field map, Wheeling 7.5-minute quadrangle. The gray lines paralleling the topographic contours trace the outcrops of critical horizons which, in the Appalachian Plateau, commonly are widespread coal beds.

topographic surfaces that cannot be reliably used for prediction of the extent of geologic units.

During field work for our mapping project in the Wheeling, West Virginia, area we found several areas where the topography had been so significantly altered that the most recent topographic data could not be used to map the original locations of outcrops. It was therefore necessary to substitute DEMs based on older topography, or use contours based on plane-tabled topography (U.S. Geological Survey, 2005) from a 15-minute, 1:62,500 series map, in order to better identify the correct locations of geologic unit contacts.

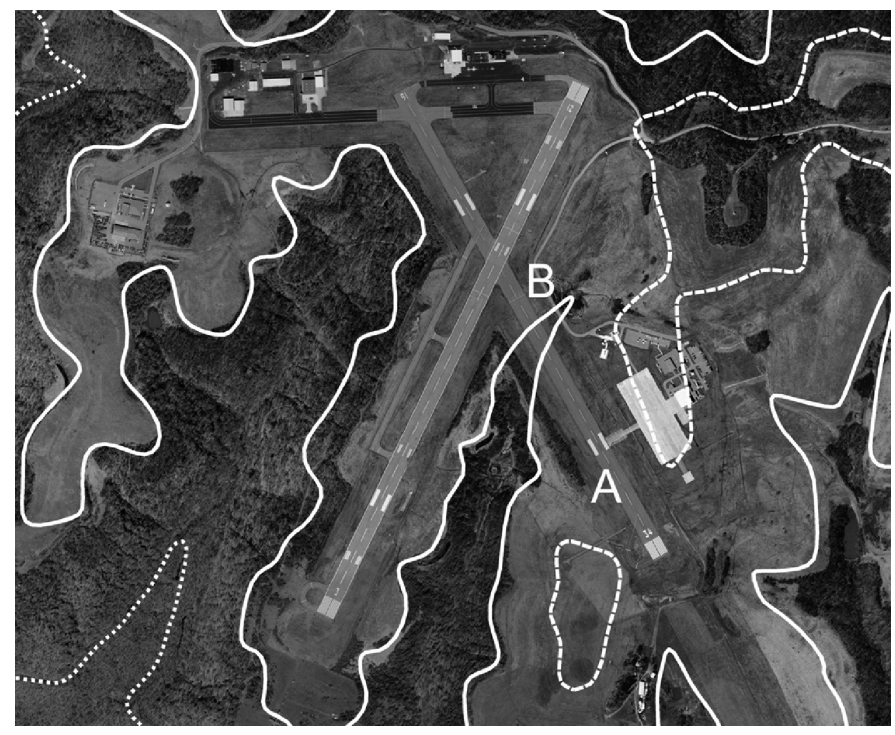

Figure 2. The outcrops of the Pittsburgh (dotted line), Waynesburg (solid line), and Washington (dashed line) coals, in the Wheeling-Ohio County Airport area, Tiltonsville 7.5-minute quadrangle. Locations " $A$ " and " $B$ " are discussed in the text.
An excellent example of geologic mapping problems related to altered topography is the Wheeling-Ohio County Airport area on the Tiltonsville 7.5-minute quadrangle (Figure 2). When the airport was built in the 1946 (Quarles, 2008), cut and fill associated with runway construction and surface mining of coal seams in the immediate vicinity of the airport significantly disturbed the original topography. The topography shown on the Tiltonsville quadrangle was produced in 1966 (U.S. Geological Survey, 1997b), and therefore shows the altered landscape. To produce outcrops that show the pre-construction topography, we used pertinent information from the 1:62,500 Wheeling 15-minute topographic map (U.S. Geological Survey, 1902). The outcrop lines of the Pittsburgh, Waynesburg, and Washington coals were delineated from the DEM that was derived from the 1966 topography modified using 1902 vintage 15-minute maps, and is shown on Figure 2 superimposed on a 2003 aerial photo image of the Wheeling-Ohio County Airport area. In the figure, the dashed line represents the outcrop location of the Washington coal, before construction of the airport. The Washington was initially surface-mined at location A in the mid 1940s to make room for the runway alignment. The solid line represents the outcrop of the Waynesburg coal; it was covered at location B by fill, most of which was apparently removed from location A to construct the runway. The dotted line represents the outcrop of the Pittsburgh coal. Recently, aside from the airport excavation all three coals were extensively surface mined and the land has been returned to the original contour so the outcrop lines approximate those of the early 1940s, before the airport was constructed.

Another example of profoundly altered topography that required us to use older topographic information is along Browns Run near Benwood, in the Wheeling 7.5-minute quadrangle (Figure 3). This location is near the Consolidation Coal Company's Shoemaker underground mine. The mine portal is located along the Ohio River, and a coal preparation facility and a barge loading dock are located adjacent to it. This facility required a nearby mine dump to receive material cleaned from the coal by the preparation plant. We found two types of topography-related errors that required correction in this area.

The most obvious problem was the incorrectly mapped outcrop lines of the Jollytown coal, which were produced by intersecting the coal's structure contour map with the DEM produced from the 2003 topography (see Figure 3, area "A"). By that time, the valleys had been extensively filled with mine waste, significantly changing the topography. The Shoemaker mine began production in 1966 (West Virginia Department of Mines, 1966) and so we consulted the topography compiled in 1956 (U.S. Geological Survey, 1994) in order to more correctly map the Jollytown coal's original outcrop pattern. For the areas of valley fill, a small part of the 1956 DEM was used to recompute the Jollytown's original outcrop. This was patched into the outcrop for the rest of the quadrangle. The resulting outcrop is shown as the dashed line within area "A" in Figure 3. 


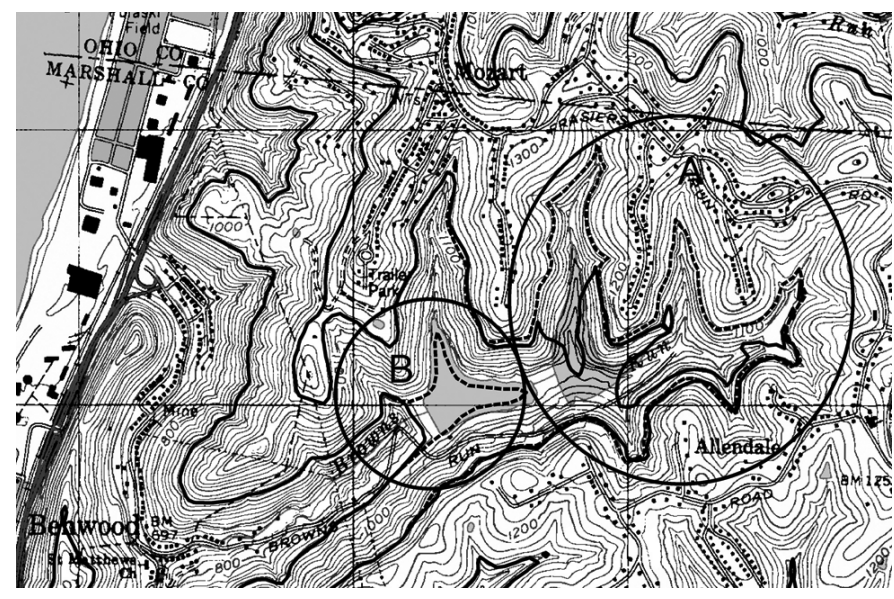

Figure 3. Changes in the topographic surface near Browns Run, Wheeling 7.5-minute quadrangle map. The solid and dashed geologic lines within areas " $A$ " and " $B$ " are discussed in the text

While applying this patch, a problem was found with the projected location of the Waynesburg coal outcrop. Because ponds obscure the underlying topographic contours, they are treated by the algorithm used to produce the DEM as flat surfaces. Therefore, when the Waynesburg coal outcrop locations were generated by intersecting the structure contours with the DEM, the outcrop pattern was affected by the earthen dam instead of extending up the valley, into the settling pond in the area labeled " $\mathrm{B}$ " on Figure 3. This error was easily corrected by projecting the topography through the pond area. A similar problem was noted in another area where the outcrop of the Waynesburg coal intersects a farm pond on the Bethany 7.5-minute quadrangle.

Another area where topographic changes have affected the projected location of a critical horizon is on the Valley Grove 7.5-minute quadrangle, which we encountered during our 2007-08 mapping project. An extensive shopping area, the Highlands Complex, is being built partially on a mine refuse dump associated with a preparation facility near the Valley Camp Coal Company's Number 3 mine in the Pittsburgh coal (Figure 4). The location where the photo in Figure 4 was taken is labeled "E" in Figure 5. The site topography has been constantly changing since site development began in 2002 or 2003. We estimate the area affected to be in excess of 300 acres with a maximum fill thickness of as much as 100 feet.

Between 1938, when the first air photos of the area were taken, and 1956, when the first photo-derived topography was produced from the first version of the Valley Grove 7.5-minute quadrangle (U.S. Geological Survey, 1997c), the mine dump appears to have significantly altered the topography. Valley Camp Coal Company has a long and complex history in the area, and it is difficult to determine from available public records an exact date for the construction of the preparation facility. Stereo pairs of the first air photos are unavailable, so the only source that shows the original topography is the 15-minute Wheeling Quadrangle, which was completed in

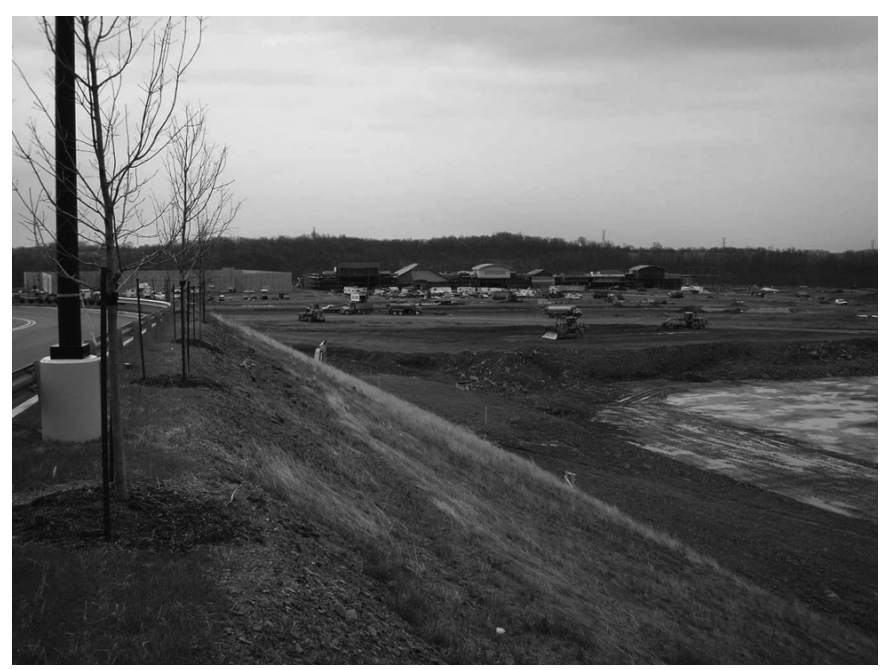

Figure 4. View of a small area of the Highlands Complex that is being built partially on a mine refuse dump. The buildings in the background are not located on the mine refuse fill. The area in the foreground is located over part of the refuse dump that has been subsequently filled with material from the current site preparation. During a recent site visit we observed new construction taking place on this filled area.

1902 (USGS, 1902). This topography is imperfect when compared to more recent topographic mapping, but it is good enough to suggest that our outcrops are probably near the original location. The areas labeled "A" and "B" on the left side of Figure 5 illustrate the problem. The solid gray line labeled " $\mathrm{B}$ " is the original outcrop of the Jollytown coal, as validated by the 1902 USGS map. The line marked with short dashes labeled " $A$ " is based on the 2003 topography and has been influenced by the mine dump.

Another, less pronounced, but potentially more common, outcrop alteration occurred when I-70 was constructed in the 1970s. Fill has significantly altered the projected outcrop of the Jollytown coal nearby. Two versions of the Jollytown coal outcrop are shown on a small area of the Valley Grove 7.5-minute quadrangle (right side of Figure 5). The solid gray line labeled " $\mathrm{D}$ " shows the outcrop derived from the 7.5-minute topography. The dashed black line labeled "C" shows the outcrop derived from the 2003 1/9 arc-second data that reflects excavations for I-70 and earliest preliminary site preparation for the Highlands Complex.

\section{CONCLUSIONS}

Today, the tendency is to assume that newer data are almost, by definition, better than older data. Although newer data are generally more precise and up to date, many reasons exist to preserve older data. We have found that it is critically important to preserve all versions of historical topographic data for geologic mapping in areas that have been disturbed by human activity. 


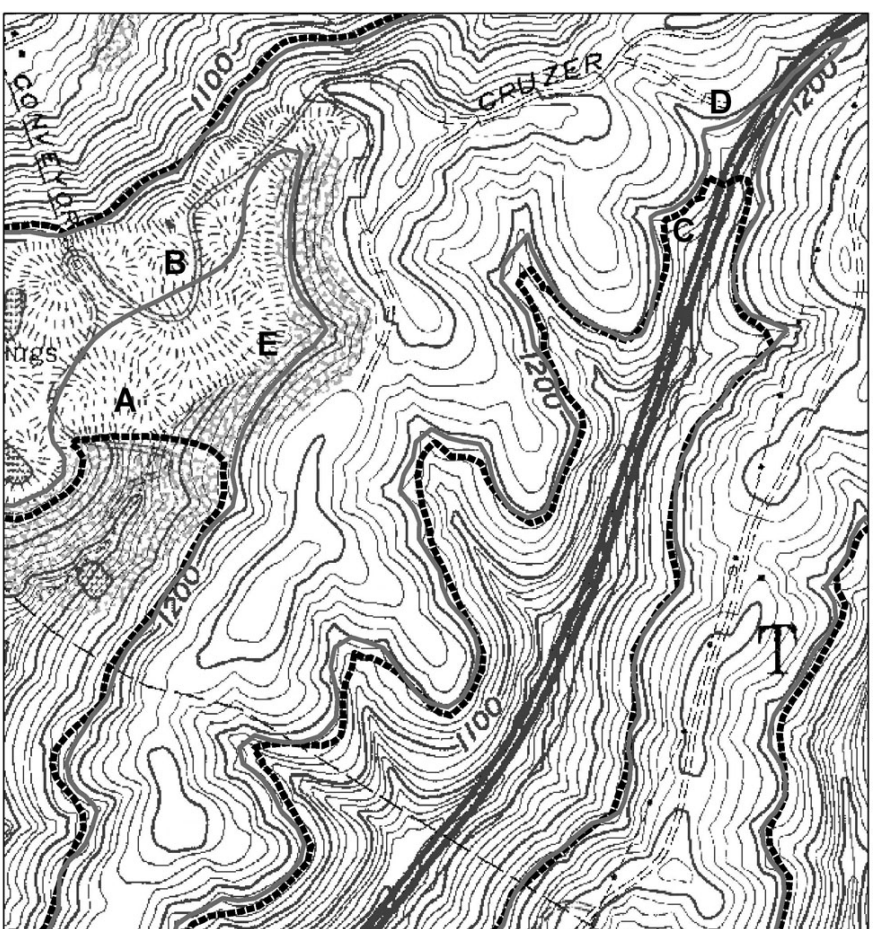

Figure 5. Two versions of the Jollytown coal outcrop are shown on a small area of the Valley Grove 7.5-minute quadrangle including Interstate 70 and the developing area known as the Highlands Complex. Locations A-D are discussed in the text.

\section{REFERENCES}

Quarles, C.C., 2008, Wheeling-Ohio County Airport (HLG) Wheeling, West Virginia: available at http://www.rfci.net/ airliner/wheeling.html, accessed January 15, 2008.

U.S. Geological Survey, 1902, Wheeling Quadrangle West Virginia-Ohio-Pennsylvania, 15-minute series (topographic): Washington, DC, U.S. Geological Survey, scale $1: 62,500$.
U.S. Geological Survey, 1994, Wheeling Quadrangle West Virginia-Ohio, 7.5-minute series (topographic): Denver, CO, U.S. Geological Survey, scale 1:24,000.

U.S. Geological Survey, 2005, Topographic Mapping: Online Edition: available at http://erg.usgs.gov/isb/pubs/booklets/ topo/topo.html\#top, accessed January 14, 2008.

U.S. Geological Survey, 1997a, Bethany Quadrangle OhioWest Virginia, 7.5-minute series (topographic): Denver, CO, U.S. Geological Survey, scale 1:24,000.

U.S. Geological Survey, 1997b, Tiltonsville Quadrangle OhioWest Virginia, 7.5-minute series (topographic): Denver, CO, U.S. Geological Survey, scale 1:24,000.

U.S. Geological Survey, 1997c, Valley Grove Quadrangle Ohio-West Virginia, 7.5-minute series (topographic): Denver, CO, U.S. Geological Survey, scale 1:24,000.

U.S. Geological Survey (USGS), West Virginia Statewide Addressing and Mapping Board (WVSAMB), and West Virginia University GIS Technical Center, 2005a, High Resolution 7.5' Quarter-Quad Orthoimages for the state of West Virginia, UTM Zone 17 for entire state, MrSID Compressed: Sioux Falls, SD, U.S. Geological Survey, available at http://wvgis.wvu.edu/data/dataset. php? action $=$ search $\& I D=254$.

U.S. Geological Survey (USGS), West Virginia Statewide Addressing and Mapping Board (WVSAMB), 2005b West Virginia Statewide Digital Elevation Models: Rolla, MO, U.S. Geological Survey, available at http://wvgis.wvu.edu/ data/dataset.php? action $=$ search $\& I D=261$.

West Virginia Department of Mines, 1966, West Virginia Department of Mines Annual Report: West Virginia Department of Mines, $256 \mathrm{p}$. 


\title{
The National Map - Products And Services
}

\author{
By William J. Carswell ${ }^{1}$ and Stafford Binder ${ }^{2}$ \\ ${ }^{1}$ U.S. Geological Survey \\ National Center, MS 590 \\ 12201 Sunrise Valley Drive \\ Reston, VA 20192 \\ Telephone: (703) 648-4140 \\ Fax: (703) 648-4722 \\ email: carswell@usgs.gov \\ ${ }^{2}$ U. S. Geological Survey \\ P.O. Box 25046, MS-510 \\ Denver, CO, 80225-0046 \\ Telephone (303) 202-4444 \\ Fax (303) 202-4020 \\ email: sgbinder@usgs.gov
}

\section{THE U.S. NATIONAL GEOSPATIAL PROGRAM (NGP)}

The U.S. Geological Survey NGP provides 19 geospatial products and services. This paper provides some background information on the NGP with emphasis on The National Map, Geospatial One-Stop, and the Graphics Project. The information in this paper is current as of May, 2007.

\section{NGP Purposes}

The U. S. Geological Survey's National Geospatial Program provides leadership to:

- Place geographic knowledge at the fingertips of the Nation,

- Assure the availability of current and accurate geospatial data on a local, national and global basis in order to contribute to economic growth, environmental quality and stability, and social progress,

- Establish a unified approach to accomplishing the National Spatial Data - Infrastructure (NSDI) through the Federal Geographic Data Committee (FGDC), The National Map, Geospatial One-Stop (GOS), and the National Atlas of the United States, and

- Develop partnerships to build the NSDI with Federal, State, tribal, academic, private, and local partners.

\section{The NGP Portfolio}

The NGP has a broad portfolio that:

- Provides Department of the Interior (DOI) geospatial leadership and coordination among DOI bureaus,

- Provides geospatial readiness for emergency operations,

- Conducts a formal geospatial coordination among Federal agencies and with State, local, and tribal governments,

- Hosts the FGDC Secretariat providing coordination among Federal agencies and with other nations,

- Hosts the USGS geospatial liaison network,

- Hosts The National Map,

- Hosts the National Atlas, to provide consistent, national-scale, organized information about physical, historical, economic, and socio-cultural characteristics of the United States,

- Hosts the GOS for discovery and access to geospatial data in a common infrastructure,

- Hosts the Board on Geographic Names Secretariat for a formal coordination among Federal agencies and with other nations,

- Hosts the National Geospatial Technical Operations Center as the NGP's operational asset focused on "putting geographic knowledge at the fingertips of the nation", and

- Hosts the Center of Excellence for Geospatial Information Science for leadership in basic research about geospatial information. 


\section{The National Map}

User access to The National Map is primarily through its on-line viewer found at http://nmviewogc.cr.usgs.gov/viewer. htm. The National Map viewer offers an array of functions and tools for viewing and creating maps. The National Map provides base content data for the Nation. Base content is made up of eight data themes, elevation, imagery, names, transportation, structures, boundaries, hydrography, and land use land cover. Developed and maintained through partnerships, it is a national foundation data set for science, land and resource management, recreation, policy making, and homeland security. Through The National Map's portal, the user accesses U.S. Geological Survey (USGS) and partner data from multiple map services. FGDC-compliant metadata is available for each of the eight data themes. Data within each of the eight data themes can be viewed and printed as PDF images. It is also the source for revised topographic maps. Many of the layers can be downloaded. The National Map is many things to many people, maps, a data viewer, systems, work flows and processes, and applications.

Orthorectified imagery, land cover, elevation, hydrography, geographic names, transportation, structures, and boundaries data are available from The National Map (Figure 1). As stipulated in the Office of Management and Budget (OMB) Circular A-16 (http://www.whitehouse.gov/omb/ circulars/a016/a016_rev.html), the USGS has responsibility for each of the eight data themes but the transportation, structures, and boundaries themes or layers. The NGP acquires these data for these three themes through partnerships and purchases. The acquired data are used to upgrade national

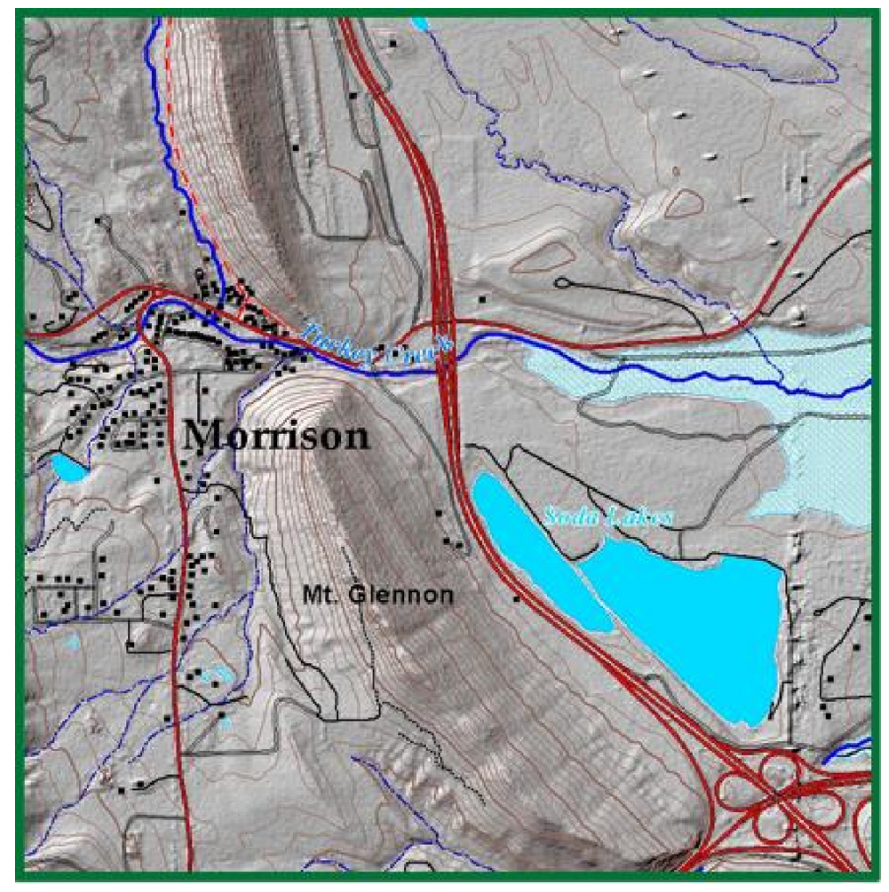

Figure 1. The vision of The National Map as a fully integrated set of data accurately representing features on the earth. databases of base content, to produce topographic maps, and by customers for various applications. The status of these data layers is available from the National Geospatial Program Office (http://www.usgs.gov/ngpo/ngpo_contacts.html).

USGS's roles are changing from producing topographic maps to being the guarantor of national data completeness. The NGP is the organizer responsible for awareness, availability, and utility of geospatial data. The NGP is the catalyst and collaborator for creating and stimulating data partnerships, the partner in standards development, the integrator of data from other participants, and the data producer and owner when no other source exists.

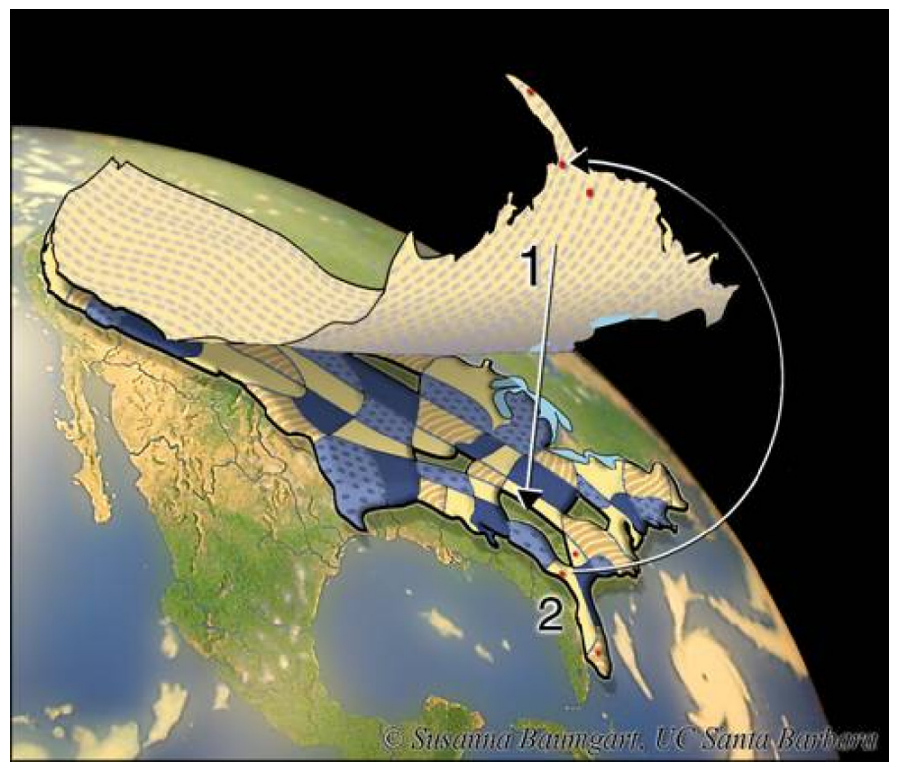

Figure 2. Data content of The National Map as a national seamless coverage of data acquired from partners for all eight data themes of The National Map

USGS's vision for The National Map (Figure 2), is that of a seamless, continuously maintained, nationally consistent set of base geographic data. USGS envisions the availability, through The National Map, of legacy topographic maps, standard digital image maps with overlays, standard digital topographic maps, and custom topographic maps. Users will be provided with scalable geospatial services, systems, and workflows.

\section{Geospatial One-Stop (GOS)}

GOS contains Federal data sets, state/regional data sets, integrated national data sets, and scientific knowledge contained in reports, models, and applications. GOS provides access and discovery of all these data sets. In 2006, records in these categories grew from 81,000 to 123,000 . In October 2006, the USGS NGP was designated the managing partner for GOS by the Department of the Interior. The USGS will continue to enhance the capabilities of GOS. 


\section{Graphics Project}

The national coverage of the 1:24,000-scale Primary Series Topographic Maps (those which are now available as lithographically printed maps) was completed in May, 1991. It was an immense engineering feat, for which the cost of replication today would be over two billion dollars. This primary series of the topographic maps is the only national synthesis of topographic content that is comprehensive, transjursidictional, and border-to-border (and coast-to-coast) coverage at a consistent scale and content.

The legacy topographic maps' value is eroding rapidly as they become increasingly outdated and the divergence between base data and topographic maps increase. Another impact on their value is the duplication of effort among and between geographic information sectors.

Today USGS's focus is on building The National Map by building the Nation's database of topographic information, and maintaining those data. In addition, USGS is building GOS. Using The National Map data, USGS is producing new image maps (Figure 3) over hurricane-prone areas of the Atlantic and Gulf Coasts. The focus for the graphics project over the next two years will be to begin production of new topographic maps from The National Map data and to develop a capability by which users can make new topographic maps on-line. Standards for the new topographic and the new image maps' content, format, and file structure are being developed. The new topographic maps will use only suitable data where they are available. Because of the availability of suitable data and new technology the new topographic maps and image maps will be enhanced from the published primary series topographic maps. Where suitable data are not available, an image map made from an orthophotograph will be available.

USGS is considering a program by which the legacy topographic maps (published Primary Series Topographic

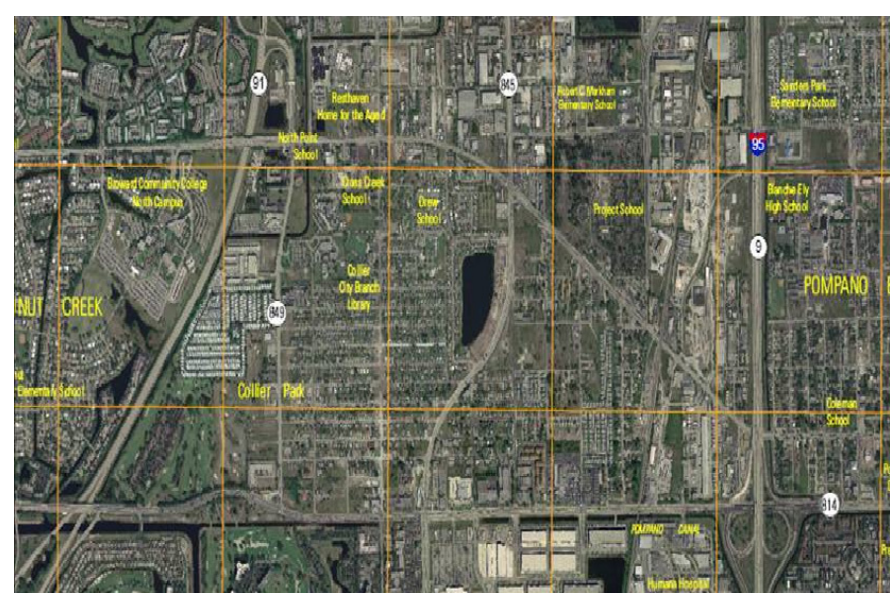

Figure 3. Digital image map (draft made from The National Map data).
Maps) available from USGS's warehouse will be scanned and enhanced to replace the existing Digital Raster Graphic (DRG) files. These files will be available to the public as a supplement, if not a replacement, for the published paper editions of the primary series topographic maps. USGS is also considering scanning the map separates from which the published topographic maps were printed.

\section{FINAL REMARKS}

The National Map is a critical asset, providing geospatial data and map products. Interoperability standards being applied to both GOS to leverage The National Map will allow The National Map to both see and use GOS information. Integrated databases (local, regional, and national) are key to The National Map's success. New enhancements for The National Map are either now being implemented or are in development. Map separates used to print the topographic maps will continue to be available.

\section{RESOURCES}

The National Map Team, 2003, Implementation Plan for The National Map: U.S. Geological Survey, October 18, 2003, ver. 1.0., available at http://nationalmap.gov/nmreports. html.

Zulick, C.A., 2008, The National Map 2.0 Tactical Plan Toward The (Integrated) National Map: U.S. Geological Survey Open-file Report 2008-1263, 57 p., available at http://pubs.er.usgs.gov/usgspubs/ofr/ofr20081263. [Preprint accessed by permission from the National Geospatial Program Office.] 



\title{
When Maps Were Scribed: USGS Geologic Map Production in the 1970's
}

\author{
By Will R. Stettner and Paul Mathieux \\ U.S. Geological Survey \\ National Center, MS 903 \\ 12201 Sunrise Valley Drive \\ Reston, VA 20192 \\ Telephone: (703) 648-4343 \\ Fax: (703) 648-6138 \\ email: wstettne@usgs.gov
}

\section{INTRODUCTION}

With its history as a science and mapping agency, the U.S. Geological Survey (USGS) has always been on the forefront of embracing new technologies that would improve how maps are produced. During the 1960's, the USGS evaluated plastic films, known as mylars, and mylar engraving tools for use in map production. This technological advance would replace the production method of inking on board and metal mounts. In the 1970's, scribing on coated mylars and color separation using peelcoats became the method for producing maps and would not change significantly until the introduction of computers.

\section{PUBLICATIONS DIVISION}

Except for topographic maps, which were the responsibility of the Topographic Division, the production of geologic and hydrologic map products and book size publications was the responsibility of the Publications Division, which provided editorial review, cartographic preparation, typesetting, photo lab support, and printing services. By the 1970's the Publications Division had established an efficient map production process using various types of films and mylars and a documented set of cartographic standards that addressed every aspect of geologic map production, including layout, symbols, fonts, line weights, colors, and materials to be used.

\section{CARTOGRAPHIC TOOLS}

Cartographic production was performed by individuals who were classified as cartographic technicians. The tools required by a technician included an assortment of scribing tools used to engrave or remove the red- or yellow-colored emulsion on mylar known as Scribecoat. Basic three-legged metal engraving tools, using phonograph needles as scribing points, were developed into an array of specialized tools with attached magnification lenses; some had swivel points, ideal for scribing smooth, flowing lines. The 1970's saw the introduction of a lighter plastic scribing tool, known as an Astrascribe, with interchangeable and predefined sapphire points that never required sharpening. Rapidograph pens, magnifiers, opaque brushes, X-Acto knives, burnishing tools, and leathercovered weights rounded out most of the tools required for cartographic preparation (Figure 1). All films and mylars had to be punch-registered. The Aldis punch system, an offset punch hole system, was used to punch film so that registration pins could hold all working copies in perfect registration.

\section{MAP DESIGN}

Cartographic preparation could not begin until the author's materials or mill copy received a technical review and had subsequently been given Director's Approval for publication. Only then could the technician begin with map design or "lay out" using the geologist's compilation. The compilation would be an inked copy on a greenline, which consisted of a topographic base photographically applied in green on to a piece of frosted mylar. The layout used all the components (for example, the map itself, correlation of map units, explanation of map symbols, text, title, and explanatory notes) that a geologist identified to be part of the report. The layout would be "locked into position" on a pre-punched $34 \times 44$ inch or $42 \times 58$ inch piece of clear mylar which would then be submitted to the photo lab for a negative. This negative would be exposed onto a color-coated opaque mylar (Scribecoat) that 


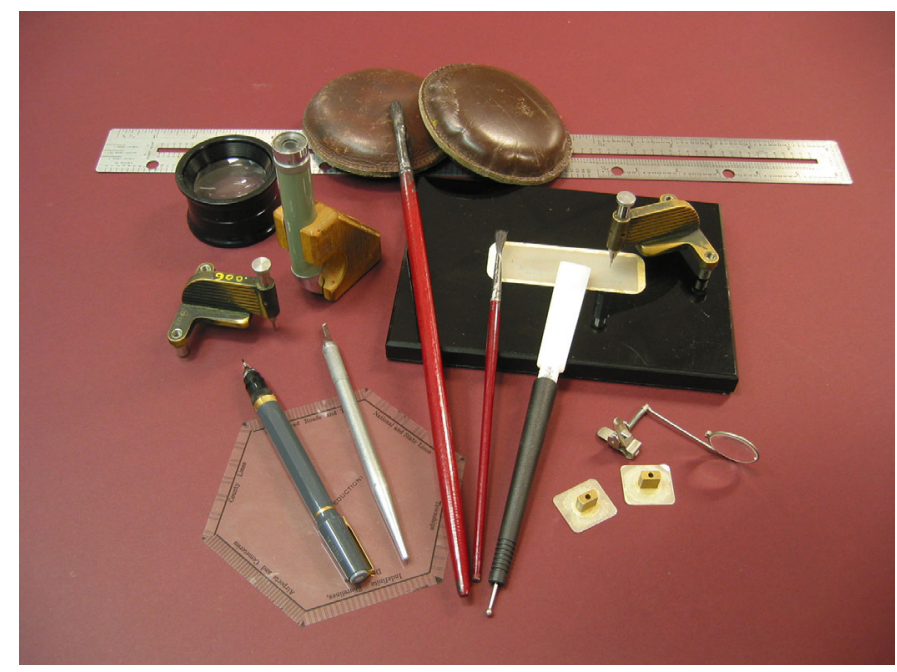

Figure 1. Shown are some of the tools such as scribing tools, a sharpening stone, magnifiers, registration pins, and various other tools, required by the cartographic technician of the 1970's.

was then used to scribe all color boundaries, such as geologic map units and water bodies. That same Scribecoat would later be used to finish scribing all other line features, such as faults, anticlines, and synclines.

\section{COLOR SELECTION}

Early in the Survey's history, a standard color and pattern scheme was established for geologic age groupings (browns for Proterozoic; yellows for Quaternary; and so on). This color scheme is still in use today. Selecting map unit colors was identified as a specialized activity and required a color expert and was not done by the cartographic technicians. The ages and type of rocks identified in the correlation and explanation of map units served as a starting point for color and pattern selection. Colors were defined using percentages and combinations of cyan, magenta, yellow, and black (CMYK), known to printers as the process colors. The color and pattern scheme for a particular map was identified on the map's color guide. The color guide identified each geologic map unit and its letter symbol, the percentages of CMYK identified for each map unit, and any additional information, such as units whose colors were determined from adjoining maps (Figure 2). This color guide could then be used by the technician to identify the number of peelcoats needed to create the map's color scheme.

\section{TYPE SETTING}

Irrespective of the methods used in map production, activities are defined by a set of procedures that reflect current technology. During the 1970's, typesetting services were provided by the Publications Division for all USGS offices by using teletype communications. Type was set on a Merganthaler photo typesetter. The cartographic standards defined how text and type were to be written, coded, and submitted on a type order form. Every characteristic, such as type font, size of type, alignment and spacing of type, and the pica width of lines had to be identified on this form. A film or paper proof of the typeset type was then returned to the technician for review and then resubmitted for corrections. When all corrections were finalized, a photographic exposure was made onto thin waxed-backed film or strip film. Type on the strip film would then be cut out by the technician with an X-Acto knife and positioned and burnished onto a punch-registered clear piece of mylar, known as the type overlay.

\section{SYMBOL AND TYPE PLACEMENT}

A green plastic template (also used for topographic maps) became a critical tool for scribing consistent and uniform symbols on a geologic map. Following the instructions provided by the cartographic standards, this template could be used to construct complex geologic map symbols (Figure 3). Even though scribed symbols produced a high-quality reproducible copy, it was determined that the scribing of complex symbols was inefficient because once scribed, symbols could not be repositioned. For that reason a set of scribed symbols was reproduced photographically onto strip film, which could then be cut out with an X-Acto knife and correctly positioned on the type overlay. All map text, base and credit notes, and other miscellaneous type was placed on this type overlay, which was then made into a negative and used in conjunction with the other black printing separates.

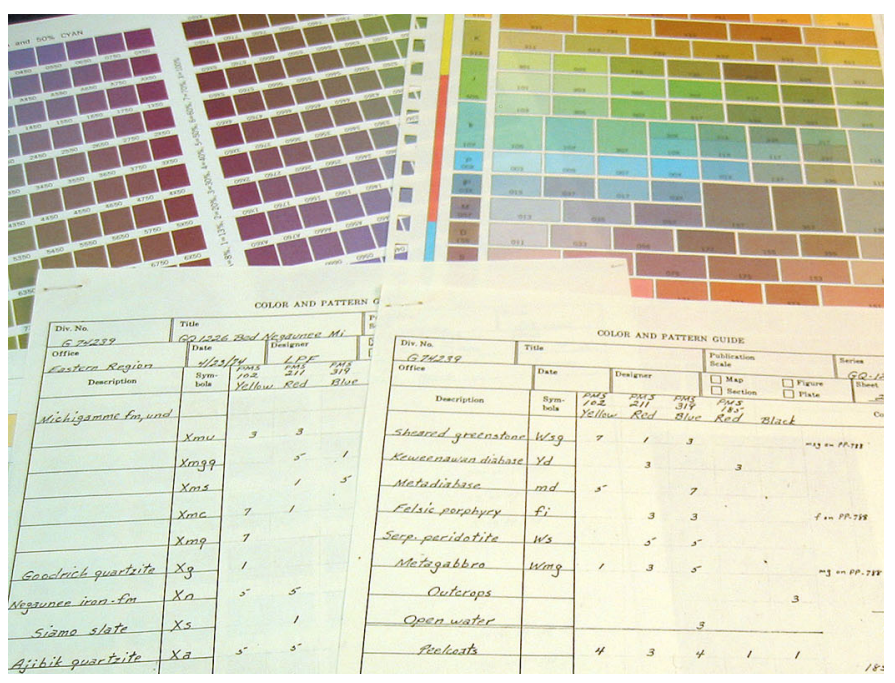

Figure 2. The CMYK color and pattern charts from which selections were made and entered onto the map's color and pattern guide. 


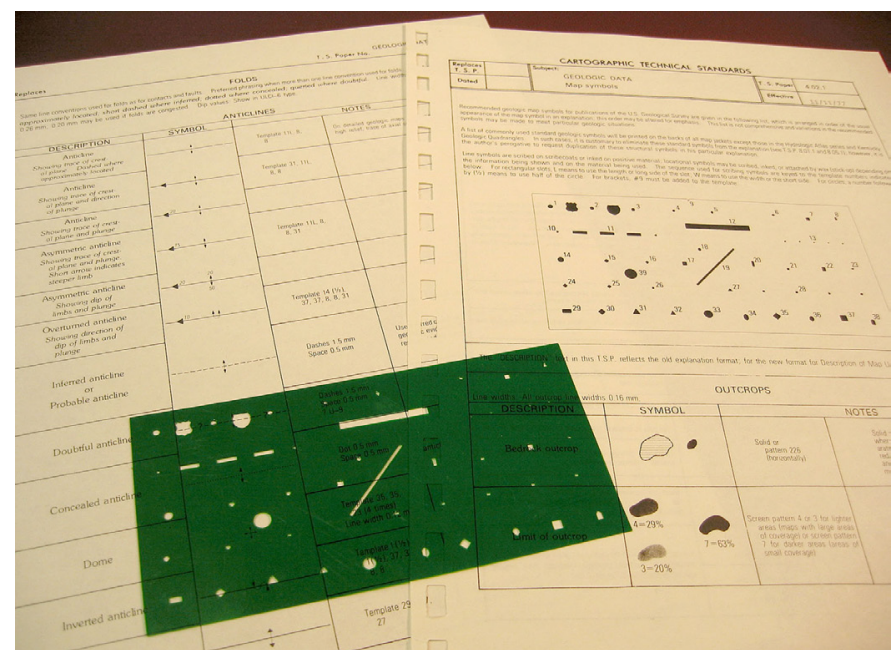

Figure 3. The plastic template used to construct geologic structure symbols. When following the USGS Cartographic Technical Standards, the combination of template numbers 14, 37, 8 , and 31 would result in the symbol for an overturned, plunging anticline

\section{COLOR SEPARATION}

Peelcoats were mylars with a photosensitive coating that when developed were etched with lines that replicated the scribed color contacts on the Scribecoat (Figure 4). Because the peeling up of the thin film between contact lines left the mylar clear, halftone screens identifying screen percentages could be placed on the peelcoat and would later be exposed in the photo lab for combination negatives. Depending on the CMYK color, the technician was also required to apply these screens at their appropriate angles in order to avoid moirés. This was done with the aid of various screen angle determination devices that identified a screen offset of $15^{\circ}$ for each color.

\section{MAP PROOF}

Once all the map components (Scribecoats, type overlays, peelcoats, and base separates) were prepared, these separates were submitted to the photo lab for a proof. A proof was made by applying one of the CMYK colors to a

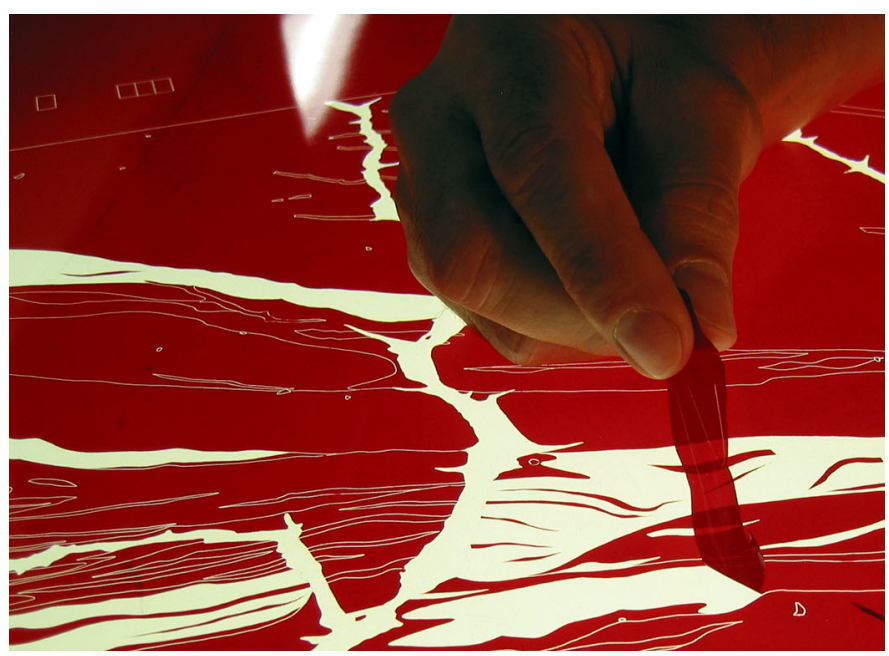

Figure 4. A peelcoat where the thin film is being removed within the two etched lines that define a geologic unit. The open area will then have a halftone screen applied, required for the unit's color as defined by the color and pattern guide.

white opaque mylar and exposing it to all the separate pieces of mylar requiring that color. Exposed areas were fixed, unexposed areas were washed off, and the process continued until all items were exposed for their appropriate colors. The proof would then be reviewed by the technician's supervisor, the technical editor, and the author for omissions and errors. Once corrections were made, all separates were then combined onto the printing negatives required for process color (CMYK) printing.

\section{SUMMARY}

This was the cartographic procedure employed during the 1970's, which, of course, could always be complicated by using additional colors, graphics, cross sections, and bases that didn't fit. It should be kept in mind that many of the procedures used in the 1970's evolved from procedures and standards developed during the previous 100 years. It can also be stated that the digital procedures in place today reflect the developments and procedures of the 1970's. 



\title{
Open Access Journal Publication: Implementation, Copyright and Dissemination, Using the Journal of Maps as a Case Study
}

\author{
By Mike J. Smith \\ School of Geography, Geology, and the Environment \\ Kingston University \\ Penrhyn Road \\ Kingston upon Thames, Surrey, KT1 2EE \\ Telephone: +44 (207) 099-2817 \\ Fax: +44 (870) 063-3061 \\ email: michael.smith@kingston.ac.uk
}

\section{INTRODUCTION}

Open access (OA) journals are rapidly becoming an important channel for publishing academic articles (Rightscom, 2005) and, although they represent a small proportion of the total number of journals published annually, it is significant that organisations such as British Medical Journals (BMJ) operate in this manner. This article explores the broad implementation of OA journals, issues pertaining to copyright and the distribution of (geospatial) research data.

Much of the material elicited in the preparation of this article was derived from experiences as editor of the Journal of Maps (JoM; http://www.journalofmaps.com) and therefore the discussion should be understood within this context. The Journal of Maps was established against the backdrop of a perceived decline in the publication of research based maps (Smith, 2005a). With the movement of print published journals towards a standardised A4 copy format, large maps are not easily publishable. The inclusion of "inserts" (folded or stitched) into journals appears to have declined over the last century (Smith, 2005a) and, with the high cost of colour printing, there is an apparent decline in research map publication. Maps are also rarely seen as a research goal in their own right, with the focus of journal publication often upon the communication of research results. JoM was therefore founded as a charity with the specific remit of publishing research maps.

\section{OPEN ACCESS}

Open access can be defined as material that is free $a t$ the point of consumption. Although simple in concept in that you "give" content away, there are a variety of implementations currently used by journal publishers. There are also hybrid publication models, being part $\mathrm{OA}$ and part "paid-for". Rightscom (2005) summarised the main publishing models currently used for academic publications in the UK, highlighting the growing importance of OA, as well as listing the main methods that are currently implemented.

Research Councils UK (2005) state that over $60 \%$ of university research in the UK is funded directly by the government. The dissemination of research results is traditionally performed through academic journals, after peer review has taken place. Indeed, editorial boards that make up the academic component of journals are normally non-stipendiary positions, indirectly funded by the institution at which they are employed. This work is deemed to be "scholarly activity" and part of the duties of an academic. The journal publishers, however, are interested in making a "reasonable profit" from the publication of a journal title, whilst the "consumers" of journals are typically research institutions (universities). The position that the funding body (in this instance the government) finds itself in, is paying to access the results (through a subscription based publishing model) of research it has already funded. This position is considered untenable by the UK government (House of Commons Science and Technology Committee, 2004) and it recommends greater access to research findings, possibly through the lodgment of results in institutional repositories. This position was subsequently backed by the principal research funding bodies, represented by Research Councils UK (2005), who now require the deposition of the results of all funded projects in research council specific repositories (e.g. Natural Environment Research Council; http://www.neodc.rl.ac.uk/). Such moves have been partially mirrored in the USA where the National Institutes of Health (NIH) have announced a similar move, requiring the deposition of results from funded work in PubMedCentral (http://www.pubmedcentral.nih.gov). 
The government initiatives outlined above will clearly be driving the agenda for the establishment of OA journals over the next few years. Other effects of a subscription-based journal publishing model are the restriction of access to current research for developing nations, as well as the increased financial burden placed upon libraries. However it is important to note that journals will never be free to publish (Morris and Powell, 2005), as there are always costs associated with review and publication. Rowland (2002) estimates a cost of \$200-400 per article, so the main concern is whether journals can be appropriately funded.

OA does therefore not mean a "no cost" publishing model. To re-iterate, it is free at the point of consumption. Users (or consumers) of the material do not have to pay to access the material. Funding sources for OA journals are therefore required from elsewhere. Two broad categories can be identified:

1. Author Pays

This is the most common funding model and has been adopted by large volume OA publishers such as BioMed Central (http://www.biomedcentral.com/info/, accessed 2004) and the Public Library of Science (http://www.plos. org). The financial result of this model is that it shifts the cost of article publication from the consumer to the grant body, which may be a research council or the host institution, however it produces barriers to those with little funding. This can be mitigated against with free submission for low income groups.

2. Those that can afford

This has been implemented by the BMJ (Delamothe and Smith, 2003), who previously operated an OA publication methodology, cross-funded by other activities of the organisation. This has not proved sustainable and it now charges "some users some of the time." Articles are freely distributed immediately upon publication (1 week), followed by a period (1 year) where charges are levied against users from wealthy nations. Developing nations are not charged. The importance of this methodology is that it charges those nations that can afford to subscribe, whilst still freely distributing material elsewhere (defined by the World Bank's list of 120 low and lower middle income countries).

\section{COPYRIGHT}

This section discusses copyright, within the context of JoM, and is based around two issues. The first relates to the copyright that JoM claims based upon the material it publishes. The second relates to third party data included within maps that are published by JoM.

\section{Publishing Copyright}

It is common when submitting a research article for publication for the author to retain full copyright up to the point where it is accepted for publication. Many journals, after accepting the article, will require the submission of a copyright transfer form that assigns full, irrevocable, copyright for the material to the publisher. Some authors are unhappy at the requirement to transfer the copyright of their own work to a third party and, for government employees, a separate agreement is often used.

JoM allows the author to retain full copyright, whilst granting JoM an irrevocable license to publish the material. In essence the author and publisher share the copyright. JoM is also open access, with a requirement to make material freely distributable. It has therefore adopted the Creative Commons licensing model (http://www. creativecommons.org) that allows detailed specification in the use of published material, whilst still retaining copyright. Specifically, the license allows the freedom to copy, distribute, and display all published material for non-commercial purposes, whilst requiring full attribution in its use and non-alteration.

\section{Third Party Copyright}

The incorporation of third party material (e.g. photo, diagram, table) in a journal article requires agreement from the owner of the copyright. Within the context of JoM, this principally means the incorporation of third party data within published maps. The copyright restrictions are dependent upon the data supplier and will vary from organisation to organisation. For example, the USA federal government cannot claim copyright (see http://www.copyright.gov/title17/92chap1. $h t m l$ ) for data that has been acquired through the use of public funding and has a mandate to make it available at the cost of distribution. This includes data sets such as the Shuttle Radar Topography Mission digital elevation models and Landsat ETM+ satellite imagery. As these products are public domain, they can be incorporated into other materials.

Within the UK the national mapping agency, the Ordnance Survey (OS), is the primary supplier of geospatial data. Detailed licensing restrictions for universities cover the use and reproduction of data in print and electronically for local and international distribution (see Ordnance Survey data sub-licence agreement, at $h t t p: / / w w w . e d i n a . a c . u k /$ digimap/osterms.html). In particular, the license is flexible with respect to use of data in posters, presentations, teaching materials, and internal use. However, greater restrictions are imposed upon electronic, publicly accessible, publications; these are based upon a combination of the maximum (print) size of an individual image $\left(200 \mathrm{~cm}^{2}\right)$ and the maximum ground area it represents (e.g. the island of Ireland has an area $\sim 84,000 \mathrm{~km}^{2}$ ). The latter restriction varies by product, so that, for example, a ground area no bigger than $50 \mathrm{~km}^{2}$ can be published for Land-Form PANORAMA ${ }^{\mathrm{TM}}$ data. This 
generally means that any map larger than $\sim \mathrm{A} 5\left(200 \mathrm{~cm}^{2}\right)$ is not publishable. It is important to understand the implications of this restriction. As most peer-reviewed journals are now distributed over the internet, either solely electronically or in tandem with a traditional print process, it means that any OS digital product is effectively unpublishable in any journal. However the ramifications of this policy are more far reaching in that the license also covers all data derived from the original OS data source. Smith (2005a) has outlined an example where JoM could not publish a map that had been accepted for publication due to these restrictions.

\section{DATA DISTRIBUTION}

The move towards open access publication has, in part, been driven by the requirements of funding bodies to access research results. This mandate has also been extended to data deposition, with institutional repositories often accepting data. In addition there are also data centres maintained by funding bodies (e.g. Natural Environment Research Council; http://www.nerc.ac.uk/research/sites/data/). Despite this move towards data deposition, sharing and distribution, access to research data remains $a d h o c$, particularly when research has no direct funding. There is often less impetus to share data and this is partly due to research publications driving the research agenda, not data. And, within geosciences at least, there is little historical context for data sharing.

Researcher's willingness to share data are slowly changing, however the publishing agenda also needs to change. In much the same way that JoM provides an opportunity to publish maps, so there should also be an opportunity to publish the observational, analytical, and interpretive data from which the map was created. This must be citable, with an original, definitive, version stored in an appropriate location. And in the same way that journal articles are peer reviewed, so data should also be.

There are further complications to data sharing that remain active areas of research, e.g. GRADE (Geospatial Repository for Academic Deposit and Extraction) Project, http://edina.ac.uk/projects/grade/index.html. These include:

1. Data Sharing: which digital data formats should be used to distribute data?

2. Data Preservation: which digital data formats will allow maximum preservation (durability)?

3. Data Presentation: how can cartographic presentation be preserved?

In terms of data sharing, geospatial data types simplify to raster, vector, and attribute data. These form the lowest common denominator meaning that they should be both easy to share and easy to preserve, however there remains no preservation of the cartographic presentation. Increasingly the complexity of data formats will allow a greater richness in data sets and, in particular, data presentation (e.g. an ESRI .mxd file), however this will often be at the cost of proprietary formats and therefore the ability to both share and preserve data. Simple, open, data formats remain an essential starting point. At JoM, data can be incorporated as part of the journal article and is distributed in the following formats:

1. Vector: the Shapefile remains a good file format as it is openly published, with open source tools available to manipulate them. Unfortunately it does not preserve topological relationships and a format such as E00 might be required in these situations.

2. Raster: GeoTIFF remains the predominant open format that is widely supported, however both JPG and JPG2000 have wide application and remain suitable for distribution.

3. Attributes: there currently remains no open database format ideally suitable to supporting the distribution of attribute data. DBASE IV is widely supported, however text-base CSV remains the lowest common denominator.

One format that isn't noted above is the Geographical Markup Language, an Open Geospatial Consortium specification for the encoding of geospatial data (http://www. opengeospatial.org/standards/gml). Whilst only ratified in 2002 , over 40 vendors formally support the format and it has the potential to provide a widely supported, open format for data distribution.

JoM supports the distribution of data and, in particular, the ethos that "data should follow the research." Separating data and content is problematic in that an explicit link needs to be maintained between the two. Journals from the 19th century were able to distribute "data" in the form of photos, tables, maps and drawings and it is clear how effective this immediacy was. The peer review process also becomes much simpler.

The distribution of data also touches upon both open access and copyright. With an increase in OA journals the potential to have free and immediate data distribution is an attractive proposal. However there needs to be considerable care taken in resolving remaining copyright issues. Not only are appropriate licensing arrangements for third party data required, but the vested interest of stakeholders in data that is deposited must be considered. Third party copyright remains an active research area, although initial reports suggest that this may not be as restrictive as previously thought (Waelde and McGinley, 2007). The issues related to stakeholder interests, however, requires further investigation. For example, what are the interests of the employer, employee, funding agency, and any co-investigators?

Additionally, the complexity of dealing with data formats and, in particular, data volumes, makes coupling data distribution and publishing a difficult task. The de facto solution is for an author to reference their data as residing in a separate data repository, although many request that third parties contact them directly. However there is a strong argument to maintain the article-data link, placing the emphasis for data review, storage and dissemination with the publishers. This may increase the cost of publishing, but would provide a consistent approach, across disciplines. 


\section{CONCLUSIONS}

This article has covered material related to journal publication, yet the central thrust is actually far more general. Grant awarding bodies do not want to pay to view research they have already funded and the preference is that these are "free to access" (i.e. open access). OA does not necessarily mean a "traditional" journal, but can also incorporate e-only journals, institutional repositories, subject repositories, and grant body repositories. These may or may not incorporate peer review as part of the lodgment procedure. Preservation of research remains a central issue and it is clear that publishers take this issue seriously with, for example, Elsevier and the National Library of the Netherlands (http://www.elsevier.com/wps/find/authored_newsitem. cws_home/companynews05_00020, accessed 2007) providing a permanent digital archive for current journals. All of the content published by JoM is permanently archived by the British Library under the UK Web Preservation Programme (http://www.webarchive.org.uk/).

Preservation goes beyond the publication of research results in journals, with the requirement in the United Kingdom for research grant holders to deposit research data in repositories. Data distribution is a key component in any data preservation strategy and should be closely linked to the published, peer reviewed, research outputs. For the time being, journal publication and data repositories remain separate entities, however there is a strong argument to, at least in part, merge the activities of these two areas.

There also remain more practical considerations, with a move to greater emphasis on data distribution. In particular, what data formats should be used for the storage of spatial data? These need to be fit-for-purpose and open, with a high potential for preservation. Geospatial repositories remain in their infancy and the subject of active research, such as the GRADE Project (scoping report accessed 2005, at http://www. jisc.ac.uk/index.cfm?name=project_grade).

The final link in this chain revolves around legal aspects of data sharing and, in particular, copyright. The above discussion outlines some of the fundamental issues concerning the use and re-use of research outputs and geospatial data. Can the interests of multiple stakeholders be satisfactorily resolved to allow data distribution? Should geospatial data be considered under copyright or, in Europe, is the Database Directive (covering "collections" of data) more appropriate (Waelde and McGinley, 2007)? Are licensing restrictions concerning the use of derivative datasets satisfactory? Whilst the first question remains unresolved, the second has been highlighted as being actively researched. Derivative datasets are an important area, with licensing conditions varying between suppliers. For example, Intermap, with the sale of the NEXTMap Britain product, does not claim intellectual property rights for thematically derived data (product handbook accessed in 2005, at http://www.intermap.com/images/ handbook/producthandbook.pdf), whilst the OS do claim these rights (see Ordnance Survey data sub-licence agreement, at http://www.edina.ac.uk/digimap/osterms.html).

\section{ACKNOWLEDGMENTS}

Some of this material appeared in an earlier article

(Smith, 2005b) and is now significantly updated.

\section{REFERENCES}

Delamothe, Tony, and Smith, Richard, 2003, Editorial; Paying for bmj.com: British Medical Journal, v. 327, no. 7409, p. 241-242, available at $h t t p: / / w w w . b m j . c o m / c g i / c o n t e n t /$ full/327/7409/241.

House of Commons Science and Technology Committee, 2004, Scientific Publications: Free for all?; Tenth Report of Session 2003-04: London, The Stationery Office Limited, HC 399-1, v. 1, 114 p., available at http://www.publications. parliament.uk/pa/cm200304/cmselect/cmsctech/399/399. $p d f$.

Morris, S., and Powell, A., 2005, Dissemination of and access to UK research outputs: response from the Association of Learned and Professional Society Publishers (ALPSP) to the Research Councils UK position statement. [Accessed in 2005, no longer available online.]

Research Councils UK, 2005, RCUK Position Statement on Access to Research Outputs: Research Councils UK Report, 15 p., available at http://www.rcuk.ac.uk/cmsweb/ downloads/rcuk/documents/2005statement.pdf.

Rightscom, 2005, Business models for Journal Content; Final Report: London, Rightscom Ltd., 64 p. Submitted to Joint Information Services Committee. Available at $h t t p: / / w w w$. nesli2.ac.uk/JBM_o_20050401Final_report_redacted_for_ publication.pdf.

Rowland, J.F.B., 2002, The peer-review process: Learned Publishing, v. 15, no. 4, p. 247-258.

Smith, M. J., 2005a, The Journal of Maps: an electronic journal for the presentation and dissemination of map based data: Journal of Maps, v. 2005, p. 1-6, available at $h t t p: / /$ www.journalofmaps.com/.

Smith, M.J., 2005b, Open access journal publication: methods of implementation and copyright issues: Society of Cartographers Bulletin, v. 39, p. 21-24.

Waelde, Charlotte, and McGinley, Mags, 2007, Designing a licensing strategy for sharing and re-use of geospatial data in the academic sector: [publisher unknown], 40 p. Final report to the GRADE Project. Available at http://edina. ac.uk/projects/grade/gradeDigitalRightsIssues.pdf. 


\title{
The National Cooperative Geologic Mapping Program and Insight Into the Future of Geologic Map Production
}

\author{
By Randall C. Orndorff, Peter T. Lyttle, Laurel M. Bybell, and Lydia Quintana \\ U.S. Geological Survey \\ 908 National Center \\ Reston, VA 20192 \\ Telephone: (703) 648-4316 \\ Fax: (703) 648-6937 \\ email: rorndorf@usgs.gov; plyttle@usgs.gov; \\ lbybell@usgs.gov; lquintan@usgs.gov
}

\section{INTRODUCTION}

Geologic maps form a primary foundation for virtually all applied and basic earth-science investigations. The process of constructing a geologic map involves basic scientific research on the Earth's history and the processes that operated to form the planet's rocks and surficial materials. The definition of what constitutes a geologic map has changed over the years from a traditional paper product to multi-use digital geologic map databases. In this paper, the term "geologic map" refers to the representation of the geology at the earth's surface, as well as the related subsurface interpretations of the geology, and includes any related databases.

The U.S. National Cooperative Geologic Mapping Program (NCGMP) has a mission to produce accurate geologic maps and three-dimensional geologic framework models that provide indispensable data and improved understanding of earth surface processes, ground-water availability, and onshore-offshore sediment transport processes. Collectively, this information is used to sustain and improve the quality of life and economic vitality of the Nation. These maps and frameworks support Department of Interior (DOI) land management decisions, mitigate hazards, and assist in ecological and climatic monitoring and modeling. This paper provides some background about the NCGMP and explores the impact of changing technology on geologic map products.

\section{THE U.S. NATIONAL COOPERATIVE GEOLOGIC MAPPING PROGRAM}

\section{History and Background}

In 1992 , the $102^{\text {nd }}$ Congress recognized that a coordinated program was needed to facilitate geologic map production for the Nation by means of a uniform system in which priorities are established according to customer needs. In the late 1980s, less than 20 percent of the United States had detailed geologic map coverage at scales necessary for land-use and resource managers to make wise decisions (National Research Council, 1987) and very few of these geologic maps were in a digital format that now is the standard for geologic map production.

The National Geologic Mapping Act (NGMA, Public Law 102-285), which was signed into law in 1992, created the National Cooperative Geologic Mapping Program to implement and coordinate an expanded geologic mapping effort by the U.S. Geological Survey (USGS) and the State geological surveys. The Act has been re-authorized twice, in 1997 (Public Law 105-36) and in 1999 (Public Law 106-148), and currently is in the process of its third reauthorization. The NGMA and its reauthorizations are available at http://ncgmp. usgs.gov/ncgmpabout/ngmact/. 
The program today represents successful cooperation among Federal, State, and academic partners to deliver modern digital geologic maps to the communities and users that need them. In doing so, the program delivers the regionalscale (generally 1:24,000 or smaller) geologic maps that are critically needed by society. For example, private sector geotechnical consultants have come to depend on these maps as a base for constructing their larger-scale, site-specific geologic maps to support planning and engineering projects. The metadata from these efforts across all of the U.S. will continue to be stored and made available in the National Geologic Map Database's Map Catalog (NGMDB, http://ngmdb.usgs. gov). In support of geologic mapping, a common set of geologic map cartographic standards was published in 2006 (Federal Geographic Data Committee, Geologic Data Subcommittee, 2006); this was developed by NCGMP in cooperation other Federal agencies, the state geological surveys, and the NGMDB.

The success of the NCGMP is evident as recent geologic mapping has been an important part of scientific advancement in areas as diverse as earthquake mechanisms, groundwater flow modeling, mineral and petroleum exploration, and the mitigation of natural hazards. The success of these efforts can also be gauged by the fact that the percentage of the Nation with geologic map coverage has risen dramatically. Also, geologic map production, compilation, and training have been promoted in 49 of the 50 states and Puerto Rico during the past 13 years (Figure 1).

\section{Program Components}

Each of three components of the program, as described below, has a unique role, yet all work cooperatively in the process of determining priorities for and producing new geologic maps. The Federal component of the program, FEDMAP, which officially began in 1993, creates regional geologic frameworks for areas that are vital to the economic, social, or scientific welfare of the Nation. The program annually supports approximately 25-30 multi-year USGS projects, which frequently include interdisciplinary studies that add value to the geologic mapping and promote dissemination of these products to a wide variety of consumers. National priorities are set with the advice of both a Federal Advisory Committee and a FEDMAP Review Panel, which have Federal, State, private industry, and academic members, and through less formal meetings with customers, collaborators, and cooperators. Program funding is also used to maintain the National Geologic Map Database (NGMDB), an effort mandated by the NGMA. The NGMDB provides information to the public about all geologic maps produced in the United States. Through the NGMDB, the Program also is

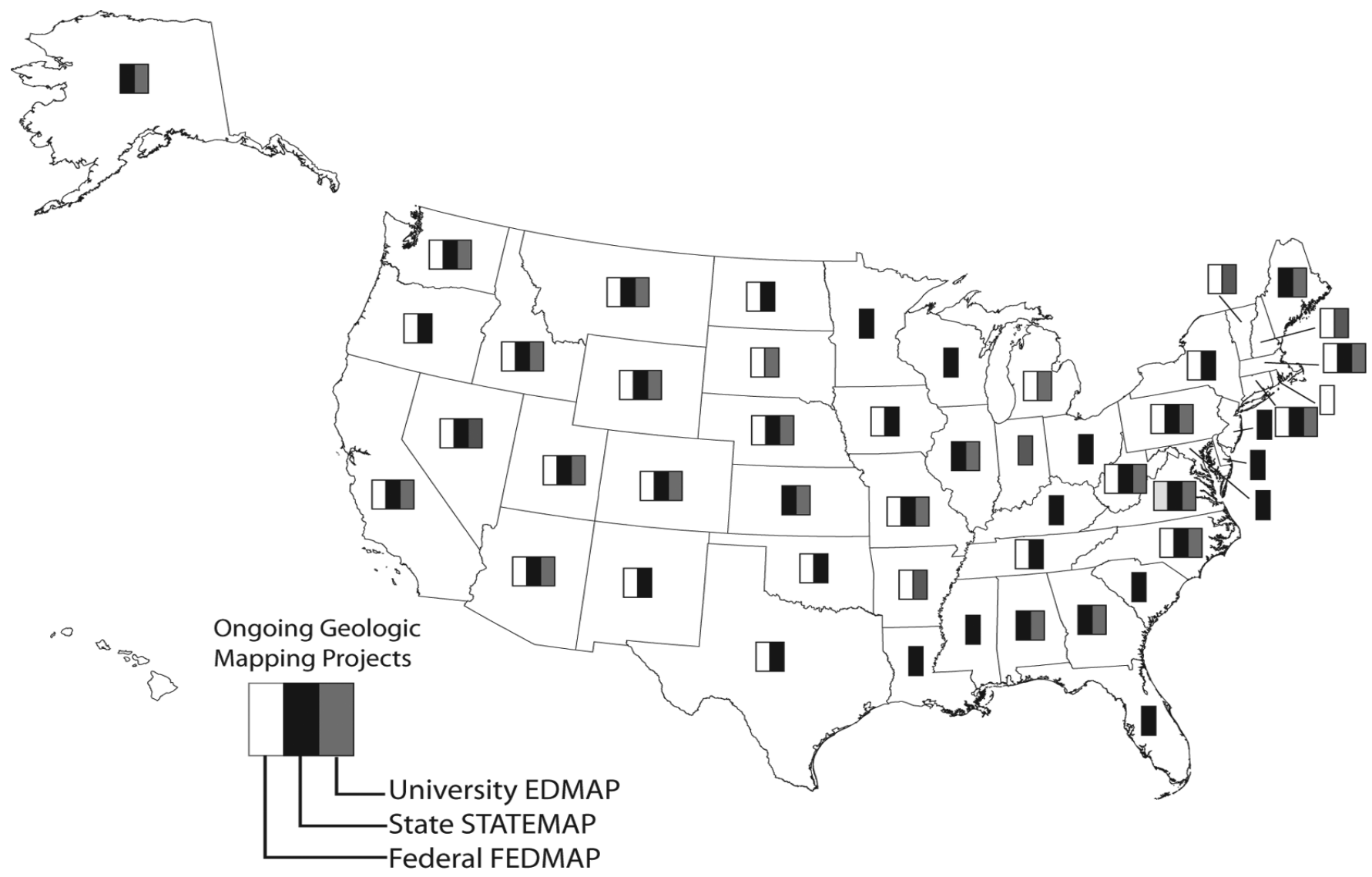

Figure 1. Geologic mapping projects by component of NCGMP for FY 2007. 
developing a uniform set of map production standards for use by all Program components and the entire geologic mapping community, and is promoting the use of sophisticated data models for the construction and dissemination of geologic maps.

The STATEMAP component creates geologic frameworks for areas that are vital to the economic, social, or scientific welfare of individual States. State geological surveys first received STATEMAP funding in 1993. While contributing to the NCGMP mission priorities, each State Geologist determines the State's mapping priorities in consultation with a State Mapping Advisory Committee. The highest priority efforts address multiple societal issues, a compelling single issue, or where geologic maps are essential for solving critical Earth science problems in a given State. The Association of American State Geologists, an organization consisting of all 50 State Geologists, routinely provides the Program with insightful guidance on critical issues that affect the States collectively. Each year, the NCGMP funds approximately 120 projects in as many as 47 States. STATEMAP is a competitive grants program where Federal funding is matched one-to-one with State funds. Proposals are reviewed by national award panels made up of scientists from the USGS and selected representatives from the State geological surveys.

EDMAP, which began in 1996, provides university students with a carefully mentored education in the fundamental principles of geologic mapping and field studies. College or university geology professors, who are skilled in geologic mapping and willing to provide appropriate mentorship, request EDMAP funding to support their undergraduate and graduate students' participation in geologic mapping field projects. EDMAP geology professors and their students are required to have a partner geologist from a State geological survey or USGS project, which provides opportunities for shared information and resources. The NCGMP allocates funds to colleges and universities in the United States and Puerto Rico through an annual competitive grant process. Proposals are reviewed by national award panels made up of scientists from the USGS, State geological surveys, and universities. Every Federal dollar that is awarded is matched one-to-one with university or other non-federal funds.

The success of this component is realized in that more than $90 \%$ of EDMAP students have pursued additional geoscience degrees or developed geoscience careers. The program fills a unique role in its training of new geologic mappers because other programs, such as the National Science Foundation, rarely support basic research devoted to geologic mapping.

\section{USES OF GEOLOGIC MAPS}

Decision makers at the Federal, State, and local levels are increasingly in need of objective scientific information to make sound decisions regarding planning, development and natural resource use. A modern digital geologic map often is the best scientific product for conveying this information because such a map is the single best source for understanding the history of the Earth. Geologic maps depict and interpret the bedrock and surficial geologic units that occur at and beneath the Earth's surface. They also present information about the complex depositional and tectonic histories that the rocks have undergone, and may provide information about geologic age, mineral resources, fossils, geochemistry, and a host of other basic earth science information. Although the original decision to map an area may have been based on a specific need or issue, the resulting maps have significant derivative value because of the quality and type of information found in the geologic maps. These maps also are being used to address a multitude of other land-use issues for years after their original publication. The derivative uses continue to provide a substantial and prolonged return on the initial research investment. Bernknopf and others (1996) discussed the uses, derivatives and values of geologic maps and how land-use decisions are based on these products. In 2000, Bhagwat and Ipe (2000) found through a survey of geologic map users in the state of Kentucky that the return on the investment of producing geologic maps for the entire state was about 30 times the cost of production. This economic value was realized through multiple uses of the maps for energy exploration in the 1970's and water resources in the 1990's and 2000's.

Prior to the NGMA, the major justifications for geologic mapping in the U.S. involved the use of maps in discovering and developing energy and mineral resources. In recent years, the need to maintain adequate clean water resources has become a major impetus for geologic mapping (Figure 2). Another recent demand for geologic maps is to solve a broad array of environmental concerns, such as ecosystem restoration and proper siting of waste facilities. The NCGMP will continue to recognize and support new uses for geologic

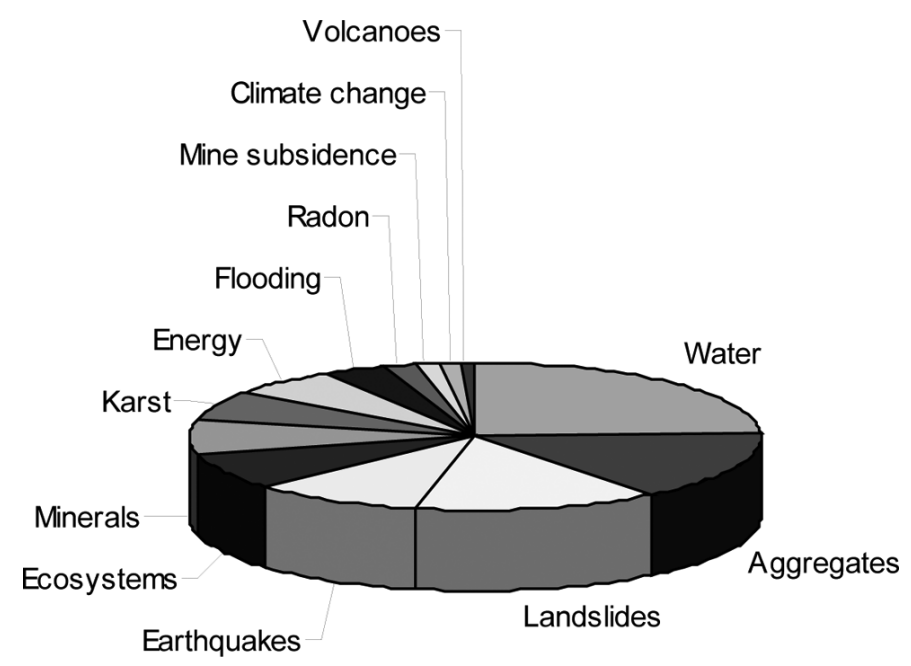

Figure 2. Justifications and purposes of geologic mapping for FY 2007 FEDMAP and STATEMAP projects. Information was compiled from NCGMP project descriptions. 
maps through sustained close communication with customers and stakeholders, especially the input received through the State Geologic Mapping Advisory Committees.

\section{NCGMP MAPPING IN PROGRESS}

The productivity of NCGMP is measured in the number of geologic maps and the square miles mapped each year. The Program has developed a mapping-in-progress database to track all geologic mapping occurring through the Program across the U.S. This database is linked to internal NCGMP spreadsheets, USGS Geography Discipline databases showing the square miles for each quadrangle in the U.S., and the NGMDB where information can be obtained by the public (http://ngmdb.usgs.gov/MapProgress/MapProgress_home. $h t m l)$. Information stored in the mapping-in-progress database includes quadrangle name and state, square miles to be mapped, bedrock or surficial mapping, and principal investigator contact information (Figure 3). Within one year of notification that a map is published and recorded in the NGMDB, it will be removed from the mapping-in-progress database.

The mapping-in-progress database serves several functions. If a geologic map is unpublished or not included in the geologic map catalog of the NGMDB, it directs the public to the organization (USGS, State geological survey, or university) that is currently mapping a particular area. Also, the NCGMP uses this database to internally track geologic maps from time of proposal, to formal agreement, and to delivery of the map to the Program. The Program can evaluate trends in geologic mapping such as amount of bedrock and surficial geologic mapping, amount of digital compilation of previously published geologic maps, and differences in costs of geologic mapping over time and regions of the U.S. Another important use of this database is the ability to compile information to respond to requests from Government accountability programs for the Office of Management and Budget and for Congress (see also Soller, 2005).

Although there is information on past geologic mapping projects for NCGMP dating back to 1996, the most

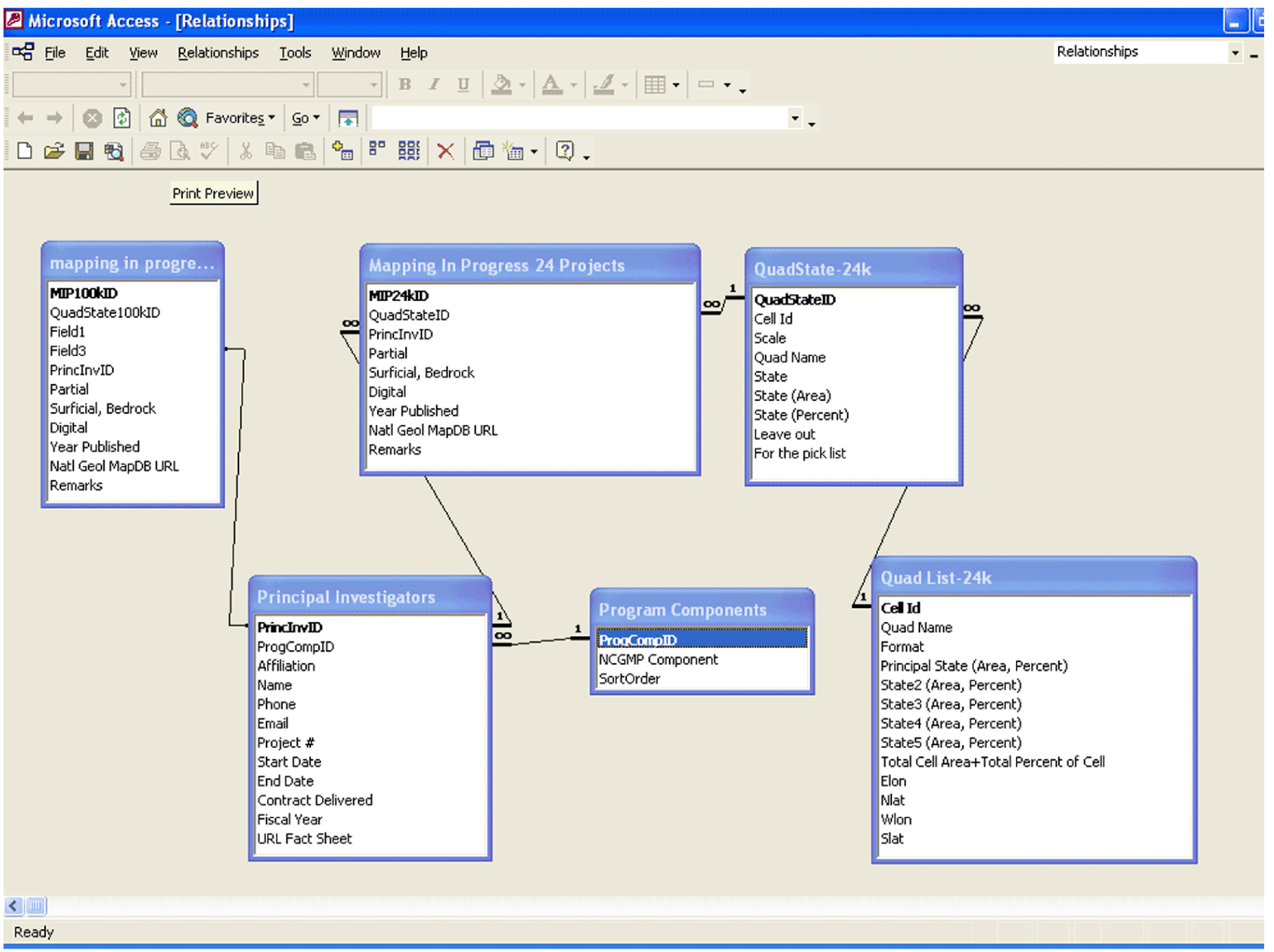

Figure 3. Diagram showing linkages within NCGMP mapping-in-progress database. 

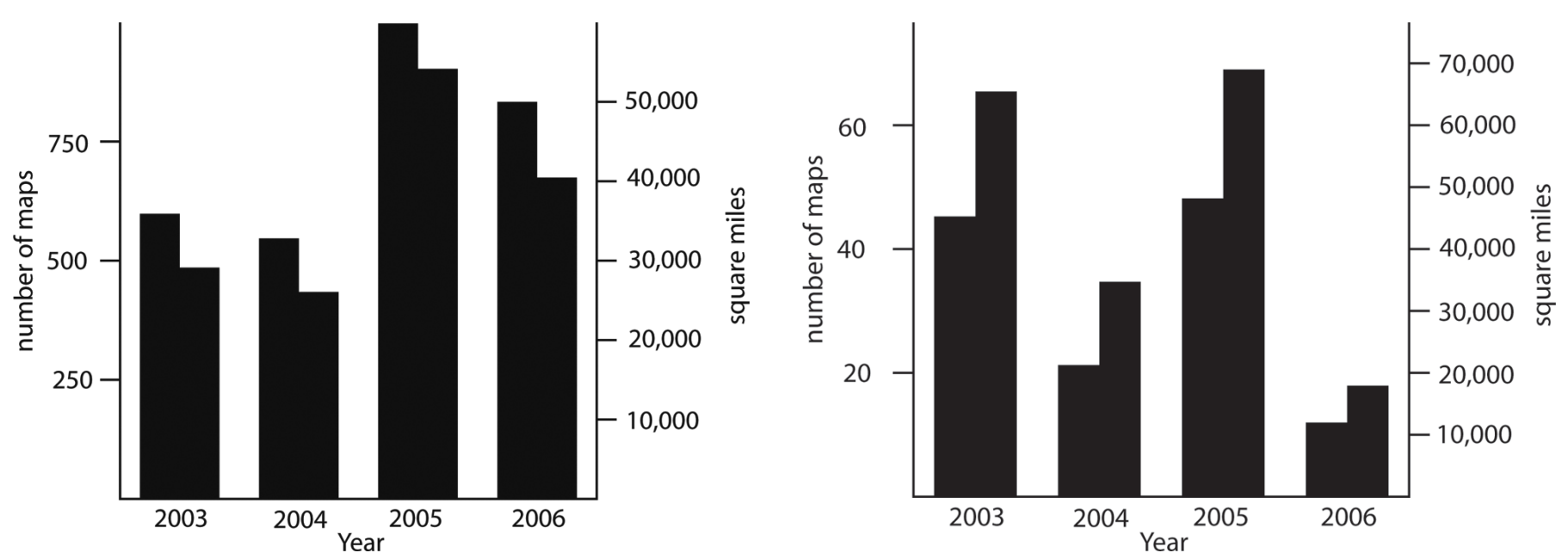

Figure 4. Number of maps (left bar) and square miles (right bar) funded for geologic mapping each year from 2003 through 2006 for $1: 24,000$ and $1: 100,000$ scales.

comprehensive data for the mapping-in-progress database has been collected since 2003. Since 2003, the USGS, state geological surveys, and university geoscience departments have mapped nearly 30007 1/2-minute quadrangles (full or in part) equaling nearly 150,000 square miles (Figure 4). For 30' $\mathrm{x}$ 60 ' quadrangles, these same organizations have mapped 126 quadrangles (full or in part) equaling 171,968 square miles.

\section{THE FUTURE OF GEOLOGIC MAPPING}

While a traditional geologic map portrays all of its information on a large sheet of paper, new digital techniques and computer software enable geologic mappers to represent the information in ways that are easier for their customers to visualize, understand, and use. These digital presentations frequently include additional information that was difficult or impossible to portray on paper maps. For instance, regional geophysical data sets such as gravity and aeromagnetic anomalies can be combined with a robust set of point data such as earthquake epicenters and water wells, to form one component or layer of the digital geologic map.

The dilemma of geologic mapping in the $21^{\text {st }}$ Century is the need to bridge a transition from the traditional paper map products to digital geologic map databases that can be used in Geographic Information Systems (GIS). The paper geologic map places all information from the geologic mapping study in one place displayed at the scale it was intended by the author. Descriptions of the map units, cross sections, explanations of map symbols, correlation charts, and other information are presented with the map and can be carried in the field by the map user. In many cases, the paper map can be used in places that a computer is not practical. Also, the entire map can be viewed at its proper scale and in its entirety, something that cannot be done on a computer screen.

However, the power and usefulness of digital map products is limitless. Various geologic layers can be displayed and combined with other map products to produce desired derivative products for decision-making. Derivative maps from geologic maps have long existed and are one of the most powerful products of the original comprehensive geologic map. Geologic maps from the early $19^{\text {th }}$ Century of Great Britain were used to develop engineering maps for building of canals and resource maps of coal resources (Winchester, 2001). With the advent of GIS, geologic layers can now be combined with many other types of map products to allow for maps useful for land-use decisions. Geologic maps combined with land-use maps help to define zoning, protect sensitive ecosystems, and define critical recharge areas for ground water.

The concept of scale has changed with the advent of digital maps. Scale has traditionally referred to the ratio of linear distance on a map to the corresponding distance on the Earth's surface being mapped. However, with digitally displayed map information, it is possible to zoom in and out on maps that can be viewed on computer monitors projecting the map at various scales. Therefore, the term scale in digital mapping becomes the resolution of the map, or the scale at which the map data was compiled. This can cause map users to misuse maps by looking at detail that is not part of the original compilation. For example, a map compiled at 1:100,000 scale should not be used to zoom into a site at a much larger scale of 1:24,000 or larger. Contacts and other map information lose their accuracy when viewed at inappropriate scales. Digital geologic maps should include disclaimers notifying the user of the accuracy of the maps at particular scales. Ideally, digital maps could include an algorithm that prohibits the map user from zooming in too far.

Another powerful aspect of digital geologic maps is the inclusion of the third dimension. The term "threedimensional geologic maps" can mean different things to different people. As one example, the draping of geologic map polygons on digital elevation models shows the threedimensional relationships of geologic units where they occur 

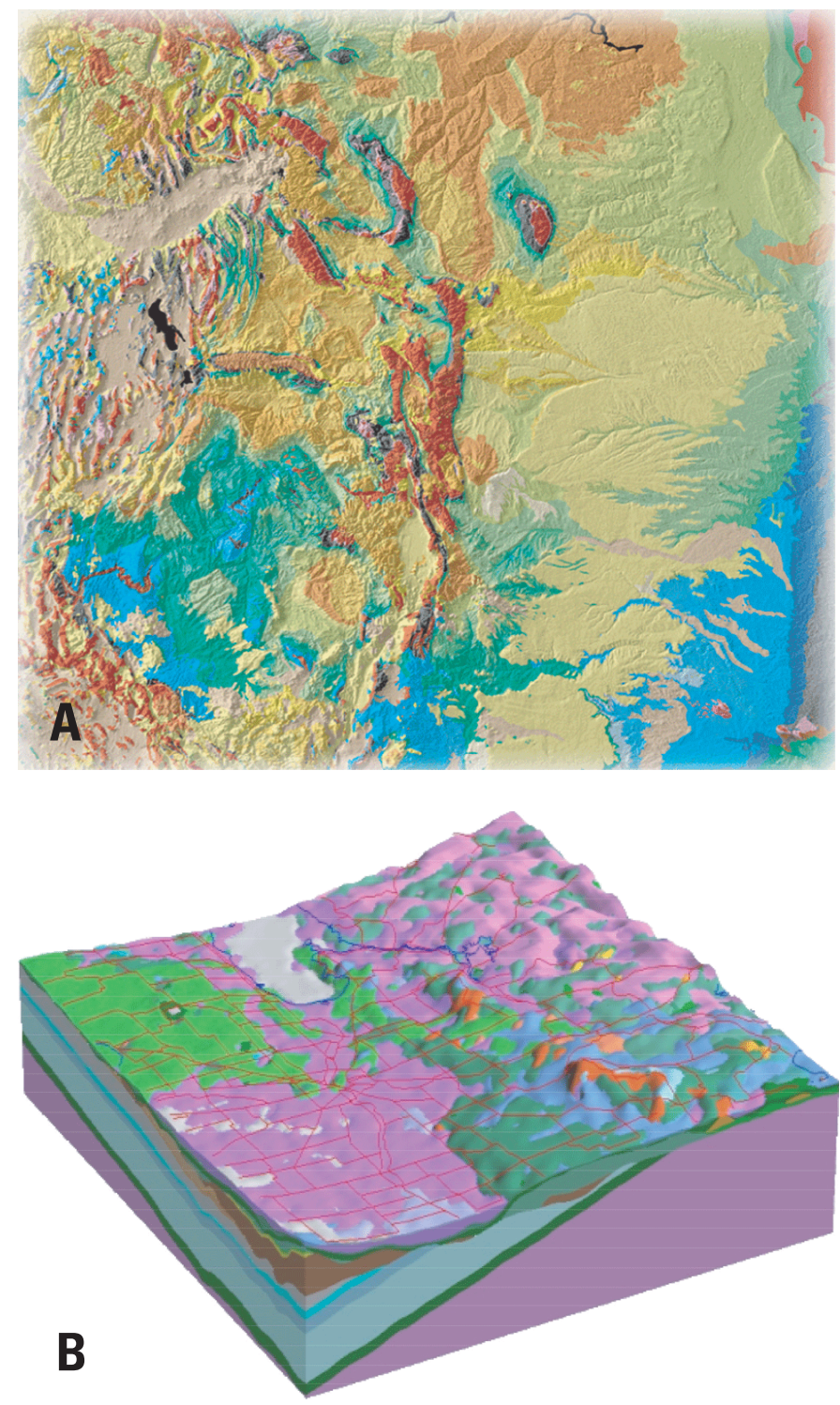

Figure 5. Examples of three-dimensional geologic maps. A) Geologic units draped over a digital elevation model, from North Dakota (Thomas, 2004). B) Geologic framework showing subsurface extent of geologic units.

at land surface (Figure 5a). In another example, cross sections developed from drillhole and other information can be interpolated to make a block diagram showing geology in the third dimension (Figure 5b). The power of the block geologic map is that it can be used as the boundary and threedimensional conditions for models. For instance, geologic conditions related to faulting and shaking can be displayed and interpreted for earthquake hazards. Also, three-dimensional geologic maps are used to build ground-water models to assess recharge, storage, and discharge of aquifers.
The need for both the traditional geologic map product and digital geology layers requires more resources than previously, when just a paper map was produced. Development of digital geologic maps does not necessarily make production more efficient. However, efficiency can be increased by digitally collecting field data on handheld computers with mapping software. Efficiency is also realized in map compilation where the field data can be easily transferred to a GIS to develop the digital map and database. However, to effectively develop digital geologic map data, knowledge of geology (geologic mapping), cartography, GIS, and computer programming is necessary. Also, effective distribution of digital maps requires use of the worldwide web.

\section{REFERENCES}

Bhagwat, S.B., and Ipe, V.C., 2000, Economic benefits of detailed geologic mapping to Kentucky: Illinois Geological Survey, Special Report 3, 30 p.

Bernknopf, R.L., Brookshire, D.S., Soller, D.R., McKee, M.J., Sutter, J.F., Matti, J.C., and Campbell, R.H., 1996, Societal Value of Geologic Maps: U.S. Geological Survey Circular 1111, 53 p., available at http://pubs.er.usgs.gov/usgspubs/ cir/cirl111.

Federal Geographic Data Committee, Geologic Data Subcommittee, 2006, FGDC digital cartographic standard for geologic map symbolization: Federal Geographic Data Committee Document Number FGDC-STD-013-2006, 290 p., 2 pls., available at http://ngmdb.usgs.gov/fgdc_gds/.

National Research Council, 1987, Geologic mapping in the U.S. Geological Survey: Washington, D.C., National Academy Press, 22 p.

Soller, D.R., 2005, Assessing the Status of Geologic Map Coverage of the United States - A New Application of the National Geologic Map Database, in D.R. Soller, ed., Digital Mapping Techniques '05 - Workshop Proceedings: U.S. Geological Survey Open-file Report 2005-1428, p. 41-47, available at http://pubs.usgs.gov/ of/2005/1428/soller2/index.html.

Thomas, W.A., 2004, Meeting challenges with geologic maps: American Geological Institute, Environmental Awareness Series, 64 p.

Winchester, Simon, 2001, The map that changed the world - William Smith and the birth of modern geology: New York, Harper Collins, 329 p. 


\title{
Geologic Field Mapping Using a Rugged Tablet Computer
}

\author{
By Kent D. Brown and Douglas A. Sprinkel \\ Utah Geological Survey \\ 1594 W. North Temple \\ Salt Lake City, Utah 84116 \\ Telephone: (801) 537-3300 \\ Fax: (801) 537-3400 \\ email: kentbrown@utah.gov; douglassprinkel@utah.gov
}

\section{INTRODUCTION}

The Utah Geological Survey (UGS) publishes geologic maps principally at scales of 1:24,000 and 1:100,000. Each geologic map, regardless of scale, requires a certain level of field mapping where data are recorded on aerial photographs and in field books. Traditionally, geologic line work is hand-transferred to a topographic base map on which the final map is prepared for publication using accepted cartographic techniques. Since about 1991, however, the UGS has used digital technologies to prepare the final map for publication, and for the past few years to record data in the field, making geologic fieldwork and map preparation more efficient. This is particularly true for some of our 1:100,000-scale geologic maps.

Using digital technologies for geologic field mapping has many distinct advantages: (1) improved precision in placement of geologic features and sample locations using Global Positioning System (GPS) and on-screen display of geospatially corrected imagery and topographic base maps for reference, (2) increased efficiency in drawing field-attributed geologic lines because they do not need to be hand-transferred or redrawn on another map in the office and then digitized, (3) graphical notation on digital photographs with geologic relationships, and (4) accessing key publications in a digital library.

Utah Geological Survey mapping geologist Doug Sprinkel began a field trial in 2005 using a rugged tablet computer and GIS software to create and attribute geologic map data for the Dutch John, Vernal, and Seep Ridge 30' x 60' quadrangles in northeastern Utah. This paper describes the experience of that trial.

\section{TECHNOLOGY CHOICES}

The merits of using various electronic devices and software for field collection of geologic map data has been studied and debated by numerous researchers (e.g., Struik and others, 1991; Brodaric, 1997; Walsh and others, 1999; Kramer, 2000; Edmondo, 2002; McCaffrey and others, 2005; Clegg and others, 2006). Many geoscientists have used a palmsized Personal Digital Assistant (PDA) or similar device and customized software applications (Brodaric, 1997; Walsh and others, 1999; Brimhall and others, 2002; Edmondo, 2002), while others have chosen systems based on a larger rugged tablet computer (De Donatis and others, 2005, Sprinkel and Brown, 2008), which is bulkier but offers distinct advantages. A detailed comparison of both types of systems (Clegg and others, 2006) along with the development of Map IT GIS software for geologic field mapping (De Donatis and others, 2005; De Donatis and Bruciatelli, 2006) convinced us to choose a rugged tablet computer and Map IT GIS software for a UGS mapping program field trial.

Several brands and models of rugged tablet computers are now available. We chose a rugged tablet model from Xplore Technologies that meets military specifications for water, dust, and shock resistance and has a relatively large 10.4" LCD screen and illumination technology that enhances the display's legibility, even in bright sunlight. The tablet has a $1.2 \mathrm{GHz}$ Intel Pentium M 753 - ULV processor, 1 GB of RAM, an 80 GB hard drive, Integrated 802.11 wireless networking, and Microsoft Windows XP Tablet Edition. Although the tablet and software will work with a full range of GPS devices from the simplest inexpensive USB units, Bluetooth devices, or survey-grade equipment costing thousands of dollars, we chose the integrated GPS receiver.

\section{OVERVIEW OF METHODS}

Geologic mapping using digital field techniques is really not that much different from traditional methods. A geologist still has to go in the field with a rock hammer, hand lens, and compass, aided by stereo pairs of aerial photographs and a stereoscope (needed to see the map area in three dimensions) to determine formation contacts and faults, measure bedding 
attitudes (strike and dip), collect samples, and take field notes. However, instead of carrying a map board and drawing lines on paper-based aerial photographs or topographic base maps using an ink pen, the geologist uses a rugged tablet computer with a touch-screen as the map board and GIS software and a stylus to draw lines on digital base map images that are displayed on the screen for positional reference; digital images could be topographic, geospatially corrected photographic (orthophoto) images (Figure 1) or shaded relief maps, as well as images of other geologic maps.

In addition to drawing lines using the stylus, line data can be collected using an active GPS receiver while walking the contact or fault. Point data such as bedding attitudes and sample locations can also be easily and accurately collected using the GPS receiver and displayed on the digital base (Figure 2). Field notes are electronically written into word processing software using the stylus or a portable external keyboard. Finally, digital photography permits the geologist to capture an image of a scene, transfer the image to the tablet computer, and then easily make graphical notations on the photograph in the field.

Map IT, the GIS software, allows us to create custom data input forms with pull-down pick-lists to simplify and standardize the collection of geologic data. This allows the geologist to create a digital map while still in the field, with attributed and colored map unit polygons, geologic symbols, and feature labels.

\section{Pre-Field Mapping Procedures}

Any successful mapping project begins with a certain amount of office preparation before the first step is taken in the field. This is particularly true for digital field mapping. For example, in Map IT and other spatial database software, the geologic database must be configured, and tables must be created to accept the necessary feature attributes. When the

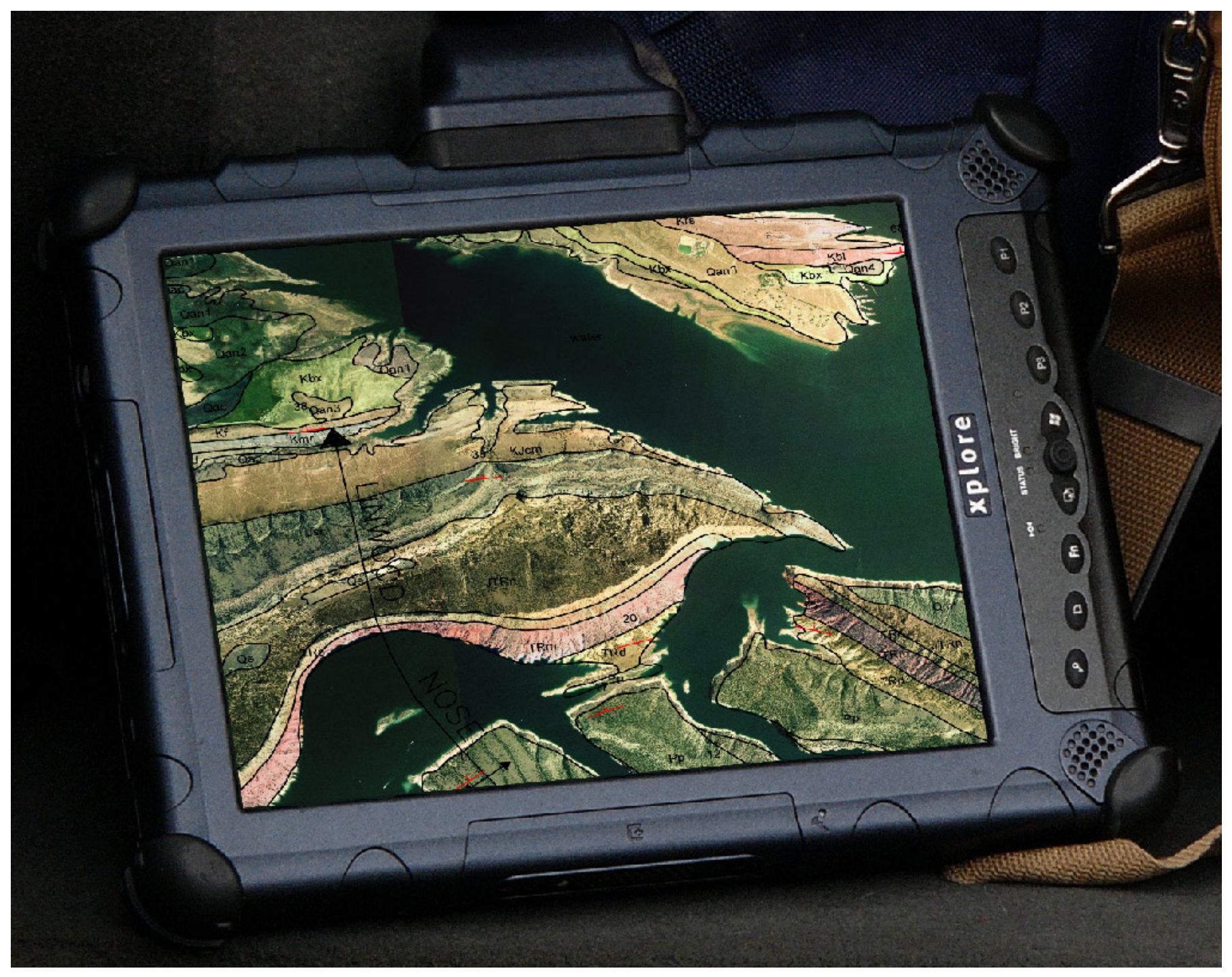

Figure 1. Rugged tablet computer showing geology mapped in the field superimposed over digital orthophoto 


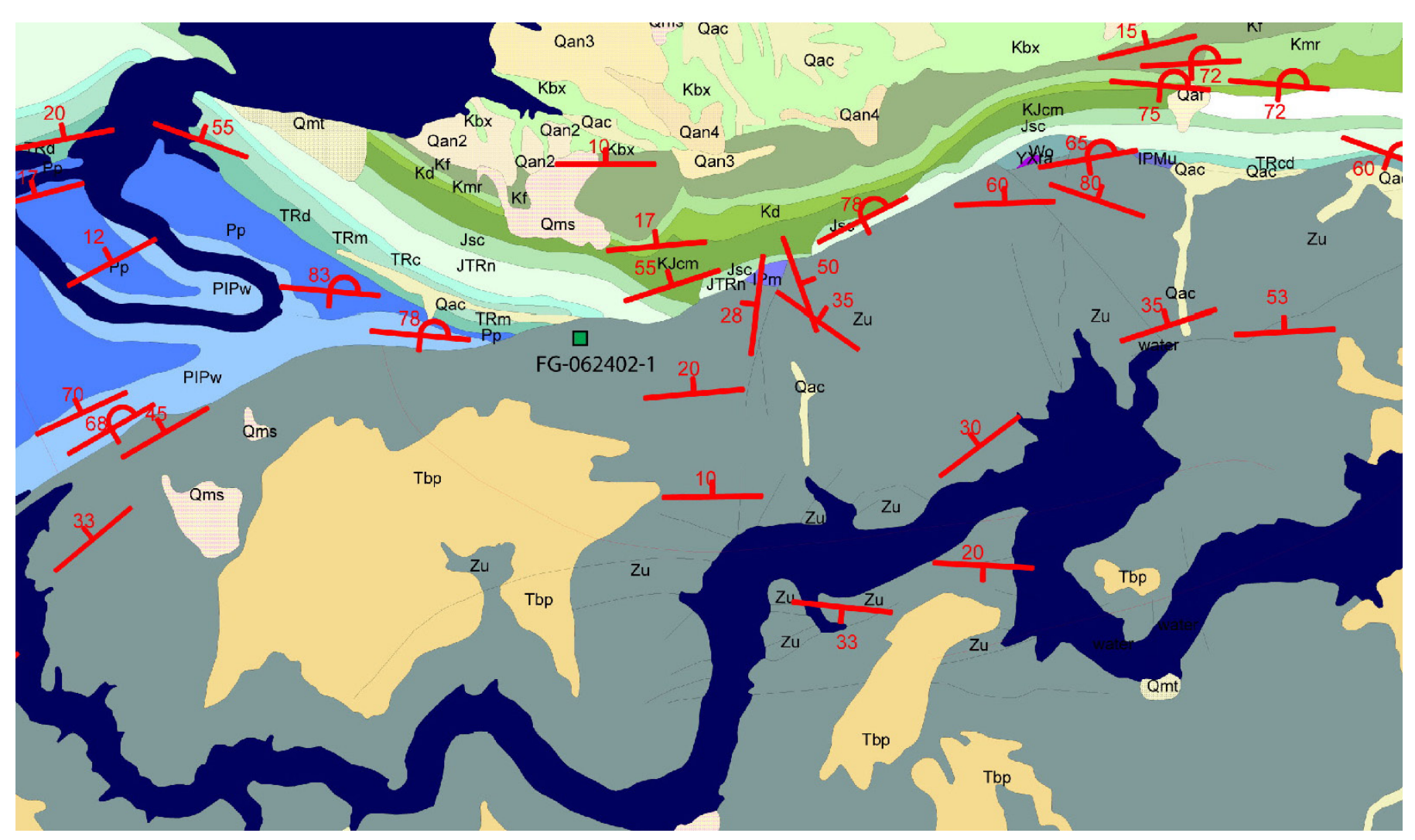

Figure 2. Field-collected bedding attitudes on a geologic map. Symbol size is exaggerated for clarity.

tables are ready for feature attributes, then data entry forms are created, one for each data type (e.g., points, lines, and polygons). On a tablet computer using Map IT, these forms are important so the geologist can draw lines and points and easily select their attributes from choices in a list. These pick-list choices populate the data tables' attribute fields. The forms are fairly easy to create and using them keeps errors to a minimum and makes the data consistent from map to map. Forms are simple to very complex depending on our needs and they can be reused from one project to the next. We prepare and check project files in Map IT to ensure that all of the forms, scripts, and data tables are in the new project and that they function properly. There is nothing more frustrating than to be in the field attempting to enter a data point, only to discover that the data table or forms linked to lookup tables are not present. Data tables and forms can be created on the fly in the field but that takes up valuable field time.

We still use paper copies of stereo pairs of aerial photographs, and a pocket stereoscope, so the geologist can see the field area in 3-D. In addition to assembling the aerial photographs needed, we gather the best-available digital orthophoto files and DRG topographic map files. Finally, we assemble a library of digital documents on the tablet computer containing important articles and existing geologic maps that pertain to the map area. Most journal and government-agency articles and maps are available in PDF format. Accessing these digital publications on the outcrop is handy and may save you a repeat trip to the outcrop.

\section{IN THE FIELD}

We believe that digitally collecting geologic field data using the tablet PC with Map IT permits the geologist to easily and consistently attribute data, reduces potential errors in transferring line work and point locations, and saves time by not having to redraw line work from one step in the map production process to the next. Line work and data points are directly mapped in layers using the tablet's stylus, or their positions are recorded from the GPS receiver. Lines and points representing contacts, faults, fold axes, bedding attitudes, structural data, and sample locations are attributed in the field using pull-down dialog boxes linked to look-up tables (Figure 3).

Map IT has many tools very similar to those in other GIS software. For example, it is easy for the field mapper to create preliminary geologic unit polygons with attributes, and to color the polygons by their unique values. With this in mind, unit symbol annotations are placed in each unit so they can be used as ID points to automatically generate polygon attributes for use in the field, as well as in the publication process.

Another viable use for this wireless-enabled system is collecting and transferring time-sensitive data (maps, field notes, and images) from the field to the office during geologic hazard events or other natural disasters. Earthquake hazard is relatively high in the western US and these systems could prove to be valuable assets to government agencies involved in emergency response. 


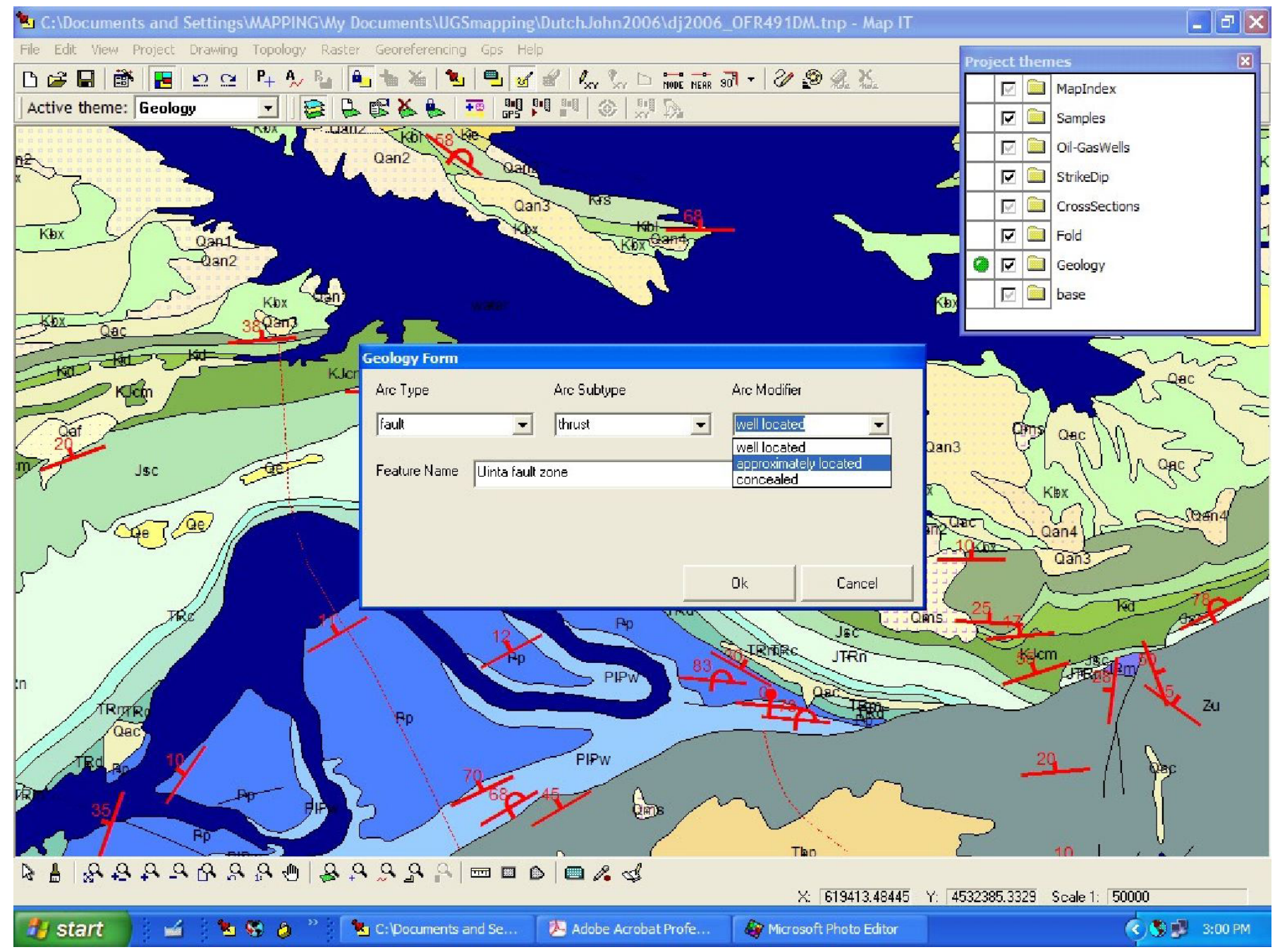

Figure 3. A simple Map IT data form with pick-lists is used for field-attributing geologic features.

\section{Photos and Field Sketches}

Photographs of key outcrops, sample locations, or field relationships are taken using a digital camera and the images are transferred to the tablet via USB cable where the geologist can draw graphical interpretations on the photos, in the field, using a simple image viewing and editing tool included with Map IT. By these means, traditional paper field sketches can be replaced with digital drawings and photos (Figure 4).

\section{Voice Recordings}

The Xplore tablet computer has both a built-in microphone and an external microphone line-in port, which is useful because Map IT includes an easy-to-use voice-recording tool. This is a great way to audibly record thoughts and interpretations as they occur without having to grab a notebook and write everything down. It is likely that voice recognition software eventually will enable conversion of these recordings to text!

\section{Easy-Notes}

The Map IT Easy-Notes tool is arguably the most interesting and useful tool we've seen in a GIS. It allows the user to tie all sorts of information to a single clickable geographic point on a map. It works by pointing to a spot on your map and making it a point of interest, symbolized with a pushpin icon. Clicking on this icon pops-up a yellow note box similar to the familiar paper "Sticky Notes" (Figure 5) commonly used in the office. In this yellow note box, you can use the stylus to make handwritten notes, to drag-and-drop photo images, text documents of any type, or Internet URL's, and to link your personal voice recordings to that locality. As you drop documents into your Easy-Note, they are listed there with the familiar icons of their associated software. Display of Easy-Note pushpin icons can be turned on or off. Clicking on a pushpin opens the Easy-Note to reveal documents tagged to that geographic location, which you can then open with the touch of the stylus. This is very useful for indexing annotated photos, field sketches, and notations to a particular outcrop or viewpoint, for example. 


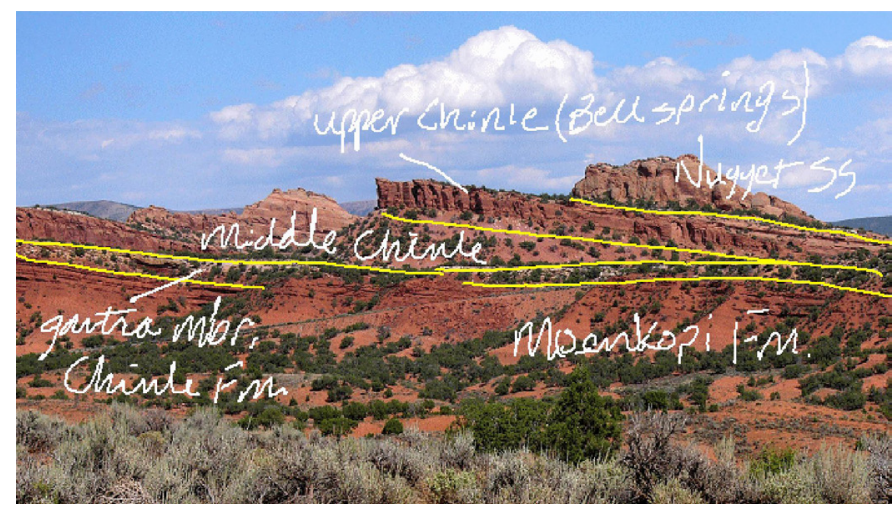

Figure 4. Digital photographs can be annotated and sketched upon, in the field, with a simple image-editing tool included in Map IT.

\section{Concerns}

Disadvantages of this technology include a fairly steep learning curve for the software, and getting accustomed to using a tablet computer and stylus in the field. Newer models of the Xplore tablets have much improved screen brightness technology, although at times it is still difficult to see the display in the field, which can be very frustrating. This is particularly true in bright sunlight when wearing sunglasses; polarizing sunglasses especially tend to darken the display. This can be somewhat remedied by using a case with a flap (Figure 6) to shade the screen from direct sunlight.

A more important issue is, of course, reliance on battery power and the fact that the rugged tablet craves

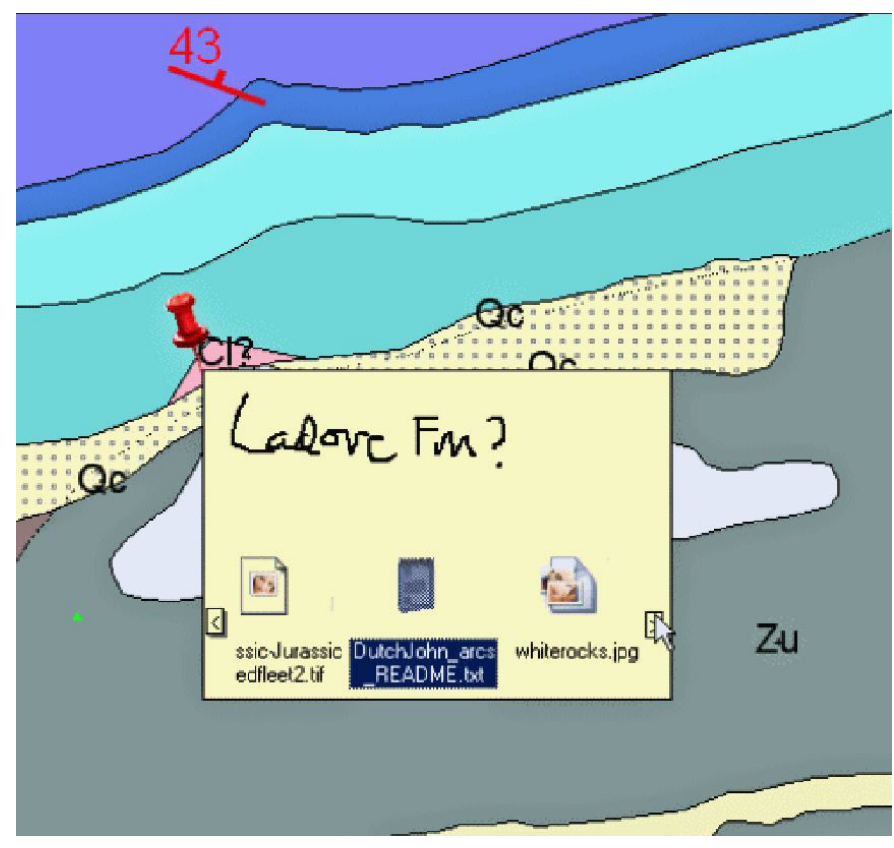

Figure 5. The Map IT Easy-Note tool is a useful way to link to or access various information files relating to a single geographic point on a map. power! These devices run on fairly powerful batteries that can operate continuously for up to 4 hours; however, battery life can be extended if the power-saving schemes are enabled such as using the hibernation mode when you are not entering data. Our newest rugged Xplore tablet uses a more energyefficient Intel processor, which should help with this problem, but no matter what power-saving scheme is employed or the number of spare batteries, you still need daily access to a power source to charge the batteries. This means using a vehicle power adapter or returning to your motel each evening to charge the tablet's batteries for the next day of field mapping. Digital mapping in remote areas for more than a couple of days may not be an option, unless solar panels or other compatible remote power sources are used.

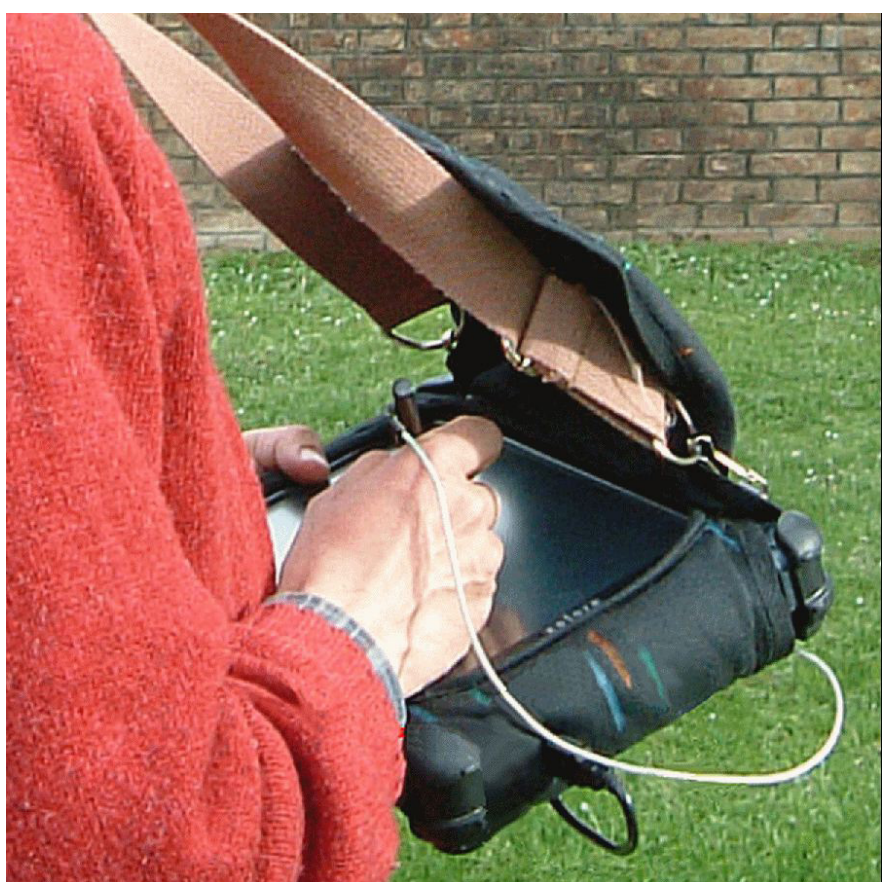

Figure 6. To improve readability in the bright sun, a tablet PC carrying case with sunshade can be used, as this soft case made from durable rip-stop nylon shows.

\section{CONCLUSIONS}

Each field-mapping technique, ranging in complexity from pen and field notebook to a rugged tablet computer and software, has advantages and disadvantages. Regarding the modern, computer-based systems, acquiring geologic data in the field using the tablet with a GPS receiver and Map IT GIS software saves time, and in our opinion, is more efficient than other tested methods. Being able to capture digital images of outcrops, sample locations, and key geologic relationships, and carefully annotating them while still at the spot where the image was captured and then tagging them to a geographic point of interest on the digital map is very useful and greatly improves our ability to interpret our field observations as we compile our geologic maps. 
The disadvantages of using this system include a fairly steep learning curve (unless the field geologist is already familiar with GIS software) and the insatiable appetite that any field computer system has for power. However, we think these are manageable problems.

Digital acquisition of geologic data in the field will likely increase as organizations discover the advantages of porting data seamlessly from a geologist's tablet computer to the GIS analyst's desktop. This may be particularly true as more wireless-enabled tablets are deployed to geologists who must transfer time-sensitive data from the field to the office during times of natural disasters.

\section{NOTE}

The UGS does not endorse any computer software or hardware products or manufacturers. Reference to any specific commercial product or process by trade name, trademark, or otherwise, does not constitute endorsement or recommendation by the UGS.

\section{REFERENCES}

Brimhall, G.H., Vanegas, Abel, and Lerch, Derek, 2002, Geomapper Program for Paperless Field Mapping with Seamless Map Production in ESRI ArcMap and GeoLogger for Drill-Hole Data Capture: Applications in Geology, Astronomy, Environmental Remediation, and Raised-Relief Models, in Soller, D.R., editor, Digital Mapping Techniques '02 - Workshop Proceedings: U.S. Geological Survey Open-file Report 02-370, p. 141-152, http://pubs.usgs.gov/ of/2002/of02-370/brimhall.html.

Brodaric, Boyan, 1997, Field Data Capture and Manipulation using GSC FIELDLOG v3.0, in Soller, D.R., editor, Proceedings of a Workshop on Digital Mapping Techniques: Methods for Geologic Map Capture, Management, and Publication: U.S. Geological Survey Open-file Report 97-269, p. 77-81, http://pubs.usgs.gov/of/1997/of97-269/brodaric. html.

Clegg, P., Bruciatelli, L., Domingos, F., Jones, R.R., De Donatis, M., and Wilson, R.W., 2006, Digital Geological Mapping with Tablet PC and PDA - A Comparison: Computers \& Geosciences, v. 32, p. 1682-1698, http://www.dur.ac.uk/ grl/Downloads/C\&G2006-v32-Clegg.pdf.

De Donatis, Mauro, and Bruciatelli, Lorenzo, 2006, MAP IT- The GIS Software for Field Mapping with a Tablet PC: Computers \& Geosciences, v. 32, p. 673-680.
De Donatis, Mauro, Bruciatelli, Lorenzo, and Susini, Sara, 2005, MAP IT- A GIS/GPS Software Solution for Digital Mapping, in Soller, D.R., editor, Digital Mapping Techniques '05 - Workshop Proceedings: U.S. Geological Survey Open-file Report 2005-1428, p. 97-101, http://pubs. usgs.gov/of/2005/1428/dedonatis1/index.html.

Edmondo, G.P., 2002, Digital Geologic Field Mapping using ArcPad, in Soller, D.R., editor, Digital Mapping Techniques '02 - Workshop Proceedings: U.S. Geological Survey Open-file Report 02-370, p. 129-134, http://pubs.usgs.gov/ of/2002/of02-370/edmondo.html.

Kramer, J.H., 2000, Digital Mapping Systems for Field Data, in Soller, D.R., editor, Digital Mapping Techniques '00 Workshop proceedings: U.S. Geological Survey Open-file Report 00-325, p. 13-19, http://pubs.usgs.gov/openfile/of00325/kramer.html.

McCaffrey, K.J.W., Jones, R.R., Holdsworth, R.E., Wilson, R.W., Clegg, P., Imber, J., Holliman, N., and Trinks, I., 2005, Unlocking the Spatial Dimension - Digital Technologies and the Future of Geoscience Fieldwork: Journal of the Geological Society, v. 162, p. 927-938.

Sprinkel, D.A., and Brown, K.D., 2008, Using Digital Technology in the Field: Utah Geological Survey, Survey Notes, v. 40 , no. 1 , p. $1-2$.

Struik, L.C., Atrens, A., and Haynes, A., 1991, Handheld Computer as a Field Notebook, and its Integration with the Ontario Geological Survey's “Fieldlog” Program, in Current research; Part A, Cordillera and Pacific Margin: Geological Survey of Canada Paper No. 91-01A, p. 279-284.

Walsh, G.J., Reddy, J.E., and Armstrong, T.R., 1999, Geologic Mapping and Collection of Geologic Structure Data with a GPS Receiver and a Personal Digital Assistance (PDA) Computer, in Soller, D.R., editor, Digital Mapping Techniques '99 - Workshop Proceedings: U.S. Geological Survey Open-file Report 99-386, p. 127-131, http://pubs. usgs.gov/of/of99-386/walsh.html.

\section{RESOURCES}

\author{
Xplore Technologies Corporation of America \\ 14000 Summit Drive, Suite 900 \\ Austin, TX 78728 \\ Web: http://www.xploretech.com/index.pl
}

\section{For information on Map IT: \\ Prof. Mauro De Donatis}

Universita' degli Studi di Urbino "Carlo Bo"

Facolta' di Scienze Ambientali - Campus Scientifico Loc.

Crocicchia

61029 Urbino, Italy

Email:dedonatis@uniurb.it

Web: http://www.uniurb.it/ISDA/MAPIT/index.htm 


\title{
Proposal for an ArcGeology Version 1 A Geodatabase Design for Digital Geologic Maps using $\operatorname{ArcGIS}^{\circledR}$
}

\author{
By Jordan T. Hastings ${ }^{1,2}$, Gary L. Raines ${ }^{2}$, Lorre A. Moyer ${ }^{2}$ \\ ${ }^{1}$ Nevada Bureau of Mines and Geology (as of August 2007) \\ Mackay School of Earth Sciences and Engineering \\ University of Nevada, Reno, NV 89557-0178 \\ email: hastings@unr.edu \\ ${ }^{2}$ U.S. Geological Survey \\ Mackay School of Earth Sciences and Engineering \\ University of Nevada, Reno, NV 89557-0176 \\ email: graines@usgs.gov; lorre@usgs.gov
}

\section{ABSTRACT}

This document presents a geodatabase design, proposed as an "ArcGeology Version 1", for digital geologic maps utilizing ESRI ArcGIS® 9.1 or 9.2 software. The design outlines a specific set of feature datasets and feature classes, together with feature attributes, subtypes and domains, suitable for a variety of geologic maps. In addition to basic geology (lithology, contacts and faults, etc.), the maps may include rock/mineral alteration and other overprints, cross-sections, and explanatory legend-graphics such as descriptive lists of map units and correlation charts, used to supplement columnar legends automatically produced by ArcGIS. Setup files are provided to create a new empty geodatabase and companion map document. The geodatabase design is compatible with field work using $\operatorname{ArcPad}{ }^{\circledR} 6$ or 7 .

This proposal is demonstrated with a fictitious geologic map, UNRCampus, set on the University of Nevada, Reno campus (Figure 1). This demonstration, as a completed ArcMap document and geodatabase with FGDC-compliant metadata, plus the setup files to create similar databases, is available for download at http://ngmdb.usgs.gov/info/dmt/ docs/AG1b.zip. To better understand this report and geodatabase design, the reader invited to fully explore the UNRCampus demonstration.

Throughout this document, proficiency with ArcGIS and geodatabases is presumed. For simplicity and portability, only ArcGIS software is used. To create new maps, at least an ArcEditor-level license is required.

\section{INTRODUCTION}

The following typographic conventions are adopted in this document. Geologic mapping and ArcGIS-related technical terms are italicized on first use, and concepts and practices of particular importance are noted in bold italics. Specific data structures, fields, etc., are shown in roman Title Case, without quotes to avoid clutter. Sans serif font is used for Windows-specific file names and also for ArcGIS tool names; the latter are bolded on every use (optionally followed by a parenthetical comment about the user-interface context in which they can be found).

Geologic maps present a complex amalgam of basic topographic facts, verifiable field observations, and subjective interpretations (Bain and Giles, 1997); they are among the most intricate of cartographic products. Widespread automation in geosciences, including the use of geographic information systems (GIS), presents the opportunity to capture geologic knowledge into map-databases. In addition to their cartographic sophistication, such map-databases afford more versatility and analytical capability than is possible with traditional paper maps.

Based on ESRI ArcGIS software, this proposal for an "ArcGeology Version 1" (AG1) outlines a simple but flexible system for producing a geologic map-database (GMDB) that serves both cartographic and analytical purposes. Because the geoscience community and ESRI have not yet engaged in a collective process to design such a GMDB structure, which by ESRI convention might then be formally named 

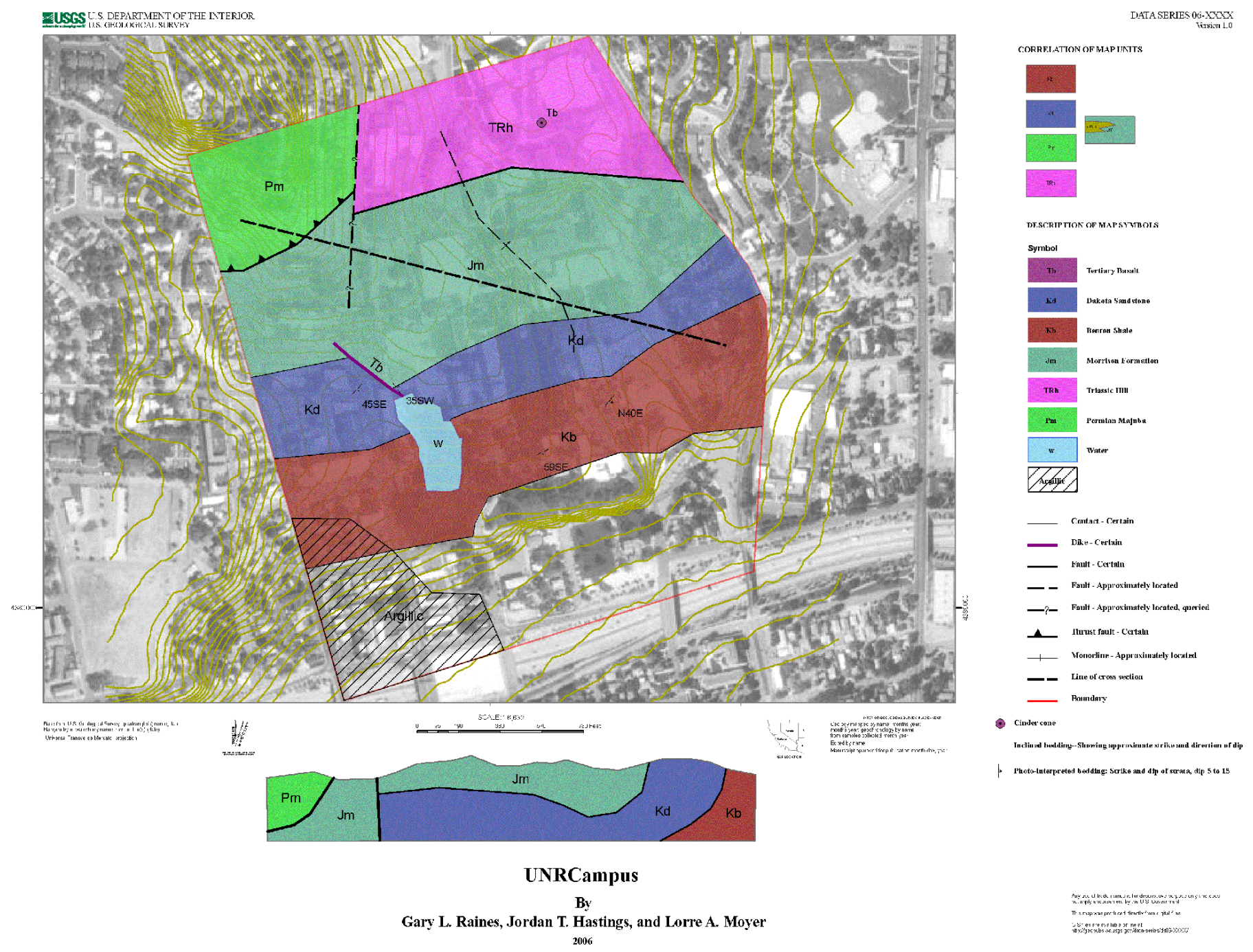

Figure 1. Fictitious Geological Map of UNR Campus.

"ArcGeology", in this article our proposal will be referred to only as AG1.

Specifically, AG1 comprises an ArcGIS geodatabase data model and companion operational procedures that predominantly address the geospatial features of a GMDB. Other groups (NADMSC, 2004 et seq.) have been active in developing a general conceptual model for geoscience information, originally known as "C1.0", which might eventually be integrated with AG1. Richard (2003) and Richard and others $(2004,2005)$ have progressively implemented portions of C1.0 in geodatabases with different structures and techniques than those proposed here. Various geological surveys, projects, and individual geologists have developed GMDB designs for their own purposes. Recently, interest has grown around the GeoSciML notation (Commission for the Management and Application of Geoscience Information, http://www.geosciml. org) as a means of sharing geoscience information in more generality than a GMDB.

Harmonization of the various GMDB designs is urgently needed in order to make digital geologic map data more widely accessible and more useful, to non-geologists particularly. Accordingly, AG1 has taken a minimalist approach, focused on the geospatial aspects of the map, with the goal of fostering harmony by: 1) simplifying and generalizing the spatial feature classes using subtypes and domains to support essential description for cartography; and 2) deferring the selection/standardization of extended descriptive attributes to the geologic community, where discussion is already underway. In short, the AG1 proposal is intended to evolve to AG2, AG3, etc. with participation and support of the community.

AG1 utilizes ArcMap, ArcCatalog, and their associated tools "out of the box," avoiding any additional software. In addition, AG1 is immediately functional with ArcPad for field mapping. Our expectation is that geologists will become proficient with ArcGIS and its related software in order to produce high-quality GMDB products.

Several known problems with ArcGIS also cause problems in the implementation of AG1; these are discussed in Appendix C. 


\section{DESIGN OVERVIEW}

This section provides an overview of the AG1 geodatabase structure, operational concepts, and metadata.

\section{Geodatabase}

The traditional paper geologic map presents: a main spatial figure - "the map" itself; optionally, one or more crosssections, which may be superimposed on the main map and/ or shown separately; optionally, one or more legend-graphics, which depict the map units in descriptive lists, correlation diagrams, etc., parallel to the main map; and a substantial block of explanatory text. Tables and charts also may be present, along with index maps(s), graticules, scale bars, title and credits, logos, etc. The layout of these elements is an art form, varying from map to map. AG1 focuses on the first three map elements: the main map, cross-section(s), and legendgraphic(s), each of which is treated in a parallel manner and data structure.

The AG1 geodatabase design is organized around feature datasets corresponding to the three principal elements above, plus a fourth catch-all for basemap/framework materials. For details refer to Appendix A. These feature datasets are:

- Geology - holds the primary content of the map: the geologic "unit" polygons as bounded by contacts, faults, and other "structure" lines on some mapping horizon, plus a variety of "station" data points. In AG1, polygons are primarily handled as derivative features, constructed on demand from lines and points using ArcGIS utilities and tools, as discussed in Operational Concepts below. This approach automatically achieves the topological relationships required for geologic maps, and greatly facilitates map editing and compilation.

- CrossSection \$ (where \$ is a single capital letter) - holds a more-or-less vertical profile of geology along a line-of-section through the main map. Each cross-section is managed as a small free-standing map in the same coordinate system as the main figure, even though the two datasets are not, in fact, co-registered. By this trick, a cross-section can be drawn directly on top of the main map, and will appear to "stand up" just by the superposition. Alternatively, when placed in a separate data frame, the cross-section can be rotated into an "upright" orientation.

- LegendGraphic\# (where \# is a single numeric digit) holds an auxiliary diagram that explains relationships within a map (as distinct from the columnar legend that can be produced directly by ArcMap). The prototypical legend-graphic is a correlation chart, showing the temporal and spatial relationships among geologic units; this also may include block diagrams of the units themselves, depicting facies, intrusions, etc.

- Basemap - holds foundational vector data (elevation contours, lake outlines, streams, roads, etc.) and/ or raster data (topographic maps, air photos, etc.) that provide a framework for mapping. Point data, such as tic marks (useful for verifying map registration) also occur in this dataset.

Images and rasters can be included directly in a file geodatabase (new at ArcGIS 9.2); in a personal geodatabase, they are stored in a separate folder indirectly referenced through the geodatabase. For efficiency, images and rasters should be in the same projection as the Basemap and Geology feature datasets, although because of ArcGIS' capability for projection on-the-fly, this is not mandatory.

Within each feature dataset, other than Basemap, three or four feature classes may appear. For the Geology feature dataset, the three essential feature classes are: GeoFrame, which delimits the study area; GeoLines, which presents all the raw geologic "line work" (contacts, faults, etc.); and GeoPolys, which contains the geologic polygon features (rock units, alteration units, etc.) constructed from GeoFrame and GeoLines. GeoPoints is an optional feature class, corollary to GeoLines, which presents the geologic "point data" (observation points, structural measurements, sample localities, etc.) relevant to the map. Parallel feature classes with the same attributes pertain to the CrossSection\$ and LegendGraphic\# components (Table 1).

Table 1. Summary of feature datasets and feature classes.

\begin{tabular}{|c|c|c|c|c|}
\hline \multirow[b]{2}{*}{ Feature Dataset } & \multicolumn{4}{|l|}{ Feature Classes } \\
\hline & $\begin{array}{l}\text { Polygons (in) } \\
\text { (Requirements vary) }\end{array}$ & $\begin{array}{l}\text { Lines } \\
\text { (Required) }\end{array}$ & $\begin{array}{l}\text { Points } \\
\text { (Optional) }\end{array}$ & $\begin{array}{l}\text { Polygons (out) } \\
\text { (Derived) }\end{array}$ \\
\hline Geology & $\begin{array}{l}\text { GeoFrame, } \\
\text { GeoPolys (optional) }\end{array}$ & GeoLines & GeoPoints & GeoPolys \\
\hline CrossSection\$ & XS\$Frame & XS\$Lines & XS\$Points & XS\$Polys \\
\hline LegendGraphic\# & LG\#Frame (opt.) & LG\#Lines & LG\#Points & LG\#Polys \\
\hline
\end{tabular}


For each feature class other than the "Frames", which are in general simple perimeters, a group of up to seven common feature attributes is present. These attributes are described in Table 2 with regard to the Geology feature dataset, and Table 3 presents some examples of their use. See Appendix A for additional details.

The first five entries deal with the basic symbolization of the features in the map. Kind, Type, and Style are closely controlled fields, established via ArcGIS domains and subtypes. These fields encode AG1's knowledge organization system (World Wide Web Consortium; http://www. w3.org/2004/02/skos/) for GMDBs in general, and should not be modified casually. Kind subdivides geologic features into tiers (rock, alteration, overprint, etc.), while Type and Style define rough and fine categorizations, respectively, of features within a tier. In some regards, these three fields function hierarchically and in other regards independently (Table 3). Note that only a few example entries are shown.

By contrast, Symbol and Symval are unconstrained user-supplied fields, providing cartographic and descriptive details for particular features as needed. Typically, Symbol is used for map-unit labels, dip amounts (which may be blank or non-numeric, e.g. $<10$ ), station identifiers, etc. Symval is available for various purposes where a number is required, such as symbol transparency or rotation. Domain-based control of Symbols (but not Symvals) is also possible, if for example the stratigraphy of units that may appear on a map is fixed in advance.

ItemID serves to link the geospatial features to extended desciptions in other tables, if present: it is a generic foreign key. Depending on the complexity of these tables, ItemID may link directly from feature classes to particular tables on a class-by-class basis, or indirectly from feature classes through an intermediary "dispatch table" to any number of tables concurrently. The built-in Item table is designed for the latter purpose. Taken altogether, these first six feature attributes are sufficient to record, symbolize, and label the features in a geologic map, and to arrange further description of these features as desired.

Table 2. Common feature attributes for all feature classes.

\begin{tabular}{|c|c|}
\hline Attribute & Description \\
\hline $\begin{array}{l}\text { Kind } \\
\text { (Short Int: Coded Text*, Global Domain) }\end{array}$ & $\begin{array}{l}\text { Top-level category of geologic features, e.g. Rock, Alteration and other } \\
\text { Overprints, etc. Several geologic Kinds may be present in GeoPoints, } \\
\text { GeoLines and GeoPolys concurrently. Thus new Kinds (e.g. Soils) can be } \\
\text { defined and added to the underlying domain, if needed, without creating } \\
\text { additional feature classes. (*Coded Text denotes a text field automatically } \\
\text { derived from a numeric code via an ArcGIS domain.) }\end{array}$ \\
\hline $\begin{array}{l}\text { Type } \\
\text { (Short Int: Subtype selector) }\end{array}$ & $\begin{array}{l}\text { Sub-category of feature, e.g. Contact, Fault, Attitude measurement, etc. } \\
\text { Types can be adjusted by editing the underlying subtype lists for GeoPoints, } \\
\text { GeoLines and GeoPolys as needed. By convention, the zero subtype is } \\
\text { always available, generally as "not applicable" (N/A) catch-all. }\end{array}$ \\
\hline $\begin{array}{l}\text { Style } \\
\text { (Long Int: Coded Text, Domain per Type) }\end{array}$ & $\begin{array}{l}\text { More-specific term for a feature within its Type, e.g. Contact, Certain; Nor- } \\
\text { mal Fault, Concealed; Sedimentary Bedding Attitude. As for Kind, Style } \\
\text { terms are maintained in an underlying domain; however, these terms also } \\
\text { interface through the ESRI Style Manager with standard symbology, which } \\
\text { must be updated concurrently. }\end{array}$ \\
\hline $\begin{array}{l}\text { Symbol } \\
\text { (Free Text, 20-character max.) }\end{array}$ & $\begin{array}{l}\text { Mnemonic assigned to support cartographic representation of individual fea- } \\
\text { tures, e.g. dip amounts, sample numbers, fault names, and notably the geo- } \\
\text { logic unit codes for GeoPolys. The latter codes are typically not managed } \\
\text { through Styles, because they vary greatly across mapping projects. Symbols } \\
\text { in addition to Styles may be used with any feature class; for example, to } \\
\text { import pre-existing line symbology coded as text. }\end{array}$ \\
\hline $\begin{array}{l}\text { Symval } \\
\text { (Floating-Pt) }\end{array}$ & $\begin{array}{l}\text { Numeric value providing additional cartographic detail or control, e.g. ra- } \\
\text { diometric age, strike/plunge direction for attitude symbols, etc. }\end{array}$ \\
\hline $\begin{array}{l}\text { ItemID } \\
\text { (Long Int) }\end{array}$ & $\begin{array}{l}\text { Per feature link to rows of related table(s), optionally providing extended } \\
\text { descriptions for documentation or analysis, over and above the symboliza- } \\
\text { tion and labeling of features on the map. }\end{array}$ \\
\hline $\begin{array}{l}\text { Selected } \\
\text { (Boolean, as Short Int) }\end{array}$ & $\begin{array}{l}\text { Persistent control (True/False }=0 \text { ) on selection of individual features and } \\
\text { their participation in various operations, especially polygon construction. }\end{array}$ \\
\hline
\end{tabular}


Table 3. Examples of Kind, Type, and Style attributes.

[Free text entries are shown in quotes for clarity; the quotes are not included in the database. Type and Style fields in GeoPolys are set to zero during polygon construction (from GeoPoints); these fields may be deleted after construction (see Appendix A, footnote), but are shown here for completeness]

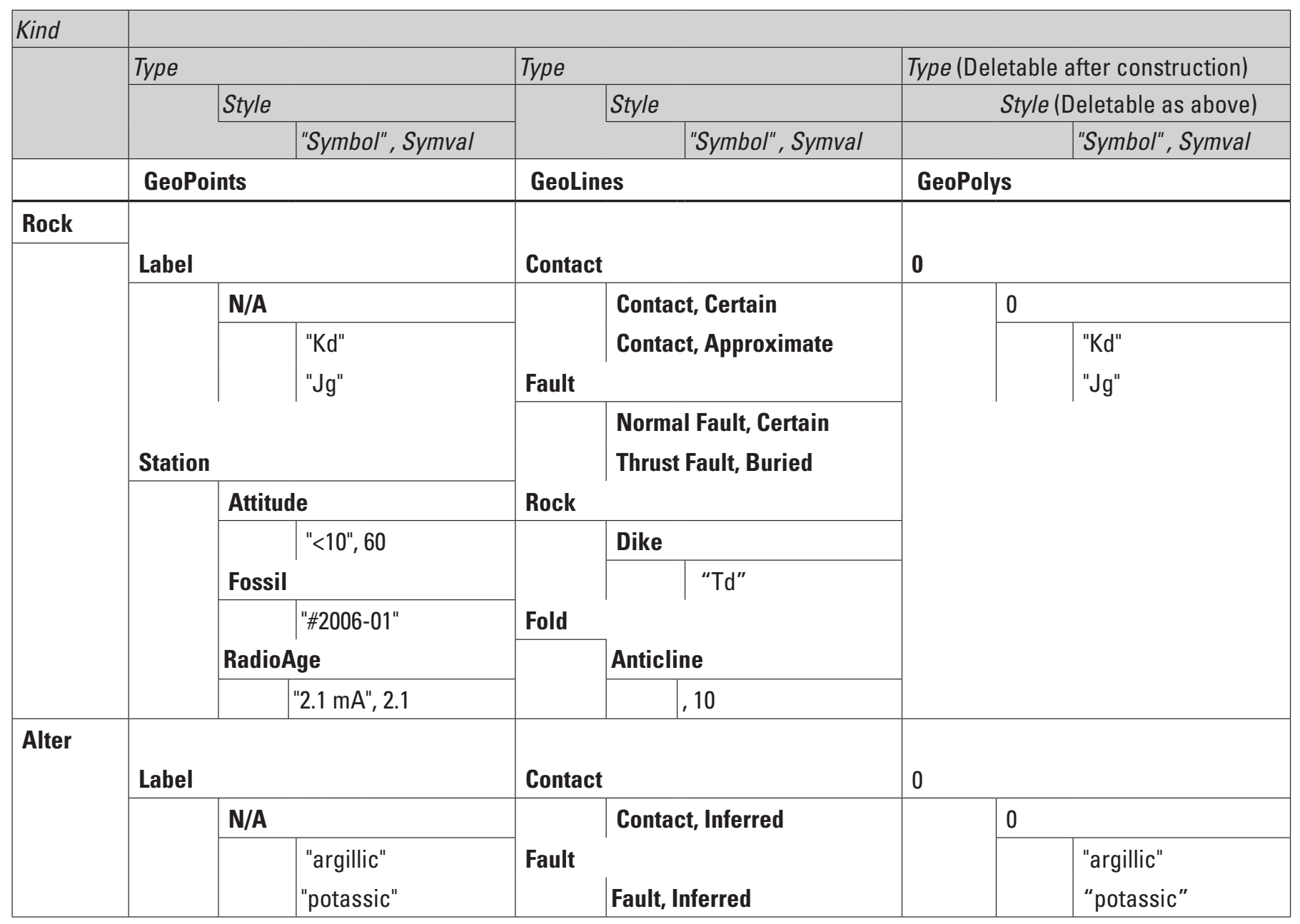

The final field, Selected, is used to persistently mark individual features for inclusion or exclusion in various procedural steps, particularly polygon construction (see below). For example, it is often desirable to exclude intraformational contacts and faults, so that the associated map-unit polygons are not "broken" by these lines. Similarly, it may be desirable to include some but not all strike-and-dip symbols within some "busy" portions of a map.

A GMDB inherently involves deep integration of spatial features and aspatial tabular data, beyond that required for map production. Even using databases, this integration can become technically complex. In AG1, the linkage between features and tabular data is effected via the single field, ItemID, leaving the spatial and tabular aspects otherwise free-standing. In general, two sets of relationship classes are involved: first, the spatial features "link in" to a central Item table, built-in to the geodatabase; from here, the Item entries "link out" again (are dispatched) to the aspatial, user-supplied tables, which can vary by map author and across maps of different areas or emphases. For details, refer to Appendix B.
A sample tabular data schema for the UNRCampus.mdb prototype is included in Appendix B. The tables and attributes shown in this prototype are intended only to demonstrate the capabilities of the AG1 design; they are not a formal recommendation. Other organizations of tabular data for geologic maps are presented in the NADMSC "C1.0" specification (2004), Brodaric and Hastings (2002), and Johnson and others (1999).

The doubly linked approach to extended descriptions (Figure 2, solid lines) provides the greatest flexibility both in the design of the user-supplied tables and in the timing of relationships (implying persistence of categorization). Each feature is linkable to and through a unique row in the Item table to any number of other tables, which themselves can have any desired (or pre-existing) organization. If several features link to the same Item row, then a group description results, e.g. multiple pieces of a named fault, all occurrences of a particular map unit. By repeating columns in the Item table, a single feature can have both individual and group descriptions, e.g. an outcrop of a generalized map unit that 
has a more detailed individual description. As an example of persistence, in a geodatabase comprising multiple maps, the Item table can be used to enumerate the distinctly identifiable features across all maps; this can be completed even before the first map is started.

Alternatively, in a singly linked approach (Figure 2, dashed lines), each feature is linkable directly to a single row in one other table, as is customary with ArcGIS joins. Multiple features that link to the same row will share a group definition, as above; however, each feature can have at most one description. Using the current ArcGIS utilities, singly linked tables are required in preparing shapefile exports for ArcPad.

In either approach, definition queries allow ramification of the linkage from a single feature class to various descriptive tables according to Kind, e.g. Rock and Alteration to separate tables. The only requirement is that primary keys in all tables be integers.

The sample tabular data in Appendix B demonstrate both approaches simultaneously, because of the way the IDs have been assigned. Specifically, the descriptive table Unit can be linked either directly to GeoPolys or indirectly through Item.

\section{Operational Concepts}

At the outset of a new mapping project, both a geodatabase and a map document must be established. The ArcGeology1.xml schema is used to populate an empty AG1 geodatabase for a new geologic map. Importing this schema (in ArcGIS, a "workspace document") creates all the geodatabase feature datasets, feature classes, and associated tables (Appendix A), together with relationship classes among them, and also populates their domains. At the same time, "stock" metadata (below) for the feature datasets and feature classes are created. Although empty, the geodatabase is fully functional after coordinate systems have been specified for the feature datasets.
The companion ArcGeology1.mxt template, shown schematically in Figure 3, can be used to create an AG1 map document that incorporates the USGS-style map layout depicted in Figure 1; this is easily adaptable to other layouts. Hierarchical layer (.lyr) files also are provided for flexibility: the geology.lyr file for the Geologic Map data frame, which embeds a single Cross-Section A; a stand-alone CrossSection.lyr file for additional Cross-Section data frames; and similarly a generic LegendGraphic.lyr file for Legend-Graphic data frames.

The arrangement of data frames and data layers produced in ArcMap by these .mxt and .lyr files reflect just one of many possible ways that a geologic map can be "laid out". Map layout and cartography are not currently specified in AG1; however, increased standardization of maps in these regards would be beneficial, both to facilitate understanding of geologic maps by non-geologists and to simplify development of software tools for map-making.

The geospatial features of a GMDB are assembled based on field work and/or transcribed from existing paper maps. In either case, the majority of map-unit polygons, GeoPolys, are constructed from other features, GeoFrame, GeoLines, and optionally GeoPoints, using various ArcGIS utilities and tools (below). With the exception of areal outcrops (directly entered into GeoPolys), and GeoFrame (used as the study-area perimeter), polygons are not directly edited in $\mathrm{AG} 1$.

Figure 4 shows the fundamental polygon construction process schematically. GeoLines $\left(\mathbf{L}_{\mathrm{x}}\right)$ and optionally GeoPoints $\left(\mathbf{P}_{\mathrm{n}}\right)$ features are drawn, digitized, or otherwise obtained within the GeoFrame (F). From the combination of these inputs, GeoPolys $\left(\mathbf{P}_{\mathrm{n}}\right)$ are constructed as an output using either the ArcCatalog Polygons from Lines utility or the ArcToolbox Feature to Polygon tool (ArcInfo-level license). The latter is preferred because it honors feature selections in GeoLines and GeoPoints, set in ArcMap. In either case, the attributes from GeoPoints are automatically copied to GeoPolys. If some GeoPolys already exist, for example from

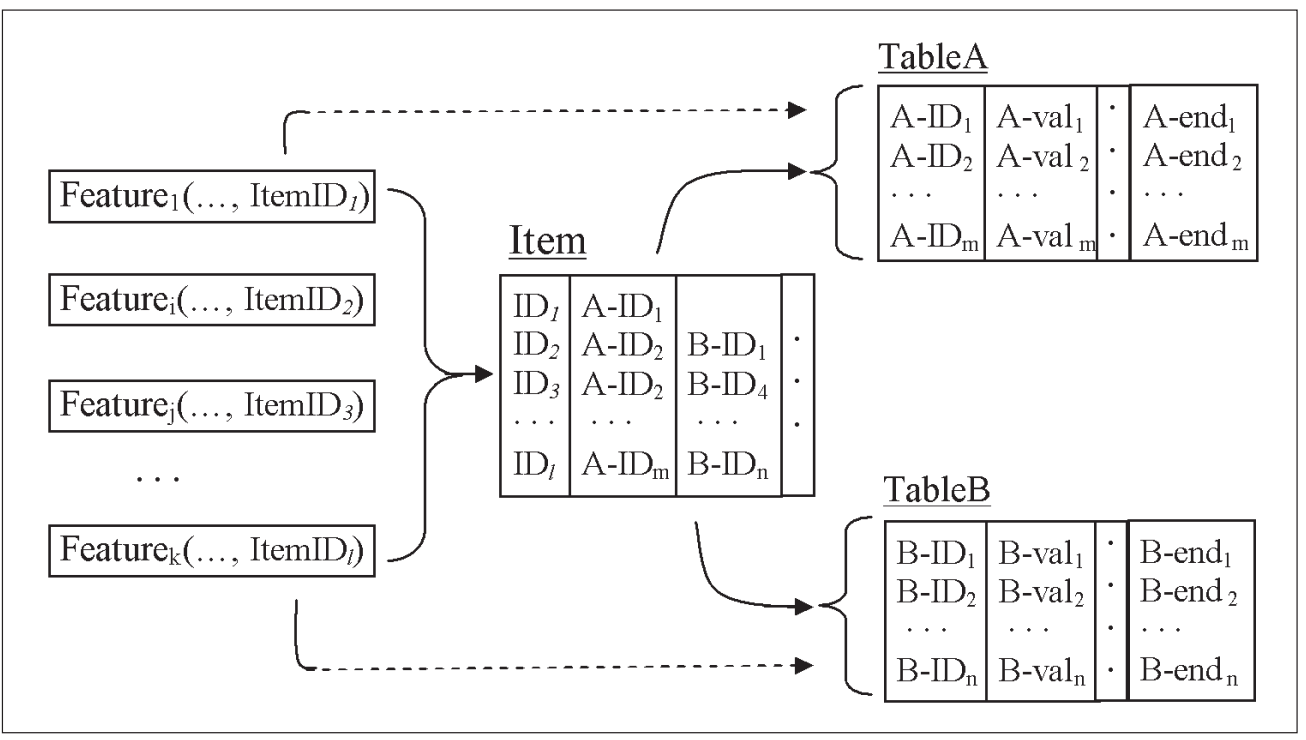

Figure 2. Inter-linkage between features and attribute tables. 


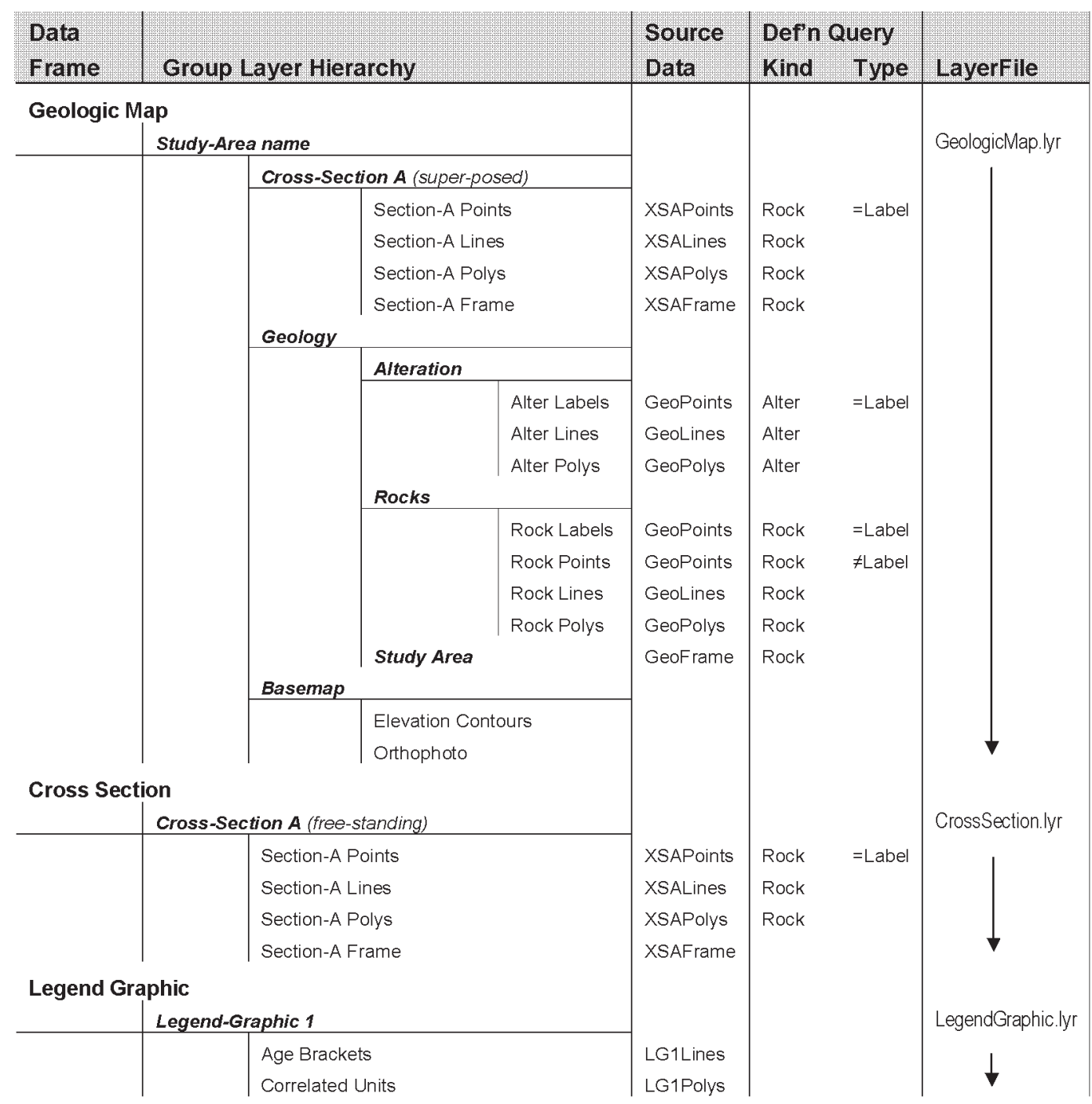

Figure 3. Sample geologic map table of contents. This organization of the map document provides a logical grouping of the map feature classes by layers. Each of the three top-level data frames, far left, indicated in large bold font, can be added via a separate layer (.lyr) file; within these, group layers are indicated in bold italics. Regular text denotes the actual layer content, i.e. feature classes. Definition Queries based on Kind and Type, extract specific data from generic feature classes. All entries in the Basemap feature dataset are optional.

outcrop mapping, they may used as an additional input to the construction. Previously constructed GeoPolys can re-appear as inputs because duplicate output features are automatically suppressed. Also, GeoPolys can be reconstructed "in place", i.e. with new GeoPolys overwriting old GeoPolys, if the geoprocessing option (ArcMap Options menu) is set to allow this behavior. Completely reconstructing a geologic map from several thousand lines and points takes only a few seconds.

The routine reconstruction of GeoPolys is particularly advantageous for field mapping, in which the boundaries of geologic map units often emerge incrementally over a period of days or weeks. In such cases, it may be desirable to focus/ restrict reconstruction to a particular subset of features that can be quickly reselected. The Selected attribute in GeoLines and GeoPoints persists control of selection at the individual feature level; for example, deselecting intraformational contacts. Another use of Selected is to suppress features from particular sources and/or prior drafts, without removing them physically from the geodatabase.

As indicated in Table 3, GeoPolys, GeoLines, and GeoPoints are generic feature classes that may contain multiple tiers of geology, viz. Rocks, or Alteration and other overprints. The features in a particular tier have the same Kind and are separated out as needed using ArcMap Definition Querys (in layer Properties).

Because the semantics of GeoLines and GeoPoints are controlled via fixed domains and subtypes, the construction of GeoPolys is technically straightforward. Nonetheless, the geologist is presented with many subtle choices during map construction. Some lines (e.g. ordinary contacts and 


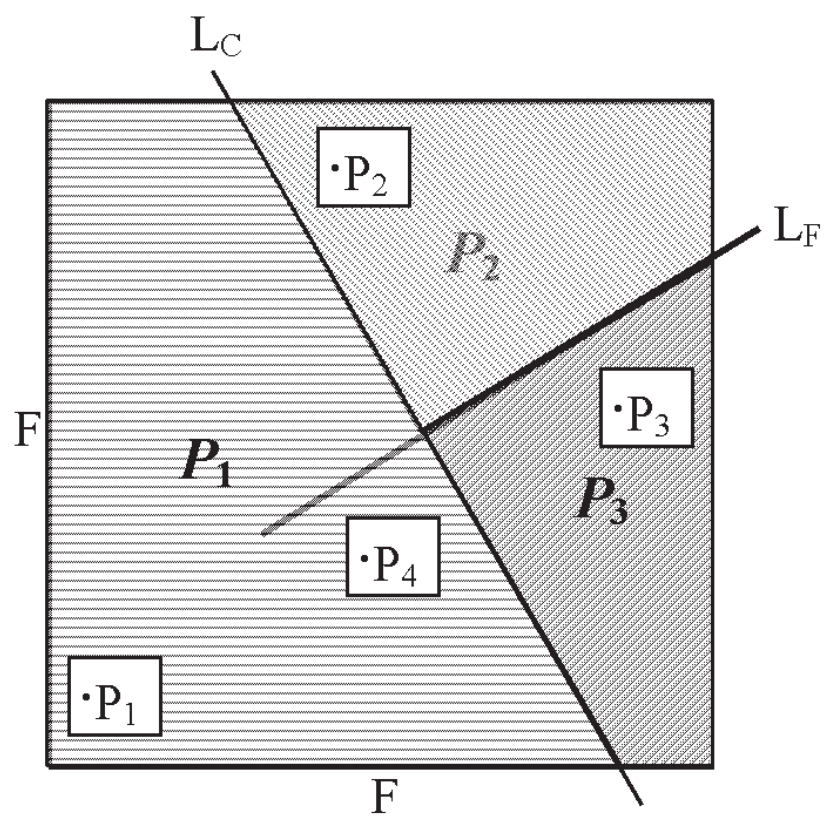

Figure 4. Polygon reconstruction from lines and points. $\mathrm{F}$ is the study area, entered in GeoFrame; $L_{C}$ is a contact and $L_{F}$ is a fault, entered in GeoLines; $\mathrm{P}_{1}, \mathrm{P}_{2}, \mathrm{P}_{3}$ and $\mathrm{P}_{4}$ are unit labels, entered in GeoPoints; $\boldsymbol{P}_{1}, \boldsymbol{P}_{2}$, and $\boldsymbol{P}_{3}$ are resulting polygons, constructed in GeoPolys.

through-going faults) dissect polygons, while others (intraformational contacts, faults that die out, fold axes, etc.) do not. Confidence in the type/description and even the existence of some lines comes into question. Multiple labels may be proposed over time within large polygons (cf. $\mathrm{P}_{1}$ and $\mathrm{P}_{4}$ in Figure 4), and conversely label-points may be missed out of small polygons. (The polygon construction process chooses the chronologically first-entered label-point to assign GeoPolys attributes.) Getting the map "right" requires that the geologist be directly engaged throughout the construction process, which implies familiarity with the ArcGIS software. Then, ArcMap's on-screen map display is at once a cartographic product and an emerging proof-of-correctness of the underlying geodatabase.

\section{Metadata}

Metadata within an AG1 geodatabase is hierarchically organized and stored, mirroring the overall structure at three main levels: the geodatabase (project level), the feature dataset (geometric structural level), and the feature class (thematic level). Only basic metadata is carried at the geodatabase level, with progressively more detail at the feature dataset and feature class levels. This approach addresses a hierarchy of user needs with GMDBs, providing enough project-level metadata to support general search, and more detailed metadata for technical work as needed.
The metadata hierarchy can be extended upwards, too. When managing several related geodatabases in a common folder, it is useful to consider additional "collection level" metadata for the folder, in effect a card-catalog for its contents.

At the outset of work on a new map, the following metadata should be entered at the project level using ArcCatalog: abstract, purpose, contact, citation, timeframe, status, constraints, completeness, logical consistency tests performed, keywords, and spatial extent specific to the project. These project-level metadata are designed to answer the basic questions that users commonly ask when deciding whether a geodatabase is of interest for their purposes. Once the map projection is defined, ArcCatalog fills in the spatial reference system metadata automatically.

Below the project level, "stock" metadata for all the feature datasets and feature classes listed in Table 1, plus the seven basic feature attributes in Table 2, are built-in to AG1. These metadata will not normally require modification except when additional feature attributes or user-specific attribute values are added; if so, they should be described in the affected feature classes.

The AG1 metadata design meets the minimum requirements of the Federal Geographic Data Committee (1998 et seq.) as implemented in ArcCatalog. The design also includes overviews of the feature datasets from the project level as well as feature classes from the thematic level, which are important to geodatabase users. Further, Enclosures (on

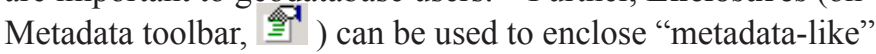
items that are not by default tabularized in a geodatabase, such as .mxd, .lyr and .style files, so that the whole project is selfcontained. Thumbnails of the map and feature classes along with the customizable metadata stylesheets implemented in ArcGIS can be used to view the different levels of metadata in a variety of user-friendly ways.

\section{SUGGESTED WORKFLOW}

Following is a suggested workflow to create an AG1 geodatabase for a new, single-map project, suitable for work in the office using ArcGIS and/or in the field using ArcPad. Depending on project requirements, local conventions, and personal preferences, many other workflows are possible. Additional considerations, particularly regarding domains and key fields, apply when dealing with a multi-map database, e.g. a compilation; these are not addressed in the current design.

This workflow also shows one of many possible organizations of the map document used to visualize the geodatabase. As noted above, AG1 does not impose a specific organization on the map document or specific naming conventions on its layers (distinct from features in the geodatabase); these can all be adapted to meet the needs and preferences of map makers and map users. 


\section{Setup}

1. Establish a working folder for the project. The name of this folder is arbitrary, adaptable to the user's map-naming conventions, viz. UNRCampus

2. Within the working folder:

a. Create a simple shapefile, StudyArea, with polygon(s) depicting the study area boundaries and apply the appropriate map projection to it. Water bodies, excluded areas, etc. appearing within StudyArea should be detailed as "NoData" areas. (Note: For use with ArcPad, spatial data must be in projected units.)

b. Optionally, use StudyArea to clip other framework layers of interest.

3. Then, using ArcCatalog:

a. Create a new empty geodatabase for the project; rename this as desired. A recommended convention is to name the geodatabase in parallel with the enclosing folder name, viz. UNRCampus।UNRCampus.mdb

b. Use Import | XML Workspace Document (geodatabase context menu) to set up the new geodatabase according to the ArcGeology1.xml schema.

c. Import (feature dataset context menu) the StudyArea shapefile into a StudyArea feature class within the Basemap geodatabase feature dataset. This step establishes the spatial reference system for Basemap.

d. Import (feature dataset context menu) other desired framework/ reference data into Basemap. Note that images and rasters will appear as stand-alone objects in a personal geodatabase, outside any feature dataset.

e. Use Load Data (feature class context menu) to load the StudyArea feature class (from 3c) into the empty GeoFrame feature class in the Geology feature dataset. This step establishes the spatial reference system for Geology.

f. Import (feature dataset Properties $\mid$ XY Coordinate System) the coordinate system from the Geology feature dataset, established via the loading operation (3e above) to the CrossSectionA feature dataset, to ensure that their spatial reference systems are the same.

g. Enter the project-level metadata for the map. Optionally, enter any feature-level metadata regarding modified Styles, Symbols and Symvals, etc.
4. Finally, using ArcMap:

a. Create a new empty map document for the project; rename this as desired. A recommended convention is to name the map document in parallel with the enclosing folder name, viz. UNRCampus। UNRCampus.mxd. If the map document is based on a template, proceed to step $4 \mathrm{e}$.

b. Rename the default data frame from "Layers" to "Geologic Map"; add the GeologicMap.lyr file to this data frame, and rename the added layer to reflect the study area. This step will define a grouped layer structure ("table of contents") for the main map, although the layers themselves will be flagged with a red exclamation mark, indicating that they are not yet connected to geospatial data.

c. If the project involves cross-section(s), for each of them insert a "Cross Section $\$$ " data frame (where $\$$ is A, B, C, etc.); add the CrossSection.lyr file to each inserted data frame and rename the layer as appropriate. Alternatively, the "Cross Section A" group layer from the Geologic Map data frame can be cutand-pasted into the stand-alone data frame(s). Note that the .lyr files should be made with relative paths.

d. If the project involves legend-graphic(s), for each of them insert a "Legend Graphic \#" data frame (where \# is $1,2,3$, etc.); add the LegendGraphic.lyr file to each inserted data frame and rename the layer as appropriate.

e. Finally, if any feature class has a red exclamation mark following it, double-click on that mark and navigate to the corresponding feature class in the geodatabase (e.g. GeoFrame layer to GeoFrame feature class). Doing this will automatically reconnect all the feature classes in the data frame, so the red flags will disappear.

\section{Data Development}

In a typical workflow, ArcMap is used to edit incremental sets of GeoLines and GeoPoints, after which GeoPolys are reconstructed on demand. GeoLines and GeoPoints contain, respectively, the raw "line work" and "point data" of the map, which can be input directly on-screen (heads-up digitizing), transcribed from paper maps using ArcScan, or captured in the field via ArcPad. Regardless of origin, the fundamental AG1 map construction process is as follows:

- Sketch, digitize, download or otherwise obtain an increment of GeoLines and, optionally, GeoPolys (outcrops) and GeoPoints (label-points) for the map. 
- Review the Kind, Type and associated Style terms for all new features, according to the guidelines below:

- The Kind of primary interest in a geologic map, for all feature classes, is Rock; this is the default. Other Types include Alteration and a generic Overprint.

- The Type of primary interest for GeoLines is Structure: a Contact, Fault, or Rock Body, e.g. dike or marker bed; Contact is the default. Other Types are Folds, Geomorphics (lineaments, slickensides, etc), and Miscellaneous non-geologic lines, such as lines of section. By default, Contacts, Faults, and RockBodies are marked as Selected.

- Types of interest for GeoPoints are Labels (for label-points to be constructed into map-unit polygons) and Stations (for field measurements and observations); Label is the default. Both Labels and Stations are marked as Selected.

- Optionally, set/clear the Selected attribute to indicate features that should be included/excluded in construction of polygons, e.g. features newly acquired from a field system or features to be omitted from polygon construction.

- Construct GeoPolys from the selected GeoLines and optionally GeoPolys (outcrops) and GeoPoints (labelpoints only) together with GeoFrame, preferably using the ArcToolbox Feature to Polygon tool. Polygons constructed around label-points will have attributes from them transferred automatically; polygons without label-points must be attributed manually.

- Repeat as necessary, augmenting GeoLines and GeoPoints until all GeoPolys have been constructed, filling the GeoFrame. Each successive set of polygons is, by construction, topologically consistent with the then-current lines and points and no slivering occurs. Also, duplicate polygons are automatically suppressed. Because label-point attributes are automatically transferred to polygons, rework is negligible.

For polygons that are constructed around label-points, in addition to the label-point attributes, their metadata also is transferred, which is erroneous. After the map is completed, importing the supplied GeoPolys.xml metadata document into GeoPolys will correct this error.

When the Geology feature classes include multiple Kinds of data, e.g. Alteration and Rock tiers, the above procedures must be limited to pre-selections (usually established via Definition Querys) of features, so that only one Kind is processed at a time. Repeated processing with different selections builds up the complete Geology feature dataset. See Appendix C for a known problem with ArcGIS Definition Queries.

Cross-section(s) are treated in the same manner as Geology, but using XS\$Points and XS\$Lines to construct XS\$Polys. Cross-section(s) also may include multiple
Kinds of data, as for Geology. An important difference from Geology is that XS\$Frame has for its base the line of section and for its top the section's topographic profile, connected by vertical sides left and right. The authors are developing a geoprocessing tool that will automate extraction of XS\$Frame.

Legend-graphic(s) too are treated in the same manner as Geology, but using LG\#Points and LG\#Lines to construct LG\#Polys. Sets of intersecting horizontal and vertical lines can be used to define rectangular polygons in the desired configuration; alternatively, a prototypical polygon can be drawn, then repeatedly copied/moved as needed. A LG\#Frame is optional. Finished Legend-graphic "units" are parallel to the Geology units in the main figure, just abstracted in shape and usually arranged in some temporal way. The authors are developing a geoprocessing tool that will automate the process of defining the LG\#Lines and/or LG\#Polys.

\section{Symbolization}

A combination of layer (.lyr) and style (.style) files are used to achieve consistent map symbolization in AG1. The convention is to symbolize feature attributes controlled by domains and subtypes using styles, and to symbolize other, user-defined feature attributes using layers. In particular, the symbolization of geological units, GeoPolys, is generally mapspecific, based on Symbol. To achieve consistency across the Geologic Map, Cross Section, and Legend Graphic data frames, the GeoPolys symbolization can be easily imported between layers. The completed map symbolization, for all feature geometries and symbolization methods, can be re-exported to a map-specific style file, if desired. Moyer and others (2005) provide a detailed discussion of style-based symbolization for geologic maps.

Currently, the built-in terminology for GeoLines and GeoPoints matches the U.S. Geological Survey Open-File Report 95-525 (USGS, 1995), which also forms the basis of ArcGIS' Geology24K style. (The symbols in that report, with modifications, formed the basis for the Federal Geographic Data Committee's recently-published standard for geologic map symbolization (FGDC, 2006), which could be supported in future.) As supplied in the ArcGeology.xml schema, GeoLines and GeoPoints domains are predefined in conformance with USGS 95-525 styles, so that the Match Features in a Style tool works using the Geology24K style "out of the box". If additional GeoLines or GeoPoints symbols are desired, the changes should be made to a copy of the Geology24K style and substituted for it, after which corresponding changes will need to be made in various domains. See Appendix C for a known problem with ArcGIS symbolization.

\section{Layout Template}

An ArcMap template (.mxt) file provides a convenient way to assemble geospatial features in a standard map layout 
with marginalia suitable for printing a paper map. The supplied template, ArcGeology1.mxt, which follows USGS publication conventions, is designed so that each data frame corresponds to a geodatabase feature dataset; for example, the Legend Graphic data frame displays the data for the LegendGraphic1 feature dataset. To use this template, open it in ArcMap, apply the proper page and print settings (e.g. 11 x17 in., landscape), then Save an appropriately named map document. Click on one of the red exclamation points (adjacent to a layer) and navigate to the corresponding geodatabase feature class to set the data source path for all the layers in the Data Frame.

Alternatively, if starting from an existing layout, select Change Layout (Layout toolbar, 国回), browse to and select the ArcGeology1.mxt template; afterward, it may also be necessary to re-order for the data frames in the dialog box. Either method will likely require further adjustment to map elements (scalebar, graticule, legend, text box, font size, etc.) in order to achieve the best use of space while maintaining the visual emphasis on the most important elements of the map, usually the main figure and cross section(s).

\section{SUMMARY}

AG1 is a simple but flexible system for producing digital geologic map-databases using ESRI ArcGIS and ArcPad software. By taking advantage of the many ArcGIS utilities and tools, AG1 avoids custom programming while simultaneously fostering user skill with the ESRI products. Further, AG1 strongly encourages standardization of basic geologic map terminology through its integrated system of subtypes, domains, and styles. These design choices facilitate the "migratability" of AG1-formatted datasets to future versions of ArcGIS and their "sharability" with other GIS software systems.

Development of an AG2 should, we feel, concentrate in two areas: 1) design and integration of comprehensive "standard" descriptive data attributes, based on the NADMSC and GeoSciML recommendations; and 2) collateral integration of the FGDC 2006 standard for cartographic representation.

If, ultimately, some AGx becomes widely adopted, full documentation of its design, implementation, and operational use will be needed for use by the general geologist. The present document is a bare sketch of these topics. The authors heartily encourage comments and suggestions for improvement of these ideas.

\section{REFERENCES}

Bain, K.A., and Giles, J.R.A., 1997, A standard model for storage of geologic map data: Computers and Geosciences, v. 23 , no. 6, p. 613-620.
Brodaric, Boyan, and Hastings, Jordan, 2002, An object model for geologic map information, in Richardson, D., and van Oosterom, P., eds., Advances in Spatial Data Handling, 10th International Symposium on Spatial Data Handling: Springer-Verlag, p.55-68.

Federal Geographic Data Committee, 1998, Content standard for digital geospatial metadata: Reston, Va., Federal Geographic Data Committee Document Number FGDCSTD-001-1998, available at $h t t p: / / w w w . f g d c . g o v /$ standards/ projects/FGDC-standards-projects/metadata/basemetadatal.

Federal Geographic Data Committee [prepared for the Federal Geographic Data Committee by the U.S. Geological Survey], 2006, FGDC Digital Cartographic Standard for Geologic Map Symbolization: Reston, Va., Federal Geographic Data Committee Document Number FGDCSTD-013-2006, 290 p., 2 plates, available at $h t t p: / / n g m d b$. usgs.gov/fgdc_gds/.

Johnson, B.R., Brodaric, B., Raines, G.L., Hastings, J.T., and Wahl, Ron, 1999, Digital Geologic Map Data Model, v4.3: AASG/USGS Data Model Working Group report, accessed at $h t t p: / / w w w . n a d m-g e o . o r g / d m d t / M o d e l 43 a . p d f$.

Moyer, L.A., Hastings, J.T., and Raines, G.L., 2005, Methods to create ArcMap styles with examples for lithology and time: U.S. Geological Survey Open-file Report 2005-1314, 21 p., available at $h t t p: / / p u b s . u s g s . g o v / o f / 2005 / 1314 /$.

NADMSC [North American Geologic Map Data Model (NADM) Steering Committee] Data Model Design Team (2004) NADM conceptual model 1.0 - A conceptual model for geologic map information: U.S. Geological Survey Open-file Report 2004-1334, 60 p., available at http://pubs. usgs.gov/of/2004/1334/.

Richard, S.M., 2003, Geologic map database implementation in the ESRI Geodatabase environment, in Soller, D.R., ed., Digital Mapping Techniques '03 - Workshop Proceedings: U.S. Geological Survey Open-file Report 03-471, p. 169183, available at $h t t p: / / p u b s . u s g s . g o v / o f / 2003 / o f 03-471 /$ richard2/.

Richard, S.M., Craigue, J.A., and Soller, D.R., 2004, Implementing NADM C1 for the National Geologic Map Database, in Soller, D.R., ed., Digital Mapping Techniques '04 - Workshop Proceedings: U.S. Geological Survey Open-file Report 2004-1451, p. 111-144, available at http://pubs.usgs. gov/of/2004/1451/richard/.

Richard, S.M., Craigue, J.A., and Soller, D.R., 2005, NGMDB Geologic Map Feature Class Model, in Soller, D.R., ed., Digital Mapping Techniques '05 - Workshop Proceedings: U.S. Geological Survey Open-file Report 2005-1428, p. 143-158, available at http://pubs.usgs.gov/of/2005/1428/ richard/.

U.S. Geological Survey, 1995, Cartographic and digital standard for geologic map information: U.S. Geological Survey Open-file Report 1995-525, 257 p. 


\section{Appendix A. Geospatial feature schema}

The core AG1 geospatial feature schema, minus the Item table and its relationship classes, appears below. Data elements defined by ArcGIS are shown in italics.

Geology

GeoFrame (OID, Shape, Symbol, ItemID, Shape_Length, Shape_Area)

GeoPoints (OID, Shape, Kind, Type $\rightarrow$, Style, Symbol, Symval, ItemID, Selected)

GeoLines (OID, Shape, Kind, Type $\rightarrow$, Style, Symbol, Symval, ItemID, Selected, Shape_Length)

GeoPolys (OID, Shape, Kind, Symbol, Symval, ItemID, Shape_Length, Shape_Area) †

CrossSection\$

XsAFrame (OID, Shape, Symbol, ItemID, Shape_Length, Shape_Area)

XsAPoints (OID, Shape, Kind, Type $\rightarrow$, Style, Symbol, Symval, ItemID, Selected)

XsALines (OID, Shape, Kind, Type $\rightarrow$, Style, Symbol, Symval, ItemID, Selected, Shape_Length)

XsAPolys (OID, Shape, Kind, Symbol, Symval, ItemID, Shape_Length, Shape_Area) †

LegendGraphic\#

LGFrame (OID, Shape, Symbol, ItemID, Shape_Length, Shape_Area)

LGPoints (OID, Shape, Kind, Type $\rightarrow$, Style, Symbol, Symval, ItemID, Selected)

LGLines (OID, Shape, Kind, Type $\rightarrow$, Style, Symbol, Symval, ItemID, Selected, Shape_Length)

LGPolys (OID, Shape, Kind, Symbol, Symval, ItemID, Shape_Length, Shape_Area) †

Basemap (All optional contents; but with consistent spatial reference imposed.)

MapTics (OID, Shape, Label)

StudyArea (OID, Shape, Symbol, ItemID)

topoquad-DLG

etc.

topoquad-DRG

imagery

Explanation:

name : feature dataset OID, Shape, Shape_Length, Shape_Area: ESRI reserved attributes

name : feature class name $\rightarrow$ subtyped; name domain-controlled

† After construction using Feature to Polygon tool, the "Polys" feature class will contain three extra attributes - Type, Style, and Selected - from the associated "Points" feature class; if unused, these attributes can be simply deleted. 


\section{Appendix B. Tabular Data Schema (Sample)}

The sample tabular data schema for extended descriptions, which appears in UML below (Figure B-1), is intentionally simplistic. Its main purpose is to show how additional tables - here map sources and basic map-unit descriptions - are linked to the geospatial features via the Item relationship classes built-in to AG1. Also utilizing these linkages, the ArcGIS Identify (i) and Attributes 国 tools are immediately useful for feature identification, attribute data entry/editing, and relationship-tracking. The UNRCampus.mdb demonstration contains data in this sample schema. Numerous other table structures could be created and connected via the Item table.

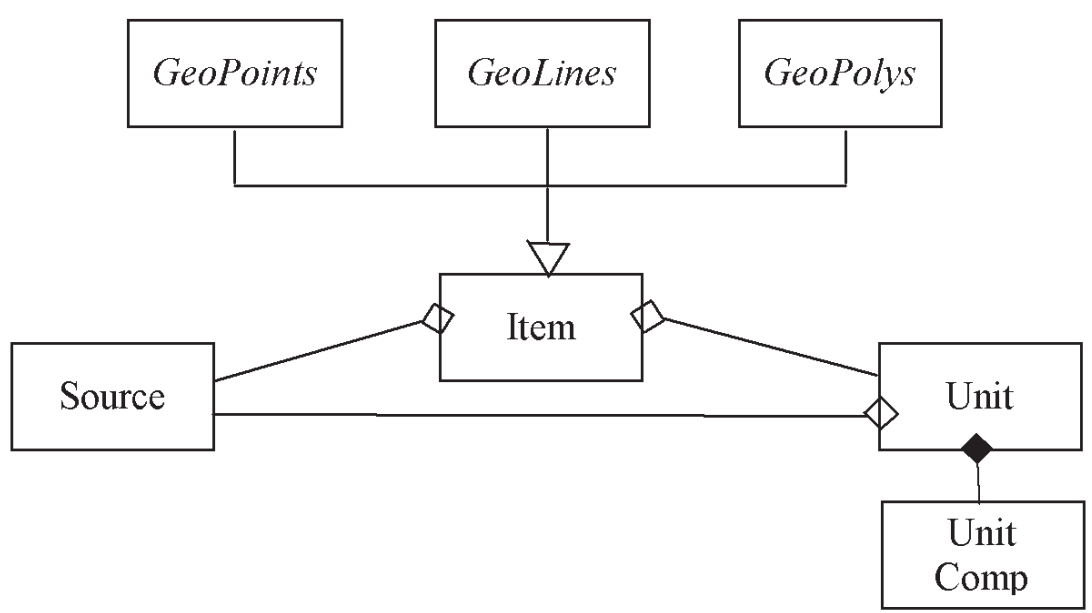

Figure B-1. Sample tabular schema, showing Item lineage.

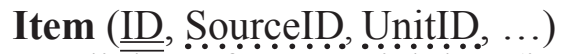

- linkage from spatial data (implemented as ArcGIS relationship class)

Source (ID, Title, Authors, Year, Citation, Webref)

- citable source reference

Unit (ID, Soụrcẹ!I, UnitName, AgeType, MinAgeCode, MaxAgeCode, ThickWid, Remarks)

- summary attributes for a geologic unit (applies to any geometry)

UnitComp (UnitID, SeqNo, Lithtype $\rightarrow$ Lithcode, LithName, VolPct, VolQual, Remarks)

- detailed attributes for lithologic components of a geologic unit.

Explanation:

ID: primary key

otherẹ!lD: foreign key

type: domain-controlled

$\Longrightarrow$ : sub-typed

$\nabla$ subclassing

$\diamond$ association (m:1)

— aggregation (m:1) 


\section{Appendix C: Known Problems}

1. Feature construction: Using the ArcToolbox Feature to Polygon tool, but not the ArcCatalog Features from Lines utility, if the (optional) point feature class is supplied, its metadata is transferred onto the newly constructed polygons. This transfer occurs even if the polygons are being reconstructed. The workaround is to import the supplied GeoPolys.xml metadata document into GeoPolys after all construction is completed.

2. Definition queries: The existence of a Definition Query interferes with the reconstruction of polygons from lines and (other) polygons. Specifically, it is not possible to use the ArcToolbox Feature to Polygon tool to reconstruct GeoPolys in a feature class that has such a query in place, e.g. for Kind (Rock, Alteration, etc.). Removing the query temporarily allows the reconstruction, but also results in all contents of GeoPolys being overwritten, not just the features of the chosen Kind. The workaround is to always construct into a new feature class (GeoPolys1, GeoPolys2, etc.), and when satisfactory, delete/re-merge them into GeoPolys. GeoPolys itself should not be deleted; doing so will also delete its relationship classes and destroy its metadata.

3. Matching to styles: When a feature class is symbolized using Match to Symbols in a Style, all of the symbols in the style are added to the map table of contents, whereas when the feature class is symbolized directly, only symbols for the features that are actually present appear. The workaround is to delete unwanted entries from the map table of contents after the feature class has been symbolized. 


\title{
Exchanging Observations and Measurements: a Generic Model and Encoding
}

\author{
By Simon J. D. Cox \\ CSIRO Exploration and Mining \\ PO Box 1130 \\ Bentley, WA 6102 \\ Australia \\ Telephone: +61 864368639 \\ Fax: +61 864368555 \\ email: Simon.Cox@csiro.au
}

\section{INTRODUCTION}

Much of the information concerning the natural world that is transferred or otherwise shared is based on Observations and Sampling. These provide the evidence that forms the basis for the description of features, interpretations and models. In many cases, the detail of how the observations were actually made is of little interest, and it is sufficient to embed the results in the description of a feature instance. However, in other cases, more information is needed. It turns out that the kinds of information that are associated with the report of an act of observation are common, across all disciplines, when classified appropriately. Consider the following statements:

- The 7 th banana weighed $270 \mathrm{gm}$ on the kitchen scales this morning

- The attitude of the foliation at outcrop 321 of the Leederville Formation was 63/085, measured using a Brunton on 2006-08-08

- Specimen H69 was determined on 1999-01-14 by Amy Bachrach to be of the species Eucalyptus Caesia

- IR image ASgh67c of Camp Iota was obtained by Aster in 2003

- Sample WMC997t collected at Empire Dam on 199603-30 was found to have $5.6 \mathrm{~g} / \mathrm{T}$ Au as measured by ICPMS at ABC Labs on 1996-05-31

- The X-Z Geobarometer determined that the ore-body was at depth $3.5 \mathrm{~km}$ at $1.75 \mathrm{Ga}$

- The simulation run on 2004-09-09 indicated a pressure reduction of $4 \mathrm{MPa}$ in geologic unit Q at $600 \mathrm{Ma}$.
All of these sentences contain the same kinds of information, though not in the same order. Recognizing this, we may encode the descriptions of observations and their results in a common way. This will allow observational data to be shared across discipline boundaries, satisfying a common requirement in applications concerning natural resources and the environment. It will also encourage the development of standard interfaces for observational data, and common processing and visualization systems.

Figure 1 represents the information provided in the sentences above using the formal notation of Unified Modeling Language (UML) Object Diagrams. (UML is an OMG and ISO standard. There are many introductory books and websites for the uninitiated.) The key point is that all Observations can be described in terms of the same set of properties: a feature-of-interest, observed-property, sampling-time, procedure, and result. The information may be described by a common model or schema.

In some cases some additional details are provided. For example, two of the examples include a result-time (i.e. the time that the procedure was completed) that is different than the sampling time (the time of interaction with the real-world). The descriptions of the objects related to the Observation may also be elaborated. For example, the feature-of-interest may have an associated sampled-feature, and the location of the procedure (laboratory) may be provided. The latter pattern is supported by the object-oriented analysis, which focuses on encapsulation of the information in suitable classes.

\section{INFORMATION MODEL}

Based on the analysis above, we have developed a standard model for Observations, and an associated model for the 
description of Sampling Features, such as specimens, sections, traverses, outcrops, boreholes, etc, as shown in Figures 2-5. The details of these models are provided in two Open Geospatial Consortium standards (Cox, 2007a, b).

Perhaps the key aspect of the observation model, which lends it the flexibility to be useful across such a wide array of applications, is the notion of the feature-of-interest. This general pattern was first introduced by Fowler and Odell, based on work in the medical sector (Fowler, 1998). The feature-of-interest externalizes the description of the details of the observation target, separating this from the description of the observation procedure, thus allowing both remote and insitu observations to be described using the same structure.

The addition of the Sampling Feature concept allows a sampling artifact to be interposed, which also supports the description of ex-situ observations - i.e. where a specimen is removed from the ultimate feature of interest, and analyzed in a laboratory remote from the real-world location. For some more elaborate applications of the Sampling Features model, in particular showing the usefulness of the "related sampling feature" association, see https://www.seegrid.csiro.au/twiki/ bin/view/AppSchemas/ObservationsAndSampling.

The Observations and Sampling models are imported and used in the GeoSciML information model that has been developed by the Interoperability Working Group of the IUGS Commission for Geoscience Information (Simons et al., 2006; Laxton and Wyborn, 2007) and is to be used in the OneGeology project (Jackson and Wyborn, 2007).

These standards (Cox, 2007a, b) also provide an XML encoding that may be used for transfer of observational data. The encoding is provided as a GML-conformant (Cox et al., 2001; Cox et al., 2003; Portele, 2007) XML Schema, which makes it compatible with the OGC-WFS service interface (Vretanos, 2004). The OGC Sensor Observation Service interface is specifically designed to provide access to collections of observations (Priest and Na, 2007).

\section{ACKNOWLEDGMENTS}

The work described in this paper was developed over several years, starting in the XMML project (https://www. seegrid.csiro.au/twiki/bin/view/Xmml/WebHome) which was supported by Fractal Graphics, MERIWA, GGIPAC, WMC, Snowdens, BGS, Placer-Dome, and continuing under several OGC Interoperability Program projects supported by a variety of sponsors, with later work supported by CSIRO under the WRON and Auscope projects, and by Geoscience Australia.

\section{REFERENCES}

Cox, S.J.D., 2007a, Observations and Measurements - Part 1 - Observation schema, OpenGIS® Implementation Standard, OGC document 07-022r1, available at http://portal. opengeospatial.org/files/?artifact_id $=22466$.

Cox, S.J.D., 2007b, Observations and Measurements - Part 2 - Sampling features, OpenGIS $®$ Implementation Standard, OGC document 07-002r3, available at http://portal. opengeospatial.org/files/?artifact_id $=22467$.

Cox, S.J.D., Cuthbert, Adrian, Lake, Ron, and Martell, Richard, 2001, Geography Markup Language (GML) 2.0, OpenGIS ${ }^{\circledR}$ Implementation Standard, available at http:// www.opengeospatial.org/standards/gml.

Cox, S.J.D., Daisey, P.W., Lake, Ron, Portele, Clemens, and Whiteside, Arliss, 2003, Geography Markup Language (GML) 3.00, OpenGIS $®$ Implementation Standard, available at http://www.opengeospatial.org/standards/gml.

Fowler, Martin, 1997, Analysis Patterns: reusable object models: Menlo Park, CA, Addison-Wesley, 357 p.

Jackson, Ian, and Wyborn, Lesley, 2007, One planet: OneGeology? The Google Earth revolution and the geological data deficit, in International viewpoint and news: Environmental Geology, v. 53, no. 6, p. 1377-1380, DOI 10.1007/s00254007-1085-z, available at http://www.springerlink.com/ content/v7r17962365074h8/.

Laxton, J.L., and Wyborn, Lesley, 2007, The GeoSciML Logical Model [abs.]: Eos Trans., AGU Fall Meeting Supplement, v. 88, no. 52, abstract IN53A-0949, December 10-14, 2007, San Francisco, CA.

Portele, Clemens, 2007, Geography Markup Language, 3.2.1 OpenGIS $®$ Implementation Standard, OGC document 07-036, available at http://portal.opengeospatial.org/ files/?artifact_id $=20509$.

Priest, Mark, and Na, Arthur, 2007, Sensor Observation Ser-

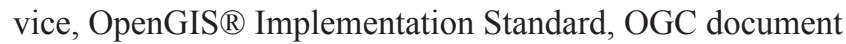
06-009r5, available at http://portal.opengeospatial.org/ files/?artifact_id $=20472 \&$ version $=1$.

Simons, Bruce, Boisvert, Eric, Brodaric, Boyan, Cox, S.J.D., Duffy, T.R., Johnson, B.R., Laxton, J.L., and Richard, S.M., 2006, GeoSciML: Enabling the Exchange of Geological Map Data [abs.]: Australian Earth Sciences Convention 2006, July 2-6, 2006, Melbourne.

Vretanos, Peter, 2004, Web Feature Service (WFS), version 1.1 OpenGIS $®$ Implementation Standard, OGC document 04-094, available at http://portal.opengeospatial.org/ files/?artifact_id=8339. 


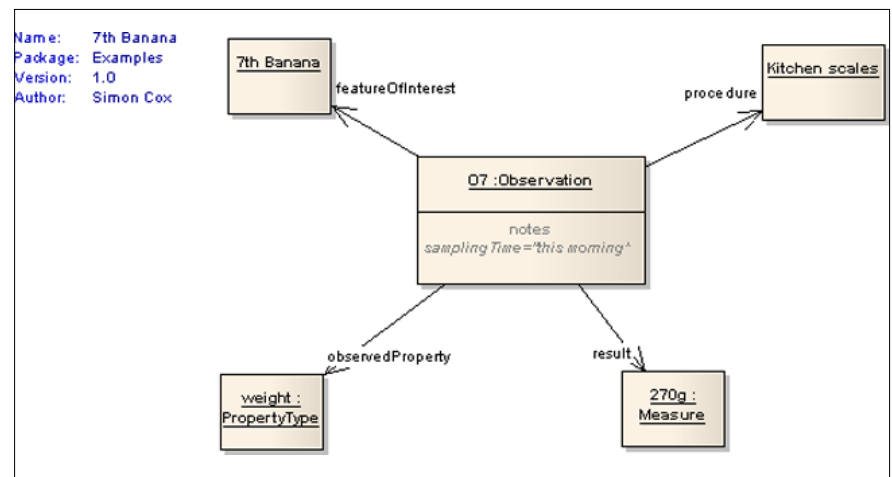

A.

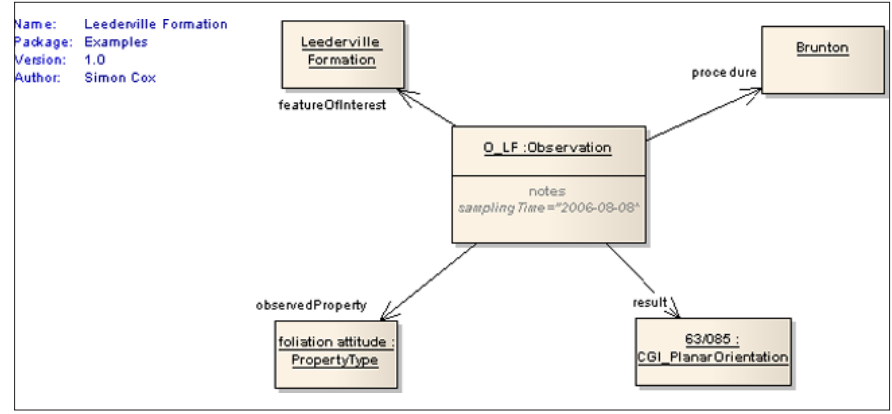

B.

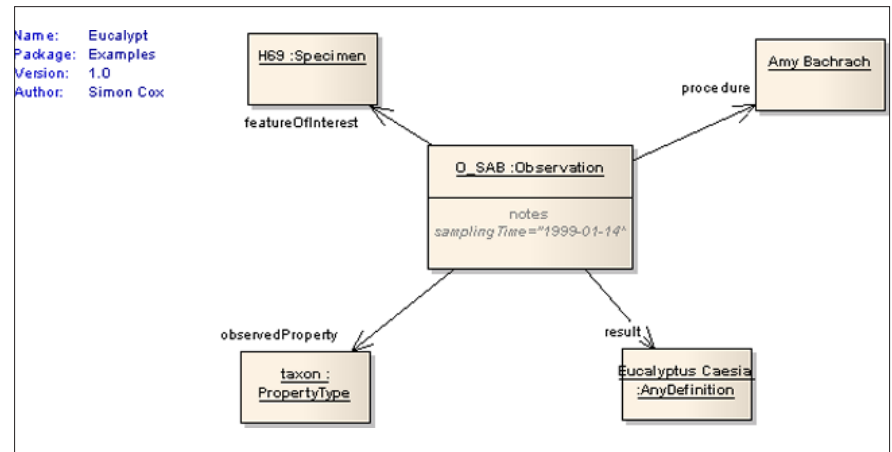

C.

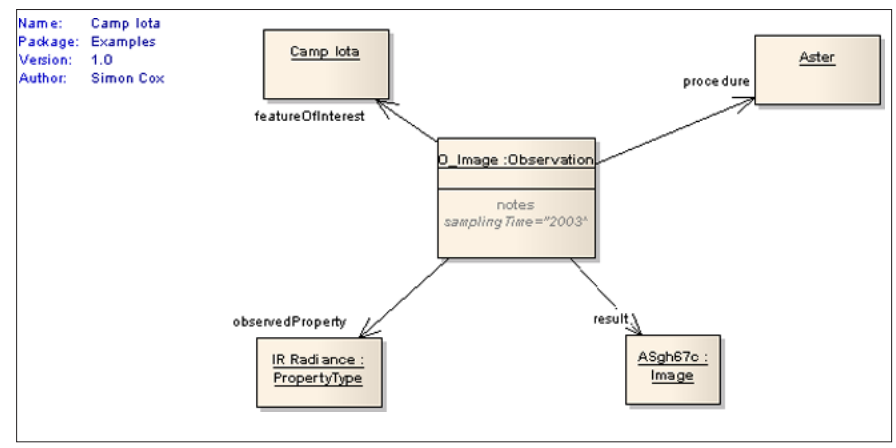

D.

Figure 1. A-G. UML Object Diagrams for the observation examples.

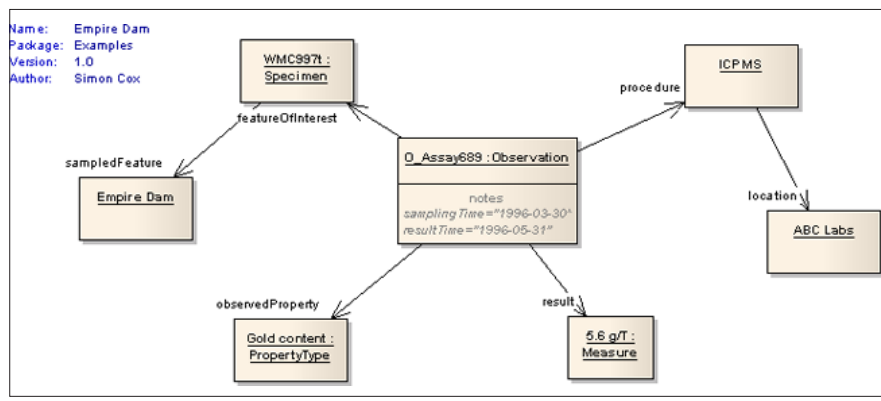

E.

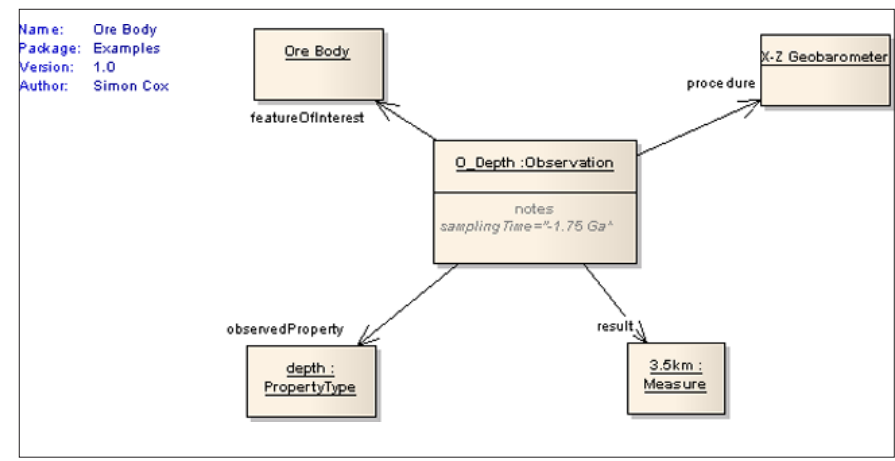

F.

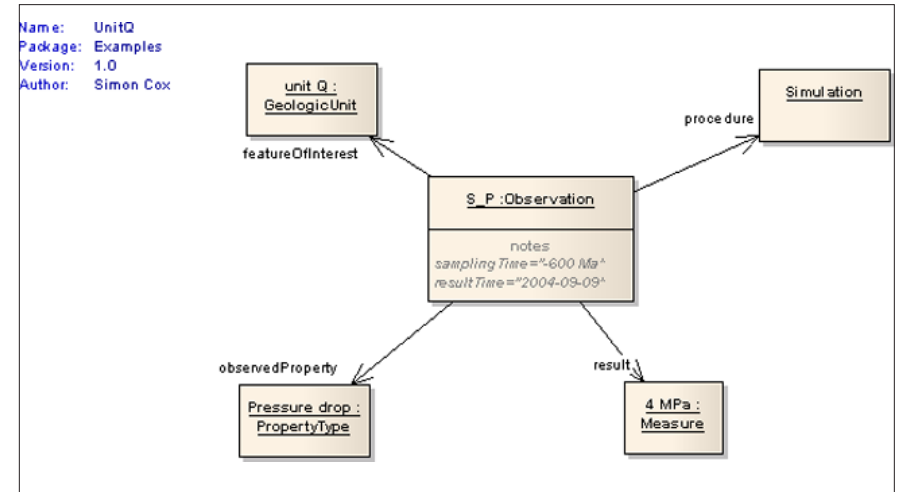

G.

lame: Unito ackage: Examples 


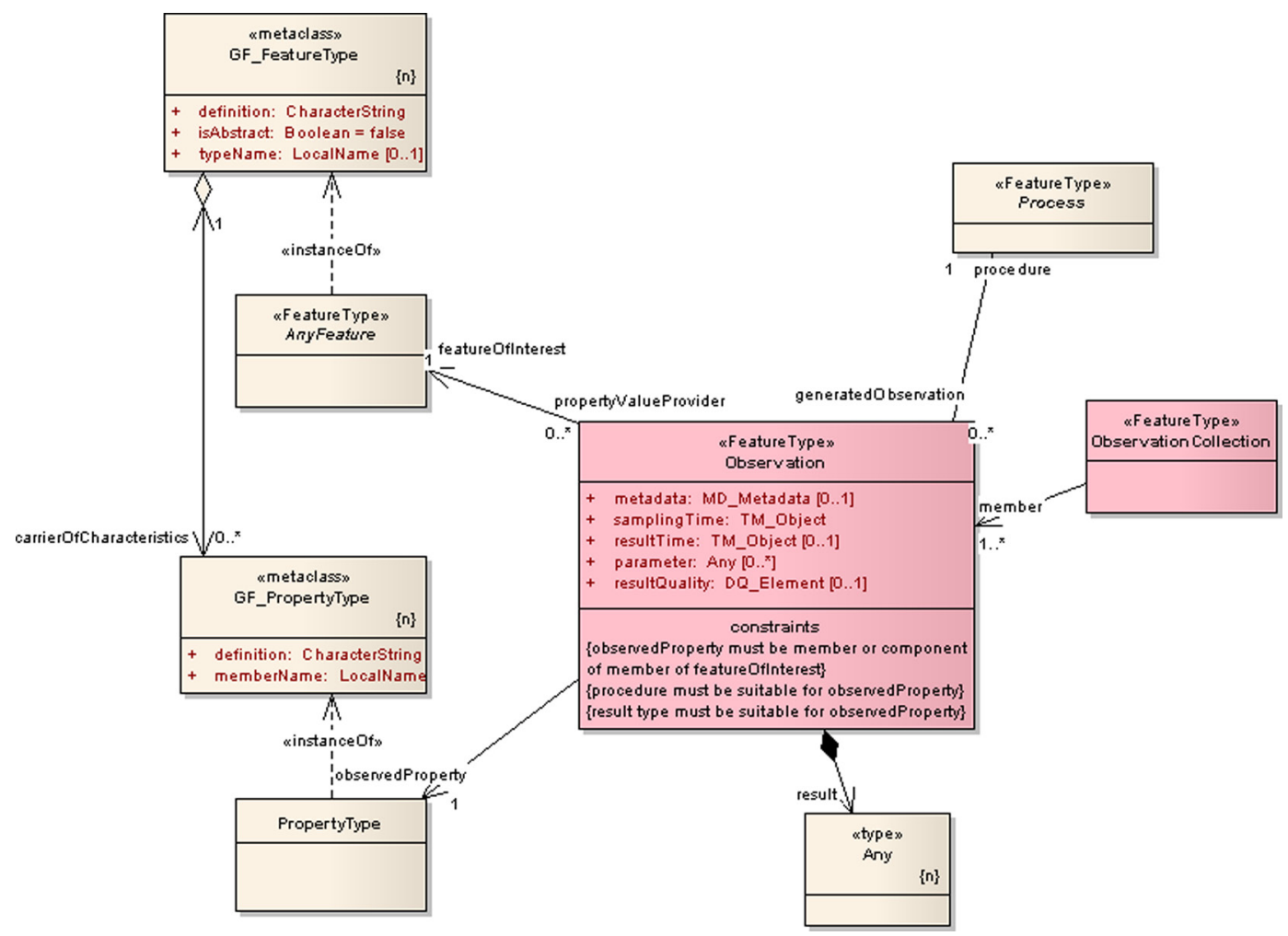

Figure 2. UML Static Class Diagram for the Observation Model (from Cox, 2007a).

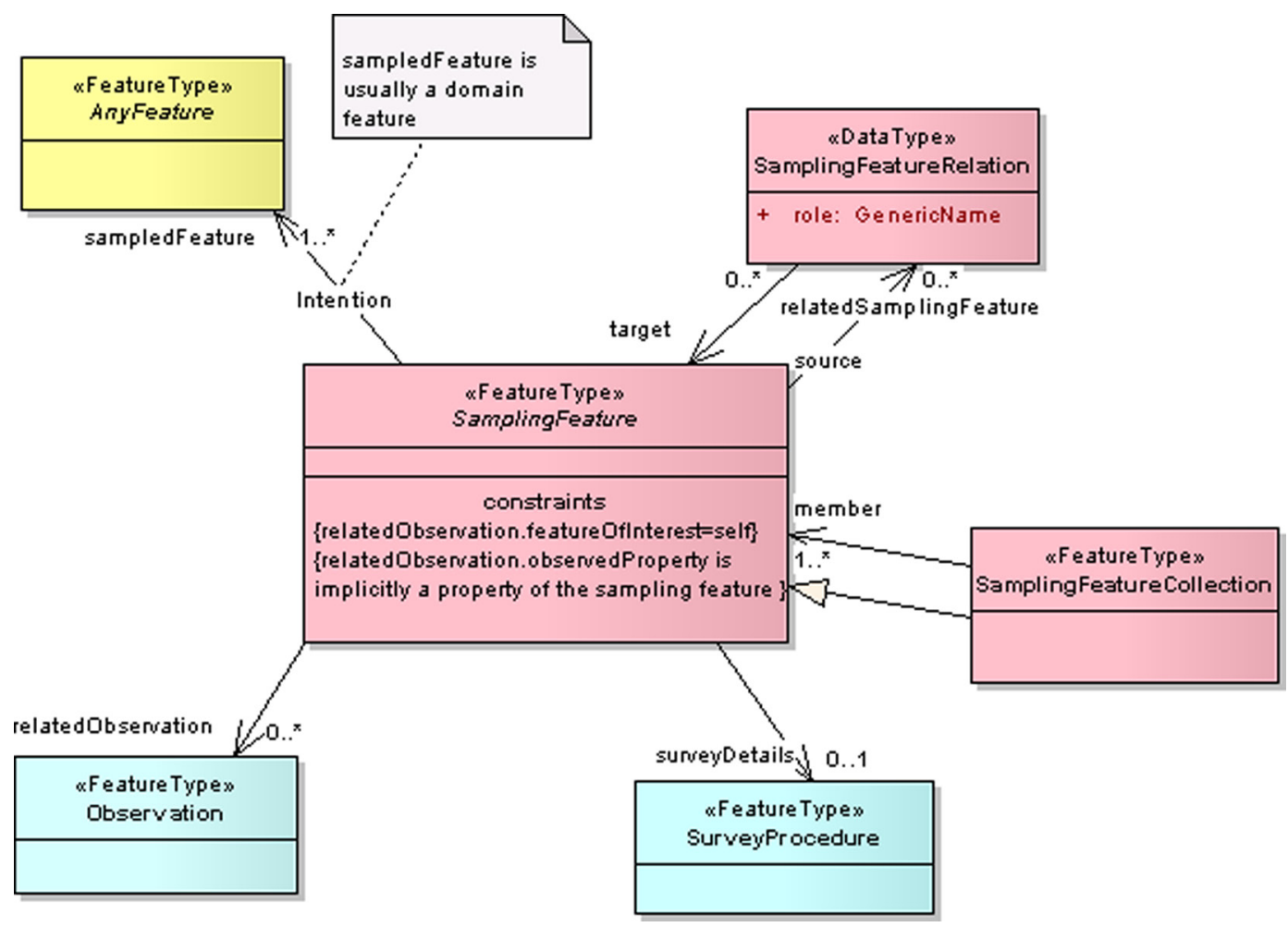

Figure 3. UML Static Class Diagram for the base Sampling Feature model (from Cox, 2007b). 


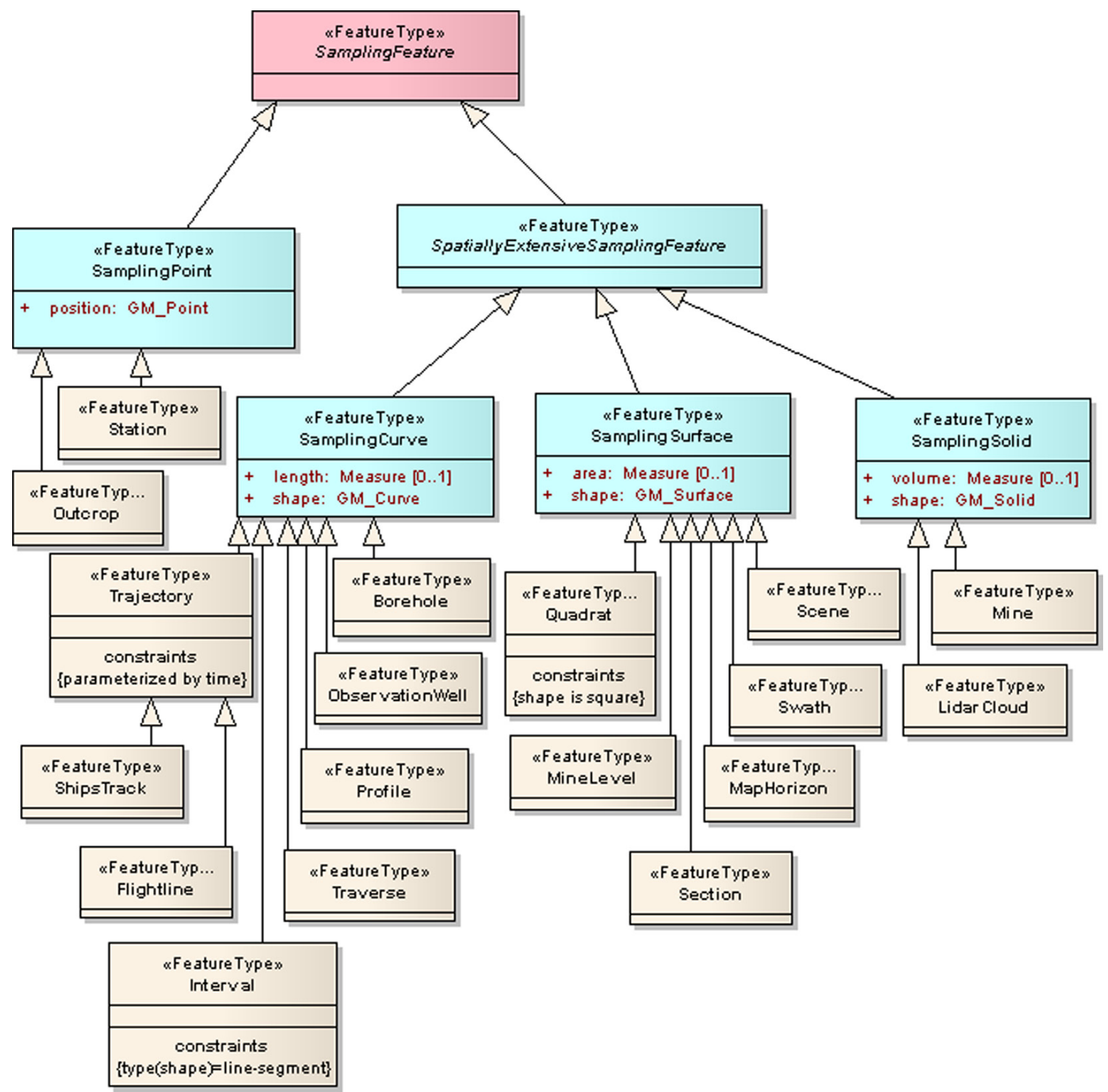

Figure 4. UML Static Class Diagram for Sampling Manifolds, showing various domain-related specializations (from Cox 2007b). 


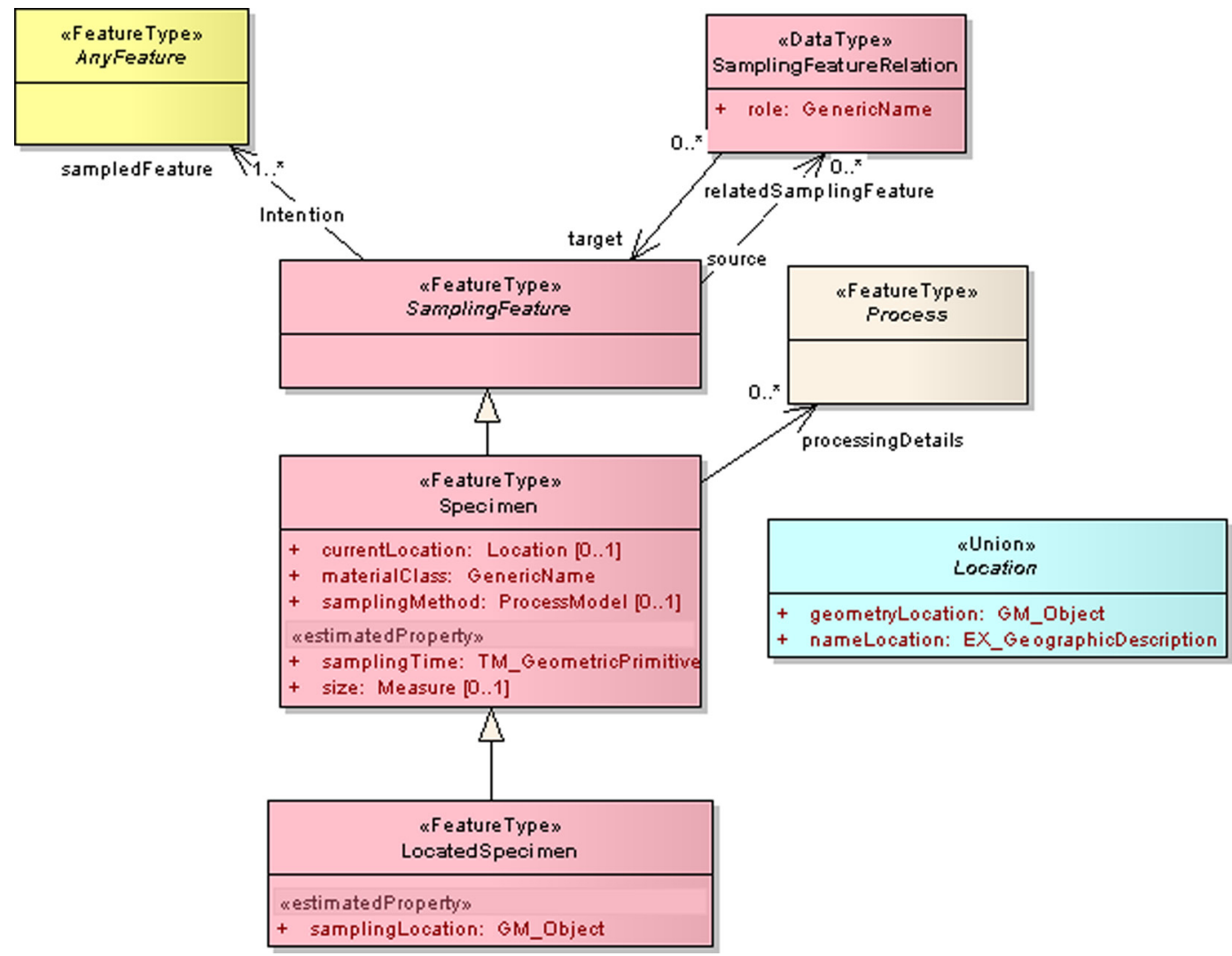

Figure 5. UML Static Class Diagram for Specimens (from Cox 2007b). 


\title{
Idaho Geologic Map Data in a Statewide Geodatabase
}

\author{
By Loudon R. Stanford' and Steve Mulberry ${ }^{2}$ \\ ${ }^{1}$ Idaho Geological Survey \\ University of Idaho \\ Moscow, ID 83844-3014 \\ Telephone: (208) 885-7479 \\ Fax: (208) 885-5826 \\ email: stanford@uidaho.edu \\ ${ }^{2}$ ESRI, Atlanta, GA \\ email: smulberry@esri.com
}

\section{INTRODUCTION}

The Idaho Geological Survey has created a statewide ESRI Geodatabase for storing, managing, and distributing Idaho geologic map data. The model for this design resulted from work done by the Idaho Survey over the past 8 years. The work flow strategy around the implementation of the geodatabase improves the productivity of the survey by capturing map data using existing procedures and automating the migration processing of data tiles into feature classes in the statewide geodatabase.

\section{HISTORY}

Idaho has been collecting geologic map data in GIS format for 15 years. In 2003, six data sets were released in ArcInfo coverage and ArcView formats using Idaho's data model v2.1 (Stanford and MacKubbin, 2000). The methods currently used for geologic map data capture have been in place for more than 10 years (Freed and Stanford, 2005).

\section{GEODATABASE DESIGN HIGHLIGHTS}

The Idaho Statewide Geologic Map Geodatabase (ISGMG) follows the physical design of the Idaho Geologic Map Data Model v3.1, which evolved from the earlier Idaho model v2.1 (http://www.idahogeology.org/Lab/datamodel. $h t m$ ). Key changes made to 2.1 allow data to be stored in one statewide database. The following are some of the highlight features of the ISGMG:

- The design is composed of four data groupings: Spatial, map unit, earth materials, and metadata.
- The design of the database allows for two levels of map object tracking or coding, by $30^{\prime}$ x $60^{\prime}$ tile or statewide.

- All contacts (poly boundaries) of a particular polygon are linked to the polygon.

- Additions and changes to earth materials section based on work done by the North American Data Model's Science Language Technical Team (SLTT) have been incorporated into the design (NADM-SLTT, 2004a, b).

- Descriptions from referenced geologic sources can be stored as well as URL links to IGS online PDF maps.

- Map unit history and changes are tracked.

- Object-level attribution including geologic source reference, line type, and feature name.

\section{WORK FLOW AND THE GEODATABASE}

\section{Data Capture}

The methods that the Idaho Geological Survey uses to capture geologic map data have been previously described (Freed and Stanford, 2005). One of the salient features of this data capture is the object-level (feature) attributing. This attributing is designed to facilitate the eventual compilation of 1:24,000-scale geologic map data (from 7.5-minute quadrangles) into $30 \times 60$ minute tiles of map data at 1:100,000 scale. These tiles then become the basic spatial-data building blocks for the Survey's mapping program and the statewide database. Publication as a traditional geologic map occurs for many of the 1:24,000 maps and for all of the 1:100,000scale maps. However, the database behind these publications 
is considered of primary importance. Simplification of map data may be done for map publication, but all original spatial data are maintained in the database for each tile.

\section{GIS Processing, Quality Control, and Data Migrations}

Map data are migrated to the statewide geodatabase via software tools where data processing, quality-control, and finally, migration of the $30 \times 60$ minute tiles into the statewide database occurs. There are tools for each geologic layer in the geodatabase. Currently, layers include the following:

- Map units (contacts and polygons)

- Faults

- Folds

- Measurements (e.g., strike and dip)

- Miscellaneous line symbols

- Miscellaneous point symbols

- Miscellaneous polygon overlays (for example, loess). New layer types can be added and do not necessarily need to cover the entire state.

During the migration process, the software tool creates fields as needed to conform and merge the tile data to the ISGMG. Part of the quality control processing includes checking the attributes on new data against existing controlled vocabularies in the geodatabase. If attributes are missing in the geodatabase, either the new data must be changed or the necessary attributes must be added to the correct ISGMG pick lists.

During the migration, each tool checks to see if the tile layer being migrated already exists in the database. If a tile layer is present it is deleted before the new data are migrated.

\section{Descriptive Data Capture}

The descriptive information about geologic map data are captured using MS Access forms created for this purpose. Currently there are two major categories for descriptive data capture: map unit description and earth material description.

Map unit descriptions are provided by the geologist who compiled the map tile. Descriptions are parsed into the appropriate data fields, where possible. Entire text versions of map unit descriptions are also captured. Entire descriptions from geologic sources used in the compilation can also be entered.

Each map unit can have many earth materials associated with it, and each earth material can have many attributes. Where possible, controlled vocabularies are being compiled or exist for various attributes stored.

\section{Geologic Reference Attributes and Other Pick Lists}

The reference for the geologic source of every map object is stored in the database. The reference listing is updated as map capture proceeds. These bibliographic sources can be used both for query and metadata purposes by the user. Other pick lists include geologic structures, line types, symbols, and special feature names.

\section{FGDC Metadata}

The Idaho Survey collects FGDC-compliant metadata for these data. A combination of ESRI built-in tools and $3^{\text {rd }}$-party plug-in tools are used (http://www.insideidaho.org/ whatsnew/whatsnew.htm\#News).

\section{SOFTWARE TOOLS FOR MIGRATING DATA INTO THE STATEWIDE GEODATABASE}

The IGS software tool set is a series of ETL scripts (Extract Transfer and Load). These scripts are used to manipulate and load 1:24,000-scale geological data into the Idaho state wide geological database. The tools were built using ArcGIS 9.2 SP1 model builder inside ArcCatalog. ModelBuilder provides a graphical modeling framework for designing and implementing geoprocessing models that can include system tools, scripts, models, and data. ModelBuilder helps make geoprocessing tasks more streamlined and efficient. In the example shown in Figures 1-3, the IMP_FC object holds the logic for processing the information. This logic is VB Script produced by ModelBuilder. The model accepts inputs from the user and executes the code. Tools are grouped together for logical execution.

\section{SUMMARY}

The Idaho Geological Survey captures geologic mapping data in a standardized format. Tiles of map data are migrated to a statewide geodatabase using tools developed in ModelBuilder. Centralizing data from separate tile or data sets allows the Idaho Survey to efficiently manage, update, and distribute one uniform set of data. The geodatabase can easily be used for online map data delivery services. 


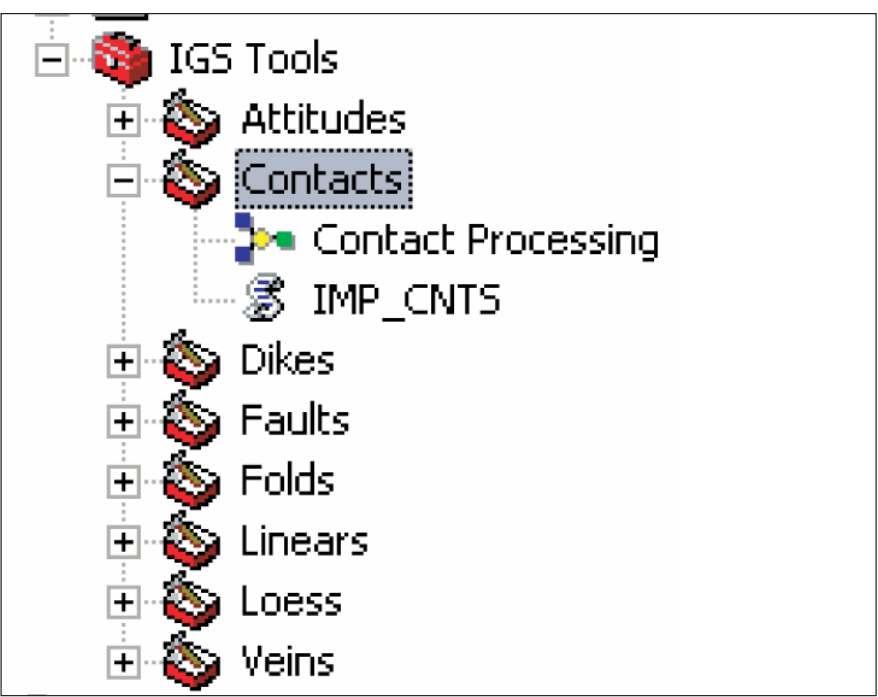

Figure 1. The IGS Tool Set as represented in ArcCatalog. Each model is associated with a VB Script which holds the logic. In this figure, the model "Contact Processing" uses the script "IMP_CNTS" to process the geologic contacts. Each model is responsible for extracting $24 \mathrm{~K}$ geological data stored in Arclnfo coverage format, performing several data transformations, loading the information into a statewide geodatabase.

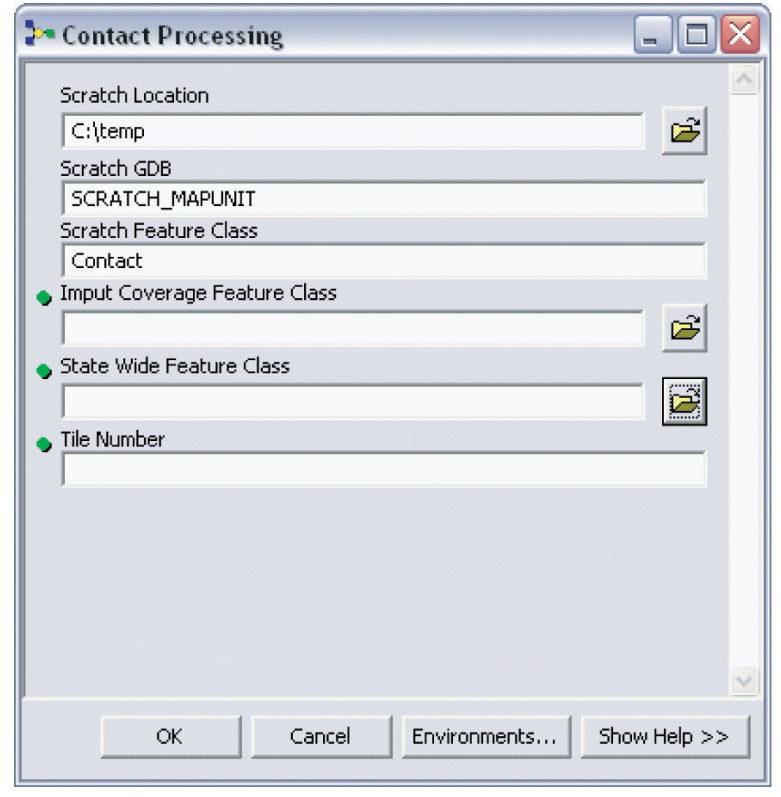

$\boldsymbol{A}$

B

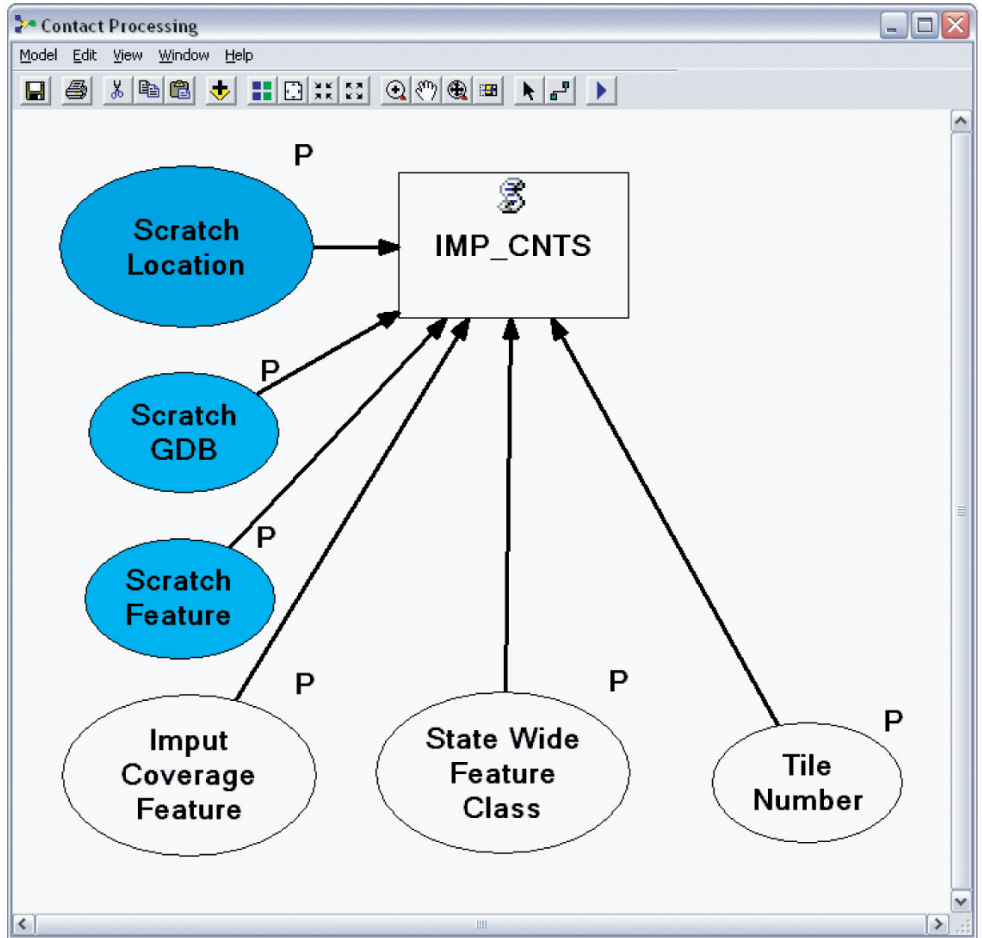

Figure 2. A. Input form for the Contact Processing model. The model expects user input for: the input coverage name, output location in the State Wide Geodatabase, and the tile number associated with the coverage area. The model creates a scratch workspace while performing the transformation, and loads the geologic contacts into the statewide Geodatabase. $B$. Diagram of the Contact Processing model. 


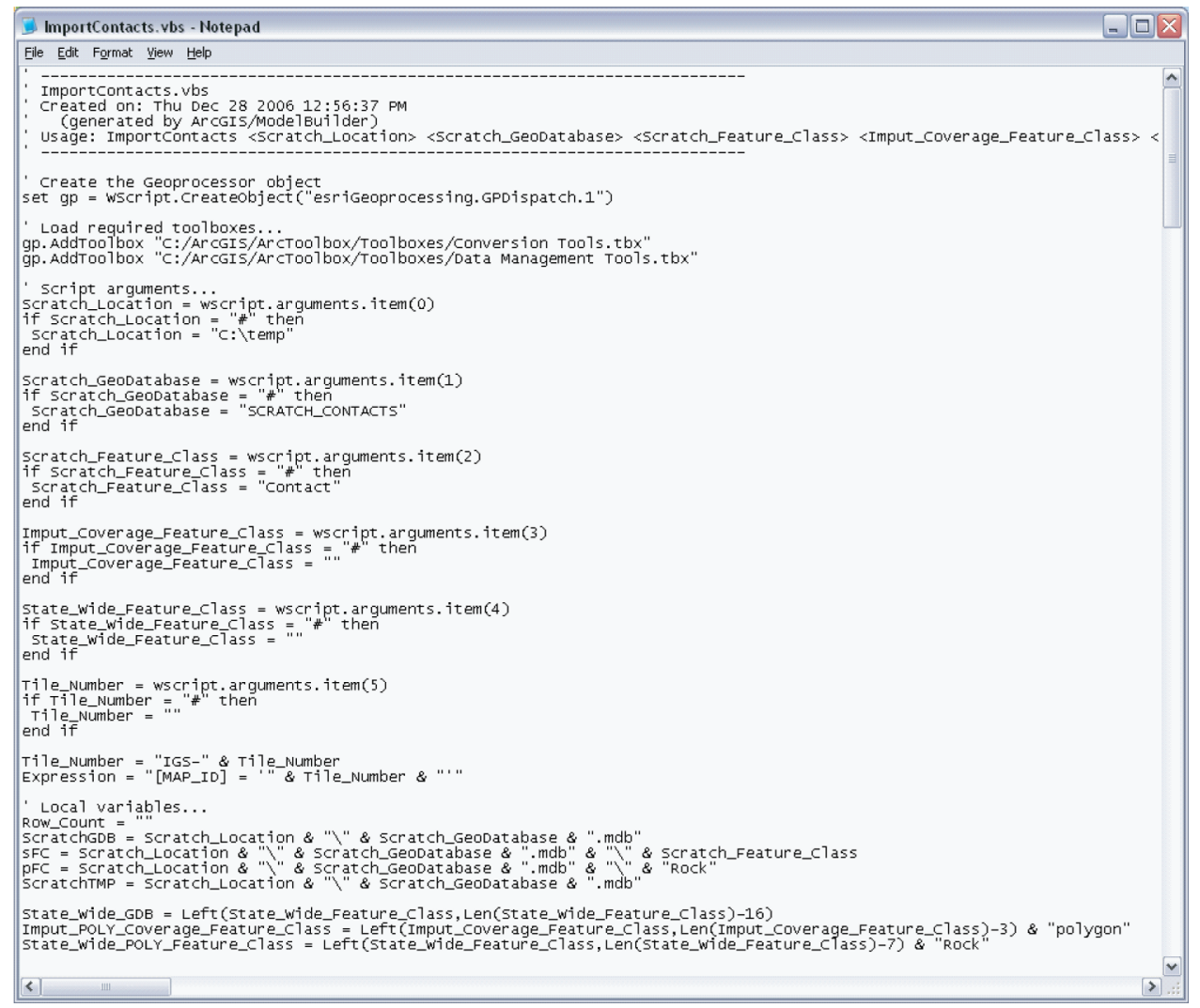

Figure 3. A sample of code within the VB Script object IMP_CNTS.

\section{REFERENCES}

Freed, J.S. and Stanford, L.R., 2005, Map Production and Data Distribution the Idaho Way: An Update, in Soller, D.R., ed., Digital Mapping Techniques '05-Workshop Proceedings: U.S. Geological Survey Open-File Report 2005-1428, p. 55-59, available at http://pubs.usgs.gov/of/2005/1428/freed/ index.html.

North American Geologic-Map Data Model Science Language Technical Team, 2004a, Report on progress to develop a North American science-language standard for digital geologic-map databases; Appendix B - Classification of metamorphic and other composite-genesis rocks, including hydrothermally altered, impact-metamorphic, mylonitic, and cataclastic rocks, Version 1.0 (12/18/2004), in Soller, D.R., ed., Digital Mapping Techniques '04-Workshop Proceedings: U.S. Geological Survey Open-File Report 20041451, 56 p. Appendix B available at http://pubs.usgs.gov/ of/2004/1451/sltt/appendixB/.
North American Geologic-Map Data Model Science Language Technical Team, 2004b, Report on progress to develop a North American science-language standard for digital geologic-map databases; Appendix C1 - Sedimentary materials: Science language for their classification, description, and interpretation in digital geologic-map databases; Version 1.0 (12/18/2004), in Soller, D.R., ed., Digital Mapping Techniques '04-Workshop Proceedings: U.S. Geological Survey Open-File Report 2004-1451, 595 p. Appendix C1 available at http://pubs.usgs.gov/of/2004/1451/sltt/ appendixC/appendix C_pdf.zip.

Stanford, L.R. and MacKubbin, V.T., 2000, Application of a Digital Geologic Map Data Model in ArcView GIS, in Soller, D.R., ed., Digital Mapping Techniques '00 — Workshop Proceedings: U.S. Geological Survey Open-File Report 00-325, p. 55-56, available at http://pubs.usgs.gov/ of/2000/of00-325/stanford.html. 


\title{
Alaska Mapper: A Web-based Tool to Access Land Ownership and Other State-wide Geospatial Data
}

\author{
By Kenneth R. Papp ${ }^{1}$ and Peter Parker ${ }^{2}$ \\ ${ }^{1}$ Alaska Division of Geological \& Geophysical Surveys \\ 3354 College Rd. \\ Fairbanks, AK 99709-3707 \\ Telephone: (907) 451-5039 \\ Fax: (907) 451-5050 \\ email:ken.papp@alaska.gov \\ ${ }^{2}$ Alaska Land Records Information Section \\ 550 W. 7th Ave. Ste. 706 \\ Anchorage, AK 99501 \\ Telephone: (907) 269-8844 \\ email: peter.parker@alaska.gov
}

\section{INTRODUCTION}

Users of the Internet are currently witnessing a revolutionary period of communication and data search capabilities. In the past several years, several research and technology corporations, like Google, Yahoo!, and Microsoft have released a number of Application Programming Interfaces (APIs) and online interactive search tools. These web applications allow users to perform a number of complex searches, with the results being displayed spatially, in an organized arrangement of layers, polygons, symbols, labels, photos, news, web links and text (Neches et al., 2001). Applications such as Google Earth (http://earth.google.com) Microsoft's Virtual Earth (http://www.microsoft.com/virtualearth) and NASA's World Wind (http://worldwind.arc.nasa.gov) have become the standard tools for curious users to discover the world, learn about far-away cities, and acquire information without leaving their desk chairs.

The accepted use of these online tools has been influenced by the media (Scharl, 2004). Scharl points out that although Google Earth was released in 2005, by the end of 2006 it had received $83 \%$ of the media coverage amongst all of the 3-D geospatial search tools. As a result, the power of searching and viewing thematic information in a 3-D, geospatial interface has started to draw attention away from mainstream search engines and 2-D, online map tools (Scharl and Tochtermann, 2007). Furthermore, approximately $20 \%$ of web pages currently contain distinguishable and clear geographic identifiers (Delboni et al., 2005). The number of web sites that provide these identifiers will no doubt continue to increase, as users quickly realize the potential and advantages of integrating thematic, temporal and contextual data with an interactive geospatial engine, called the geobrowser.

Alaska Mapper, developed by the Alaska Department of Natural Resources' (DNR) Land Records Information Section (LRIS), is one such geobrowser that provides access to the Alaska DNR's Land Administration System (LAS) and other statewide geospatial data (Figure 1). Much of the information displayed in Alaska Mapper is also used to easily access the State status plats, an index by township to the public land record and the department's case files (Figure 2). Although status plats have been accessible through the Alaska Land Records web site (http://plats.landrecords.info) since 1999, these are not interactive. With the Alaska Mapper, users can zoom to an area of interest, turn data layers on and off, make live queries to the database of records, view each layer's metadata and download selected data for use in a GIS. To access Alaska Mapper and its documentation, see http://mapper. landrecords.info.

\section{SEEING ALASKA FROM A BIRD'S EYE VIEW}

The LRIS Status Graphics Unit (SGU) uses a custombuilt ESRI application to edit DNR's land record status data. The application, written in ArcDesktop and Visual Basic, is highly sophisticated and customized to the status plat production. The data are then transformed from the ESRI feature datasets to Oracle Spatial (http://www.oracle.com) 


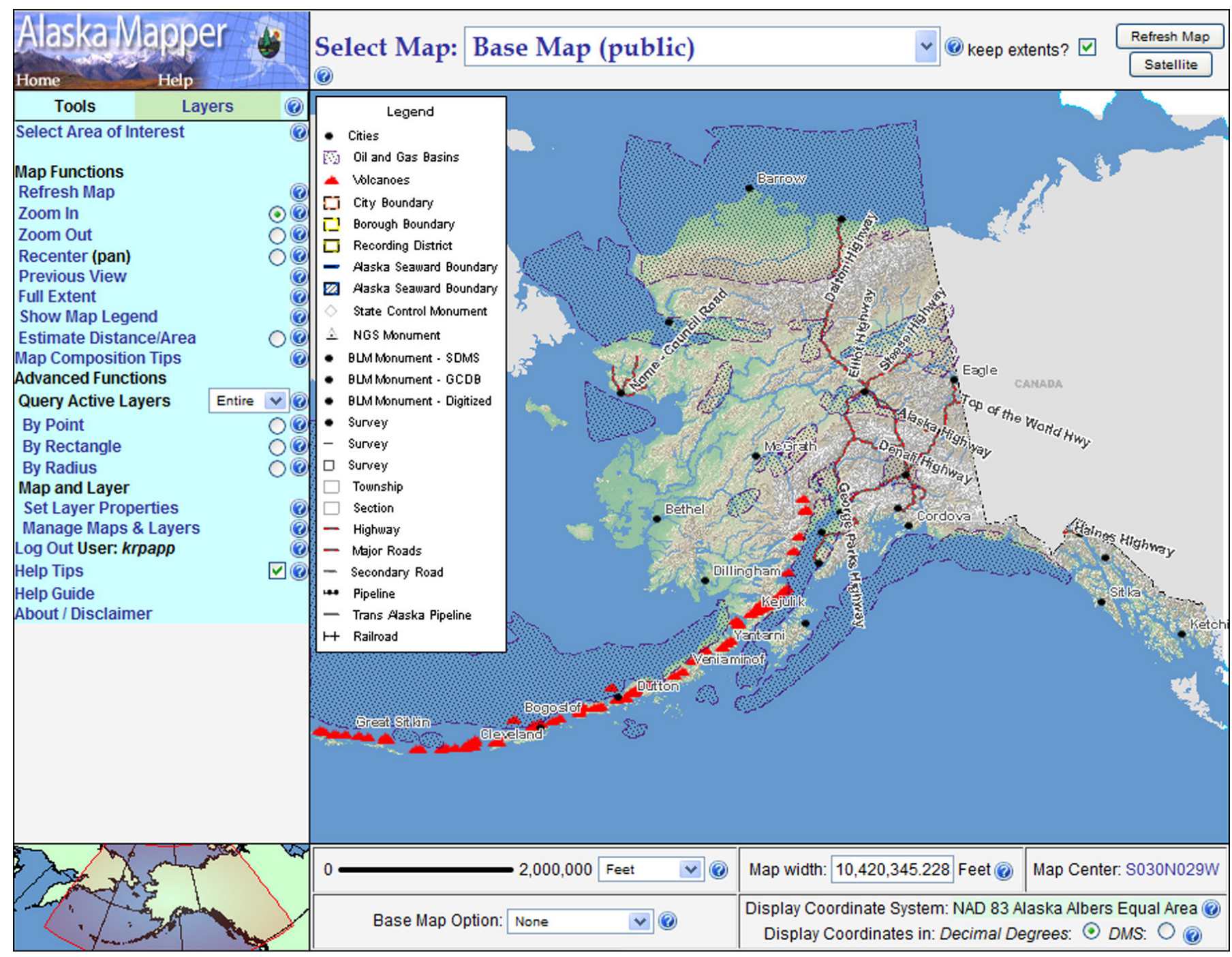

Figure 1. The Alaska Mapper geobrowser (http://mapper.landrecords.info), showing oil and gas fields and active volcanoes.

geometry objects using ArcSDE (http://www.esri.com) and then out to MapInfo TAB files from an Oracle materialized view (a cached, virtual table representing the result of a complex, database query) for the Alaska Mapper. Less complex datasets are accessed directly from an Oracle table by Alaska Mapper without being converted to TAB files. Much of this work can now be automated, which will eventually permit the data available to the public to be as current as 24 hours from the time of data-entry.

Alaska Mapper is 100\% Java-based, using MapInfo's MapXtreme (http://extranet.mapinfo.com) for Java at its rendering core. The original intent was to use an Oracle database to directly "feed" the system, but this work flow offered substandard performance. Instead, the data are exported to MapInfo TAB files on a regular basis. The data are stored in Oracle Spatial and is registered via SDE which allows ESRI clients to manipulate it. A two node, SUN Intel x86 cluster, running Solaris and Apache, serves the application with four, active implementations of Apache Tomcat to distribute the processing load. This architecture was crucial in achieving the system's current optimal performance.

Similar to the other popular geobrowsers, Alaska Mapper was designed with navigation functions, layer management features, and query tools with which people are now quite familiar. Although innovation is at the forefront of every developer's mind, it is also desirable to maintain a similar look and feel to existing complex APIs in order to maintain usability and a certain user "comfort level" with the program (Kendall, 2005). There are advantages to being "first out the gate," however. As Shapiro and Varian (1999) point out, the original design often becomes the standard and increases the likelihood of user lock-in.

Advantages of the Alaska Mapper geobrowser include (1) integrating energy resources data, for example, with existing statewide data and infrastructure in ways that were not previously possible, (2) accessing data that is updated on a regular basis, including land status, ownership, and water rights, (3) not having to install any programs or download data to use the 

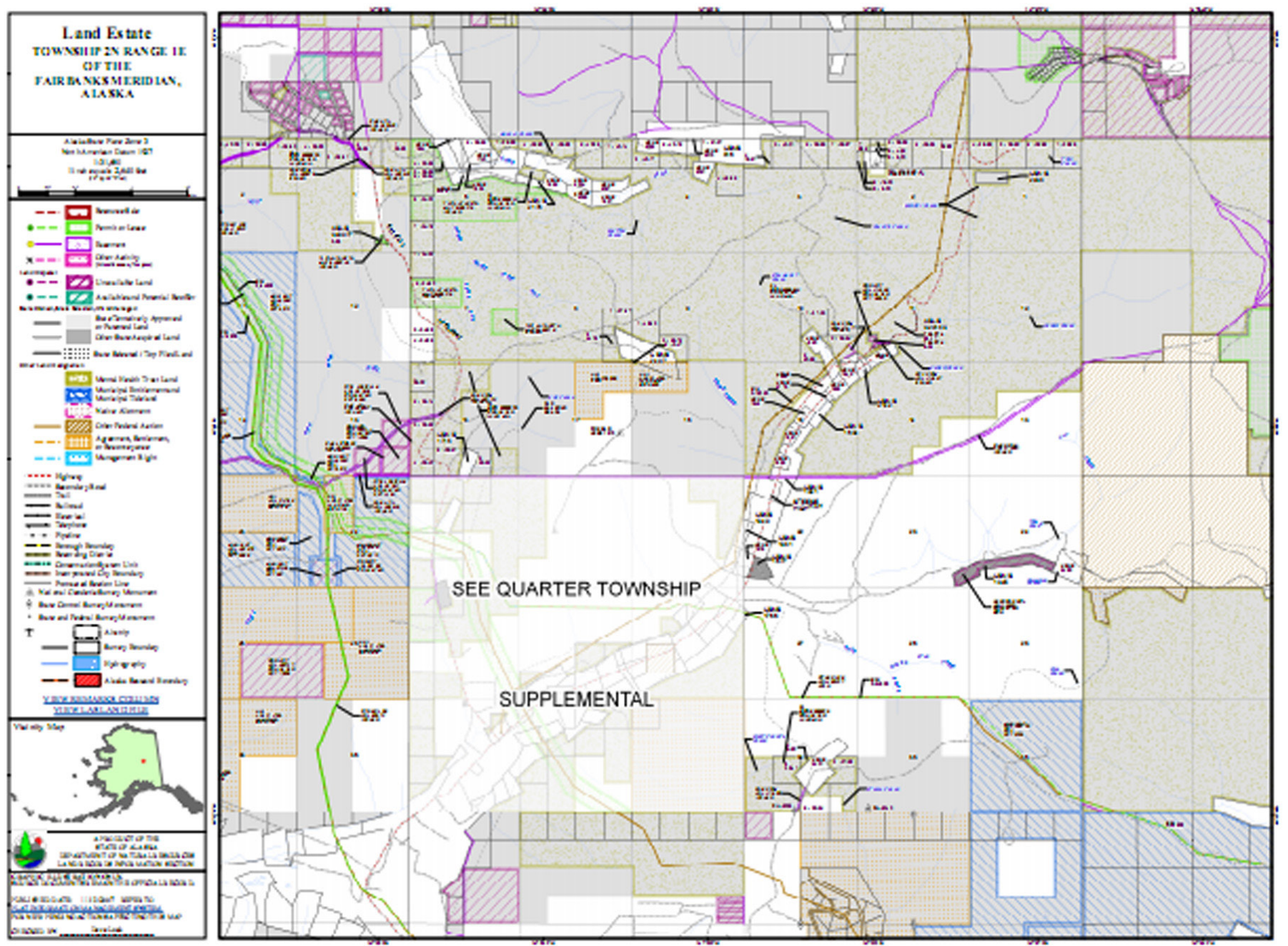

Figure 2. The status plats give a composite view of the activity on state-owned land and provide detailed information on property issues affecting state land and resources. Please see the Alaska DNR Land Records Information Section Land Records page, available at $h$ ttp://plats.landrecords.info/, for more information.

service, and (4) having the option to download the source data to use locally on your computer. It is the latter advantage of Alaska Mapper that makes the geobrowser so useful. Not only is it possible to extract all the data (see the next section) for a given dataset, but a user can also view the dataset's metadata, which answers the crucial "who, what, when, where, why, and how?" about the data. With so many users having access to the data, it is imperative to provide metadata in order to avoid misuse of the data (Browne et al., 2003) and to prevent spending valuable resources on updating legacy data many years later (McCurley, 2001).

\section{A VIRTUAL STATE OF DATA AT YOUR FINGERTIPS}

Alaska Mapper was originally designed to be the visual interface into DNR's Land Administration System, providing visual, interactive access to case-file data from status plats and links to land case file summaries, details, and abstracts. Over time, however, user needs have influenced additional features and the data capable of being displayed in the geobrowser. New features in the latest version (2.0.4, released on August 28, 2007) include (1) a new look and feel for improved operability, (2) the incorporation of satellite and ortho-images from the Geographic Information Network of Alaska (GINA), (3) the addition of tooltips, (4) user input of radius length for the "Query by Radius" tool, and (5) a core mapping software upgrade to MapInfo MapXtreme 4.8.1.

Status plats are maintained by the SGU, while DNR case file data are maintained by other DNR staff. It is important to note that since the Alaska Mapper is a representation of LAS, it's only as current and complete as the records maintained in LAS. For features that are related to LAS, the case file type and file number are displayed as feature attributes in the application. When the LAS case report submit action button is clicked, the attributes are forwarded to another 
web application that displays that case's complete case abstract. The advent of the Alaska Mapper, however, does not change the fact that land ownership issues are complicated and require training and experience to understand. It can only help the user answer the question, "Who owns the land?" In addition to status plats and land record information, Alaska Mapper is also capable of displaying geospatial information related to biology, Alaska culture, environmental observations, geology and geophysics, natural resources, physical features, transportation, and state infrastructure. Predefined mashups, or common groups of layers from multiple sources providing an integrated experience, have been generated by the LRIS team, such as Mineral Estate and Land Ownership maps (Table 1). The mashups are defined on the application's entry page and the user can choose a mashup from a simple drop-down list or by clicking on the mashup's name. These mashups are extremely useful for less savvy users, and for those users who want to find information quickly but may not have the time to browse through and select multiple layers to answer a common question about the data.

The Alaska Mapper login page presents users with two login account types. The public account may be used by anyone who wants to view or create maps, but does not need to save a map. Registered user accounts are currently only available to State of Alaska employees. These accounts do not provide access to additional layers; they only allow a user to save maps (including public maps) to a database that can be recalled later. Alaska DNR is considering a policy that will permit non-state employees to have registered user accounts.

Like other popular geobrowsers, users can query the layer data in Alaska Mapper using a number of familiar techniques. A query is based on a user-specified boundary, which can be a point, rectangle, radius, or even a geographic feature itself. After a query is performed, the total number of features (from each "active" layer) is displayed in the program's
"Status Area." A new browser window opens to display the attributes of the features selected in the query, which are grouped by layer.

One useful feature of Alaska Mapper is the option to download an entire layer or a selection of features within a layer or layers to ESRI's shape file format. If the selected dataset contains multiple feature types (e.g., points, lines, or polygons), a shape file is present for each type. After the user initiates a download request, an email is sent to the address specified. The email contains a link to a compressed file containing all the files, including metadata, that make up the requested dataset.

\section{CROSSING THE $180^{\circ}$ GREAT CIRCLE}

The issue of cartography will certainly arise as geobrowsers provide more complex information in the spatial, semantic, and temporal dimensions (Scharl and Tochtermann, 2007). Alaska's size $\left(1,477,277 \mathrm{~km}^{2}\right)$ and $54,720 \mathrm{~km}$ of tidal shoreline, spanning $130^{\circ} \mathrm{W}$ longitude, across the $180^{\circ}$ great circle (meridian) to $172^{\circ} \mathrm{E}$ longitude, often creates cartographic hurdles for map makers, GIS managers and geospatial data web-portals and complicates standard queries using polygon boundaries. The sheer number of small islands, streams, rivers and lakes as well as the intricate shorelines of Southeast Alaska and the Aleutian Islands make data managers pause, as they contemplate zoom levels and cartographic decisions involving the display of base map information, data attributes and physical features.

The advent of seemingly unlimited mashups integrates datasets that were once viewed as unrelated. However, data managers now have to deal with the organization and display of hundreds of "stackable" layers, points, lines and

Table 1. Alaska Mapper's predefined mashups.

\begin{tabular}{|c|c|}
\hline Map Name & Purpose \\
\hline Ownership Map & $\begin{array}{l}\text { This map displays current state land ownership and the availability of those lands for use under specific rules } \\
\text { and regulations of the State of Alaska. }\end{array}$ \\
\hline Surface Classification Map & This map displays how state land may be used as a result of an area plan or site specific classification. \\
\hline Land Estate Map & $\begin{array}{l}\text { This is a surface-use map that displays DNR authorizations or disposal of state uplands and tidelands to third } \\
\text { party interests, such as individuals, businesses, municipalities, boroughs, or other state agencies. }\end{array}$ \\
\hline Mineral Estate Map & $\begin{array}{l}\text { This is a subsurface-use map that displays current oil and gas, mining, and other subsurface resource uses on } \\
\text { state uplands and tidelands. This map describes state lands as open or closed to mineral entry. }\end{array}$ \\
\hline Water Estate Map & $\begin{array}{l}\text { This map displays the statewide location for water rights, water authorizations, reservations, and water manage- } \\
\text { ment areas for surface and subsurface water sources. }\end{array}$ \\
\hline Base Map & $\begin{array}{l}\text { This map contains just the basic layers that are common to the above-mentioned maps. Common layers would } \\
\text { include hydrography, township and section grids, state outlines, roads, pipelines, etc. It is a good map to start } \\
\text { with when designing your own map. }\end{array}$ \\
\hline
\end{tabular}


polygons, all within the 1280x1024-pixel viewport of a web browser. Making the situation more complex still is the possibility that the data has a temporal dimension rather than simply a temporal attribute, such as showing the diffusion of volcanic ash particles or the duration of an earthquake swarm (Johnson, 2004). Publication of maps in digital format has forced GIS experts and cartographers to also become knowledgeable in web semantics, design, Cascading Style Sheets (CSS), and programming and database components such as Ajax (Asynchronous JavaScript and XML), MySQL and PHP (Kraak and Brown, 2001; Mitchell, 2005). Utilizing these recent combinations of components has allowed groups like the Alaska LRIS to solve complex spatial problems and provide the general public with the ability to easily interact with searchable data.

\section{PUTTING YOUR FINGER ON A SPINNING GLOBE}

It is safe to say that geobrowsers are here to stay, as the effect of geobrowsers, virtual spaces, and interacting with actual data heightens our learning experiences (Roush, 2005). As computers become the media and information centers of our homes, users will continue to expect more from the Internet, both in content and ease of use. Combining technologies, programming platforms and technical skills, such as GIS, database and web design, cartography and GPS, have proven advantages in distributing and displaying spatial data to any interested user. Moreover, the utilization of opensource software and protocols in this process promotes innovation and does not restrict data flow via proprietary formats (Shapiro and Varian, 1999). The Alaska DNR, for example, is also working with, but has not yet implemented, another means of distributing the data through open-source protocols such as Web Map Service (http://www.opengeospatial. org/standards/wms) and Web Feature Service (http://www. opengeospatial.org/standards/wfs), implemented by the OpenGIS Consortium. This would allow efficient distribution of the data and leave the choice of client to the user for viewing the data (e.g. Google Earth, Alaska Mapper, or ESRI Desktop).

The next major step for Alaska is being taken by the Statewide Digital Mapping Initiative (SDMI, http://www. alaskamapped.org). Because the State of Alaska does not have an adequate digital base map, the Alaska SDMI will ultimately provide an accurate, current, seamless, single source, statewide base map to be available over the Internet, through open standards, free of charge. This is a cooperative state program endorsed by the Governor and implemented by the Department of Natural Resources, Department of Military and Veteran's Affairs and the University of Alaska. The Alaska LRIS will play a major role in this initiative and, as a result, end users will have access to new and more accurate map data via Alaska Mapper.

\section{REFERENCES}

Browne, C.L., Freeman, L.K., and Graham, G.R.C., 2003, The Alaska Division of Geological \& Geophysical Survey's Metadata Policy Development and Implementation, in Soller, D.R., ed., Digital Mapping Techniques 2003 Workshop Proceedings: U.S. Geological Survey Open-File Report 03-471, p. 201-208, available at http://pubs.usgs. gov/of/2003/of03-471/browne/index.html.

Delboni, T.M., Borges, K.A.V., and Laender, A.H.F., 2005, Geographic Web Search Based on Positioning Expressions: 2nd International Workshop on Geographic Information Retrieval (GIR-2005), Bremen, Germany, p. 61-64.

Johnson, Ian, 2004, Putting Time on the Map: Using TimeMap for Map Animation and Web Delivery: GeoInformatics, v. 7, no. 5, p. 26-29, available at http://www.timemap.net/tm/ documents/publications/200408_geoinformatics.pdf.

Kendall, J.E., 2005, Satellite Mapping and its Potential in Ecommerce: Why We Need Directions to Follow Our New Maps: Decision Line, v. 36, no. 5, p. 11-14.

Kraak, Menno-Jan, and Brown, Allan, eds., 2001, Web Cartography: Developments and Prospects: London, Taylor \& Francis, Inc., 224 p.

McCurley, K.S., 2001, Geospatial Mapping and Navigation of the Web, in Proceedings of the Tenth International World Wide Web Conference (WWW-2001): ACM Press, Hong Kong, May 1-5, 2001, p. 221-229, available at http:// www10.org/cdrom/start.htm.

Mitchell, Tyler, 2005, Web Mapping Illustrated: Sebastopol, CA, O’Reilly Media, Inc., 367 p.

Neches, Robert, Yao, Ke-Thia, Ko, In-Young, Bugacov, Alejandro, Kumar, Vished, and Eleish, Ragy, 2001, GeoWorlds: Integrating GIS and Digital Libraries for Situation Understanding and Management: New Review of Hypermedia and Multimedia, v. 7, p. 127-152.

Roush, Wade, 2005, Killer Maps: Technology Review, v. 108, no. 10, p. 54-60, available at http://www.technologyreview. com/communications $/ 14825 / ? a=f$.

Scharl, Arno, 2004, Web Coverage of Renewable Energy, Chap. 4, in Scharl, Arno, ed., Environmental Online Communication: London, Springer, p. 25-34.

Scharl, Arno, and Tochtermann, Klaus, eds., 2007, The Geospatial Web: How Geobrowsers, Social Software and the Web 2.0 are Shaping the Network Society: London, Springer, $282 \mathrm{p}$.

Shapiro, Carl, and Varian, H.R., 1999, The Art of Standards War: California Management Review, v. 41, no. 2, p. 8-32. 



\title{
Seamless Digital Geological Map of Japan 1:200,000, and its Application
}

\author{
By Toshie Igawa, Koji Wakita, and Shinji Takarada \\ Geological Survey of Japan, AIST \\ Centeral 7, 1-1-1 Higashi, \\ Tsukuba, Ibaraki \\ 305-8567 Japan \\ Telephone: +81-29-861-3663 \\ Fax: +81-29-861-3742 \\ email: toshi-igawa@aist.go.jp,koji-wakita@aist.go.jp, s-takarada@aist.go.jp
}

\section{INTRODUCTION}

Geological Survey of Japan, AIST (GSJ/AIST) has compiled geological quadrangle maps of Japan at 1:200,000-scale since the 1950's. However, as differences in year of compilation and progress in geological science have resulted in changes in interpretations, there was much discordance regarding classification of stratum or geological period in neighboring quadrangles, as well as misalignments in geological features such as contacts. The Seamless Digital Geological Map of Japan 1:200,000 (Figure 1) was compiled as a solution to this problem, to serve as a more comprehensible and accessible geological map.

This mapping project started in 2002 and will be finished in 2011. This map is the first geological map at the scale of 1:200,000 covering the whole country with the universal national legend.

\section{SEAMLESS GEOLOGICAL MAP}

The seamless geological map is based on the 1:200,000scale quadrangle geological sheet maps published by GSJ/ AIST, and also uses the engineering geological map and other geological maps published by the local governments. The universal national legend (Figure 2) for this seamless geological map is classified based on the rock types and ages. This legend is a refinement of the legend for the Geological Map of Japan at 1:1,000,000-scale (Geological Survey of Japan/AIST, 2003).

The process to produce the seamless geological map is as follows (Figure 3). 1. Geological maps are digitized into vector format. 2. Each geological attribute of the map is correlated to its closest equivalent in the universal national legend. 3. Discontinuous geological boundaries between neighboring maps are harmonized with each other in the Geographic Information System (GIS). If we are obliged to use outdated geological source maps for the seamless geological map, the newest interpretation and geologic attributes are used with these maps. Thus the seamless geological map may include the newest geological information.

\section{APPLICATION}

The seamless geological map is released on the AIST website (http://riodb02.ibase.aist.go.jp/db084/) as Research Information Database (RIO-DB). At this site, the public can view the seamless geological map with continuous zoom, and can download raster images of the map. This map on the web is shown with a shaded DEM and road map based on data from the Geographical Survey Institute, in order to more clearly indicate the location of the mapped area.

The map is simply drawn with the universal national legend, so it is easier for people without special knowledge of geology to understand the information on the map. In addition, people can change the scale of this digital map quickly, and clip any parts of the map wherever they like. The map is intended to be used for many purposes, especially in education and popularization of geology, and in interdisciplinary studies of earthquakes and geochemistry.

The seamless geological map will be updated frequently to provide the newest geoinformation. This map has been accessed 600,000 times in one year of 2006 on the internet. We aim to improve the quality of the map for society. 


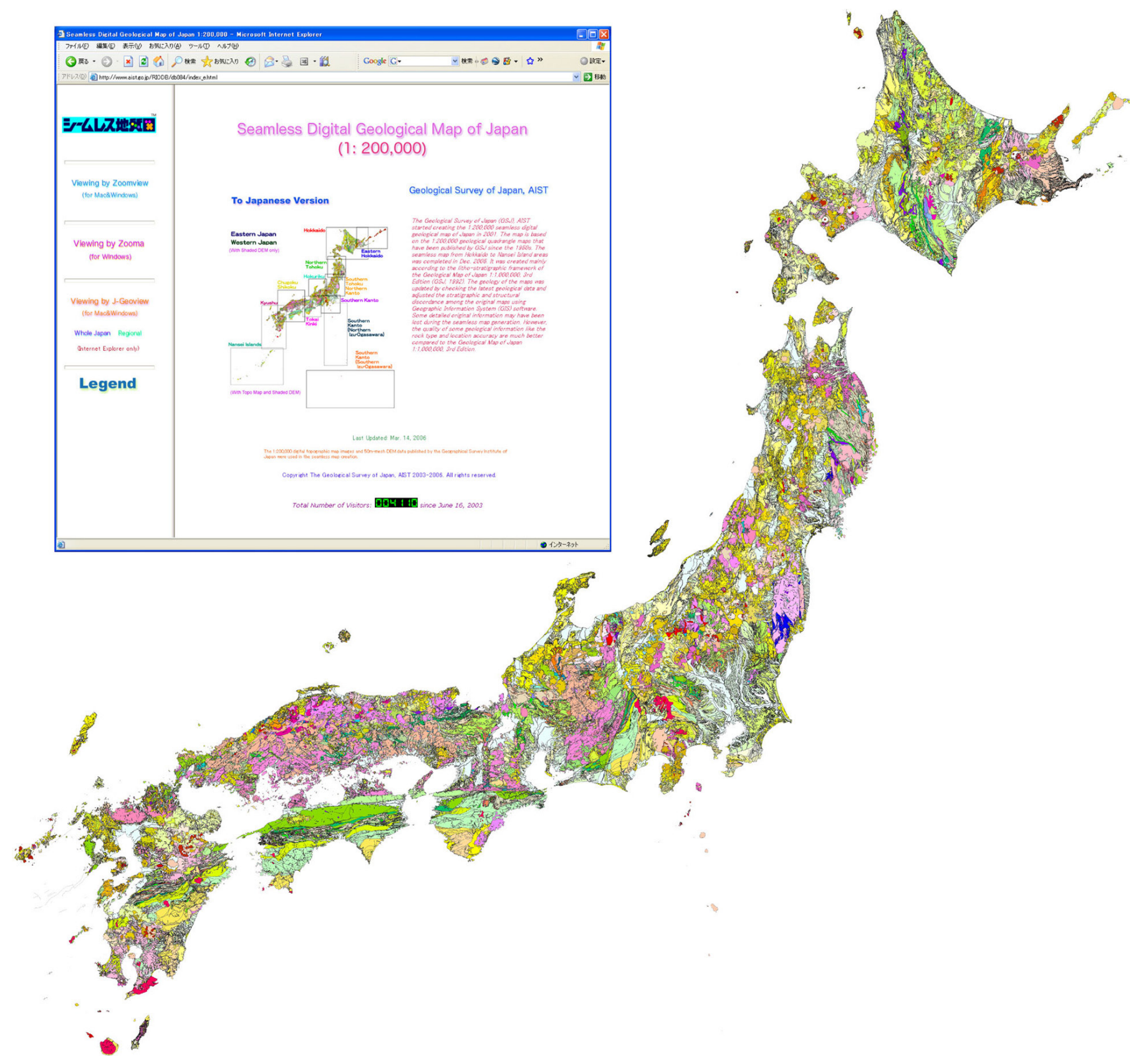

Figure 1. Seamless Digital Geological Map of Japan 1:200,000 and its website (http://riodb02.ibase.aist.go.jp/db084). 


\section{Universal National Legend}

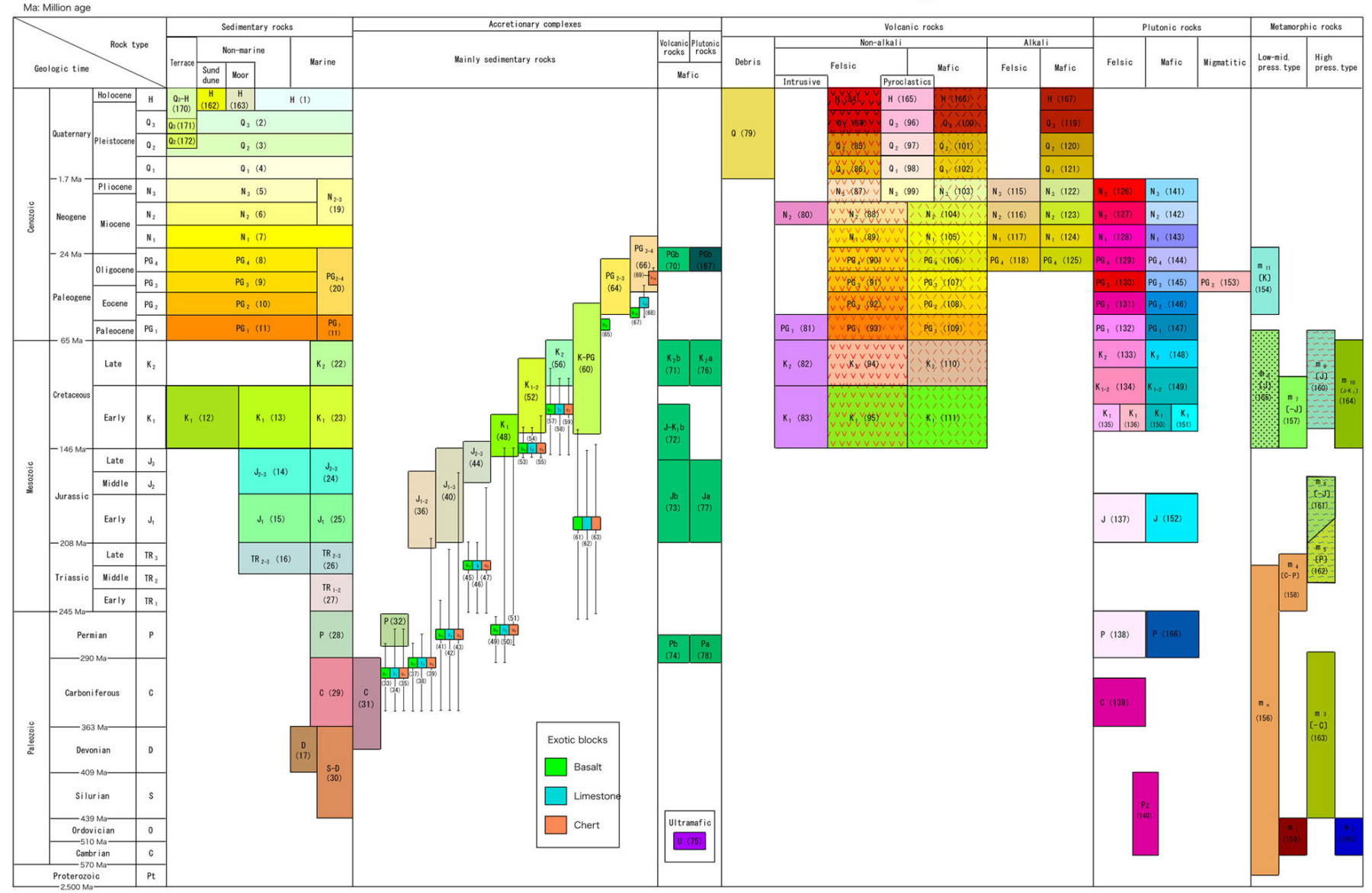

Figure 2. Universal national legend.

\section{Quadrangle of original geological maps}

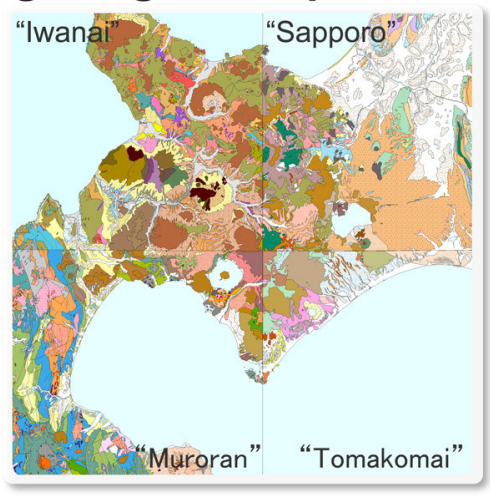

\section{Legend standardization}

\section{Conversion to} seamless maps

Geological border alignment

Figure 3. Process to produce the seamless geological map.

\section{REFERENCE}

Geological Survey of Japan/AIST, 2003, Geological Map of Japan 1:1,000,000, 3rd Edition, 2nd CD-ROM Version. 



\title{
Integrated Geological Map Database and Geological Information Index
}

\author{
By Koji Wakita, Shinji Takarada, and Yasuaki Murata \\ Geological Survey of Japan, AIST \\ Tsukuba Center No. 7 \\ 1-1-1 Higashi Tsukuba \\ Ibaraki, 305-8567 Japan \\ Telephone: +81 (29) 861-2469 \\ Fax: +81(29) 861-3742 \\ email: koji-wakita@aist.go.jp
}

\section{INTRODUCTION TO GeoMapDB AND G-Index IN JAPAN}

Geological Survey of Japan (GSJ), a branch of the National Institute of Advanced Industrial Science and Technology (AIST), recently began offering geologic information in digital format to the general public through the internet and CD-ROM. To provide easy access to the data, GSJ has been developing a digital geologic database and geologic information index. GSJ completed the construction of the database and the index system in 2006, and it was opened to the general public soon thereafter. This paper describes the database and the index system.

\section{INTEGRATED GEOLOGICAL MAP DATABASE (GeoMapDB)}

Geological Survey of Japan, AIST recently developed the Integrated Geological Map Database, called GeoMapDB. The database was launched online on September 29, 2006. The URL is http://iggis 1.muse.aist.go.jp/en/top.htm. The design of this database aims to make many kinds of geological maps published by GSJ easily accessible to the general public.

GeoMapDB database is based on WebGIS (ArcIMS) technology, and will include most of the geological maps and related geoinformation produced and compiled by the Geological Survey of Japan (Figure 1). However, it is presently still in the initial stages of development. The current contents of the database include the geologic maps of
Japan at 1:2,000,000, 1:1,000,000, 1:200,000, 1:50,000 and $1: 25,000$ scales.

At the GeoMapDB home page, you view the entire map of Japan and select the area you want to view. The system then zooms into your selected area and displays the selected geological maps of Japan,which is the essential data in the GeoMapDB database (Figure 2). From this point, you can choose the maps and data you want to view, by clicking the boxes in the right side column. For each map, you can select the degree of transparency and the presence or absence of text. If you are visiting the site for the first time, the help page is very useful. You can choose the maps by checking the visible boxes and change the transparency and the text information by checking the active boxes in the layer-control column.

Useful search tools and 3D display are also available from function buttons above the map. The processes require the user to have a VRML plug-in for viewing 3D WebGIS. You can create the Bird's-eye view using digital geologic map and digital elevation model (DEM) (Figure 3). If you download the semi-transparent geologic map data from the site, you can easily display the map in Google Earth.

\section{GEOLOGICAL INFORMATION INDEX (G-Index)}

Geological Survey of Japan, AIST has been developing a geologic information system since 2002. The system, called G-Index, was finalized and launched online in 2006. The G-Index URL is http://www.aist.go.jp/RIODB/GINDEX/ 


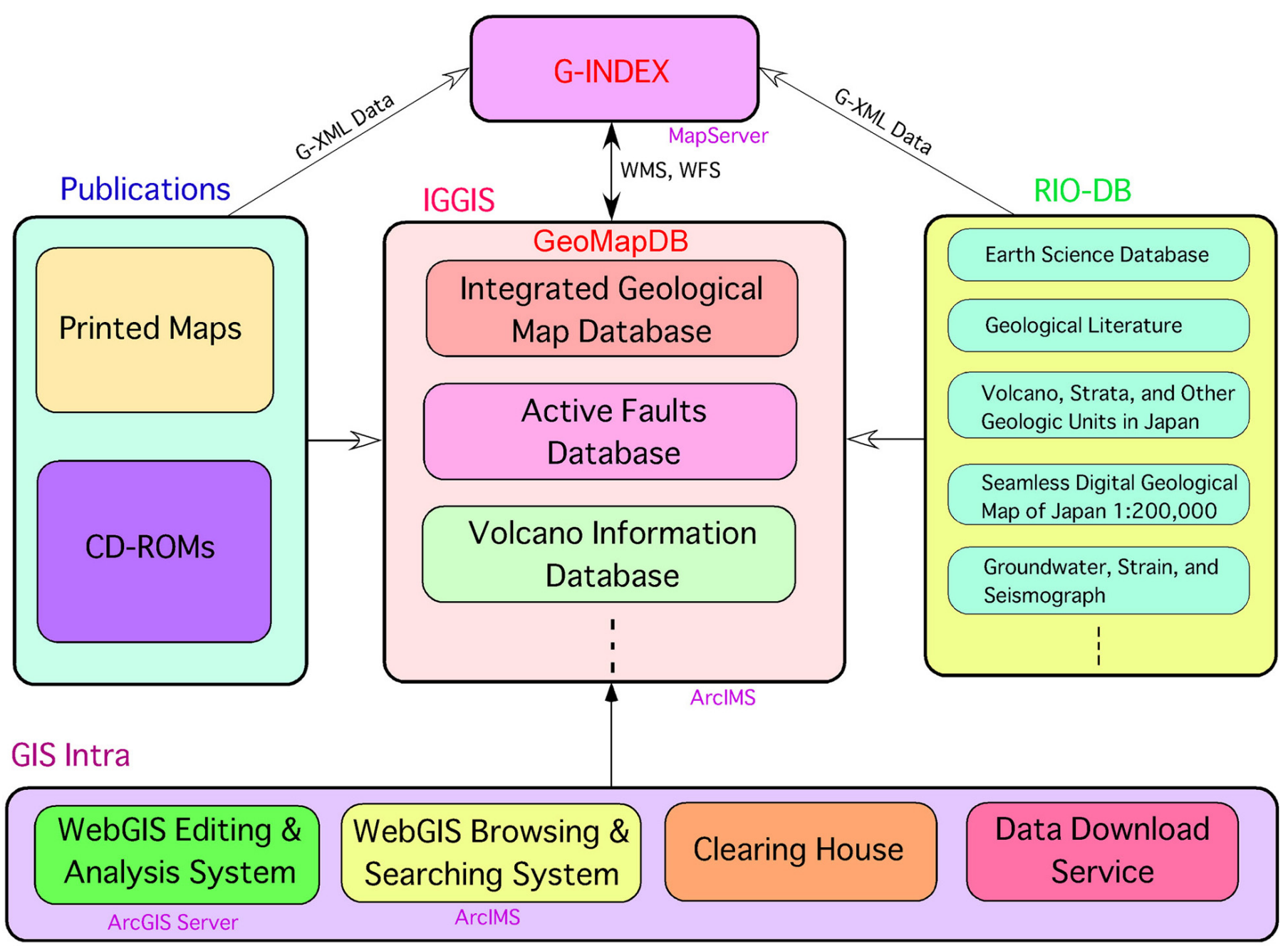

Figure 1. Overall geoinformation system of the Geological Survey of Japan, AIST. IGGIS - Platform of the GeoMapDB. GIS IntraIntra sharing server system based on Arc GIS Server. RIO-DB - Research Information Database.

GSJ_E/index.html (see Figure 4). The system combines various types of geologic information employing G-XML (Japanese Industrial Standard, JIS X 7199, http://www.jisc. go.jp/eng/) as its base and operates WebGIS.

$\mathrm{G}-\mathrm{XML}$ is a format conforming to XML to handle geographic information. G-XML is developed as a new universally applicable format using XML technique. Data such as GIS contents and digital maps described in XML would become accessible and exchangeable. G-XML will be merged with GML as a single universal format in the near future.

For the current version of G-Index, we prepared geologic maps at the scales of 1:50,000, 1:200,000, 1:1,000,000, and $2,000,000$, an environmental geologic map, marine geologic map, sedimentological map, geothermal resources map, geothermal gradient and heat flow data, and gravity map and gravity data in G-XML format. At the moment, the system is to be used to browse and view major published geologic data. However, in the near future, we intend to include data download and analysis capabilities. A dynamic linkage to other databases would also be established. We prepared several software tools to exchange data format from CSV to G-XML, G-XML to JKG, and viewer program for JKG format.

\section{SUMMARY}

Geological Survey of Japan, AIST, has just started web-based services to provide digital geologic map data and other geological information produced by the survey. We started to convert the data to fit with the international standards to distribute them all over the world. For this purpose, Geological Survey of Japan, AIST will take the OGC and CGI activities into account for the interoperability of geoinformation. 


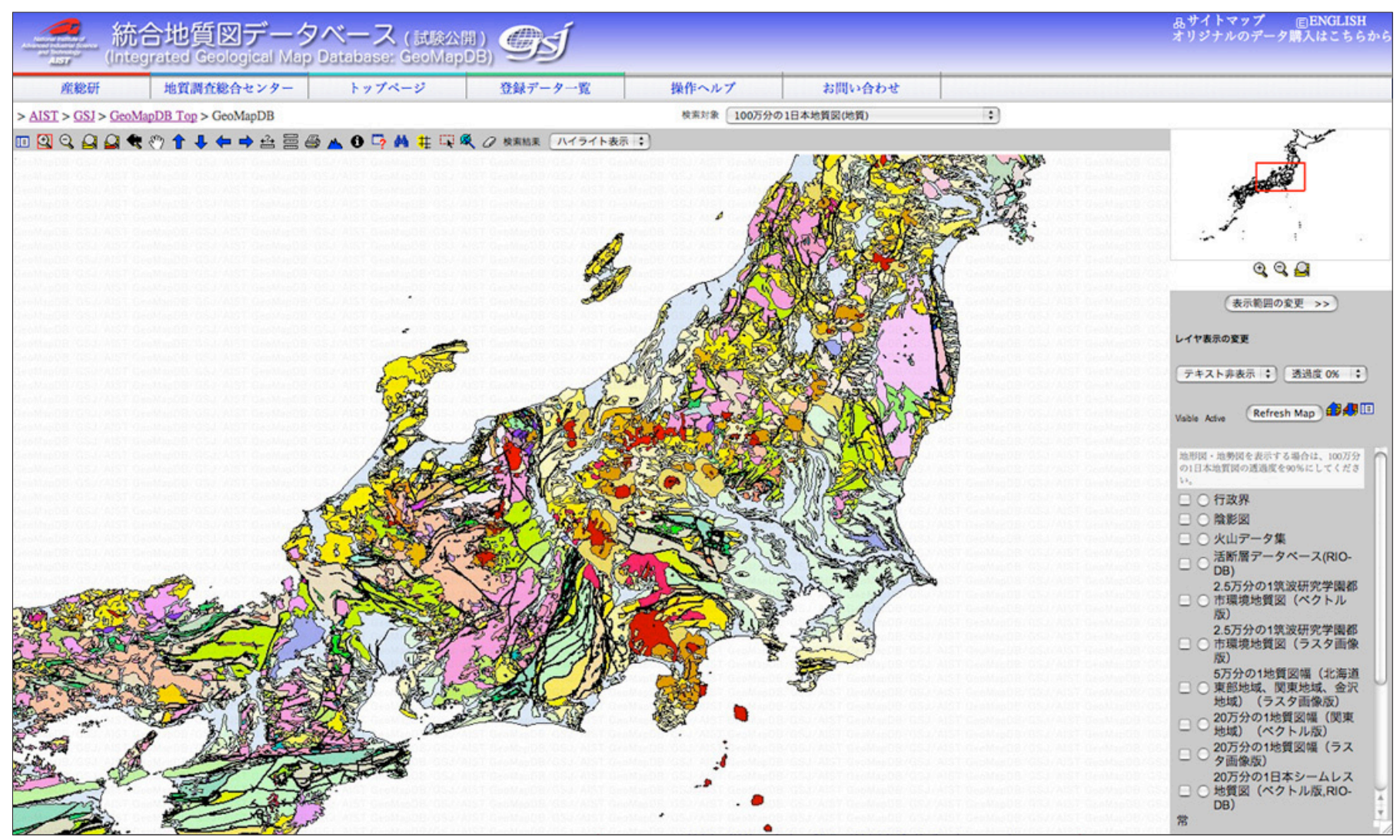

Figure 2. Example of the geological map view of GeoMapDB.

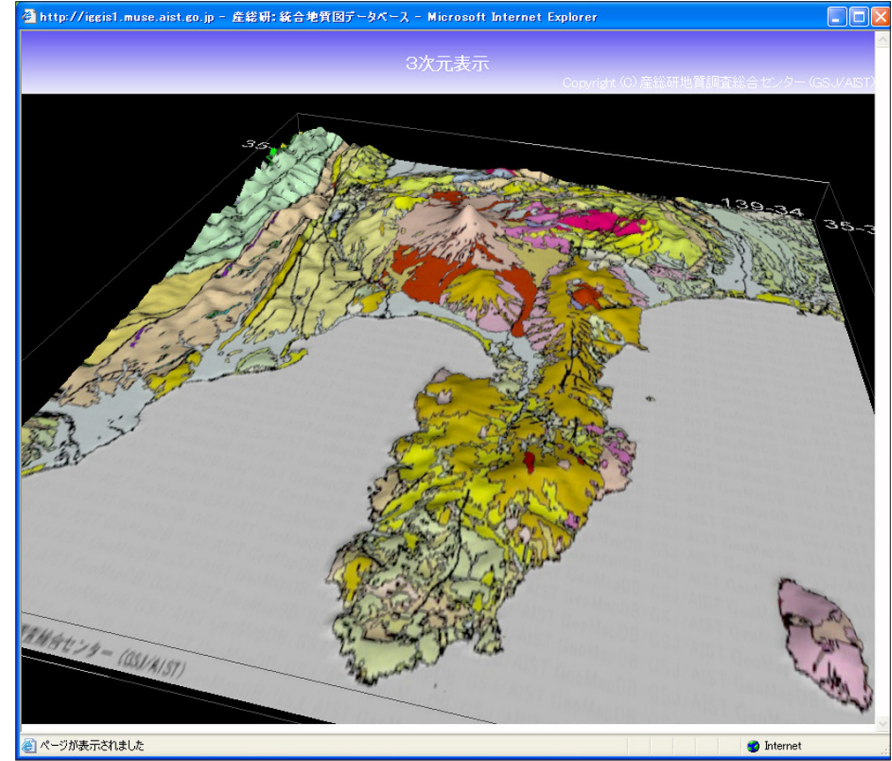

Figure 3. Bird's-eye view of Izu Peninsula using digital geologic map and DEM of GeoMapDB.

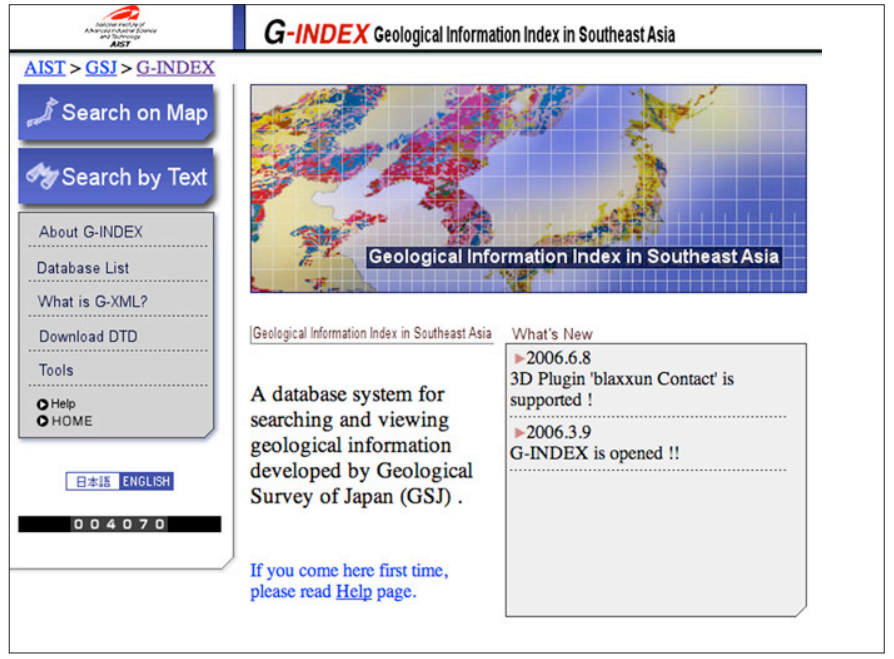

Figure 4. Top page of the G-Index. 



\title{
Developing a Web Site to Provide Geologic Data and Map Products for Allen County, Indiana
}

\author{
By Robin F. Rupp, Jennifer Olejnik, Nancy R. Hasenmueller, Marni D. Karaffa, \\ A. Chris Walls, Prem Radhakrishnan, and Nathan K. Eaton \\ Indiana Geological Survey \\ Indiana University \\ 611 North Walnut Grove \\ Bloomington, IN 47405 \\ Telephone: (812) 855-7636 \\ Fax: (812) 855-2862 \\ email: rrupp@indiana.edu
}

\section{INTRODUCTION}

For more than a century, Indiana geologists have published their analyses and interpretations of geologic data in the form of static, printed maps. Such maps are useful, providing concise interpretations and fine cartographic detail in a compact, portable format. Recently, however, with the new technologies of digital maps and the Internet, geologists are able to present more information in the form of dynamic, versatile Web-based products to a variety of users, from those in government and industry to the general public. The Indiana Geological Survey (IGS) is currently using technologies such as Environmental Systems Research Institute Internet Map Server (ArcIMSC) and Spatial Data Engine (ArcSDEC), and Adobe ${ }^{\circledR}$ ColdFusion ${ }^{\circledR}$ to create a Web-based geologic data and map site for Allen County, Indiana, http://igs.indiana.edu/ AllenCoIndiana.

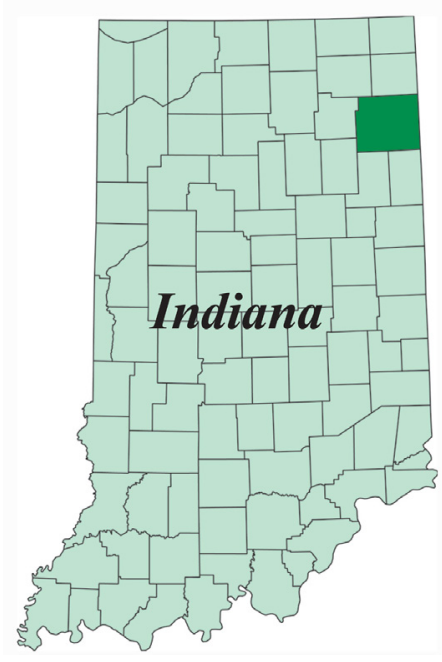
Figure 1. Allen County is located in northeastern Indiana. Fort Wayne, the county seat, is the secondlargest city in the state.
Allen County, located in northeastern Indiana (Figure 1), has an estimated 2005 population of 344,006 (U.S. Census Bureau, 2007), which includes the population of Indiana's second largest city, Fort Wayne. Interstates 69 and 469 are the dominant transportation corridors and connect the county to the rest of Indiana, as well as to Michigan. The high population density and major transportation corridors in the county make it a priority area for the IGS's mapping and outreach programs. The Allen County Web site will disseminate both interpreted maps and primary geologic information for a region whose societal and economic needs exert increasing pressure on natural resources.

\section{INTERPRETED GEOLOGY AND PRIMARY DATA}

The Allen County Web site provides written discussions, maps, images, and databases of geologic information and includes an Internet Map Server (IMS) (Figure 2). The IMS site provides a front-end to the IGS enterprise geodatabase, which contains information used simultaneously for research and general viewing. The ArcSDE geodatabase allows for the efficient creation, management, and distribution of data and maps.

Within the Allen county Web site, the IMS includes regional base map layers such as digital elevation model (DEM) terrain and high-resolution aerial photos from Indiana's 2005 Orthophotography Project. Landsat satellite imagery from the U.S. Geological Survey is also included. Additionally, the site provides interpreted maps from the IGS including surficial geology, drift thickness, bedrock topography, bedrock geology, and water-table elevation (from 


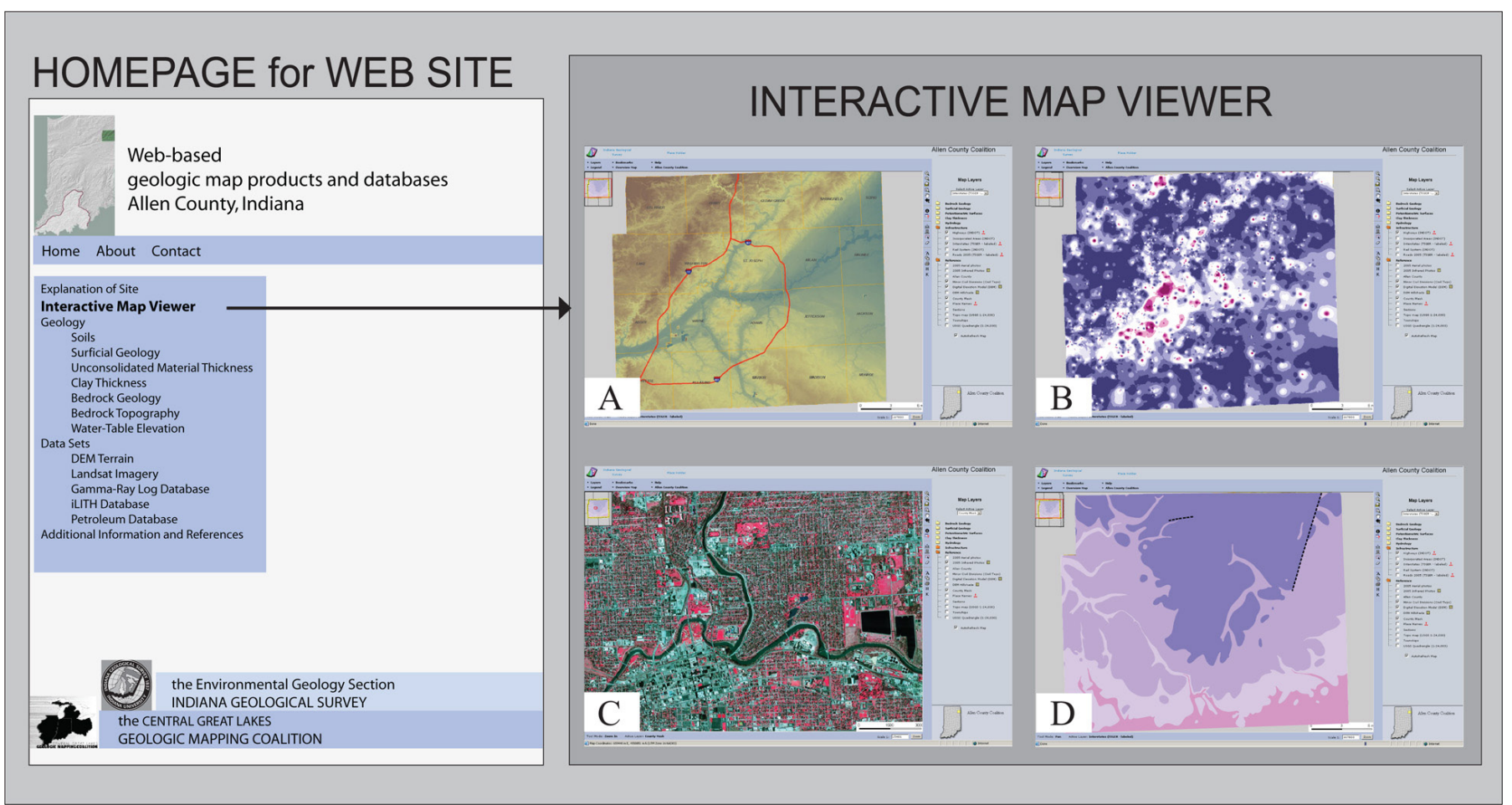

Figure 2. The Allen County Web site (to left) and some images from the Interactive Web Viewer. A. Digital elevation model of the land surface of Allen County. B. Clay thickness of the upper 50 feet of unconsolidated sediments throughout the county. C. Landsat 7 imagery of the Fort Wayne area. D. Map of the bedrock within Allen County, which is buried beneath varying thicknesses of unconsolidated sediments.

Fleming, 1994), and a clay thickness (0 to $50 \mathrm{ft}$ ) map generated from the IGS-standardized lithologic water-well data. Primary data provided at this site consists of: (1) the natural gamma-ray geophysical log data collected by the IGS; (2) the iLITH database (Brown and others, 2000), which contains IGS-standardized lithologic information from water-well records of the Indiana Department of Natural Resources, Division of Water; and (3) the stratigraphic test hole and petroleum-well records from the IGS Petroleum Database Management System (PDMS) (Indiana Geological Survey, 2007a) (Figure 3).

\section{DATABASE INTEGRATION}

The Allen County Internet Map Server is a GIS data portal that gives the user the capability to visually inspect and analyze the spatial data associated with the available geologic data sets. It also provides access to the attribute data. However, many types of information, such as well production histories or gamma-ray log data, cannot be stored efficiently in an attribute table associated with spatial features. A large amount of information can be associated with a single record and often this data can be more efficiently stored in a relational database containing multiple tables. Primary information can be attached as attributes of the record in the spatial data set, and additional information can be provided to users through links to an external relational database.

\section{ColdFusion}

ColdFusion $\AA$ is a software package that can be used to query data from relational databases and display this information to the user via a Web browser (Figure 4). In this way, ColdFusion is similar to the ArcIMS(C) technology that is used to query and display spatial data. In the case of the Allen County Web site, ColdFusion is used to query the iLITH database, which contains the standardized water-well information. While the water well GIS data set contains the spatial location data, a Microsoft ${ }^{\circledR}$ Access $\AA$ database contains more detailed information about the well location and other useful information, including lithology. The ArcIMS viewer displays the primary geographic data from the GIS data set by simply identifying a well, while ColdFusion uses a unique common identifier (well number) to query the Access database to retrieve all the information about that particular well and display it in a report format. This allows the user to access and display all the available information, whether it is contained in the spatial data set or an external database.

The PDMS provides a second example of using ColdFusion to link to an external relational database. The PDMS is an IGS Web application designed to distribute 

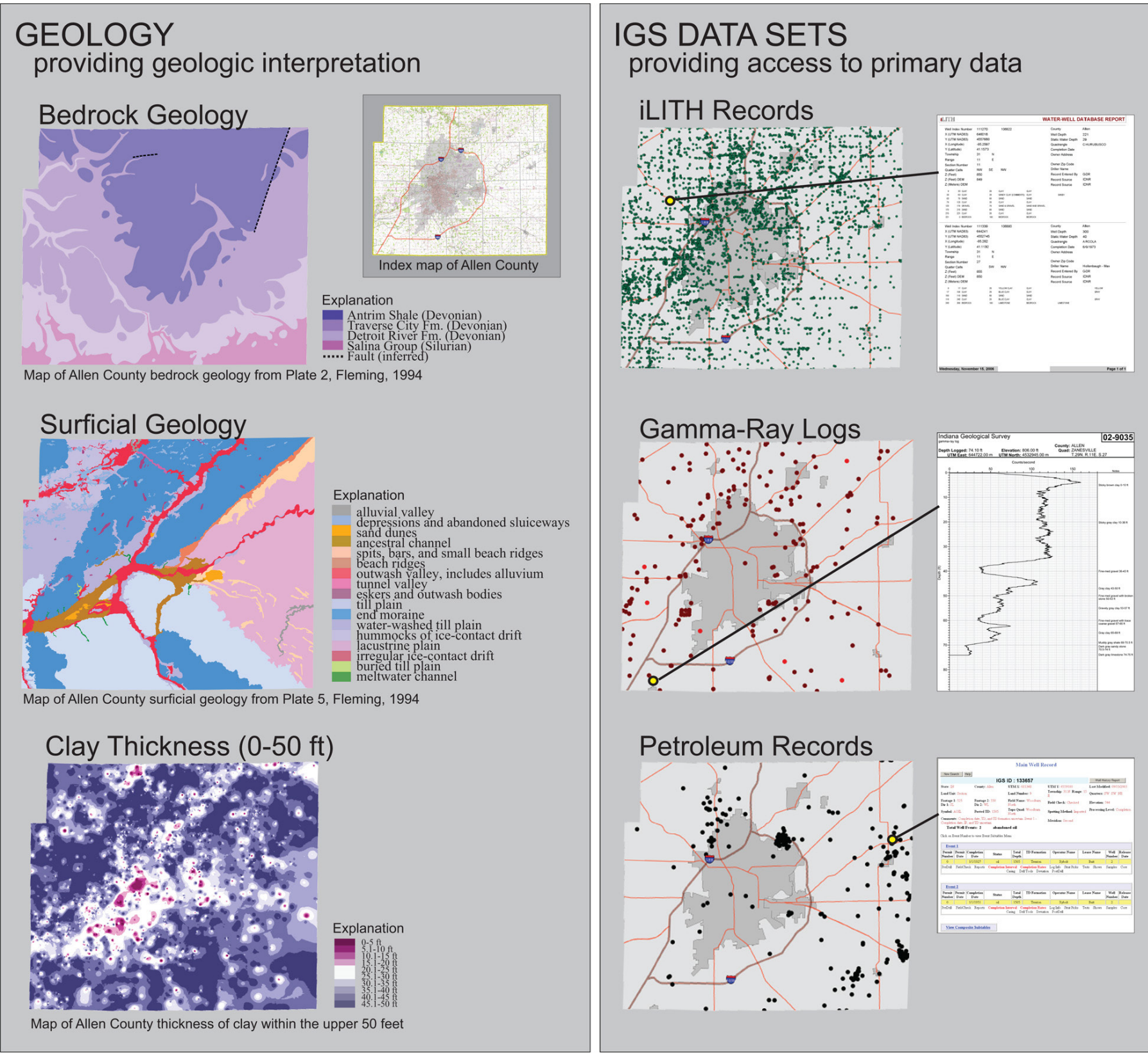

Figure 3. The Interactive Web Viewer provides geologic maps of the Allen County area as well as links to the gamma-ray log, waterwell, and petroleum data used to make these maps. The combination of primary data and interpreted maps allows users to make their own interpretations.

petroleum-related information. The PDMS database contains extensive information on more than 70,000 petroleum-related wells drilled in Indiana and several adjacent states. The Allen County IMS site uses a ColdFusion link from the petroleum well layer to connect directly to the existing PDMS database and display detailed records for more than 200 oil and gas wells in the county.

\section{GammaPlot}

Gamma-ray logs provide users with the primary data from which to make their own geologic interpretations
(Bleuer, 2004). The Allen County Web site allows users to view and download more than 200 records of gamma-ray data in Portable Document Format (PDF) and Long ASCII Standard (LAS) format.

The PDF files provide a visual representation of numeric gamma-ray data collected digitally in the field and stored as tab-delimited text files. Gamma-log curves are plotted using an IGS-created program, Gammaplot. The program uses tabbed spreadsheets to graph the numeric data and retrieve header information from the Gamma-Log Database, an internal IGS relational database that stores location and description information. The tabbed spreadsheets are also used to modify 


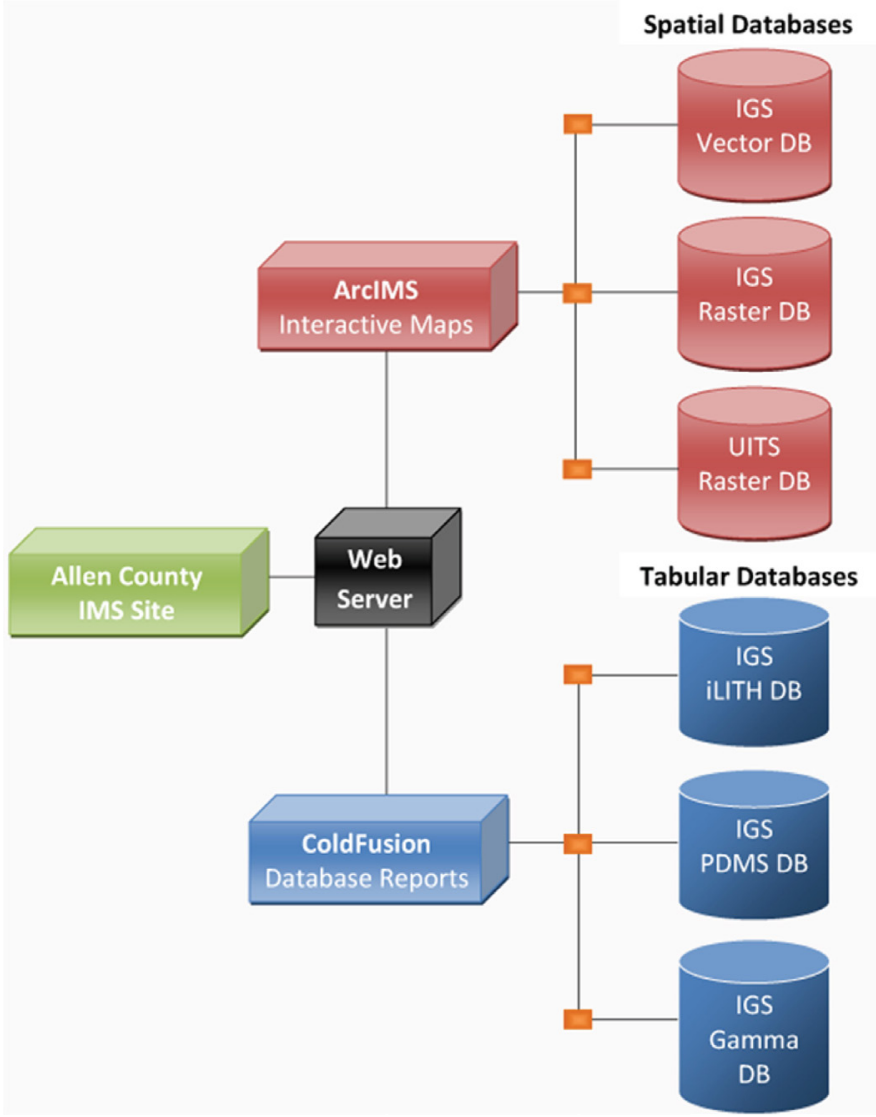

Figure 4. System diagram showing the relationship between spatial and tabular databases that support the Allen County IMS site. ArcIMS provides maps and associated attribute information, while ColdFusion presents tabular reports from related databa

the appearance of the gamma-ray log graph. Once plotted, the gamma-ray logs are printed to a PDF file.

In addition to PDF format, the numeric gamma-ray data can be downloaded as an LAS file, a standard format used primarily in the petroleum industry for plotting geophysical logs, http://www.cwls.org/docs/LAS20_Standards.txt. A custom application was developed by IGS staff to extract header information from the Gamma-Log Database, merge it with the numeric data, and convert it to a comma-delimited LAS file.

The PDF and LAS files can be accessed by identifying a gamma-ray log point in the IMS viewer using the information tool. The unique gamma-ray log number appears with the spatial attribute data and provides a link to the downloadable file.

\section{ARCIMS Application}

The tabular, nonspatial databases and the digital maps on the Allen County Web site are integrated using a single ArcIMS application (Figure 4). The IMS site accesses a variety of geographic and geologic information stored within the larger IGS enterprise geodatabase. This enterprise geodatabase provides most of the GIS layers for the IGS mapping sites, including A GIS Atlas for Indiana (Indiana Geological Survey, 2007b), which serves as a template for the Allen County Web site.

All the capabilities of the GIS Atlas for Indiana are retained in the Allen County IMS by simply placing a county mask over the statewide data, thereby displaying only specific information for Allen County. The statewide data is behind the mask, but does not interfere with the efficiency of the site. The link between the Allen County IMS and the larger IGS enterprise geodatabase allows the Allen County site to stay current because any routine updates made to the GIS Atlas site and databases will be immediately available to the Allen County site.

The GIS Atlas for Indiana started with an out-of-the-box ArcIMS HTML viewer more than 6 years ago and has since been customized by IGS staff to allow for more versatility. Improvements and additions to the ArcIMS viewer are made regularly in order to maintain a robust, user-friendly site. The customization includes making many of the standard tools and menu items easier to use. Some of the customized features available on the GIS Atlas site and the Allen County IMS site include: draw tools, bookmarks, hyperlinks, custom legends, and map output options.

The draw menu contains tools that enable users to add custom text and geometric shapes to the map view for labeling and analysis of specific cross sections or areas of interest. The text tool adds points to the map and associates text or coordinates with that point (Figure 5). Lines, polygons, and circles can be drawn on-screen with predefined measurements or simply by pointing and clicking on the map (Figure 6). These are graphics that may represent areas or locations of interest on the map.

The legends in the interactive viewer are customized to allow viewing of individual layer symbology in the Table of Contents (TOC) rather than having to toggle between a specific layer and the TOC (Figure 7). The layer symbology is represented by GIF images linked to the associated layer in the TOC. This customization also allows the user to choose the legend elements to be included in the final map layout.

Bookmarks and hyperlinks allow map users to create, save, and restore their own custom maps, as well as share them with colleagues. Bookmarks are saved in a Web browser and stored as cookies on the local computer. Hyperlinks are created in the map view from the Map menu and can be copied and pasted into an e-mail or other document, enabling an efficient transfer of data and ideas. Both links provide a means of "saving" a customized view of maps and data in the IMS. The links allow users to return to a custom view extent, with the predetermined layers turned on for viewing. Unfortunately, bookmarks and hyperlinks will not maintain the user-defined text or shapes shown in Figures 5 and 6. Users can, however, save their custom map, including text and shapes, as a JPG file for use in other applications such as a GIS. Once the image is saved, a dialog box appears with information to create a world file for georeferencing. This world file information can be copied to a TXT file and saved as a JGW file. 


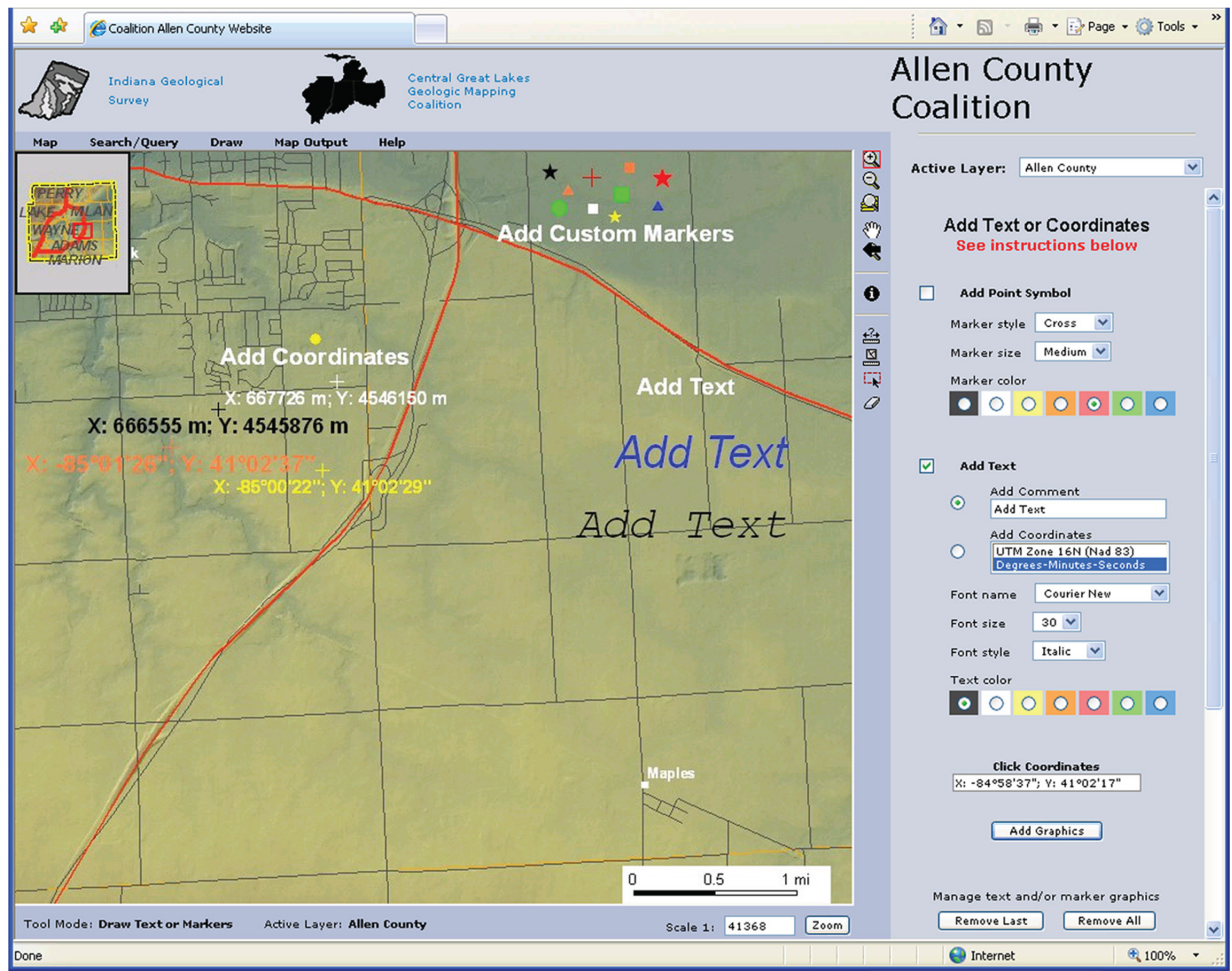

Figure 5. The custom text and marker tool allows users to select from a variety of font styles and scales, as well as points with different shapes, sizes, and colors.

The print dialog gives users additional options for map output. It allows for layouts for standard printers, as well as custom layouts for large-format plotters. Once the print dimensions are defined, the layout is automatically adjusted to fit the page. The print dialog box also gives the option of which map elements to incorporate in the layout, including title and legend elements. This feature provides users with a high degree of flexibility in presenting their data.

\section{SUMMARY}

The IGS created this Web site to provide maps, images, and databases of geologic information for Allen County, Indiana. Data included on the site are (1) digital elevation model (DEM) terrain, high-resolution aerial photos, and Landsat imagery, (2) geologic and hydrogeologic maps, and (3) primary data from geophysical log, water-well, and petroleumwell records.

Using enterprise GIS and database technologies- including an Internet Map Server, Microsoft SQL Server, and ColdFusion, the IGS is able to present data in the form of dynamic and versatile interpretive maps along with raw "primary" geologic information to an expanded group of users within Allen County, throughout the state of Indiana, and across the nation. The IMS site provides a front-end to the IGS enterprise geodatabase, which contains information used simultaneously for research and general viewing. The ArcSDE geodatabase allows for the efficient creation, management, and distribution of the data and maps. Through links to ColdFusion, the site also allows direct access to other IGS enterprise database systems containing petroleum well records, gamma-ray logs, and water well information. The combination of these spatial (geodatabase) and traditional database technologies allows users to access more information than ever before. By making 


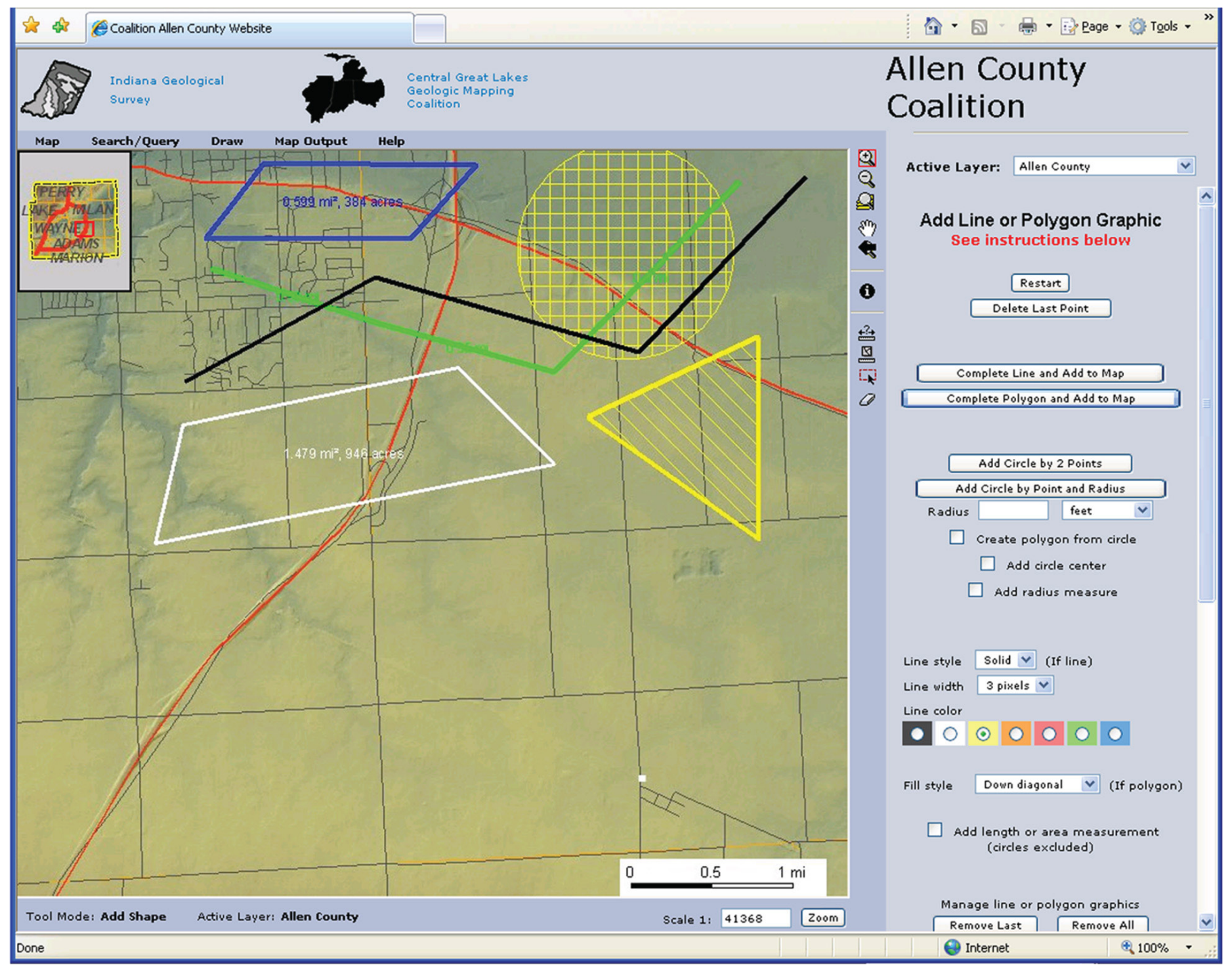

Figure 6. A variety of geometric shapes (i.e., lines and polygons) can be added to the map to define a cross

primary geologic data such as well records and gamma-ray logs widely available on the Internet, the IGS is changing its paradigm for how we distribute geologic information to the public.

The IGS was able to use an existing ArcIMS template, the GIS Atlas for Indiana IMS site, and adapt it to create the Allen County site. All the capabilities of the GIS Atlas site are retained in the Allen County IMS by placing a county mask over the statewide data, thus displaying only specific information for Allen County. The link between the Allen County IMS and the larger IGS enterprise geodatabase allows the Allen County site to always be current because updates made to the GIS Atlas site are immediately available to the county site.

The ArcIMS HTML viewer used for the GIS Atlas and Allen County IMS sites has been customized by IGS staff to make many of the standard tools and menu items more user-friendly and versatile. Some of the customized features available on IMS sites include: draw tools, bookmarks, hyperlinks, custom legends, and map output options.

\section{ACKNOWLEDGMENTS}

The development of the Allen County Web site was funded by the Indiana Geological Survey and the Central Great Lakes Geologic Mapping Coalition.

\section{REFERENCES}

Bleuer, N.K., 2004, Slow-logging subtle sequences-the gamma-ray log character of glacigenic and other unconsolidated sedimentary sequences: Indiana Geological Survey Special Report 65, 39 p. 


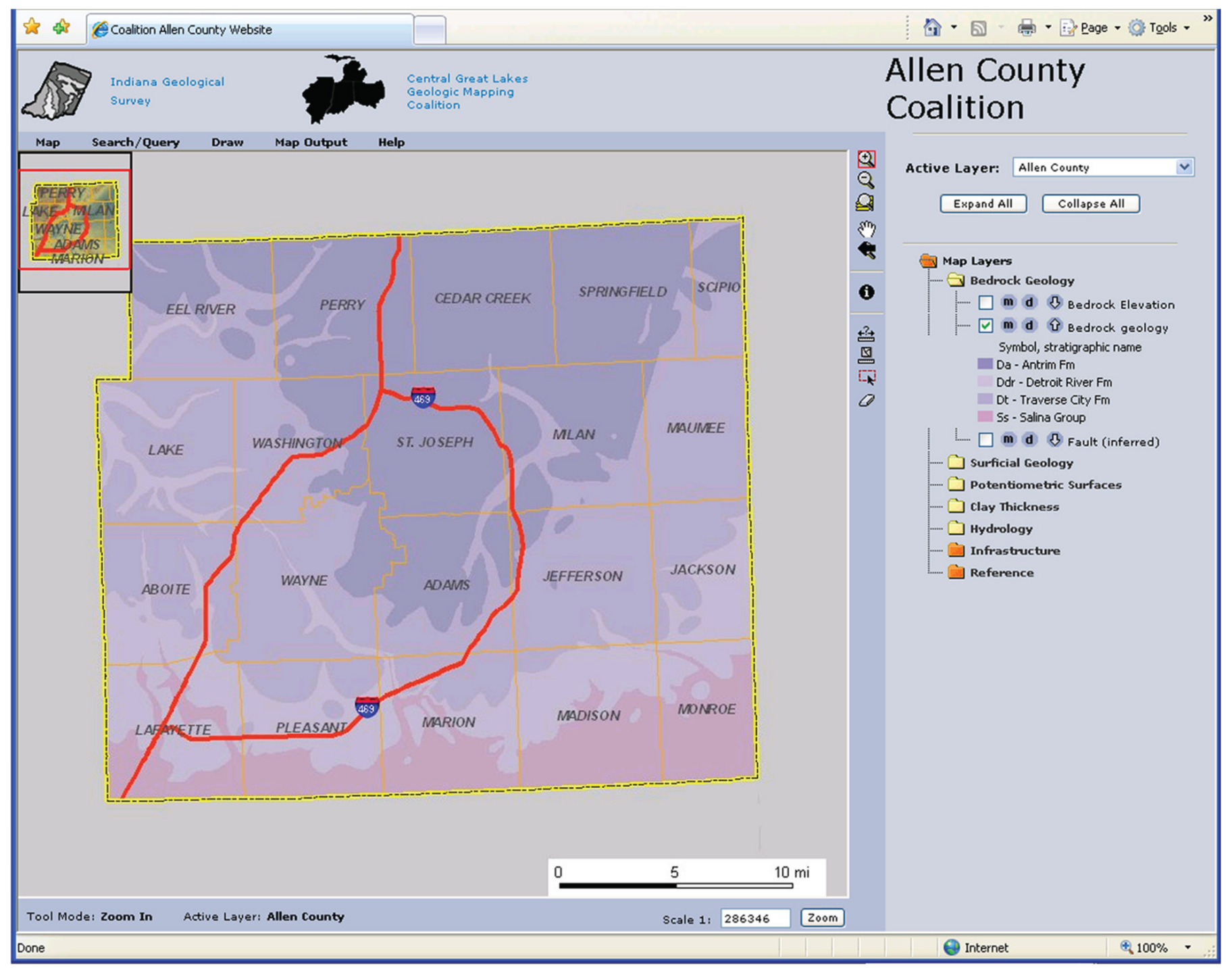

Figure 7. The custom legend in the interactive viewer allows the user to simplify viewing by activating layers from within the TOC.

Brown, S.E., Bleuer, N.K., O’Neal, M.A., Olejnik, Jennifer, and Rupp, R.F., 2000, Glacial terrain explorer: Indiana Geological Survey Open-File Study 00-08, CD-ROM.

Fleming, A.H., 1994, The hydrogeology of Allen County, Indiana - a geologic and ground-water atlas: Indiana Geological Survey Special Report 57, 111 p.

Indiana Geological Survey, 2007a, Petroleum Database Management System: Indiana Geological Survey Web site, http://igs.indiana.edu/pdms/index.cfm, accessed, May 18, 2007.

Indiana Geological Survey, 2007b, A GIS Atlas for Indiana: Indiana Geological Survey Web site, http://129.79.145.7/ arcims/statewide_mxd/index.html, accessed May 18, 2007.

U.S. Census Bureau, 2007, State \& County Quickfacts - Allen County, Indiana: U.S. Census Bureau Web page, http:// quickfacts.census.gov/qfd/states/18/18003.html, accessed March 27, 2007.

\section{SOFTWARE CITED}

ArcIMS, ArcSDE - Environmental Systems Research Institute (ESRI), Inc., 380 New York St., Redlands, CA, 923738100 USA, (909) 793-2853, http://www.esri.com/.

ColdFusion-Adobe Systems Incorporated, http://www.adobe. $\mathrm{com} /$.

Microsoft Access, SQL Server-Microsoft Corporation, http:// www.microsoft.com/. 



\title{
Glacial Striae Observations for Ireland Compiled from Historic Records
}

\author{
By Mike J. Smith, Jasper Knight, and Kenneth S. Field \\ School of Geography, Geology, and the Environment \\ Kingston University \\ Penrhyn Road \\ Kingston upon Thames, Surrey, KT1 2EE \\ Telephone: +44 (207) 099-2817 \\ Fax: +44 (870) 063-3061 \\ email: michael.smith@kingston.ac.uk
}

\section{INTRODUCTION}

Landform mapping has been a primary method of data collection across the spectrum of earth sciences. These include geology (e.g. Gold et al., 1973), glaciology (e.g. Wright, 1912), hydrology (e.g. Hooke et al., 1994), hillslope geomorphology (e.g. Evans, 1977), planetary geology (e.g. Baker, 1981), volcanology (e.g. Thouret, 1999), and coastal geomorphology (e.g. Chandler and Brunsden, 1995) amongst others. Landforms were originally mapped by hand directly in the field; however the advent of remote sensing technologies has meant that larger areas can be mapped by fewer people and in less time (e.g. Clark, 1997). In short, the economical and often accuracy advantage of mapping remotely has meant that, in some environments and for some purposes, it is the preferred technique.

Research programs employing remotely sensed data have often mapped landforms ranging from several hundreds of metres to several kilometres in length, such as drumlins, end and ribbed moraines, and eskers. Dynamical assumptions based upon landform dimensions and properties (e.g. Kleman and Borgström, 1996) allow tentative reconstructions of the extent and dynamics of former ice sheets (e.g. Clark and Meehan, 2001). In particular, it is possible to reconstruct ice flow direction and changes in flow regime (including subglacial thermal and hydrological conditions). Striae observations have previously been incorporated into palaeo-ice sheet reconstructions (Kleman, 1990), however observations are often fragmented with small areal coverage. In short, they are rarely used for reconstructions over large areas.

Much of the early work of the Geological Survey of Ireland (GSI) involved the mapping of both hard rock and surficial geologies. In particular, extensive suites of both erosional and depositional glacial landforms inspired detailed and extensive field mapping and observation, although this was not a mandatory requirement and was often ignored in some areas, depending on the mapper's own interests. The results of this mapping were presented in the First Series ("1-inch" or 1:63,360) geological map sheets, published principally between 1860 and 1890 . The geological memoirs accompanying the map sheets contained further detail and, in many instances, tabulated field observations such as striae.

This paper describes the compilation of over 4,400 historic striae observations for the island of Ireland (covering $\sim 84,000 \mathrm{~km}^{2}$ ), principally based upon the memoirs accompanying the First Series geological map sheets, but also including published (peer-reviewed journal articles and reports) and unpublished (field notes, theses) observations.

\section{METHOD}

The principal data source for this research was tabulated striae observations contained within memoirs accompanying the First Series GSI map sheets. Memoirs that contain striae observations are not equally distributed around the island, in part due to the diligence and experience of individual field geologists. However it should also be noted that striae are most clearly recorded on bedrock substrates, which are generally more exposed in the west, with central and eastern regions having a thicker till cover. Opportunities for striae observations were therefore more limited in these latter areas. As a final note, some observations also record overprinting (or cross-cutting) of different striae sets, often noting the relative ages of different sets.

The information recorded in tables contained within memoirs varies, depending upon the individual geologist with, at least, the broad location, orientation and a brief description of the specific location listed. By 1837 the Ordnance Survey had completed First Series topographic mapping of the country at the Six Inch scale $(1: 10,560)$ and these maps 
were principally used by the field geologists to identify locations. Indeed many of the tables record the county, sheet number, quadrant, and townland that the observations fall within. However the map projections used were not consistent and varied between counties. The simplest and most effective method of transcribing the location of striae involved locating the observation on an original Six Inch map sheet and identifying the same point on a modern 1:50,000 Ordnance Survey of Ireland map sheet, and recording a 12 figure grid reference in Irish National Grid coordinates.

In transcribing striae, it was also evident that descriptions of locations had different levels of locational accuracy. A subjective assessment of this accuracy was recorded on a scale from 1 to 5, ranging from the most accurate (where a full grid reference or precise identifiable location is given) to least accurate (where only a general area is known).

For the GSI memoirs, orientation was usually recorded with reference to cardinal points on a compass (rather than in degrees), generally to within $5^{\circ}$. Thus a value of $035^{\circ}$ could be recorded as $\mathrm{N} 35 \mathrm{E}$ in the memoirs, but the notation can be utilised with respect to each of the four cardinal points and so $035^{\circ}$ could also be refer to E55N. This has added some complexity to the interpretation of these original observations.

In addition to the GSI memoirs, striae were transcribed directly from the First Series geological maps. There is undoubtedly duplication between these two data sets; however there are fewer observations recorded on the maps and these are often in different locations. Both sets have therefore been included for completeness. Our database distinguishes between these data sources.

Striae observations taken directly from the published literature vary in presentation of results. Some articles provide full grid references (e.g. Meehan, 1999), whilst others just contain outline maps showing striae locations.

All striae observation information was collated in a relational database comprising:

- 12-figure Irish National Grid reference,

- the source of the record,

- orientation of striae,

- presence and orientation of any cross-cutting striae, and

- locational accuracy of the record.

\section{RESULTS}

Individual records were collated from (number in brackets):

- GSI memoirs $(2,300)$,

- Geological survey maps $(1,400)$, and

- Published and unpublished literature (700).

The database therefore totals over 4,400 individual striae measurements, although there is some duplication of individual records between sources. Smith et al (2007) presented the complete data set for Ireland showing the positions and orientations of striae that most likely date from the last (late Devensian) glaciation (c. 25,000-13,000 BP). The records were imported into ESRI ArcGIS for production of the final map. The base map was constructed from a relief-shaded digital elevation model (Shuttle Radar Topography Mission; http://www2.jpl.nasa.gov/srtm/), hydrographic data comprising lakes and rivers (Digital Chart of the World; http://www. maproom.psu.edu/dcw/), and a coastal outline (University of Ulster, Coleraine, UK, unpub. data).

\section{DISCUSSION}

Striae observation coverage of Ireland is extensive, however it is far from uniform. Areas of dense observations are to be found in the west (Connemara), north-west (Donegal), and north-east (Down) regions of the island. Additional clusters can also be noted on mountain blocks in the east (Wicklow) and south-west (Kerry). All these regions are either bedrock scoured (Connemara) or mountainous and therefore have little surficial cover. Other areas with observations are predominantly coastal (e.g. River Shannon mouth). There is an almost complete lack of observations in the central and southern areas of the island. These data are currently being used to reconstruct ice flow patterns during the late Devensian, and will be reported upon separately.

It is important to note that there are limitations to the data:

- there are potential duplications of observations between different sources,

- the accuracy of striae location varies and is qualitatively assessed,

- some observations appear just offshore and likely fall within the inter-tidal zone,

- some observations fall on islands that are not recorded on the basemap, and

- base map data are of different provenance and, whilst fit for display purposes, are not representative of "best available" data.

\section{CONCLUSIONS}

- Research presented here represents one of the largest compilations of striae observations, comprising over 4,400 individual observations.

- Striae observations have been collated using historic records dating from the 1850s onwards, and published (peer-reviewed) and unpublished literature.

- Striae observations are not uniformly distributed, being strongly clustered around mountainous (e.g. Mourne 
Mountains, Wicklow, Macgillicuddy's Reeks) and coastal zones.

- These observations will form the basis of a reconstruction of former ice sheet flow.

\section{ACKNOWLEDGMENTS}

We would like to thank Samantha Harrison (Kingston University), Robbie Meehan (independent consultant) and Steve Booth (British Geological Survey) for assistance in collating striae data.

\section{REFERENCES}

Baker, V.R., 1981, The geomorphology of Mars: Progress in Physical Geography, v. 5, p. 473-513.

Chandler, J.H., and Brunsden, D., 1995, Steady state behaviour of the Black Ven mudslide: The application of archival analytical photogrammetry to studies of landform change: Earth Surface Processes and Landforms, v. 20, p. 255-275.

Clark, C.D., 1997, Reconstructing the evolutionary dynamics of palaeo-ice sheets using multi-temporal evidence, remote sensing and GIS: Quaternary Science Reviews, v. 16, p. 1067-1092.

Clark, C.D., and Meehan, R.I., 2001, Subglacial bedform geomorphology of the Irish Ice Sheet reveals major configuration changes during growth and decay: Journal of Quaternary Science, v. 16 , no. 5, p. 483-496.

Evans, I.S., 1977, World-wide variations in the direction and concentration of cirque and glacier aspects: Geografiska Annaler, v. 59A, p. 151-175.
Gold, D.P., Parizek, R.R., and Alexander, S.A., 1973, Analysis and application of ERTS-1 data for regional geological mapping, in Freden, S.C., Mercanti, E.P., and Becker, M.A., eds., Proceedings of the [First] Symposium of Significant Results obtained from the Earth Resources Technology Satellite-1: Greenbelt, Maryland, NASA Goddard Space Flight Center, SP-327, v. 1, section A, p. 231-246.

Hooke, J.M., Horton, B.P., Moore, J., and Taylor, M.P., 1994, Upper River Severn (Caersws) Channel Study: University of Portsmouth, unpublished report to the Countryside Council for Wales, $165 \mathrm{p}$.

Kleman, Johan, 1990, On the use of glacial striae for reconstruction of palaeo-ice sheet flow patterns: Geografiska Annaler, v. 72A, p. 217-236.

Kleman, Johan, and Borgström, Ingmar, 1996, Reconstruction of palaeo-ice sheets: The use of geomorphological data: Earth Surface Processes and Landforms, v. 21, p. 893-909.

Meehan, R.T., 1999, Directions of ice flow during the last glaciation in counties Meath, Westmeath and Cavan: Irish Geography, v. 32, no. 1, p. 26-51.

Smith, M.J., Knight, Jasper, and Field, K.S. 2007, Glacial striae observations for Ireland compiled from historic records: $27^{\text {th }}$ Annual ESRI International User Conference, June, 2007. Presented in the ESRI Map Gallery.

Thouret, J.C., 1999, Volcanic geomorphology-an overview: Earth-Science Reviews, v. 47, p. 95-131.

Wright, W.B., 1912, The drumlin topography of south Donegal: Geological Magazine, v. 9, p. 153-159. 



\title{
GIS Tools for 3-D Surficial Mapping in Ohio
}

\author{
By James McDonald, Richard R. Pavey, Erik R. Venteris, and Joseph G. Wells \\ Ohio Department of Natural Resources, Division of Geological Survey \\ 2045 Morse Road, Bldg C-1 \\ Columbus, OH 43229-6693 \\ Telephone: (614) 265-6601 \\ Fax: (614) 447-1918 \\ email: \{jim.mcdonald, rick.pavey, erik.venteris, joseph.wells\}@dnr.state.oh.us
}

\section{ABSTRACT}

The Ohio Department of Natural Resources, Division of Geological Survey is currently mapping the surficial geology of Ohio in three dimensions (3-D) using a modified version of the stack-mapping technique of Kempton (1981). The stackmapping technique depicts the geology for an area in 3-D by listing the unconsolidated (mostly glacial) geologic units from the surface to bedrock, the thickness of each unit, and the underlying bedrock unit. The new mapping of the surficial geology is intended to replace the older and smaller-scale mapping that was based upon generalized, two-dimensional mapping techniques.

Three ArcMap-based software applications were developed to assist with the stack-unit mapping program. The first software application uses the lithologies from water wells to create on-screen graphics representing the stratigraphic columns for each well record. These stratigraphic columns are interpreted by the geologist to assign a generalized stack unit for each polygon. The second software application consists of two tools used to attribute and label the stack-map polygons, which will capture the information in the GIS and for cartographic display. The first tool attributes a one-to-many relationship between a surficial-geology polygon and the lithology table. The second tool labels the surficial-geology polygons with the stack text for use in map publishing. The third application performs custom queries against the lithology table that can be used to create derivative mapping products, such as location and thickness of sand and gravel resources. These three applications allow the efficient creation of 3-D surficial-geology polygons and labels within a GIS database, and provide analysis tools to facilitate the use of the 3-D surficial geology maps for specific applications.

\section{INTRODUCTION}

The Ohio Department of Natural Resources, Division of Geological Survey (ODGS) is involved in a program, partially supported by the U.S. Geological Survey STATEMAP program, to map the unconsolidated-surficial sediments of Ohio in three dimensions (3-D). It is important to characterize and understand these surficial, mostly glacial, materials because more than two-thirds of Ohio is covered by them. Mapping of the surficial geology is conducted using the stack-mapping technique of Kempton (1981). In Ohio, this technique has been modified to depict the primary lithologies of the materials and their thickness. These 3-D maps will allow geoscientists and the public to more effectively use geologic information for land-use planning, resource exploration, hydrogeologic investigations, and geohazard identification (Swinford and others, 2007).

The mapping methodology is summarized below, while a more comprehensive description of the mapping methods used to create the stack maps is found in Swinford and others (2007) and Venteris (2007). There are a number of different data sources used to conduct the mapping, including maps of soil parent materials, drift thickness, bedrock geology, and legacy (previously published) glacial-geologic maps. In addition, boring data from water wells from the Ohio Department of Natural Resources, Division of Water (ODW) (Jones and Barrett, 2007), bridge borings from the Ohio Department of Transportation, engineering boring logs, maps, field notes, and seismic-refraction lines (Swinford and others, 2007), and boring data from environmental studies of the Ohio Environmental Protection Agency are also used to help delineate the stack-unit polygons in the subsurface (Venteris, 2007). The delineation of the stack-unit polygons is generally a twostep process. First, the surface mapping units (lithologies) are derived from county-scale soils maps and digital elevation models (DEMs). The polygons of surface features are drawn by generalizing the parent material polygons from the soil surveys and interpreting geomorphic features on the DEMs. Second, subsurface polygons are delineated using the drift thickness maps and depths to bedrock from boring logs. These subsurface polygons delineate broad areas of like thicknesses. When the areas of like thicknesses are delineated, the stratigraphic model for that polygon is then assigned a stack sequence using borehole information from 
bridge borings and environmental site studies as a starting point. After the initial conceptual framework has been developed, the model is verified and extended using the water-well logs from the ODW (Venteris, 2007). Polygon and stack-unit information are hand-drawn on 1:24,000-scale Mylar overlays registered to the 1:24,000-scale topographic maps (Swinford and others, 2007).

Once the polygons have been drawn by a geologist on the Mylar overlay, the maps are digitized. The maps are scanned and georeferenced to the appropriate 7.5-minute quadrangle. The lines are then digitized into an ArcGIS geodatabase feature class, where the 7.5-minute quadrangles are mosaiced into a 30 × 60 -minute quadrangle for plotting at 1:100,000 scale. Several iterations of quality control are conducted to ensure that stack-unit polygons are edge-matched between quadrangles (Swinford and others, 2007). After the lines are digitized, polygons and topology are created in the GIS. The polygons are assigned a unique polygon ID, known as the GEOID, which is based upon a unique sequence number for each 7.5-minute quadrangle. Finally, the polygons are attributed with the correct three-dimensional stack-unit lithologies using the stack-map application. In Figure 1, these stack units are shown for the Peninsula, Ohio, 7.5-minute quadrangle. Once the GIS data are created for the project, they are given to a cartographer to create a finished print-on-demand map at 1:100,000 scale that the public can purchase.

The ODGS program to map the surficial geology began in 1997. To date, the ODGS has mapped 17 of the thirty-four $30 \times 60$-minute quadrangles covering the State of Ohio (Figure 2). Each year, a 1:100,000-scale quadrangle is selected for mapping and four to five geologists are assigned to the task. At the beginning of the program, the geologists mapping the 1:100,000-scale quadrangle used traditional techniques, such as drawing the map units onto Mylar overlays and using paper topographic base maps. In the last few years, there has been a transition from using traditional techniques to using a mixture of traditional and GIS techniques. This paper describes the first GIS tools developed to assist automating the stack-mapping process in a GIS environment. These tools allow for the more rapid mapping of surficial geology in three dimensions.

\section{GIS TOOLS}

\section{Stick Figure Application}

In order to create the stack-unit polygons, many different sources of information are used. The most abundant source is the water-well logs from the Ohio Department of Natural Resources, Division of Water (Jones and Barrett, 2007). To help the geologist interpret and map the stratigraphy for the stack units, a VBA application for ArcMap was written that draws a stratigraphic column for selected water wells based on the lithology information from the water-well logs. In this 3-D mapping program, these stratigraphic columns are called stick-figures. Stick figures changes an overwhelming amount of written lithology information into a more easily decipherable set of colorized graphics which speeds interpretation.

To create stick-figure stratigraphic columns, a geologist selects a series of wells using the native Selection Set tool in ArcMap (Figure 3). Once the desired wells have been selected, the geologist activates the Stick-Figure application, which draws a stratigraphic column for each well. The geologist can then begin to use these stratigraphic columns as an aid in the delineation of the stack-unit polygons. Before this application was created, four geologists required approximately twelve weeks to transcribe lithologic records from water wells and draw the stick-figures. Using this application, the amount of time necessary to create the stick figures has decreased to approximately 1 week. Most of this time is spent on generating the stick-figures for each 7.5-minute quadrangle, removing stick-figures for wells with suspect information, removing stick-figures in areas of dense drilling to improve readability and interpretation, and plotting the 7.5-minute quadrangles.

The creation of stick figures utilizes the one-to-many relationship between a water-well location and the water-well lithology table. During the drilling of a water well, one or more lithologies are encountered downhole; in the database, this is managed as a one-to-many relationship. This is illustrated in Figure 4, whereby a water well has been selected and the corresponding lithology records of the water well are displayed in a separate table. The upper table is the feature-attribute table of the water-well location, showing the selected record of the water well (near the bottom left of the map). The other table is the water-well lithology table, which shows the five stratigraphic records related to the selected water-well location. In the geodatabase, there is a feature class for the water wells, a table for the lithologic descriptions, and a relationship class. The relationship class provides the link for the one-to-many relationship between the water wells and the table of lithologic descriptions. The primary key between the water well feature class and the lithology table is the WELL_LOG_N field, which is the unique identification number for the water wells. During execution of the stick-figure application, the VBA code cycles through all of the selected water wells and identifies the corresponding lithologic units that are associated with each selected waterwell location. The VBA application then builds graphic polygons at the location of the water well. The polygon has a constant width and the height is defined as the along-hole depth of the lithologic unit encountered during the drilling of the water well. The application creates a stack of polygons that represent the lithology encountered during drilling of the water well.

The polygons are symbolized based on a lookup field. The original lithologic descriptions provided by the waterwell drillers were reclassified into eight standard lithologies that can be displayed by the stick-figure polygons. These 


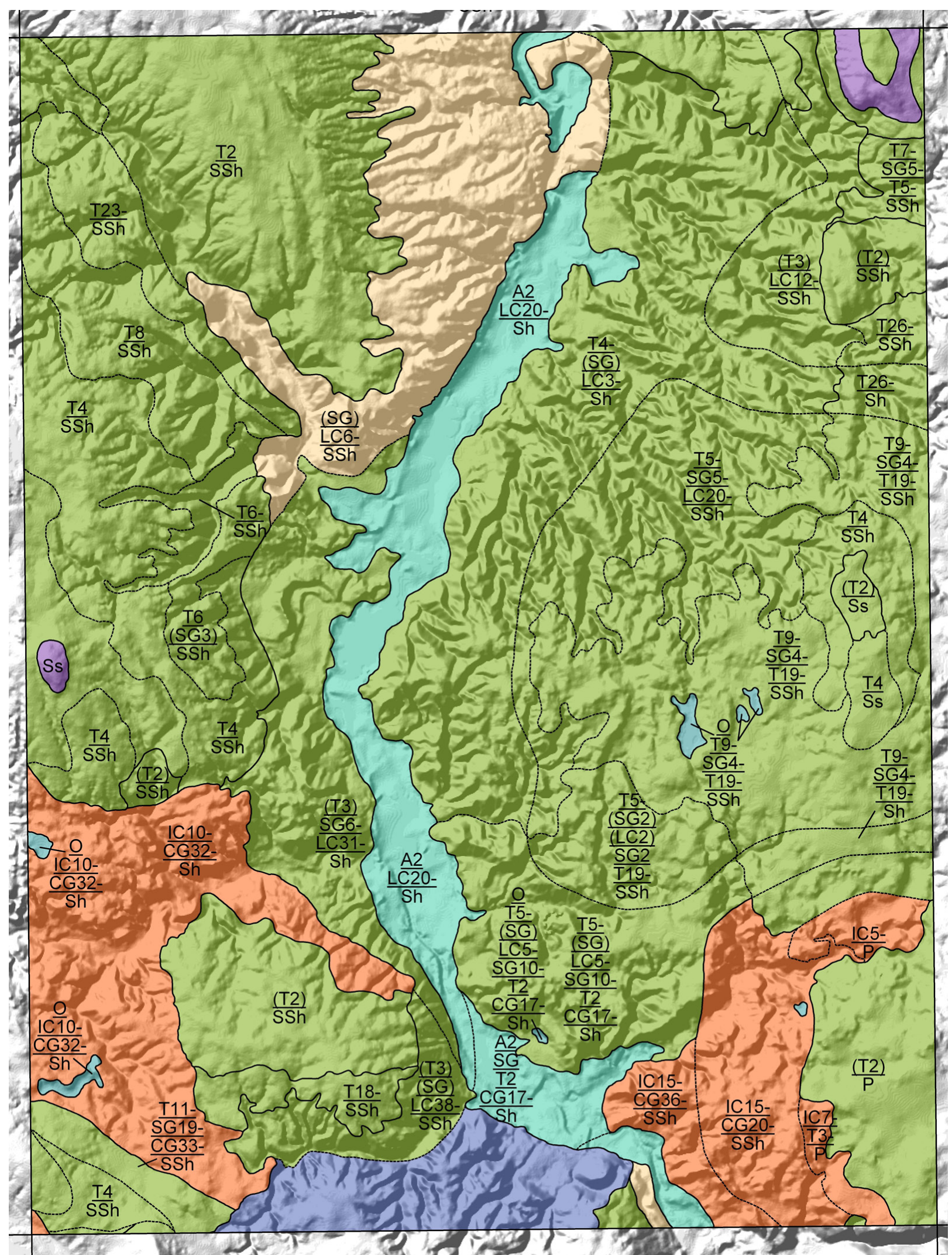

Figure 1. Map showing the surficial geology of the Peninsula Quadrangle, Cuyahoga and Summit Counties, Ohio. The topmost unit is symbolized, by color. Till units are colored green (T), Ice-contact units are colored orange (IC), Lake clay units are colored tan (LC), Alluvium and Organic units are colored blue (A and O), Sand and gravel units are colored dark blue (SG), and sandstones of the Pennsylvanian Pottsville Group are colored purple (Ss). 


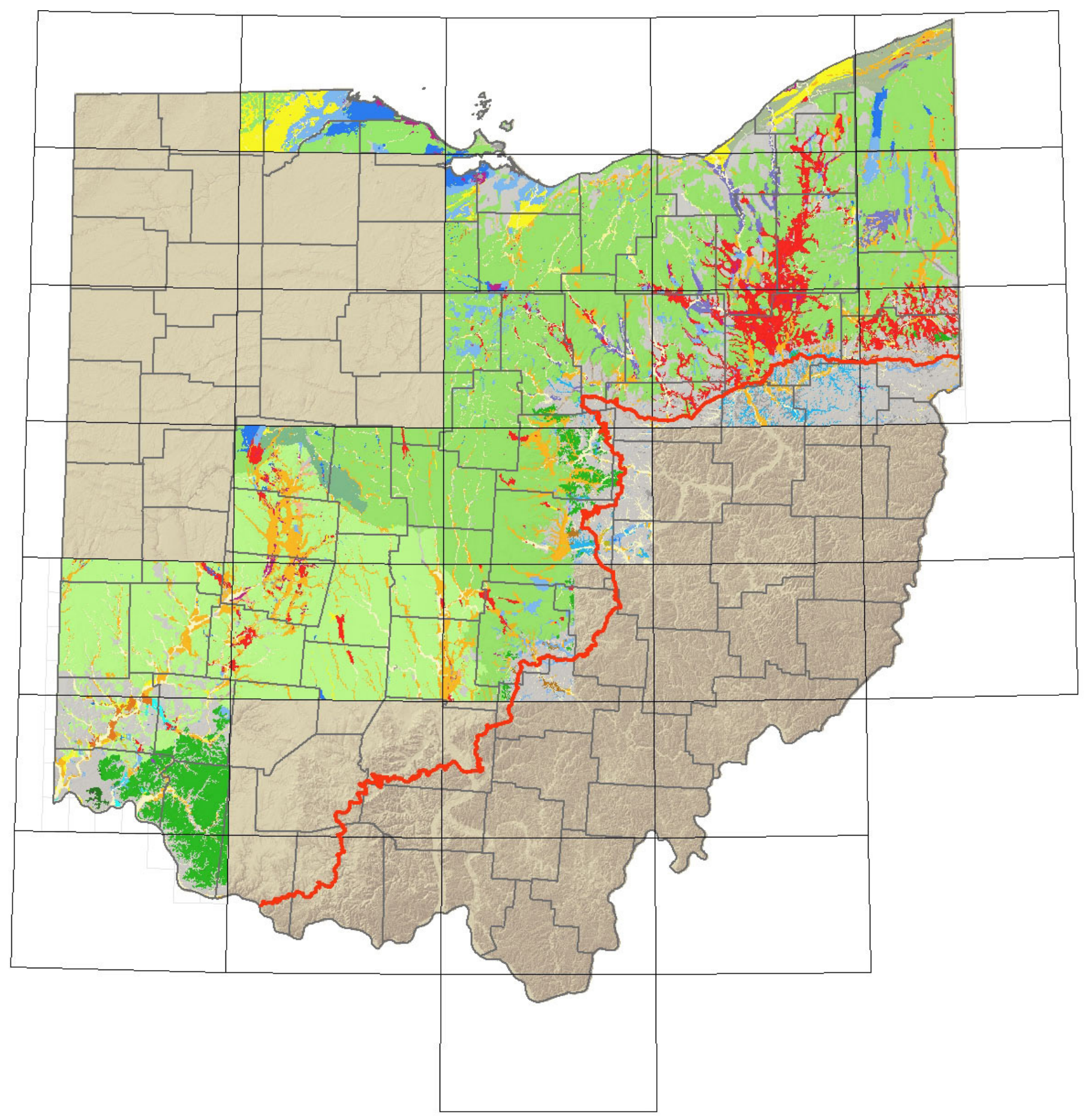

Figure 2. Map showing the completed 1:100,000-scale 3D surficial geology mapping in Ohio. This figure shows the topmost surficial geologic units, and can be compared to the Quaternary Geology Map of Ohio (Pavey and others, 1999) to show the similarities and differences between the two mapping techniques. The red line is the generalized glacial boundary in Ohio. 


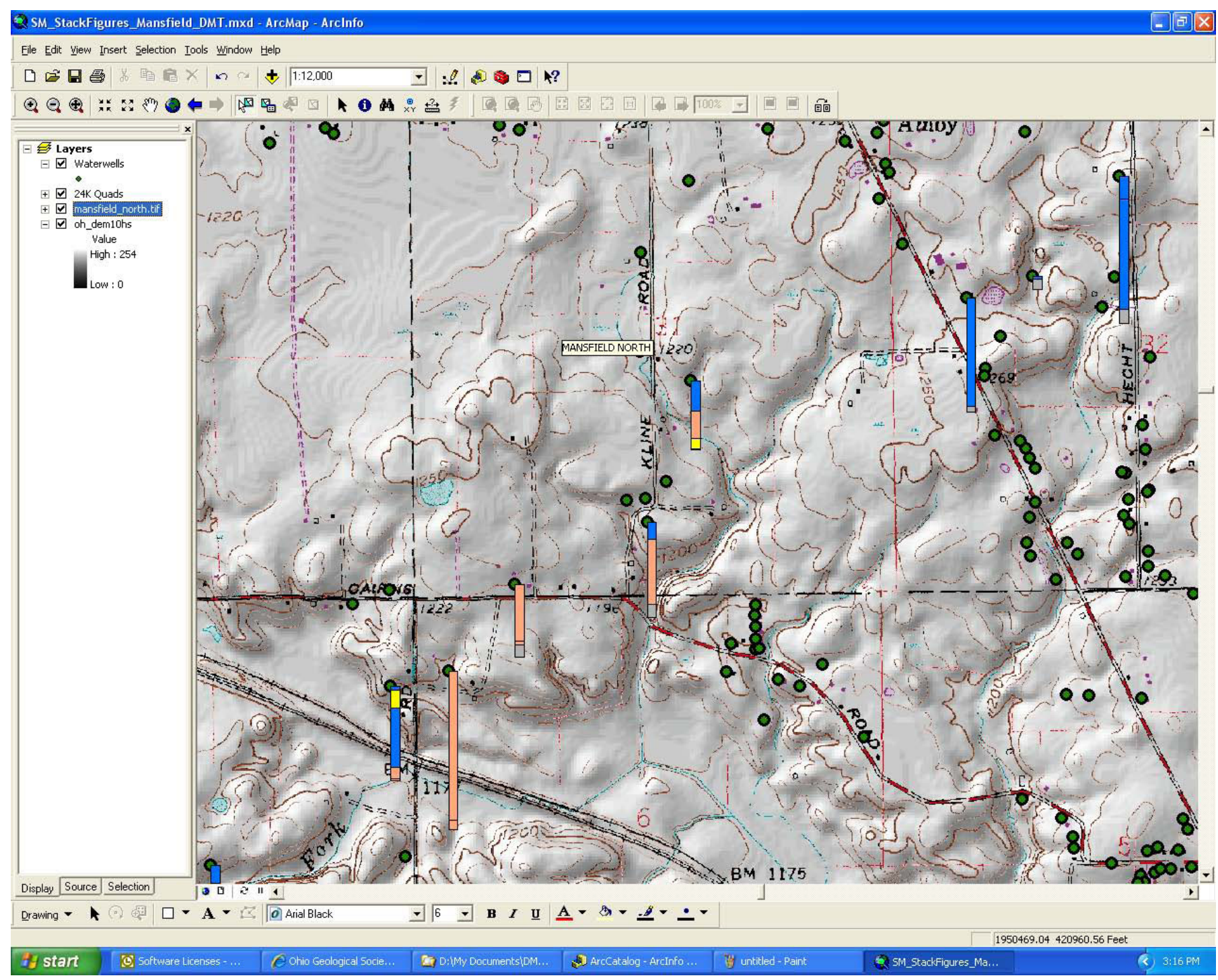

Figure 3. Selected water wells whose lithologic column is generated using the Stick-Figure Application. Colors in the stick figures represent various lithologies. Length of the stick figures corresponds to depth of the well, with deeper wells resulting in longer stick figures.

lithologies include clay, silt, sand, gravel, diamict, peat/muck, soil, and bedrock. These reclassified values are stored in a reclassification lookup field. The VBA application reads the value from the reclassification field, and then assigns the appropriate color and symbol pattern to the polygon. The entire process takes about 1 minute for a few thousand wells found in a quadrangle.

For each stick figure, the graphics polygons are grouped together so they can be moved and placed cartographically on the map. In some areas the density of water well drilling is very high, particularly in urban areas. In these areas, the density of the stick-figures can make it almost impossible to read and interpret them. At any time, a geologist can delete individual stick figures, reselect individual well locations and generate new stick figures, all of which can improve the readability of the map. This ability also allows the geologist to omit from consideration, and from display, those well logs found to contain unreliable information.

\section{Stack Map Application}

Currently, the stack-map process requires both GIS software and traditional methods of drawing the polygon boundaries using pen, paper, and Mylar. Once the maps have been drawn using traditional methods, the maps are then digitized into the GIS database. Finally, the stack-map application is used to attribute the newly digitized polygons in the GIS database. 


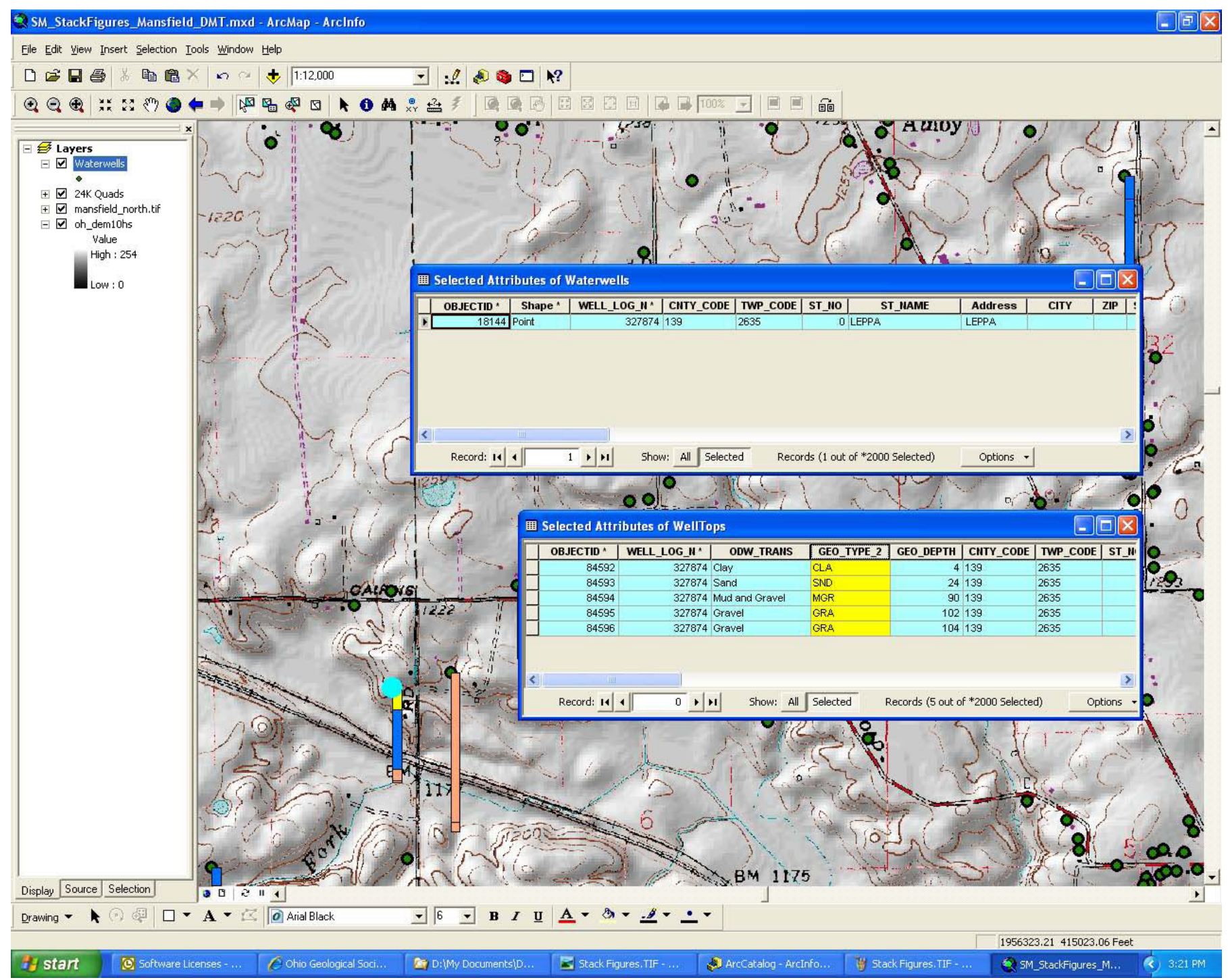

Figure 4. Example of the one-to-many relationship between the water-well location and the water-well log table. The well log record (upper table) is linked by WELL_LOG_N to the lithologies encountered downhole (lower table). The selected well is in the lower left-hand corner.

The stack-map application consists of three different toolbars in ArcMap; each toolbar has a number of different tools (Figure 5). The first toolbar is Surface Geology; it is used to attribute the surface-geology polygons and their associated one-to-many relationship lithology table. The second toolbar, Geology Annotation Editing, is used to label the surface geology polygons by reading the associated one-to-many relationship lithology table and creating the stacked text labels shown on the map. The third toolbar, Geology Query, is used to create custom queries using the one-to-many relationship lithology table.

The primary tool used to list and edit the lithology attributes is the Edit Surface Geology tool on the Surface Geology toolbar (Figure 6). By selecting the tool and then selecting the desired polygon, different forms will appear that will either list the stack-unit lithologies in stratigraphic order or allow the GIS user to attribute one or more of the stack-units for the selected surface-geology polygon. In figure 6 , the selected surface-geology polygon has been attributed, and the Edit Surface Geology tool will activate the List Stack Lithologies form. This form lists all the stack-unit lithologies and the name of the GIS user who has edited the stack-unit lithology and the date and time the last edit has occurred. The name of the GIS user and the date and time of the last edit are a form of feature-level metadata. This feature level metadata are stored in the database and is currently used for project-management quality control of the GIS conversion and editing.

Similar to the relationship between the stick-figure stratigraphic columns and the lithology table, the surface-geology 


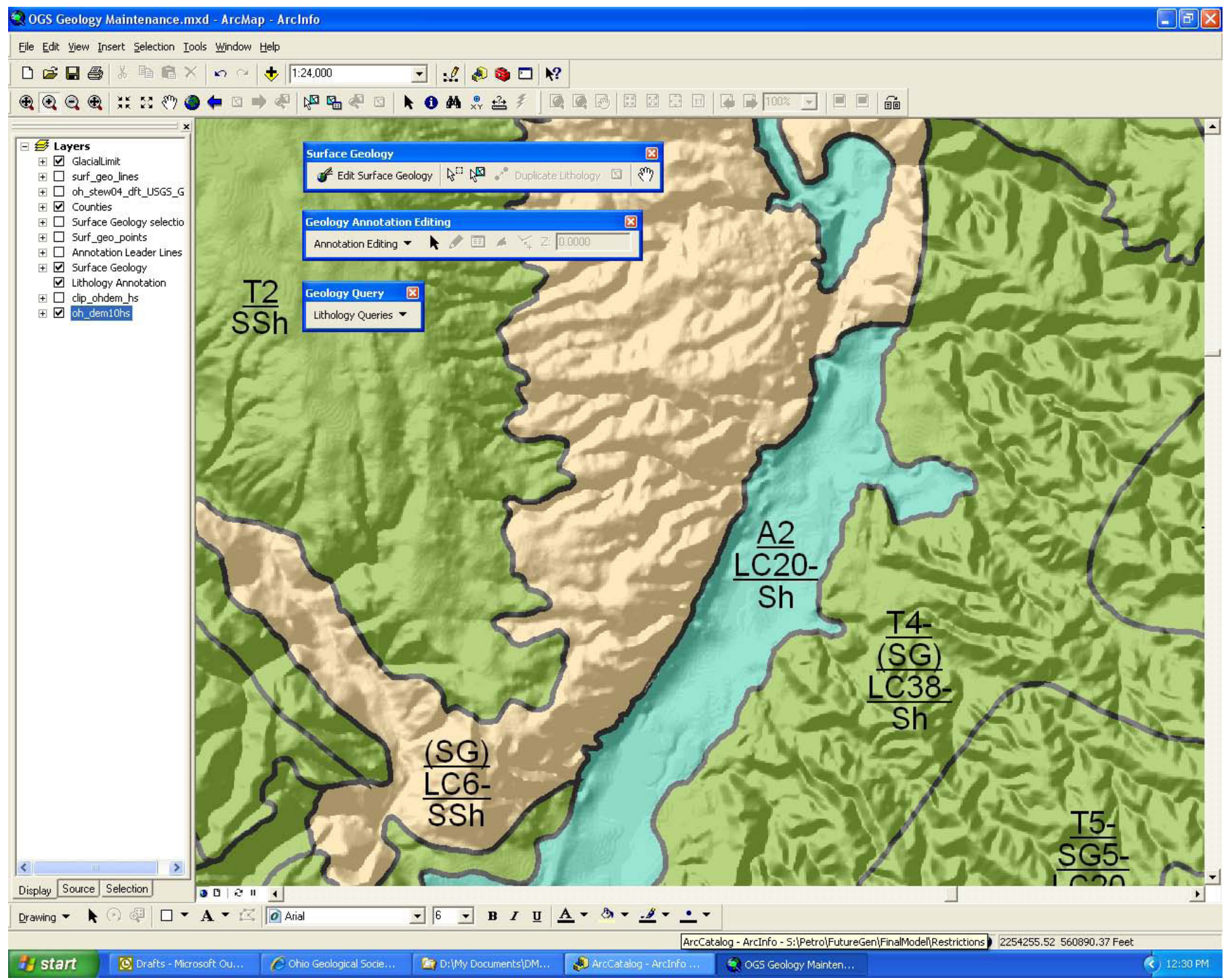

Figure 5. The three toolbars of the stack-map application: The Surface Geology toolbar, the Geology Annotation Editing toolbar, and the Geology Query toolbar.

polygon and the lithology table is a one-to-many relationship (Figure 7). The upper table is the feature-attribute table of the surface-geology polygon, showing the selected record of the selected polygon. The other table is the lithology table, showing the four records related to the selected surface-geology polygon.

To edit any of the stack-unit lithologies, the Surface Geology Input form is used (Figure 8). This form is accessed automatically if a surface-geology polygon has not been attributed, or it can be accessed through a command button ("Update...") on the List Stack Lithologies form (see Figure 6). Once the form has been activated, the GIS user can select the stack-unit sequence number, select a new lithology, input the thickness of the stack-unit and, optionally, select a unit modifier for the stack unit. In this figure, the topmost unit is being edited (Layer 1). The lithology is till (T), thickness is 40 feet, and the minus sign modifier indicates that this is the maximum thickness for the unit.

The labels for the surface-geology polygons can be placed using the Geology Annotation Editing toolbar (Figure 9). This toolbar uses the Annotation Editing tool along with a custom Add Lithology Annotation tool to place the labels for the polygons. The GIS user first turns on the annotation editing using the Annotation Editing tool. Next, they select the Add Lithology Annotation tool and then select the surface-geology polygon to be labeled. The custom Add Lithology Annotation tool, using the GEOID for the polygon, reads the related records for the polygon in the lithology table. The tool then finds the center of the polygon, builds the text and separating lines for the label in correct 


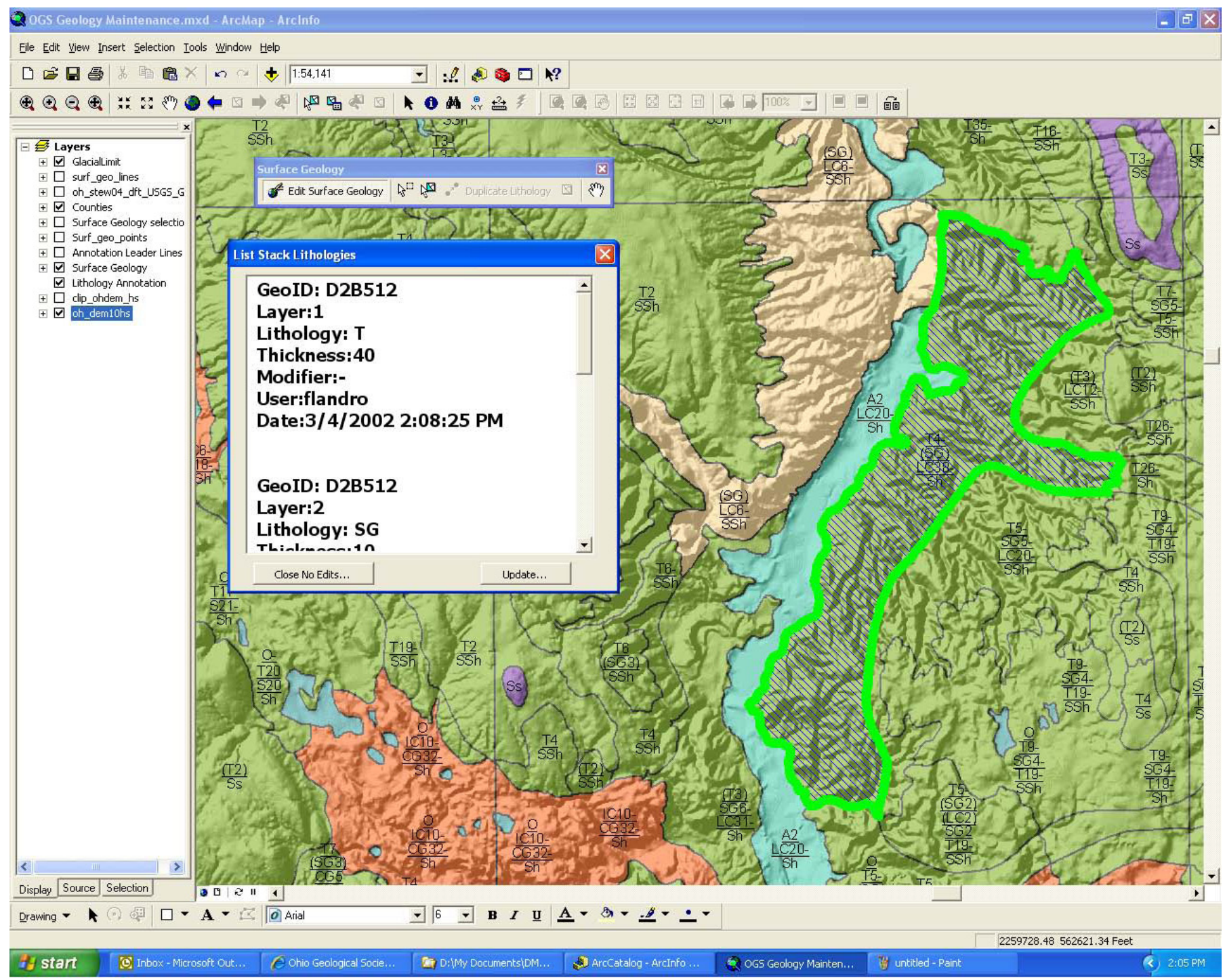

Figure 6. The Edit Surface Geology tool, and its List Stack Lithologies display. Polygon selected is in the right side of the figure and is outlined in a bold green line and has a hatchured interior.

stratigraphic order, and then snaps the label to the center of the polygon. Placing the label semi-automatically in the polygons, which can number between 1,500 to 2,000 per $30 \mathrm{x}$ 60 -minute quadrangle, creates significant time savings.

\section{Query Toolbar}

Complex queries can be generated using the Lithology Query toolbar, which has two tools within its dropdown menu. The first tool, shown on the left side of the toolbar in Figure 10, can select polygons that have one type of lithology overtop another type of lithology. The second tool, which is not shown in Figure 10, can select polygons that have a combination of thicknesses and lithologies overlying one another. In Figure 10, a query was generated for Sand and Gravel (SG) overlying Lake Clays (LC). The selected polygons are then highlighted in red. The query tools allow for easy extraction of specific data for a map area and allow the user to transition data from a surficial-geology map to a more user-specific derivative map that a layperson can comprehend.

The Lithology Query toolbar has been set up to perform some very simple queries. The query tools use the depth sequence ID number to identify the stack-unit sequence 


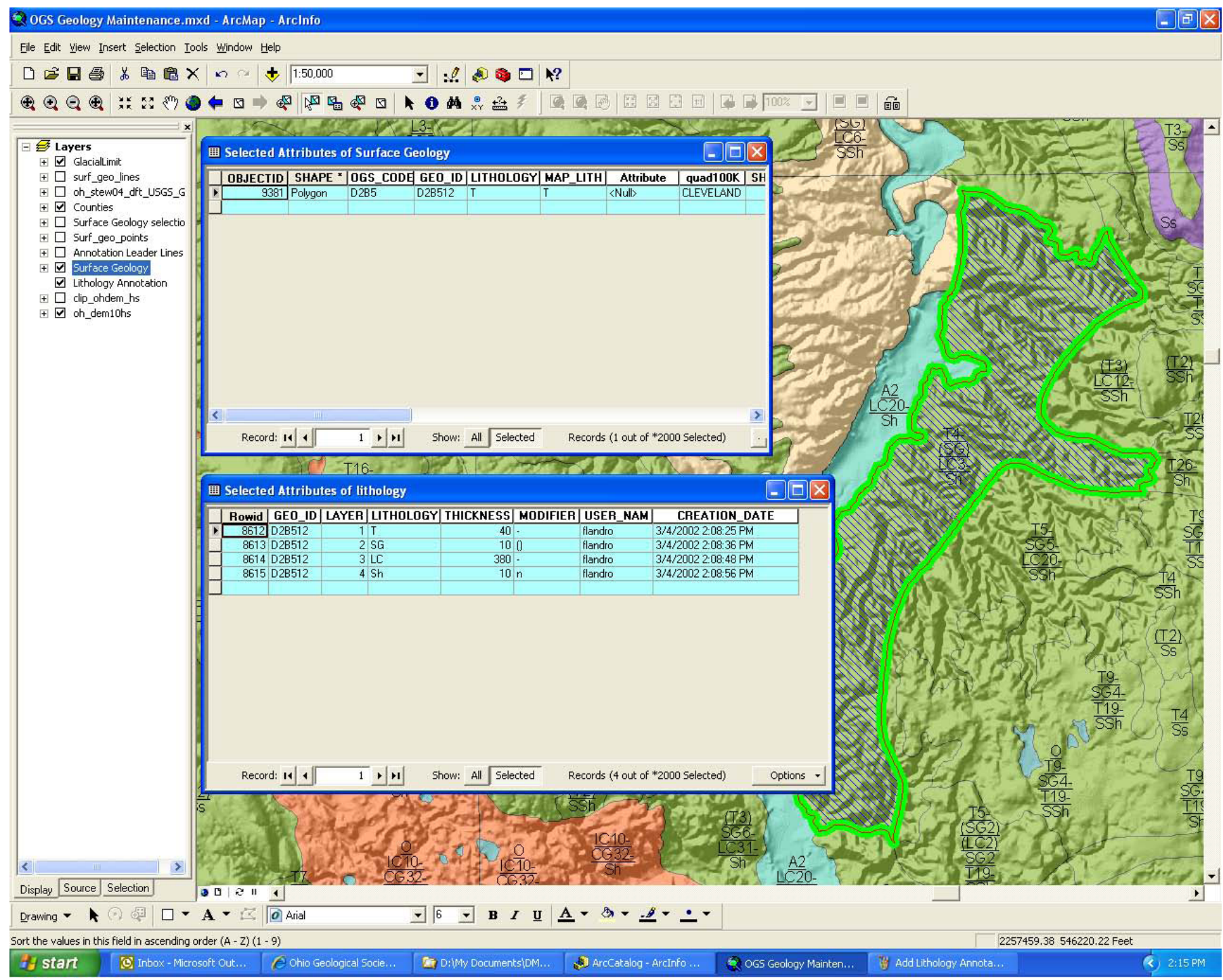

Figure 7. Example of the one-to-many relationship between the surface-geology polygon and the lithology table.

with depth. For the first query, one type of lithology above another, the SQL SELECT WHERE clause is

WHERE $\left(\right.$ LITH $=$ " 1 st Lithology" AND LITH $=$ " $2^{\text {nd }}$ Lithology”) and (SEQID of $1^{\text {st }}$ Lithology $>$ SEQID of $2^{\text {nd }}$ Lithology)

This SQL statement identifies stack-unit polygons that have both $1^{\text {st }}$ Lithology and $2^{\text {nd }}$ Lithology, and where the $1^{\text {st }}$ Lithology overlies the $2^{\text {nd }}$ Lithology. One disadvantage of this type of query is that it will also identify multiple-selected lithologic records within a polygon of $1^{\text {st }}$ Lithology overlying the $2^{\text {nd }}$ Lithology. For example, take a stack-unit polygon that has a lithologic sequence from the surface of till, sand, lake clay, till, sand, and bedrock. If a query was generated to identify till over sand, the SQL query above will select both till over sand units. The query will select multiple units and can not specify as to which till over sand unit we would like to select. Future enhancements of this type of query and the VBA code must be modified to refine the query for depth, thickness, and the selection of a single lithologic record per polygon. 


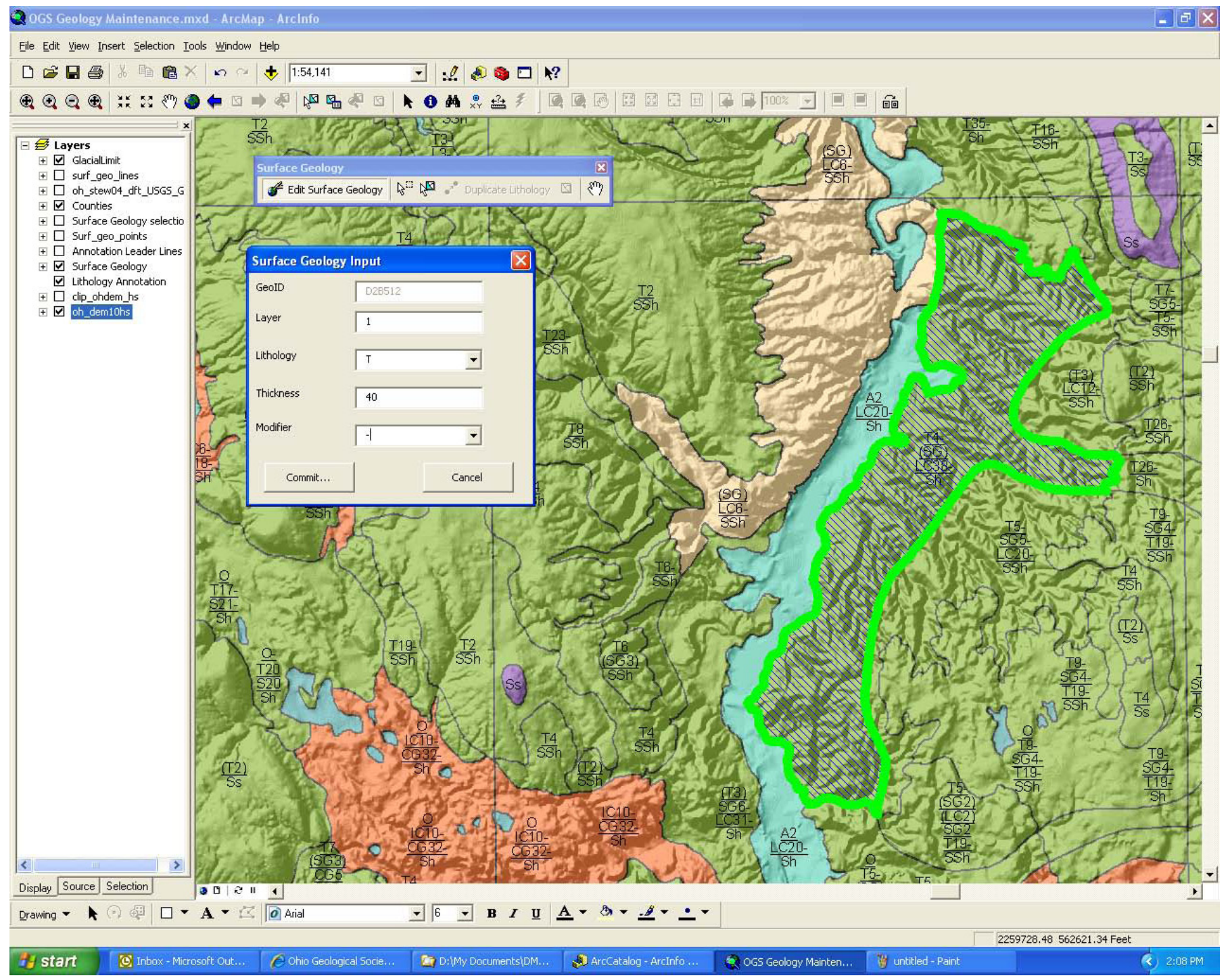

Figure 8. The Surface Geology Input form for the top layer (1) containing a lithology of till (T), a thickness of 40 feet, and a modifier of minus (-) meaning maximum thickness. 


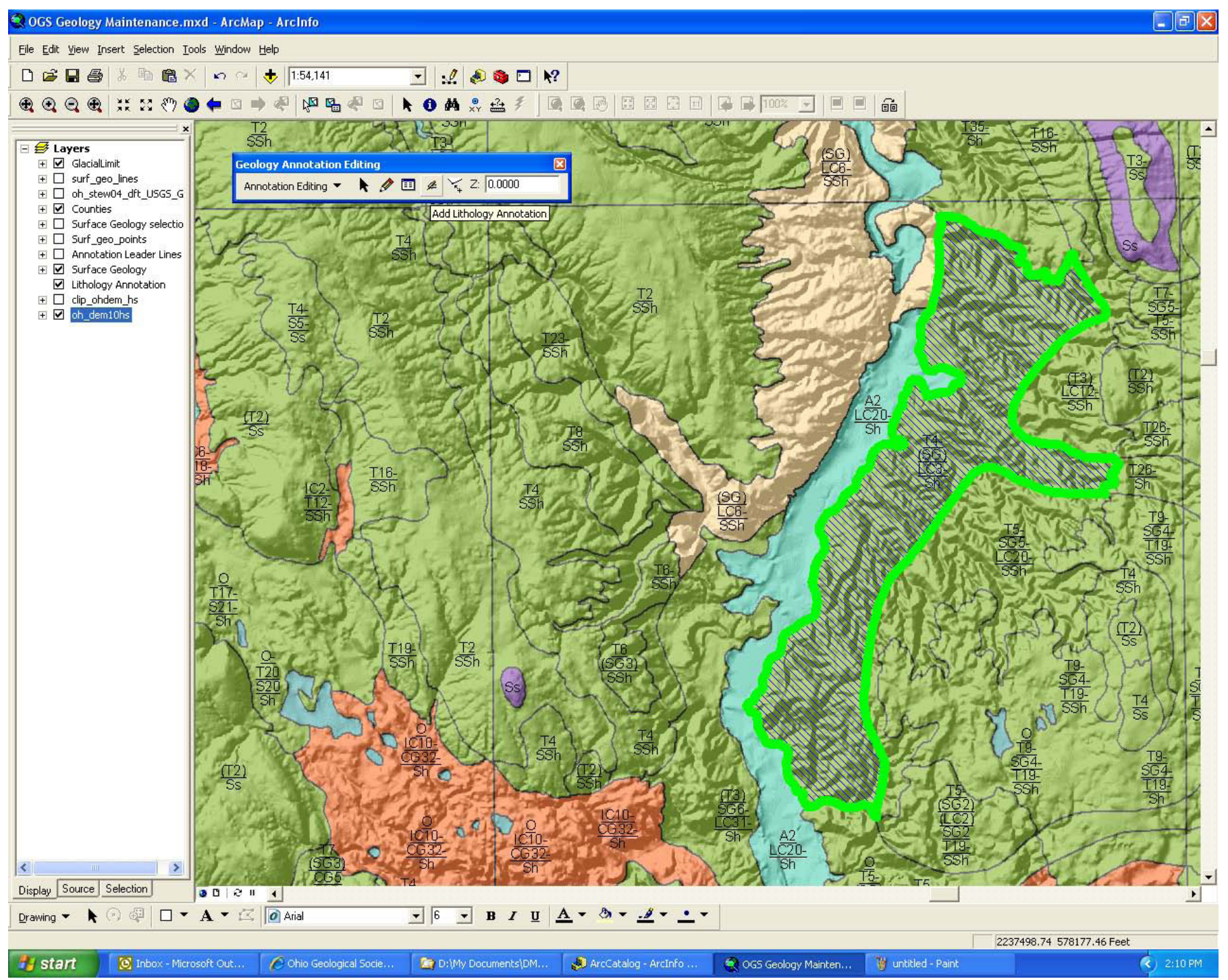

Figure 9. The Geology Annotation Editing toolbar. This toolbar contains the Annotation Editing tool and the custom Add Lithology Annotation tool. 


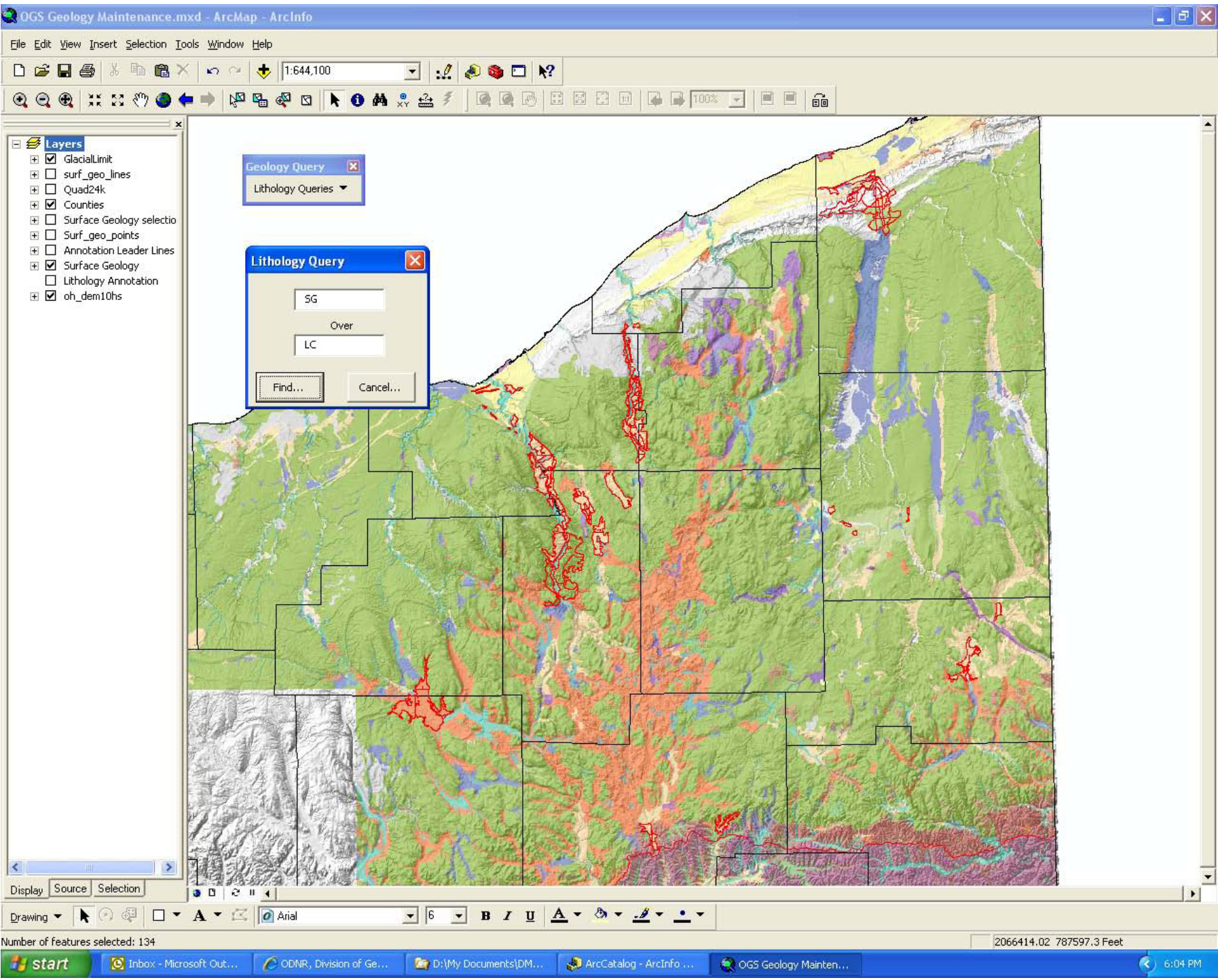

Figure 10. The Lithology Query toolbar with areas of sand and gravel (SG) overlying lake clay (LC) selected and outlined in red. 


\section{CONCLUSIONS}

Three new GIS applications have been created for the 3-D stack-unit mapping program at the Ohio Geological Survey. Two GIS applications are used to assist with the stack-unit mapping. The stick-figure application is used to draw stratigraphic columns of boreholes, adjacent to the location of the borehole. The stratigraphic columns are then used to delineate the subsurface polygons on the stack-units maps. The second application is used to attribute the oneto-many relationships between the polygons and the related attribute table; it also is used to edit and label the stack-unit polygons. These two applications have greatly increased the productivity of the geologists, reducing the amount of time it takes to produce a map. The third application queries the stack-unit polygons, allowing geologists to perform map analysis and to ask questions using the GIS database. The query tools are a first generation attempt to provide answers to typical questions that might be asked of the GIS database. These query tools will form the basis of future derivative mapping at the ODGS.

\section{ACKNOWLEDGMENTS}

We would like to thank J.D. Overton, ESRI, Inc., for providing the initial software programming for the Stack Map application toolbars.

\section{REFERENCES}

Jones, A.W., and Barrett, K.A., 2007, Building a water well database for GIS analysis, in Soller, D.R., ed., Digital Mapping Techniques '06 - Workshop Proceedings: U.S. Geological Survey Open-File Report 2007-1285, p. 27-33, available at http://pubs.usgs.gov/of/2007/1285/pdf/Jones. $p d f$.

Kempton, J.P., 1981, Three-dimensional geologic mapping for environmental studies in Illinois: Illinois State Geological Survey Environmental Geology Notes 100, 43 p.

Pavey, R.R., Goldthwait, R.P., Brockman, C.S., Hull, D.N., Swinford, E.M., and Van Horn, R.G., 1999, Quaternary geology of Ohio: Ohio Division of Geological Survey Map 2, scale 1:500,000.

Swinford, E.M., Pavey, R.R., and Larsen, G.R., 2007, New map of the surficial geology of the Lorain and Put-In-Bay 30 x 60 minute quadrangles, Ohio, in Soller, D.R., ed., Digital Mapping Techniques '06 - Workshop Proceedings: U.S. Geological Survey Open-File Report 2007-1285, p. 177-182, available at http://pubs.usgs.gov/of/2007/1285/pdf/ Swinford.pdf.

Venteris, E.R., 2007, Qualitative and quantitative 3D modeling of surficial materials at multiple scales, in Soller, D.R., ed., Digital Mapping Techniques '06 - Workshop Proceedings: U.S. Geological Survey Open-File Report 2007-1285, p. 129-149, available at http://pubs.usgs.gov/of/2007/1285/pdf/ Venteris.pdf. 



\title{
Mapping Potential Geologic Hazards for Proposed Highway Construction Projects in Pennsylvania: Route 15 in Lycoming County
}

\author{
By Stuart O. Reese, P.G. \\ Pennsylvania Geological Survey \\ 3240 Schoolhouse Road \\ Middletown, PA 17057 \\ Telephone: (717) 702-2028 \\ Fax: (717) 702-2065 \\ email: streese@state.pa.us
}

\section{INTRODUCTION}

Recently, the Pennsylvania Geological Survey has worked on behalf of the Pennsylvania Department of Transportation (PennDOT) to develop maps for specific highway construction projects. The purpose of these maps is to identify potential geologic hazards such as landslides, sinkholes, mineralization, historic deep mines, acid drainage, and groundwater conditions. Map layers have included aerial imagery, digital elevation model (DEM) datasets, digital raster graphics (DRGs), bedrock units and their contacts, surficial and structural geology features, mapped landslides, glacial boundaries, and water well locations. Possible issues are described in the accompanying poster for the proposed construction zones (Figure 1). The current example is a proposed Interstate 99 upgrade of existing U. S. Route 15 in Lycoming County, Pennsylvania.

\section{BACKGROUND}

At PennDOT's request, the Pennsylvania Geological Survey has provided overviews of potential geologic hazards for proposed construction projects. Prior to this, PennDOT had encountered numerous unexpected geologic complexities that cost hundreds of millions of dollars in additional construction and environmental mitigation costs. Examples include major sinkholes that plagued bridge repair and adjacent new bridge construction over Bushkill Creek in Northampton County; a large sulfide deposit (known to the geologic community) that created lengthy delays and expensive remediation measures for Interstate 99 in Centre County; and, in Mifflin County, acidic drainage from uncovered Marcellus Shale (a black shale with approximately 3 percent sulfur) that had to be mitigated.

The current project is situated in north-central Pennsylvania in the Deep Valleys section of the Appalachian Plateaus physiographic province in Lycoming County, Pennsylvania. Section C41 of U.S. Route 15 is located from north of Trout Run to the Village of Buttonwood in the "Steam Valley" area of Cogan House and Lewis Townships. The improved highway corridor will become part of Interstate 99, the Appalachian Thruway. This requires an upgrade of the 4 1/2 mile Steam Valley section (C41) to a four-lane limited access highway that meets current design standards comparable to adjacent sections of U.S. 15. Construction is estimated to begin in fall 2007 (pending the availability of funds). At the time this paper was written, right-of-way appraisals were completed and acquisitions and negotiations nearly finished.

\section{MAP USAGE AND PREPARATION}

The map represents information that we recommend to be considered during the construction of the highway. It also represents the Pennsylvania Geological Survey's collective knowledge of the location's geology and its potential hazards. The process of gathering this knowledge for a report begins with a geologic literature search.

The starting point for the map was a digitized version of the proposed highway realignment. The geologic map portrays the underlying bedrock and surficial geology of the region. Mapped landslide locations, glacial boundaries, and groundwater points of information were included. Text descriptions of potential hazards were added to the 


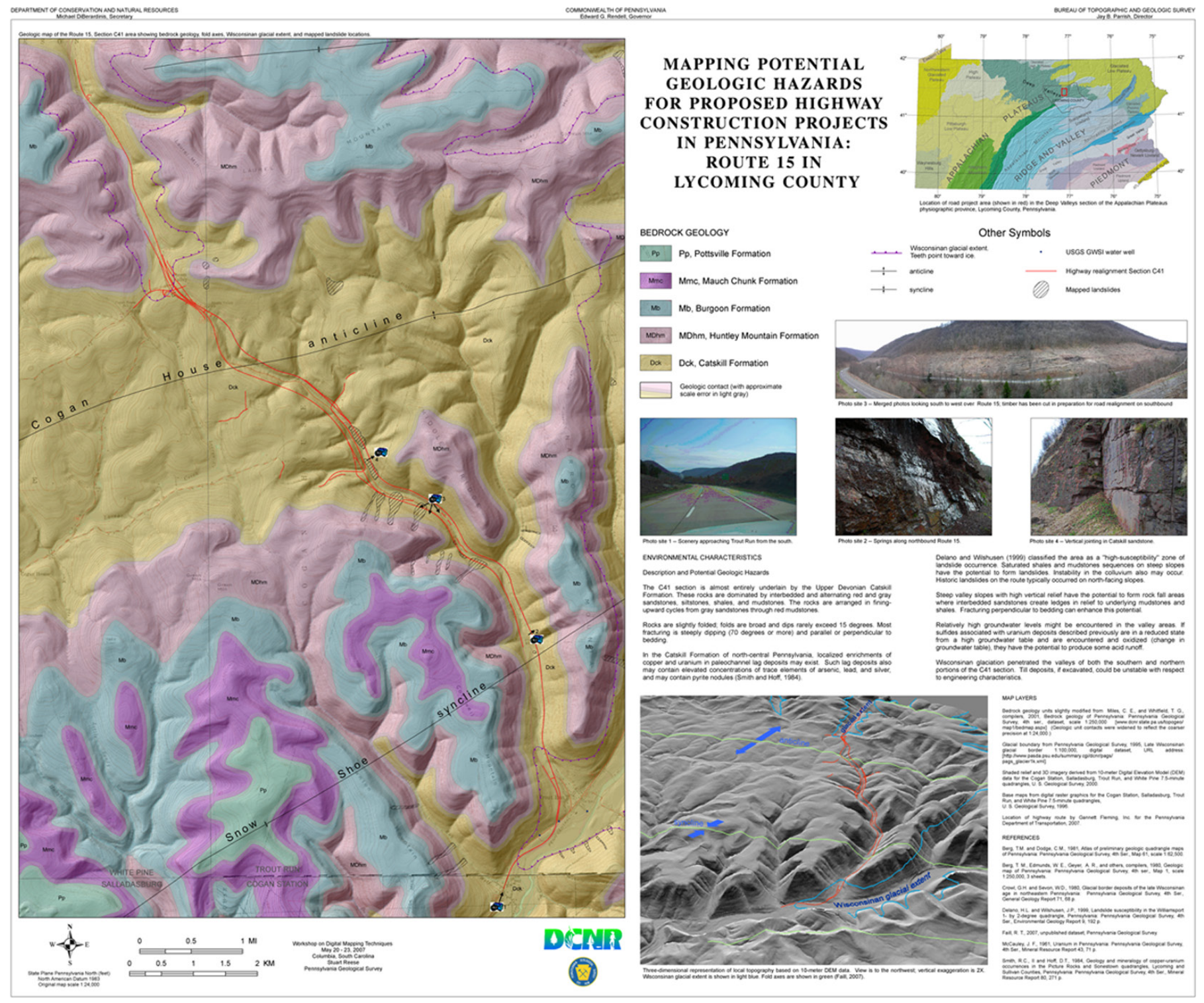

Figure 1. Mapping potential geologic hazards for proposed highway construction projects in Pennsylvania: Route 15 in Lycoming County (presented as a poster; see full-resolution image at $h t t p: / / n g m d b . u s g s . g o v / I n f o / d m t / d o c s /$ reese $07 . p d f$ ).

map. A base map using PAMAP imagery was tried but not used because it was more detailed than the presentation scale selected for this geologic hazard map (scale 1:24,000). Ultimately a transparent hillshade layer derived from the 10-meter DEM data was used over a seamless DRG layer as the base. To generate the map, ESRI ArcInfo ver. 9.2 software was used.

\section{CONSIDERATIONS AND RECOMMENDATIONS}

The following is a summary of geologic issues that were identified on the map. Regarding the bedrock geology, the C41 section is almost entirely underlain by Upper Devonian
Catskill Formation. These rocks are dominated by interbedded and alternating red and gray sandstones, siltstones, shales, and mudstones. The rocks are arranged in fining-upward cycles from gray sandstones through red mudstones. The Catskill Formation is overlain by the Huntley Mountain Formation. For the most part, the $\mathrm{C} 41$ section occurs within the Catskill Formation, though a portion of the highway at the north end intersects the Huntley Mountain Formation.

The major issue for this area is terrain stability, with shallow groundwater as an additional, related consideration. Minor issues include potential mineralization in channel lag deposits in the Catskill rocks, and a possible contribution to instability by Wisconsinan glacial deposits. Delano and Wilshusen (1999) classified the area as a "high-susceptibility" zone of landslide occurrence. Moist and saturated shales and 
mudstones sequences on steep slopes may form landslides. Instability and landsliding in the colluvium also may occur. Steep valley slopes with high vertical relief have the potential to form rock falls where interbedded sandstones create ledges, in contrast to undercutting into the underlying mudstones and shales. Jointing perpendicular to bedding can enhance this potential. Previous landslides typically occurred on northfacing slopes. Mapped landslides are included on the geologic map along with a note that other, unmapped landslides may be present.

In the Catskill Formation of north-central Pennsylvania, localized enrichments of copper and uranium in paleochannel lag deposits may exist. Such lag deposits also may contain elevated concentrations of trace elements of arsenic, lead, and silver, and may contain pyrite nodules (Smith and Hoff, 1984). Wisconsinan glaciation penetrated the valleys of both the southern and northern portions of the section including the Lycoming Creek valley past the village of Trout Run, and north of the village of Steam Valley.

The glacial deposits consist of discontinuous Quaternary Olean ground moraine, which is composed of a wide range of unsorted sediment types from clay and sand, to cobbles and boulders (collectively referred to as "till"). Till deposits have been mapped in these areas by Crowl and Sevon (1980); these deposits, if excavated, could be unstable, especially in areas where relatively high groundwater levels might be encountered. The median value of static water levels for all types of "valley" wells in the Catskill Formation of the Deep Valleys physiographic section was 20 feet ( $\mathrm{n}=116$ wells; Fleeger and others, 2004). For 25 percent of these wells, the static water level was less than 11 feet below surface. Records for three water wells near the village of Trout Run show static water levels less than 20 feet. In areas with such high water tables, slope stability is impaired where the geologic materials are excavated.

On the map delivered to PennDOT, it was noted that "This map is not a substitute for site-specific subsurface tests and investigations." The map included Pennsylvania bedrock geology units with geologic unit contacts that were widened to reflect the coarser precision at 1:24,000-scale. Geologic structure axes (e.g., folds) and measurements of their strike and dip were added to the map, based on internal data from an unpublished dataset of the Pennsylvania Geological Survey. For this area, folds are broad and dips rarely exceed 15 degrees. Most jointing is steeply dipping (70 degrees or more) and parallel or perpendicular to bedding. The late Wisconsinan glacial border was also portrayed. A shaded relief layer was used as derived from 10-meter DEM data for the Cogan Station, Salladasburg, Trout Run, and White Pine 7.5-minute quadrangles. DRGs for these quadrangles were used as the base layer for the map. Data showing the alignment of the highway centerlines were provided by a PennDOT consulting firm.

Digital and paper copies of the map were mailed to the Central and District offices of PennDOT. In a cover letter, we noted that our main concern was that new road construction might encounter some severe rockfall and landslide problems, based on the steepness and north-facing aspect of the slopes, the Catskill Formation's propensity for jointing in the sandstone, its variable lithology and subsequent differential weathering properties, known historical landslides, the presence of colluvium, and the probable shallow water table along the slopes. We also noted the expectation of a new surficial geologic map for part of the area in late spring, and that within the next year, as part of the PAMAP program, we are expecting the delivery of LiDAR data for Lycoming County. This new data will provide for a DEM and 2-foot contour data sets, and may help to identify historical stability issues with other slopes in the area.

We are hopeful that such mapping products will alert the engineers and geotechnical participants to the potential hazards that might be encountered, and that such information will benefit not only the engineering participants but the entire Commonwealth of Pennsylvania.

\section{ACKNOWLEDGMENTS}

The author thanks Michael Moore (Pennsylvania Geological Survey) for his helpful comments on the original manuscript.

\section{REFERENCES}

ArcInfo, ArcGIS - Environmental Systems Research Institute, Inc., 380 New York St., Redlands, CA 92373-8100 USA, (909) 793-2853, http://www.esri.com/.

Crowl, G.H., and Sevon, W.D., 1980, Glacial border deposits of the late Wisconsinan age in northeastern Pennsylvania: Pennsylvania Geological Survey, 4th Ser., General Geology Report 71, 68 p.

Delano, H.L., and Wilshusen, J.P., 1999, Landslide susceptibility in the Williamsport 1- by 2-degree quadrangle, Pennsylvania: Pennsylvania Geological Survey, 4th Ser., Environmental Geology Report 9, 192 p.

Fleeger, G. M., McElroy, T. A., and Moore, M. E., 2004, Hydrogeologic and well-construction characteristics of the rocks of Pennsylvania: Pennsylvania Geological Survey, 4th Ser., Water Resources Report 69, Database (Microsoft Access 97 and 2000).

Smith, R.C., II, and Hoff, D.T., 1984, Geology and mineralogy of copper-uranium occurrences in the Picture Rocks and Sonestown quadrangles, Lycoming and Sullivan Counties, Pennsylvania: Pennsylvania Geological Survey, 4th Ser., Mineral Resource Report 80, 271 p. 



\title{
Old Mapping and New LiDAR.......a Reality Check
}

\author{
By Thomas G. Whitfield \\ Bureau of Topographic and Geologic Survey \\ Pennsylvania Department of Conservation and Natural Resources \\ 3240 Schoolhouse Road \\ Middletown, PA 17057 \\ Telephone: (717) 702-2017 \\ Fax: (717) 702-2065 \\ email: twhitfield@state.pa.us
}

\section{ABSTRACT}

The Commonwealth of Pennsylvania has begun a state-wide mapping program called PAMAP; this will be a new digital map of Pennsylvania, available as a seamless, consistent, high resolution set of digital, geospatial data products. PAMAP data are being compiled from new, high-resolution aerial orthoimagery, LiDAR (Light Distancing and Ranging) elevation data, and existing digital map data developed by state and federal agencies, counties, regional agencies, and municipalities. PAMAP is part of The National Map, a cooperative effort of the U. S. Geological Survey (USGS) and the Commonwealth of Pennsylvania.

One of the components of the PAMAP project is flying high resolution, 1:2400 scale, color orthoimagery on a four year cycle. The objective is to have maps and imagery available that are no more than four years out of date. More recently, LiDAR was added to the data acquisition flight contracts.

During the 2006 flight program, several counties that were contracted to be flown for orthoimagery also were flown for LiDAR as a test. One of the counties, Luzerne, had an ongoing STATEMAP cooperative mapping project. The surficial geology of the Harveys Lake 7.5-minute quadrangle had just been compiled using traditional mapping methods by a very experienced author, Dr. Duane D. Braun, professor of Geology at Bloomsburg University of Pennsylvania.

The Pennsylvania Geological Survey (PAGS) obtained a beta version of the Luzerne County LiDAR DEMs (Digital Elevation Model) based on the "bare-earth" classified elevation points. These DEMs had not completed the Q/A process when this comparison was done so they may have some errors.

We decided to compile and print a raster hillshade of the Harveys Lake quadrangle from the DEMs and compare it to the surficial geology recently compiled. We also considered comparing the hillshade data-set to the bedrock geology of the area, but because this quadrangle has only three bedrock formations identified, $95 \%$ of which is the Devonian aged
Catskill Formation (Dck), the resulting comparison would not have been too informative.

For the original poster shown at the DMT'07 meeting, we printed the DEM-derived hillshade on glossy photopaper. We then printed the surficial geology polygons on a clear mylar overlay. Figure 1 is a rendition of the poster, and shows the raster hillshade data-set and surficial geology overlay as a single image.

\section{MAP PREPARATIONS}

In mapping the Harveys Lake quadrangle, Braun used a variety of sources and methods. Soils maps, aerial photography, previously published and unpublished mapping efforts, and good old-fashioned field work were his main sources of data. Combinations of digital and analog methods were used to compile the digital data-sets into ESRI geodatabases.

The map overlay (refer to Figure 1), is a de-constructed map of surficial geology that is part of the PAGS Open File Series of Surficial Materials (OFSM) report for the Harveys Lake quadrangle. Normally, the surficial geology and supporting Digital Raster Graphic (DRG) files are printed on the map area. For the purposes of this demonstration, we printed the surficial geology and DRG on clear film to act as an overlay, dropping the colors for the mapped Bedrock (R) and Urban (U) areas just to show the glacial deposits and some obvious manmade disturbances. We then compiled a raster hillshade from the LiDAR DEMs using ESRI ArcGIS 9.2 and printed it with our HP 5500 UV plotter on HP Durable HighGloss photo paper.

For obvious reasons, we could not reproduce the clear film overlay in the PDF version of this poster, shown in Figure 1. But, we did produce a reasonable facsimile. We took the same surficial geology data-set used in making the clear film overlay, set a $50 \%$ transparency, and applied it as a layer over the hillshade raster data-set. Some color changes were necessary so certain features would be visible against the grays of 


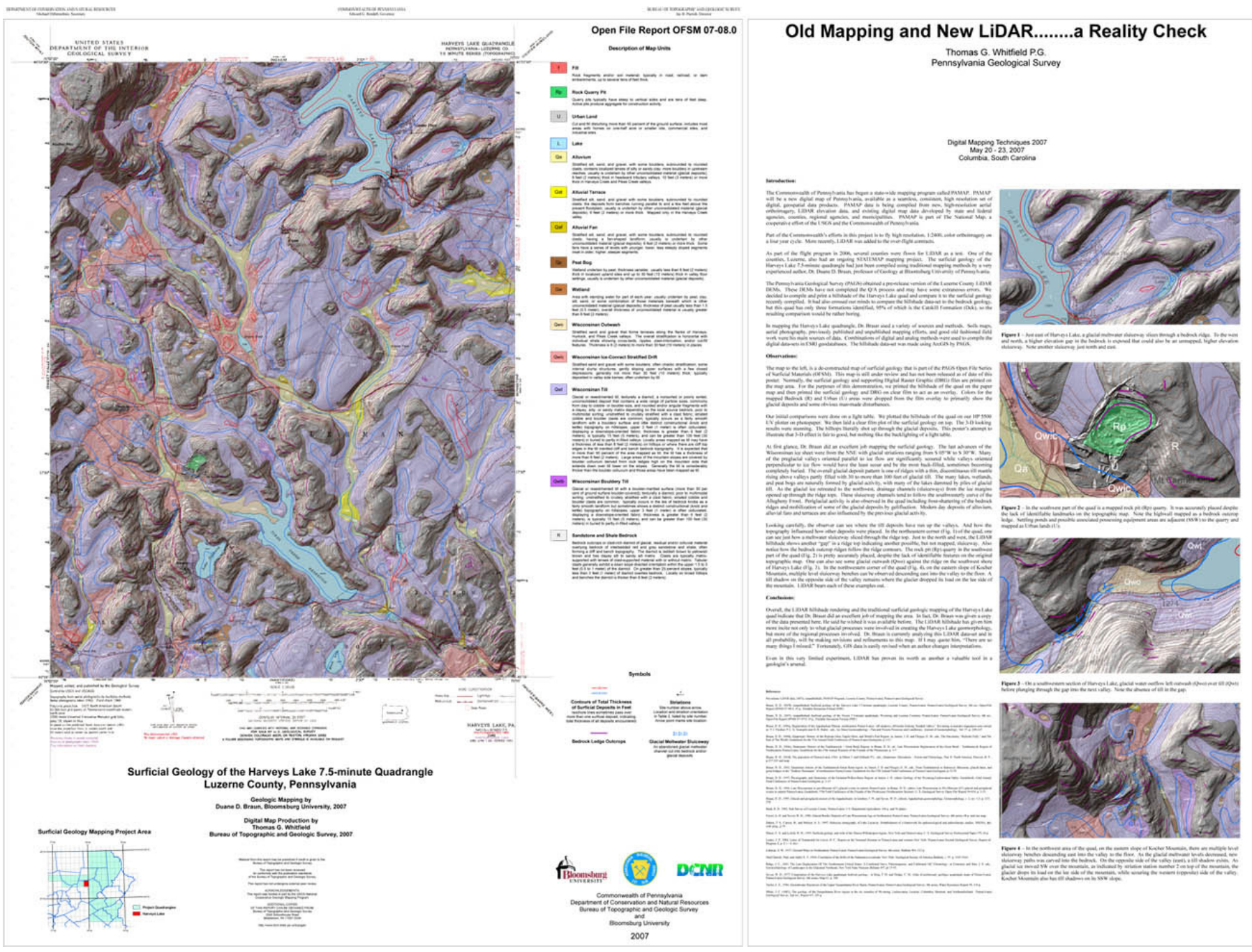

Figure 1. Old Mapping and New LiDAR........a Reality Check (presented as a poster; see full-resolution image at http://ngmdb.usgs.gov/ Info/dmt/docs/whitfield07.pdf).

the hillshade. Although the visual effects are not as spectacular as described below, they do get the point across.

\section{OBSERVATIONS}

Our initial visual analysis was done on a light table. We placed the photo paper plot of the hillshade on the light table, and then laid the clear film plot of the surficial geology on top. The simulated 3-D appearance was stunning. The higher elevation hilltops are clearly shown, surrounded by the glacial deposits. The poster and PDF file's attempt to illustrate this 3-D effect is good, but nothing like the backlighting of a light table.

At first glance, Braun did an excellent job mapping the surficial geology. The last advances of the Wisconsinan ice sheet were from the NNE with glacial striations ranging from $\mathrm{S} 05^{\circ} \mathrm{W}$ to $\mathrm{S} 30^{\circ} \mathrm{W}$. Many of the preglacial valleys oriented parallel to ice flow are significantly scoured while valleys oriented perpendicular to ice flow would have the least scour and be the most back-filled, sometimes becoming completely buried. The overall glacial deposit pattern is one of ridges with a thin, discontinuous till mantle rising above valleys partly filled with 30 to more than 100 feet of glacial till. The many lakes, wetlands, and peat bogs are naturally formed by glacial activity, with many of the lakes dammed by piles of glacial till. As the glacial ice retreated to the northeast, drainage channels (sluiceways) from the ice margins opened up through the ridge tops. These sluiceway channels tend to follow the southwesterly curve of the Allegheny Front. Periglacial activity is also observed in the quadrangle including frostshattering of the bedrock ridges and mobilization of some of the glacial deposits by gelifluction. Modern day deposits of alluvium, alluvial fans and terraces are also influenced by the previous glacial activity (Braun 2007).

Looking carefully, the observer can see where the till was deposited as ice flowed down the valleys, and where the 
topography influenced how other deposits were emplaced. In the northeastern corner (Figure 2) of the quad, one can see just how a meltwater sluiceway sliced through the ridge top. Just to the north and west, the hillshade shows another "gap" in a ridge top indicating another possible, but not mapped, sluiceway. Also notice how the bedrock outcrop ridges follow the ridge contours. Keep in mind that these ridges were mapped prior to LiDAR availability.
The rock pit (Rp) quarry in the southwest part of the quadrangle (Figure 3 ) is accurately placed, despite the lack of identifiable features on the original topographic map. One can also see some glacial outwash (Qwo) against the ridge on the southwest shore of Harveys Lake (Figure 4). In the northwestern corner of the quadrangle (Figure 5), on the eastern slope of Kocher Mountain, multiple level sluiceway benches can be observed descending east into the valley to its
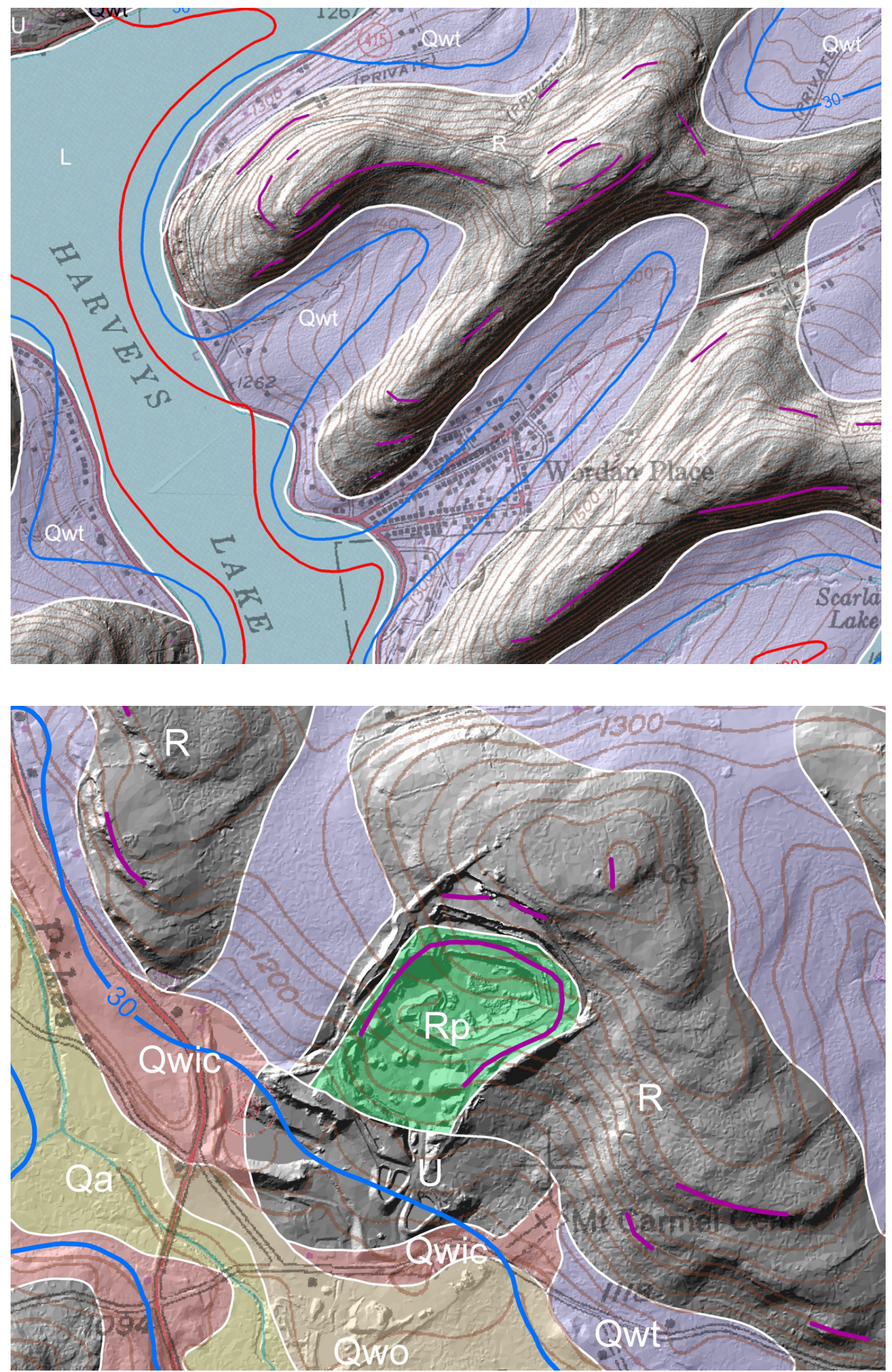

Figure 2. Just east of Harveys Lake, a glacial meltwater sluiceway cuts through a bedrock ridge. To the west and north, a higher elevation gap in the bedrock is exposed that could also be an unmapped, higher elevation sluiceway. Note another sluiceway just north and east.

Figure 3. In the southwest part of the quadrangle is a mapped rock pit (Rp) quarry. It was accurately placed despite the lack of identifiable landmarks on the topographic map. Note the high-wall mapped as a bedrock outcrop ledge. Settling ponds and possible associated possessing equipment areas are adjacent (south-southwest) to the quarry and mapped as Urban lands (U). 

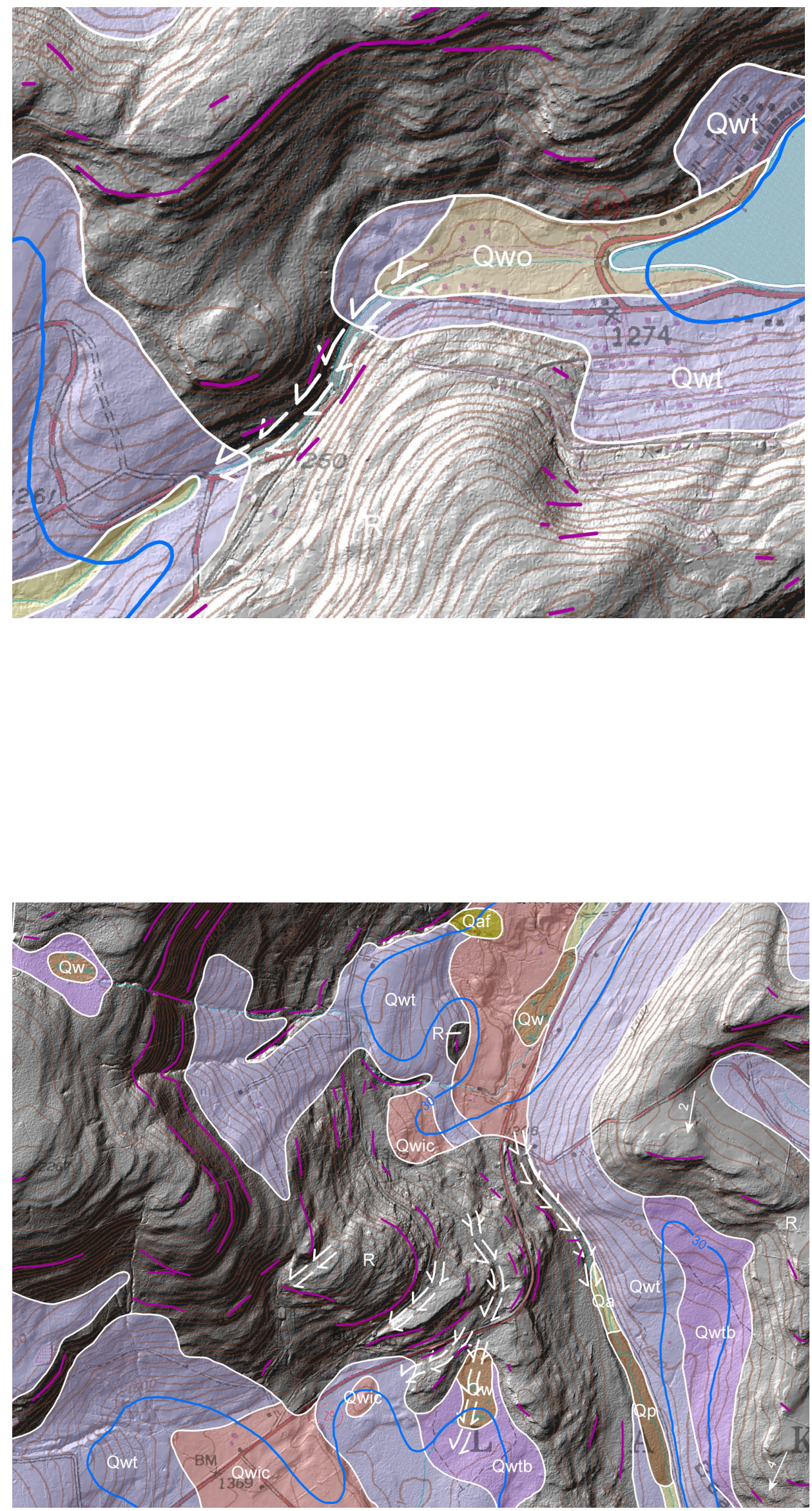

Figure 4. On a southwestern section of Harveys Lake, glacial water outflow deposited outwash (Qwo) over till (Owt) before plunging through the gap into the next valley. Note the absence of till in the gap.
Figure 5. In the northwest area of the quadrangle, on the eastern slope of Kocher Mountain, there are multiple level sluiceway benches descending east into the valley to the floor. As the glacial meltwater levels decreased, new sluiceway paths were carved into the bedrock. On the opposite side of the valley (east), a till shadow exists. As glacial ice moved southwest over the mountain, as indicated by striation station number 2 on top of the mountain, the glacier drops its load on the lee side of the mountain, while scouring the western (opposite) side of the valley. Kocher Mountain also has till shadows. 
floor. A till shadow on the opposite (eastern) side of the valley remains where the glacier dropped its load on the lee side of the mountain. LiDAR verifies each of these examples.

\section{PRELIMINARY CONCLUSIONS}

Overall, the LiDAR DEM hillshade rendering and the traditional surficial geologic mapping of the Harveys Lake quadrangle indicate that Braun (2007) did an excellent job of mapping the area. In fact, Braun was given a copy of the data presented here. He said he wished he had this data available while he was mapping. The LiDAR DEM hillshade has given him more insight not only to what glacial processes were involved in creating the Harveys Lake geomorphology, but on the regional processes involved. Braun is currently analyzing this LiDAR data-set, and in all probability will be making revisions and refinements to this map. If I may quote him, "There are so many things I missed." Fortunately, GIS data are easily revised when an author changes interpretations.

One of the biggest advantages of LiDAR derived DEMs is the level of detail of the ground surface. There is more detail than even the USGS 10-meter DEMs offered previously. They also have the distinct advantage of having all the vegetation, trees, buildings, etc., effectively filtered out and removed. Even in this very limited experiment, LiDAR has proven its worth as another valuable tool in a geologist's arsenal.

\section{REFERENCE}

Braun, D. D., 2007, Surficial geology of the Harveys Lake 7.5-minute quadrangle: Luzerne County, Pennsylvania: Pennsylvania Geological Survey, 4th series, Open-File Report OFSM 07-08.0, 19 p., Portable Document Format (PDF), available at http://www.dcnr.state.pa.us/topogeo/. 



\title{
DNAG Geologic Map of North America GIS Implementation: Overview and Progress
}

\author{
By Christopher P. Garrity and David R. Soller \\ U.S. Geological Survey \\ National Center, MS 956 \\ 12201 Sunrise Valley Drive \\ Reston, VA 20192 \\ Telephone: (703) 648-6426 \\ Fax: (703) 648-6419 \\ email: \{cgarrity, drsoller\}@usgs.gov
}

\section{PURPOSE 1}

When plans for the Geologic Map of North America (GMNA) were being made, the notion of geologic map databases was in its infancy. At that time, and for many years thereafter, few geologists were familiar with the design and use of databases to manage geologic map information. In 1998, the Geological Society of America (GSA) and the United States Geological Survey (USGS) National Geologic Map Database project agreed to cost-share the digital preparation of this map. The plan was to digitize the hand-drawn, author-prepared geologic compilations for the four map quadrants, in order to provide digital data for two purposes: (1) to allow GSA to print the map, and (2) to permit the National Geologic Map Database project to develop a prototype database for this map. When the map was printed, the National Geologic Map Database project began to design and implement the GMNA for use in a Geographic Information System (GIS), based on certain assumptions regarding the anticipated content of, and uses for, the map database as it gradually evolved from the printed map. In mid-2006, a GIS prototype of the GMNA (Garrity and Soller, 2006) was provided to the organizations principally responsible for map compilation (GSA, USGS, Geological Survey of Canada, and Woods Hole Oceanographic Institute), in order to initiate discussion and decisions on how the map database would be designed, managed, and served to the public and cooperators. These discussions were successfully concluded, and in 2007 construction of the database began. The first version of this database will contain the geologic information observable from the printed map and accompanying explanation sheet. It will serve as the fundamental entity from which products of the

${ }^{1}$ Modified from Soller, in Reed et al. (2005) map can then be derived. These products may be interpretive, or they may be future editions of the map.

To produce any future editions of the map, the database will incorporate all map revisions that are necessitated by detection of compilation errors and by new regional mapping and interpretations. Further, the geologic unit descriptions shown on the printed map can be supplemented in the database by more richly attributed information derived from the many sources that were used to compile the map. This capability to revise the printed map and to include additional descriptive information for map units is one of the primary reasons for building the database; the other reason is, of course, the analytical capabilities made possible by providing the map in a digital, GIS compatible format.

The creation of this database and its enhancement to include new mapping and more richly attributed information is a daunting task that will require a significant amount of time and effort. Recognizing that a group of dedicated and knowledgeable scientists is essential to make this database useful and to keep its content up to date, GSA will develop a consortium of geological agencies to manage the database.

\section{DATABASE DESIGN}

The design of this first version of the GMNA database reflects the information structure of the printed map. As the database evolves, data attributes will be modified to make the database more comprehensive and useful. Also, future versions of the GMNA database may incorporate elements of the North American Data Model (http://nadm-geo.org/) and be harmonized in content with the International Geological Map of Europe (http://www.bgr.de/karten/IGME5000/ igme5000.htm). Figure 1 shows the geologic features found 


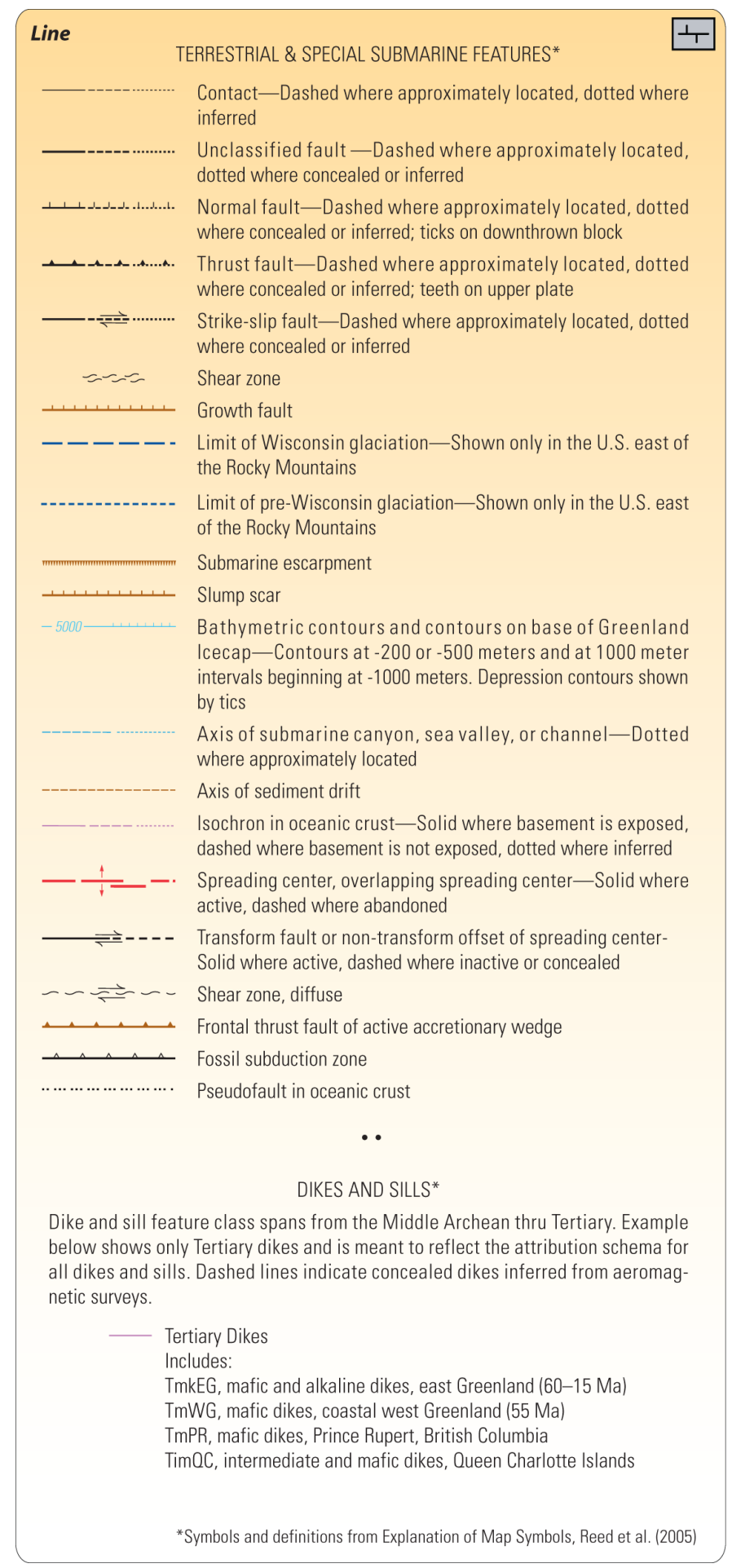

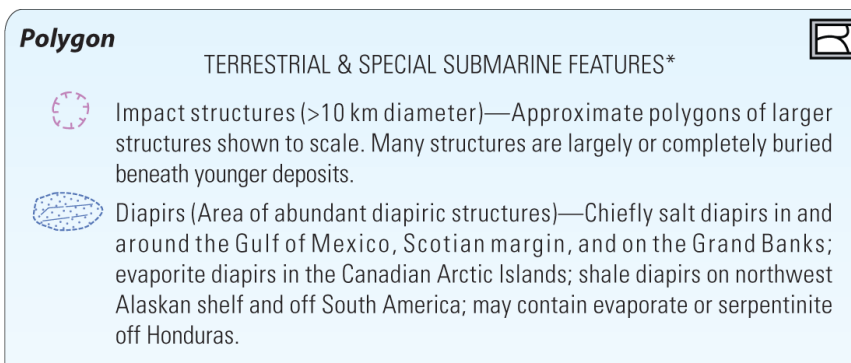

GEOLOGIC UNITS*

The GMNA contains overs 900 individual geologic unit definitions. Units are defined on the basis of age, origin, and where possible, composition (Reed et al., 2005). Example below (from Explanation of Map Units, Reed et al., 2005) illustrates the direction of geologic unit database design:

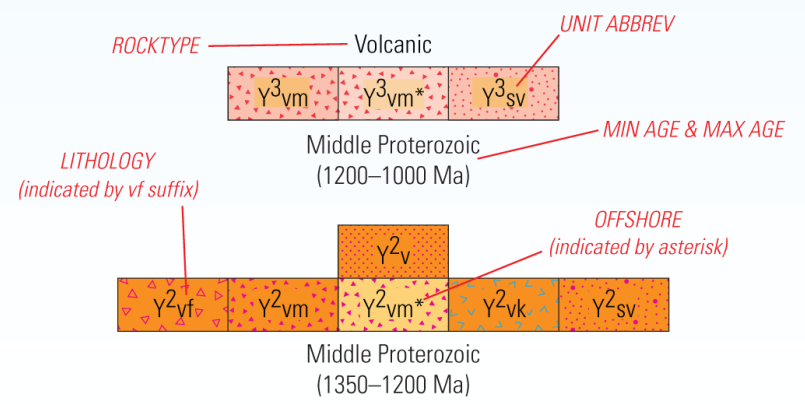

*Symbols and definitions from Explanation of Map Symbols, Reed et al. (2005)

Point

TERRESTRIAL \& SPECIAL SUBMARINE FEATURES*

\begin{tabular}{|c|c|c|c|}
\hline (1) & Hydrothermal vent & 0 & Undifferentiated \\
\hline (1) & Gas/oil seep & - & Crusts \\
\hline$\odot$ & Gas/fluid seep & $\square$ & Nodules \\
\hline 0 & Polymetallic sulfide deposits & $\Delta$ & Blocks, slabs, and pavements \\
\hline$x$ & Diatreme & $\bullet$ & $\begin{array}{l}\text { Crusts, blocks, slabs, and } \\
\text { pavements }\end{array}$ \\
\hline 0 & Ultramafic & घ & Nodules, blocks, slabs, and \\
\hline$\diamond$ & Felsic & & pavements \\
\hline$\triangle$ & Granite & $\square$ & Crusts and nodules \\
\hline 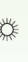 & Cinder cone or lava dome & $\downarrow$ & $\begin{array}{l}\text { Crusts, nodules, blocks, slabs, } \\
\text { and pavements }\end{array}$ \\
\hline$\star$ & Volcano & - & Phosphate nodules or pavement \\
\hline - & Dome $>10$ km diameter & $\Delta$ & Carbonatite \\
\hline - & Dome $<10 \mathrm{~km}$ diameter & $\bullet$ & Kimberlite \\
\hline
\end{tabular}

*Symbols and definitions from Explanation of Map Symbols, Reed et al. (2005)

Figure 1. Features of the geologic map of North America grouped by feature geometry type.

on the printed GMNA, and how they are generally organized in the database. Figure 2 specifies the organization of these features in the ESRI Geodatabase structure.

\section{GEOLOGIC UNIT ATTRIBUTES}

For this first version of the database, we strove to capture the information exactly as it was depicted in the GMNA explanation sheet that accompanies the published map. For geologic map units, the database's attribute list includes: 


\section{GMNA GEODATABASE DESIGN}

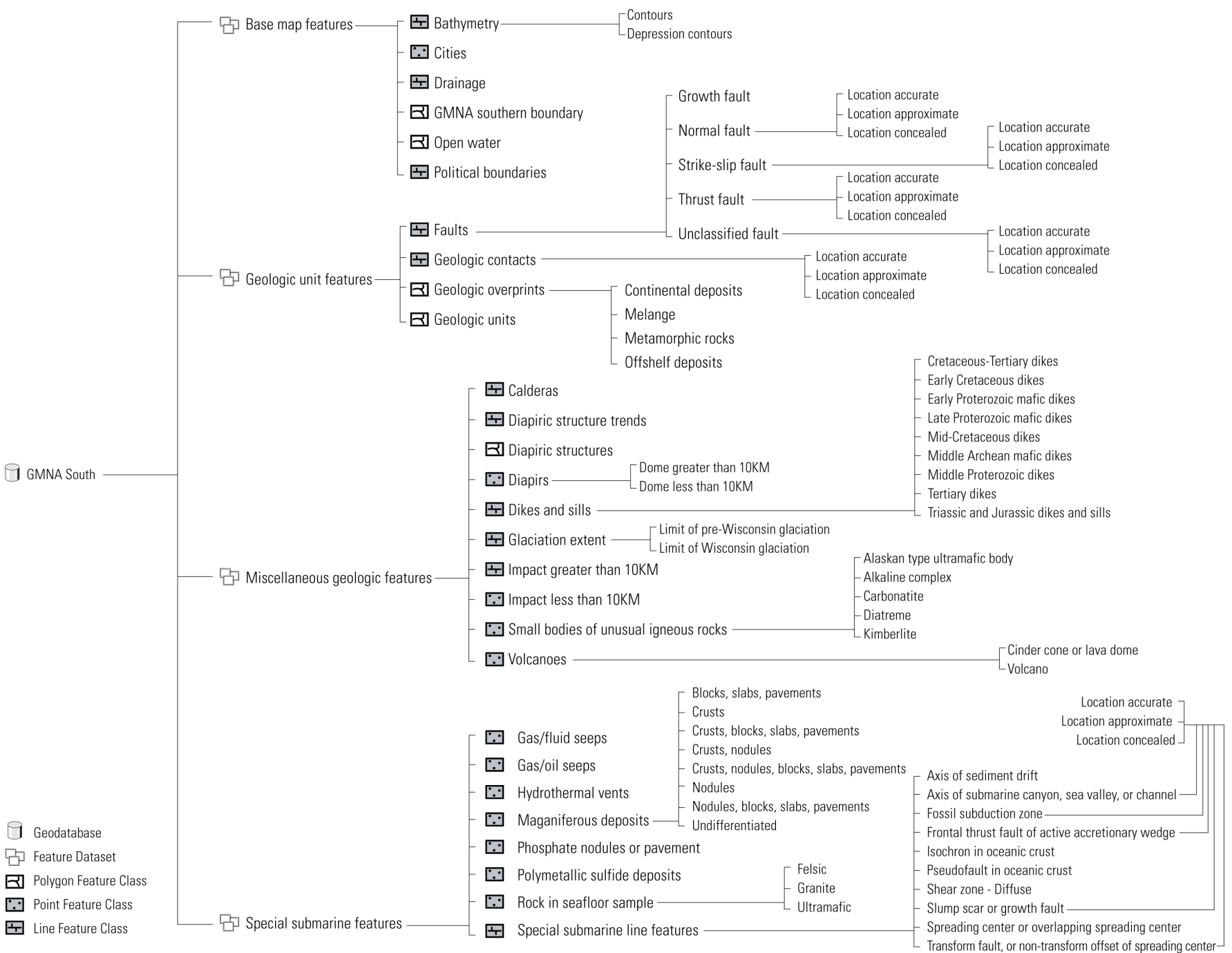

Figure 2. Database design of the Geologic Map of North America. Primary bracket includes feature datasets, secondary bracket includes features classes, tertiary and quaternary brackets include feature class subtypes.

- ROCKTYPE - the "top level" rock classification (sedimentary, plutonic, volcanic, metamorphic).

- LITHOLOGY - the simplified description included for each geologic unit on the explanation sheet of the GMNA.

- ROCK_UNIT_NOTE - special notes associated with certain units on the explanation sheet of the GMNA. For example, selected volcanic rocks are attributed "Basalt adjacent to active spreading centers", selected metamorphic rocks are attributed "Granulate facies metamorphism", and selected sedimentary rocks are attributed "Continental deposits".

- UNIT_UNCERTAINTY - a query following the map unit code indicates uncertainty about composition, or whether the rock was recovered in situ from the ocean bottom.
- MIN_AGE - minimum geologic age for the unit. Subdivisions of time-stratigraphic units are lower, middle, and upper (lower-case), and for plutonic rocks are Early, Middle, and Late

- MAX AGE - see comments for MIN AGE.

- MIN_AGE_CODE - code derived from the geologic age codes defined by the AAPG Committee on Standard Coding (1967)

- MAX_AGE_CODE - see comments for MIN_AGE_ CODE.

- AGE_UNCERTAINTY - a query preceding the map unit label indicates uncertainty about the assigned age.

- MAP_UNIT_CODE - the GMNA map unit code

- MIN_MAX_RELATE - the relationship ("and", “or", "thru") between the MIN/MAX ages of units bounded by multiple ages. 


\section{PROCESSING STEPS}

The following steps are taken to process the source digital files into the GMNA database:

1. Adobe Illustrator files containing linework used for the hard copy production of the Geologic Map of North America (GMNA) were obtained from USGS cartographers in Reston, VA. The two (northern and southern) Illustrator source files were massive, with layer counts totaling over 1,500 each.

2. Files were analyzed to determine if direct import of the entire Adobe Illustrator file to ArcGIS was possible. When observed at scales far more detailed than that of the printed map, the files showed numerous areas where problems in topological relationships existed. Common topological problems in these areas included polygons that overlapped or had gaps between them, overlying line layers (contacts, faults, etc.) which were not coincident with polygon boundaries, and line features that self-overlapped. Topological errors were estimated in the hundreds of thousands.

3. To avoid the time consuming process of correcting each topological error due to the direct import of all features from Adobe Illustrator to ArcGIS, only the non-geologic contact linework coincident with geologic unit boundaries was imported. For attribution purposes, each line type (inferred thrust fault, concealed thrust fault, etc.) was imported to ArcGIS individually.

4. The remaining linework (geologic contacts) was isolated in Adobe Illustrator and exported as a series of highresolution ( $\sim 600-1200 \mathrm{dpi})$ monochrome raster tiles. Export at lower resolutions resulted in "blobbing" of raster cells in areas where very intricate linework existed, making them undesirable for auto-vectorization purposes.

5. When computer generated graticules plotted on stable base media were overlain on the printed version of the GMNA, unsystematic registration shifts at latitudelongitude intersections were observed throughout the printed version of the GMNA. Although shrinking/ swelling of base media may have contributed to the registration inconsistency, it is more likely that error was introduced in the numerous iterations (and numerous technological changes in cartographic production) of the GMNA over its twenty year history of compilation. As a result, the monochrome tiles exported from Adobe Illustrator had to be rubber sheeted to local geographic coordinate positions using control points in the DNAG projection (Snyder, 1987).

6. Georeferenced monochrome images were auto-vectorized using ArcScan. Gaps and overlaps between tiles due to rubber sheeting were rectified via raster painting tools.
7. Topology rules were set in ArcMap and line dangles in the newly vectorized layer were snapped to the nearest unitbordering line features imported in process step 3. This resulted in a topologically clean layer.

8. Individual geologic unit layers were batch exported from Adobe Illustrator and used to overlay the feature class created in step 7. Through spatial querying, polygons in the new layer that had their center within a specific overlay layer were attributed based on the overlay's geologic unit abbreviation.

9. Remaining attribution for all other fields was completed quickly through VBA field calculator scripting based on the populated unit abbreviation field.

10. Feature class symbolization was created to closely resemble the printed version of the GMNA. Feature class symbology was exported to layer files.

\section{REFERENCES}

American Association of Petroleum Geologists, Committee on Standard Coding, George V. Cohee, Chairman, 1967, Standard stratigraphic code adopted by AAPG: American Association of Petroleum Geologists Bulletin, v. 51, no. 10, p. 2146-2150.

Garrity, C.P., and Soller, D.R., 2006, Prototype GIS Database for the DNAG Geologic Map of North America, in D.R. Soller, ed., Digital Mapping Techniques '06 - Workshop Proceedings: U.S. Geological Survey Open-File Report 2007-1285, p. 197-201, accessed at http://pubs.usgs.gov/ of/2007/1285/pdf/Garrity.pdf.

Reed, J.C. Jr., Wheeler, J.O., and Tucholke, J.E., compilers, 2004, Geologic Map of North America: Decade of North American Geology Continental Scale Map 001, Boulder, Geological Society of America, scale 1:5,000,000, accessed at http://rock.geosociety.org/bookstore/default. asp $? o I D=0 \&$ cat $I D=2 \& p I D=C S M 001 F$.

Reed, J.C. Jr., Wheeler, J.O., and Tucholke, B.E., 2005, Geologic Map of North America-Perspectives and explanation: Boulder, Colorado, Geological Society of America, Decade of North American Geology, 28 p.

Snyder, J.P., 1987, Map projections - a working manual: U.S. Geological Survey Professional Paper 1395, 383 p.

Soller, D.R., 2005, Digital Database, in Reed, J.C. Jr., Wheeler, J.O., and Tucholke, B.E., Geologic Map of North America-Perspectives and explanation: Boulder, Colorado, Geological Society of America, Decade of North American Geology, p. 20. 


\title{
Compilation and Production of the 1:500,000-scale Geologic Map of Washington State, and Some Aspects of 1:24,000-scale Map Production at the Washington Division of Geology and Earth Resources
}

\author{
By J. Eric Schuster, Charles G. Caruthers, Anne C. Heinitz, and Karen D. Meyers \\ Washington Department of Natural Resources \\ Division of Geology and Earth Resources \\ 1111 Washington St. SE \\ PO Box 47007 \\ Olympia, WA 98504 \\ Telephone: (360) 902-1455 \\ Fax: (360) 902-1785 \\ email: charles.caruthers@dnr.wa.gov
}

The 1:500,000-scale Geologic Map of Washington State (Schuster, 2005) presents the geology of Washington State at a scale that allows the entire state to be shown on one sheet of reasonable size (Figure 1). It is the first new 1:500,000scale geologic map of Washington published since 1961, and is intended primarily for wall display. Map compilation involved both digital and hard-copy sources, and production was entirely digital (Figure 2).

\section{DIGITAL CAPTURE OF THE SOURCE DATA}

This map was compiled from four 1:250,000-scale geologic maps, each covering a quadrant of Washington State (Walsh and others, 1987; Stoffel and others, 1991; Schuster and others, 1997; Dragovich and others, 2002). Much of the data presented on the 1:500,000-scale map was compiled and published at 1:100,000 and 1:250,000 scales before the Division began using digital methods. Three of the four quadrants (southwest, northeast, and southeast) of Washington State were compiled at 1:250,000 scale from open-filed 1:100,000scale geologic maps using manual and photographic methods. The 1:100,000-scale geologic maps were reduced photographically to $1: 250,000$ scale, and the authors simplified them to a level of complexity suitable for presentation at 1:250,000 scale by combining geologic units with different formal or informal names, but with the same geologic age and general lithology.
These maps were manually registered to a 1:250,000-scale mylar grid and used as masters for scribing the faults, folds, contacts, and other features. The scribecoats and peelcoats became original materials for the photographic preparation of composite negatives from which printer's press plates for the published 1:250,000-scale maps were made. The scale-stable and other materials from this process became the source documents for digitizing and attributing arcs, points, and polygons at 1:250,000 scale. Digitizing for the southwest, northeast, and southeast quadrants was done in ESRI ArcInfo 8.3 on a backlit digitizing table.

The northwest quadrant was prepared using digital methods from 1:100,000-scale geologic quadrangle maps prepared by Division and U.S. Geological Survey geologists. Some of these maps were produced using manual methods, while others were produced digitally; those that were not created digitally were digitized in ArcInfo. The digital data for all 1:100,000-scale maps in the northwest quadrant were then appended and simplified by merging geologic polygons of the same age and lithologic range. Line and point features were simplified on-screen, as guided by the authors. The resulting ArcInfo coverages were used to produce the published map of the northwest 1:250,000-scale quadrant and, eventually, in the compilation of the 1:500,000-scale map.

These procedures resulted in several ArcInfo 8.3 coverages for each of the four 1:250,000-scale quadrants of Washington State. These four groups of ArcInfo coverages were appended and converted to shapefiles in ArcGIS 9.0, and the geology was simplified for publication at 1:500,000 scale. 


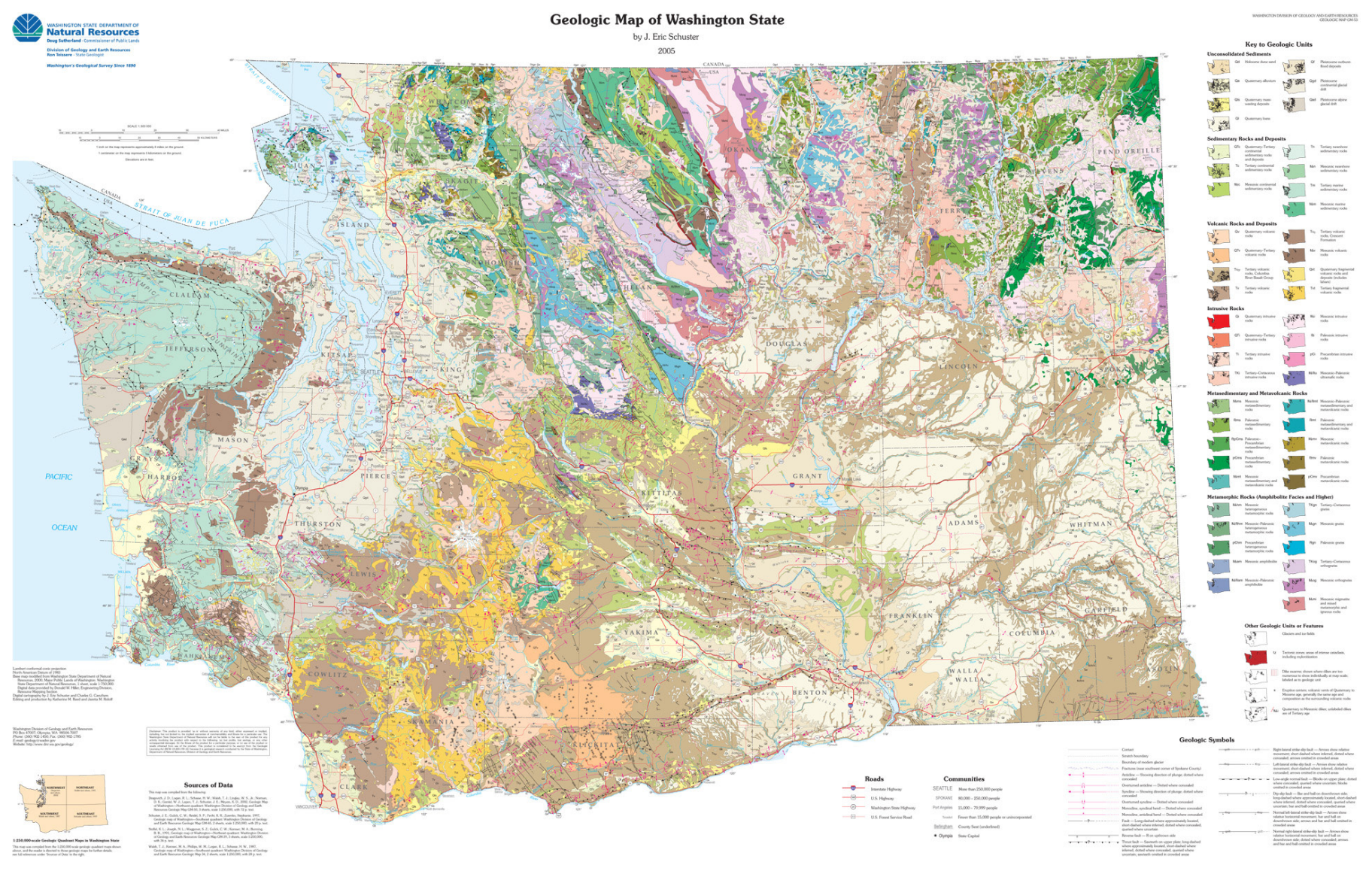

Figure 1. Geologic Map of Washington State (presented at DMT'07 as a poster; see high-resolution image at http://ngmdb.usgs.gov/Info/dmt/schuster07b.pdf).

\section{SIMPLIFICATION OF THE SOURCE DATA}

Simplification of the 1:250,000-scale geologic information was an iterative process with the goal of producing 1:500,000-scale geologic data that is easy to read everywhere on the map. Small water polygons were eliminated early-on, as were the shortest faults, folds, and dikes. Then the 1:250,000-scale map units were lumped into units with broader age and lithologic ranges. In two iterations the number of map units were decreased from about 400 at 1:250,000 scale to 53 at 1:500,000 scale. The original labels for units that were to be lumped were changed to the new label, and then a dissolve was performed on the polygons to create one polygon. Some remaining areas were too complex and not clearly legible, so additional small polygons were deleted unless they were important for defining the extent of a map unit. Small polygons in close proximity to each other were manually combined into larger polygons, which involved snapping arcs together to make the outline of the new polygon, building the coverage, running a label error check, and deleting any extra labels. Some faults, folds, and dikes in crowded areas were deleted as well.

\section{MAP PRODUCTION}

Shapefiles were imported into Adobe Illustrator using the Avenza MAPublisher plug-in. MAPublisher provided access to line and polygon attributes in order to assign line types for contacts, faults, and folds, as well as geologic unit labels and colors for geologic polygons. However, line ornaments needed to be placed directly into Illustrator as EPS files generated by ArcInfo, because we do not have the ability to ornament arcs through MAPublisher and Adobe Illustrator so that the ornaments can be displayed satisfactorily for publication.

The legend for the Washington 1:500,000-scale geologic map contains a useful detail found on the recently-published Pennsylvania statewide geologic map (Miles, 2003); that is, a small index map next to each geologic unit description in the legend shows the distribution of that unit. An ArcInfo AML is used to generate the state outline for this legend icon. Within each legend icon, the locations of each geologic feature are plotted by AML cursors. Because of the small size of the legend icons, each geologic polygon is represented as a dot, positioned at its centroid. Glaciers and ice fields, tectonic zones, dikes, dike swarms, and eruptive centers are represented in the legend in similar fashion. Finally, the AML saves the legend as an EPS file, to be loaded into Illustrator. This map won 


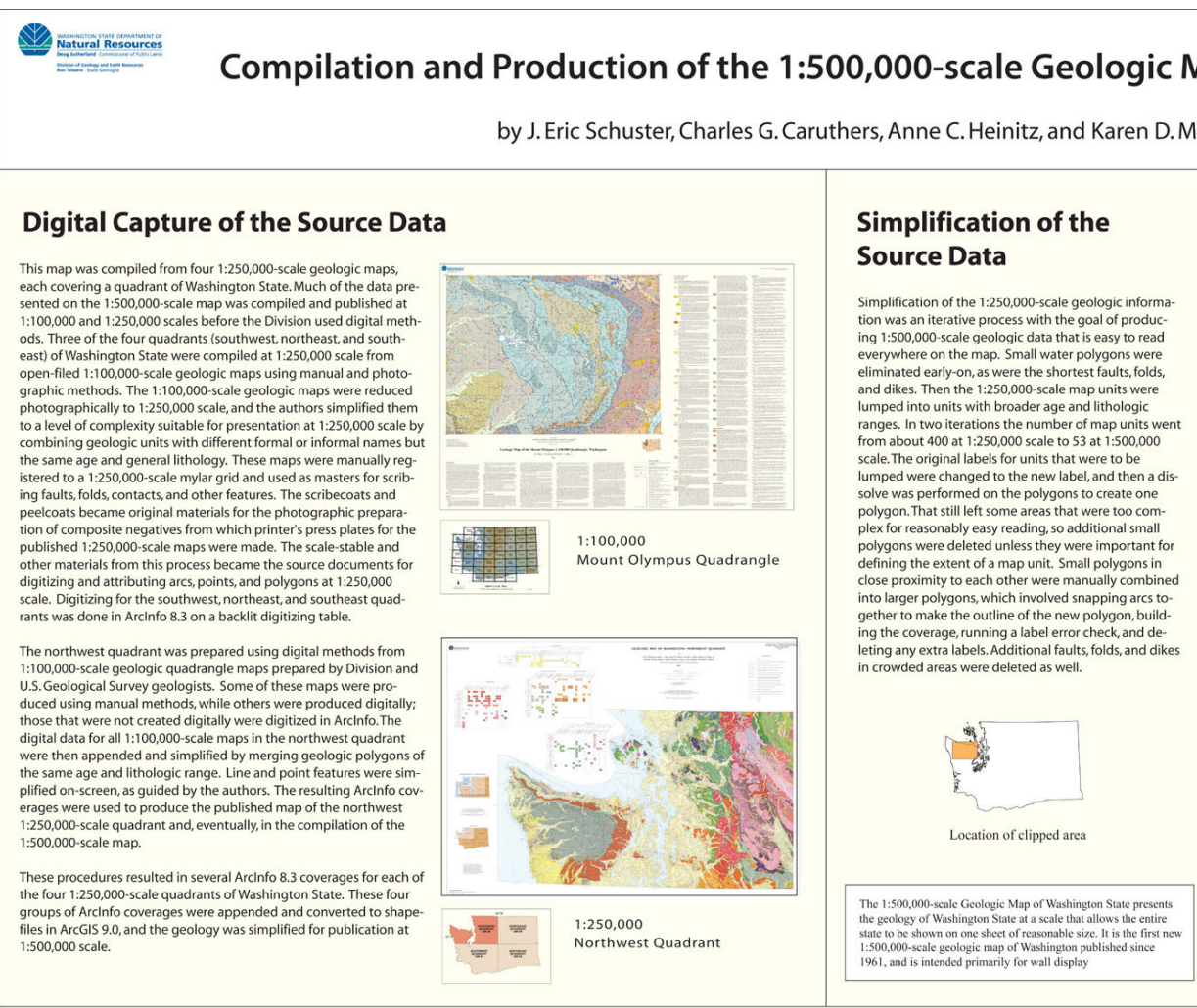

Map Production

Shapefiles were imported into Adobe lllustrator using the Avenza MAPublisher plug-in. MAPublisher provided access to line and polygon attributes
to assign line types for contacts, faults, and folds, as well as geologic unit labels and colors for geologic polygons. However, line ornaments needed to be placed directly in to ll llustrator as EPS files generated by Arclnfo because we do not have the ability to ornament arcs through MAPublisher and Adoblellustic

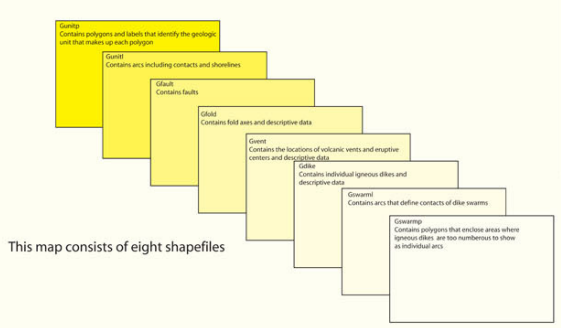

The Adobe lllustrator file is made up of 25 layers. The base map was made in house and the map went through extensive editing to insure that there were no cartographic con
and leaders, fault and fold ornamentation, and other features.

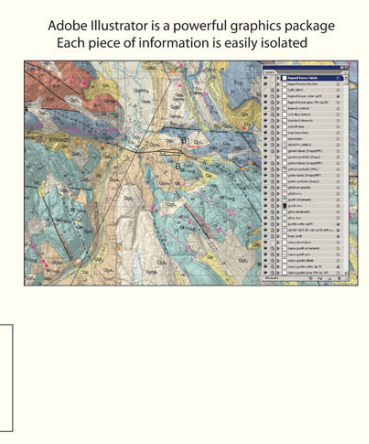

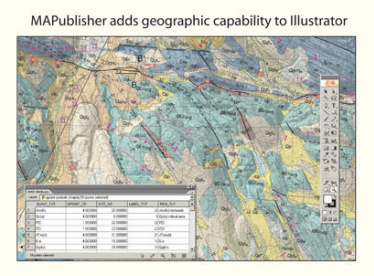

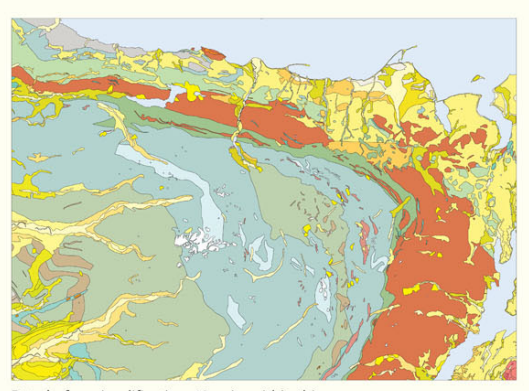

Data before simplification: 48 units within this area

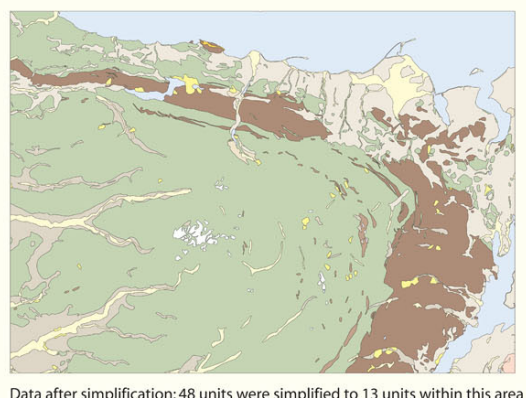

\section{Some Aspects of 1:24,000-scale Map Production}

Each year, under the US. Geological Survey STATEMAP program, we produce new 1:24,000-scale geologic maps of 75 -minute quad-
rangles in Washington. We use a variety of software to make our maps: ArcInfo, ArcGIS, MAPublisher, Adobe Illustrator, CorelDraw,
and Adobe InDesign. In the course of map production, we have de-
velooed several map production tools that may be useful to others producing similar products. We have developed some Python scripts for use in ArcGls that you may find useful; we also use some scripts that others have written.

We have also developed a set of ArcMap layer files containing geo logic symbols for draft-quality maps, and symbol polettes
Adobe lliustrator for our final publication-quality maps.
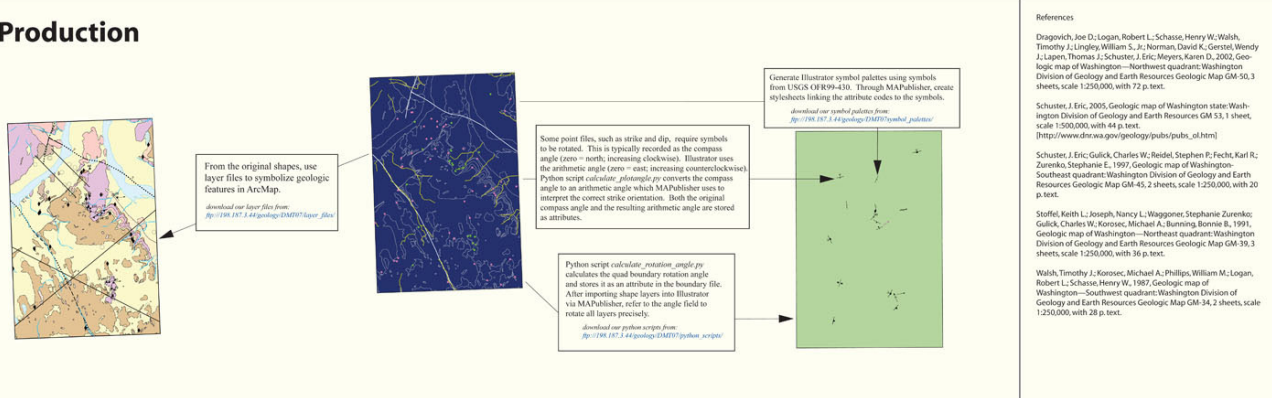

Figure 2. Compilation and production of the 1:500,000-scale Geologic Map of Washington State (presented at DMT'07 as a poster; see high-resolution image at http://ngmdb.usgs.gov/Info/dmt/schuster07a.pdf). 
both Best Map of 2005 and Best Geologic Map in the Avenza 2005 MAPublisher Map Competition. Additional information is provided on the DMT'07 poster, at http://ngmdb.usgs.gov/ Info/dmt/schuster07b.pdf.

\section{SOME ASPECTS OF 1:24,000-SCALE MAP PRODUCTION}

Each year, under the U.S. Geological Survey STATEMAP program, we produce new 1:24,000-scale geologic maps of 7.5-minute quadrangles in Washington. We use a variety of software to make our maps: ArcInfo, ArcGIS, MAPublisher, Adobe Illustrator, CorelDraw, and Adobe InDesign. In the course of map production, we have developed several map production tools that may be useful to others producing similar products.

We have developed two Python scripts for use in ArcGIS that you may find useful (see Figure 2):

- Some point files, such as strike and dip, require symbols to be rotated. The rotation angle is typically recorded as the compass angle (zero $=$ north; increasing clockwise). Illustrator, however, uses the arithmetic angle (zero = east; increasing counterclockwise). Python script calculate plotangle.py converts the compass angle to an arithmetic angle, which MAPublisher uses to interpret the correct strike orientation. Both the original compass angle and the resulting arithmetic angle are stored as attributes.

- Because of their projection, georeferenced maps are usually tilted, but for publishing purposes they are rotated into an upright position. Python script calculate_rotation_angle.py calculates the quad boundary rotation angle and stores it as an attribute in the boundary file. After importing shape layers into Illustrator via MAPublisher, the script refers to the angle field to rotate all layers precisely.

We have also developed a set of ArcMap layer files containing geologic symbols for draft-quality maps, and symbol palettes for Adobe Illustrator for our final publication-quality maps. The above-referenced scripts, layer files, and symbol palettes are available for download at ftp://198.187.3.44/ geology/DMT07/.

\section{REFERENCES}

Dragovich, J.D., Logan, R.L., Schasse, H.W., Walsh, T.J., Lingley, W.S., Jr., Norman, D.K., Gerstel, W.J., Lapen, T.J., Schuster, J.E., and Meyers, K.D., 2002, Geologic map of Washington-Northwest quadrant: Washington Division of Geology and Earth Resources Geologic Map GM-50, 3 sheets, scale 1:250,000, with $72 \mathrm{p}$. text.

Miles, C.E., compiler, 2003, Geologic shaded-relief map of Pennsylvania: Pennsylvania Bureau of Topographic and Geologic Survey Map 67, scale 1:500,000.

Schuster, J.E., 2005, Geologic map of Washington state: Washington Division of Geology and Earth Resources Geologic Map GM-53, 1 sheet, scale 1:500,000, with 44 p. text, available at http://www.dnr.wa.gov/geology/pubs/pubs_ol.htm.

Schuster, J.E., Gulick, C.W., Reidel, S.P., Fecht, K.R., and Zurenko, S.E., 1997, Geologic map of Washington-Southeast quadrant: Washington Division of Geology and Earth Resources Geologic Map GM-45, 2 sheets, scale 1:250,000, with $20 \mathrm{p}$. text.

Stoffel, K.L., Joseph, N.L., Waggoner, S.Z., Gulick, C.W., Korosec, M.A., and Bunning, B.B., 1991, Geologic map of Washington-Northeast quadrant: Washington Division of Geology and Earth Resources Geologic Map GM-39, 3 sheets, scale 1:250,000, with $36 \mathrm{p}$. text.

Walsh, T.J., Korosec, M.A., Phillips, W.M., Logan, R.L., and Schasse, H.W., 1987, Geologic map of Washington-Southwest quadrant: Washington Division of Geology and Earth Resources Geologic Map GM-34, 2 sheets, scale 1:250,000, with 28 p. text. 